\title{
Die Seele im Kosmos
}

\author{
Porphyrios, \\ Über die Nymphengrotte \\ in der Odyssee
}

\author{
Scripta Antiquitatis Posterioris \\ ad Ethicam REligionemque pertinentia \\ XXXII
}

Mohr Siebeck 


\section{SAPERE}

Scripta Antiquitatis Posterioris

ad Ethicam REligionemque pertinentia

Schriften der späteren Antike

zu ethischen und religiösen Fragen

Herausgegeben von

Reinhard Feldmeier, Rainer Hirsch-Luipold, und Heinz-Günther Nesselrath

unter der Mitarbeit von

Natalia Pedrique und Andrea Villani

Band XXXII

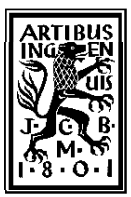





\title{
Die Seele im Kosmos
}

\author{
Porphyrios, Über die Nymphengrotte \\ in der Odyssee
}

\author{
eingeleitet, übersetzt und \\ mit interpretierenden Essays versehen von \\ Manuel Baumbach, Matthias Becker, \\ Reinhold F. Glei, Irmgard Männlein-Robert, \\ Christoph Riedweg, Benjamin Topp
}

\author{
herausgegeben von \\ Manuel Baumbach
}

Mohr Siebeck 
SAPERE ist ein Forschungsvorhaben der Akademie der Wissenschaften zu Göttingen im Rahmen des Akademienprogramms der Union der Deutschen Akademien der Wissenschaften.

ISBN 978-3-16-156933-3 / eISBN 978-3-16-156934-0

DOI 10.1628/978-3-16-156934-0

ISSN 1611-5945 / eISSN 2569-4340 (SAPERE. Scripta antiquitatis posterioris ad ethicam religionemque pertinentia)

Die Deutsche Nationalbibliothek verzeichnet diese Publikation in der Deutschen Nationalbibliographie; detaillierte bibliographische Daten sind im Internet über $h t t p: / / d n b . d n b . d e$ abrufbar.

(C) 2019 Mohr Siebeck Tübingen. www.mohrsiebeck.com

Das Werk einschließlich aller seiner Teile ist urheberrechtlich geschützt. Jede Verwertung außerhalb der engen Grenzen des Urheberrechtsgesetzes ist ohne Zustimmung des Verlags unzulässig und strafbar. Das gilt insbesondere für Vervielfältigungen, Übersetzungen, Mikroverfilmungen und die Einspeicherung und Verarbeitung in elektronischen Systemen.

Der Band wurde vonseiten des Herausgebergremiums von Rainer HirschLuipold betreut und von Marius Pfeifer, Maurice Jensen und Andrea Villani in der SAPERE-Arbeitsstelle in Göttingen gesetzt. Druck von Gulde Druck in Tübingen auf alterungsbeständiges Werkdruckpapier, gebunden von der Buchbinderei Spinner in Ottersweier. 


\section{SAPERE}

Griechische und lateinische Texte der späteren Antike (1.-4. Jh. n. Chr.) haben lange Zeit gegenüber den sogenannten ,klassischen' Epochen im Schatten gestanden. Dabei haben die ersten vier nachchristlichen Jahrhunderte im griechischen wie im lateinischen Bereich eine Fülle von Werken zu philosophischen, ethischen und religiösen Fragen hervorgebracht, die sich ihre Aktualität bis heute bewahrt haben. Die - seit Beginn des Jahres 2009 von der Union der deutschen Akademien der Wissenschaften geförderte - Reihe SAPERE (Scripta Antiquitatis Posterioris ad Ethicam REligionemque pertinentia, "Schriften der späteren Antike zu ethischen und religiösen Fragen") hat sich zur Aufgabe gemacht, gerade solche Texte über eine neuartige Verbindung von Edition, Übersetzung und interdisziplinärer Kommentierung in Essayform zu erschließen.

Der Name SAPERE knüipft bewusst an die unterschiedlichen Konnotationen des lateinischen Verbs an. Neben der intellektuellen Dimension (die Kant in der Übersetzung von sapere aude, "Habe Mut, dich deines eigenen Verstandes zu bedienen", zum Wahlspruch der Aufklärung gemacht hat), soll auch die sinnliche des, Schmeckens' zu ihrem Recht kommen: Einerseits sollen wichtige Quellentexte für den Diskurs in verschiedenen Disziplinen (Theologie und Religionswissenschaft, Philologie, Philosophie, Geschichte, Archäologie ...) aufbereitet, andererseits aber Leserinnen und Leser auch ,auf den Geschmack' der behandelten Texte gebracht werden. Deshalb wird die sorgfältige wissenschaftliche Untersuchung der Texte, die in den Essays aus unterschiedlichen Fachperspektiven beleuchtet werden, verbunden mit einer sprachlichen Präsentation, welche die geistesgeschichtliche Relevanz im Blick behält und die antiken Autoren zugleich als Gesprächspartner in gegenwärtigen Fragestellungen zur Geltung bringt. 



\section{Vorwort zu diesem Band}

Wer sich mit der Nymphengrotte im 13. Gesang der Odyssee beschäftigt, muss Zeit mitbringen bzw. mitführen: Zum einen symbolisiert der Ort auf der Erzählebene den Zeitraum von immerhin 20 Jahren, die vergangen sind, seitdem der nun heimkehrende Odysseus dort vor seiner Abreise nach Troja ein letztes Mal zu den Nymphen gebetet hat, wobei auffällt, dass die Zeitlosigkeit der Grotte die Zeitlichkeit seines (gealterten) Besuchers in besonderer Weise fokussiert. Zum anderen wirft die Beschreibung der beiden Türen der Grotte, die zwei unterschiedliche Wege für Menschen bzw. Untersterbliche darstellen, generelle Fragen nach der Sterblichkeit bzw. Unsterblichkeit, dem Werden und Vergehen sowie der Bedeutung von Zeit im Raum auf, die mit der Beschreibung der Nymphengrotte aus Sicht ihrer Rezipienten verbunden werden und ihr eine Bedeutung jenseits des zeitlichen Geschehens der Odyssee verleihen. Schlieilich sind die eigentlich schnell rezitierten elf homerischen Verse so konzipiert, dass sie den Lesefluss und ein rasches, eindeutiges Verständnis erschweren - eine Rezeptionserfahrung, die nicht nur Porphyrios, sondern eine ganze Reihe von früheren (vgl. Porph. Antr. 4) und späteren Homerexegeten zu längeren Abhandlungen und Deutungsversuchen inspirierte.

Wer Homers Nymphengrotte verstehen will, darf, ja muss sich Zeit nehmen, und genau das haben die Verfasser dieses Buches von der Konzeption des SAPERE-Projektes zu Porphyrios' De antro Nympharum im Jahr 2013 bis zu seiner Fertigstellung getan. Dabei haben wir nie den Anspruch vertreten, zu einem besseren, geschweige denn abschließendem Verständnis der homerischen Verse kommen zu wollen, im Gegenteil: Das Ziel des Projektes war es, eine bestimmte antike Exegese der Nymphengrotte in Homers Odyssee, eben die neuplatonische Allegorese des Porphyrios, zeitgeschichtlich und literaturwissenschaftlich einzuordnen und in ihren Deutungsstrategien, Wirkungsabsichten sowie über ihre kreativen Rezeptionen für ein breites Rezipientenpublikum zu erschließen. Ob Porphyrios die homerischen Verse schlüssig gedeutet hat oder inwieweit seine Allegorese den Wirkungsintentionen der Beschreibung der Nymphengrotte in der Odyssee nahekommt, bleibt dahingestellt.

Um Porphyrios' Allegorese der Homerstelle möglichst umfassend zu analysieren, war eine enge Zusammenarbeit von Kolleginnen und Kollegen mit unterschiedlichen Fachperspektiven unabdingbar: Die Beiträge in diesem Band widmen sich philosophischen, religionswissenschaftlichen, literaturwissenschaftlichen, astronomisch-astrologischen und rezeptions- 
geschichtlichen Fragestellungen. Dabei haben wir versucht, das enge Ineinandergreifen dieser Aspekte durch zahlreiche Querverweise in den Anmerkungen zur Übersetzung und zwischen den einzelnen Beiträgen zu markieren.

Christoph Riedweg, Gräzist aus Zürich, arbeitet zunächst das philosophische Gerüst, das Porphyrios' Homerauslegung zugrunde liegt, heraus. Wenig überraschend erweist sich dabei das Weltbild des platonischen $T i$ maios als besonders einflussreich. Danach wird die enge Verknüpfung philosophischer Argumente mit Verweisen auf die religiös-kultische Sphäre erörtert: Diese werden durchweg affirmativ zur Bekräftigung der philosophisch allegorisierenden Exegese eingesetzt. Eine Sonderstellung kommt den bis heute in mancher Hinsicht rätselhaften Mithrasmysterien zu, für die Porphyrios' De antro eine der wichtigsten literarischen Quellen überhaupt darstellt.

Irmgard Männlein-Robert, Professorin für Griechische Philologie in Tübingen, konzentriert sich auf das Motiv der Höhle: Während der alte Mythotopos ,Höhle' bei Porphyrios keine Rolle spielt, interpretiert der Platoniker die homerische Nymphenhöhle aus rein religionsphilosophischer Perspektive als religiösen Raum. Mit dem philologischen Habitus der Klärung einer Aporia verbindet sich in diesem Porphyriostext eine auf der Unsterblichkeit der Seele basierende platonische Interpretation, welche die Höhle als Kosmos, als Raum der Katabasis und des Mithraskultes wie als symbolische Darstellung der sinnlichen wider intelligiblen Welt deutet.

Benjamin Topp, Osnabrücker Latinist, untersucht die Bedeutung astronomisch-astrologischer Vorstellungen, die in De antro zu finden sind. Dabei wird belegt, dass in dieser Abhandlung nicht nur Vorstellungen, die zum astronomischen ,Allgemeinwissen' zählen, Erwähnung finden (z.B. der Stand der Sonne im Laufe des Jahres oder der Abstieg der Seelen durch verschiedene Planetensphären), sondern der Autor auch auf spezielle astrologische Konzepte rekurriert, wie es die astrologische Häuserlehre, das Welthoroskop oder die vier Kardinalpunkte darstellen. Bezeichnend für den Argumentationsgang bei Porphyrios ist hierbei, dass diese Konzepte mit anderen Vorstellungen verwoben werden, die den unterschiedlichsten Themengebieten (Mythos, Religion, Kult usw.) entlehnt sind.

Reinhold Glei, Latinist aus Bochum, erläutert zunächst den Begriff der ,kreativen Rezeption' von Metatexten, um dann zwei Beispiele einer solchen Rezeption von Porphyrios' De antro Nympharum vorzustellen: zum einen die Explication de l'antre des nymphes des Francois La Mothe Le Vayer (nach 1630), eine libertinistische Parodie des Porphyrios, in der Homers Beschreibung der Nymphengrotte als sexuelle Allegorie gedeutet wird, zum anderen das Gemälde ,The Sea of Time and Space' von William Blake (1821), eine allegorische Visualisierung der neuplatonischen Konzeption 
vom Ab- und Aufstieg der Seele. In einem Anhang wird darüber hinaus eine mögliche Abhängigkeit der Hypnerotomachia Poliphili des Francesco Colonna (1499) von Porphyrios' De antro untersucht.

Eine erste Fassung des kommentierten und übersetzten Textes wurde zusammen mit den Entwürfen für die vier Essays auf einem Workshop in Göttingen im Oktober 2015 diskutiert, an dem auch Glenn W. Most teilgenommen hat. Den Herausgebern der SAPERE-Reihe danken wir herzlich für zahlreiche Anregungen und die produktive Arbeitsatmosphäre, in der wichtige Impulse für die Ausarbeitung der einzelnen Beiträge aber auch für die abschließende Konzeption des Bandes gegeben wurden. Hierzu gehört auch die Idee, den spezifisch De antro Nympharum gewidmeten Beiträgen eine Einführung zum Autor und Werk voranzustellen, um einen Einstieg für mögliche weitere SAPERE-Projekte zu Porphyrios zu erhalten. Ein ganz besonderer Dank gilt Frau Jennifer Beine (Ruhr-Universität Bochum) für das unermüdliche Korrekturlesen und bibliographische Recherchen sowie dem ganzen SAPERE-Team für die langjährige geduldige und umsichtige Betreuung dieses Bandes in allen Phasen seines Entstehens. 



\section{Inhaltsverzeichnis}

SAPERE. . . . . . . . . . . . . . . . .

Vorwort zum Band . . . . . . . . . . . . . . . VII

\section{A. Einführung}

Einführung in Autor und Werk (Matthias Becker) . . . . . . . . . . . . 3

1. Leben des Porphyrios . . . . . . . . . . . . . . . . 3

2. Werkübersicht $\ldots \ldots \ldots \ldots \ldots \ldots \ldots \ldots \ldots \ldots$

Einleitung in die Schrift (Manuel Baumbach) . . . . . . . . . . . . . . 13

1. Die Nymphengrotte in Homers Odyssee: Kontext und narrative Funktion . . . 13

2. Eine zweite (Be-)Deutung: Die Nymphengrotte und die Tradition der

Allegorese . . . . . . . . . . . . . . . . . 15

3. Porphyrios und die neuplatonische Deutung von De antro Nympharum . . . 20

4. Gliederung von De antro Nymphartum . . . . . . . . . . . . . . 26

5. Textgestaltung . . . . . . . . . . . . . . . . 29

\section{B. Text, Übersetzung und Anmerkungen}

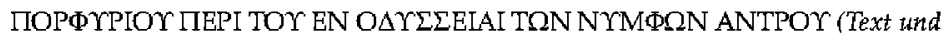

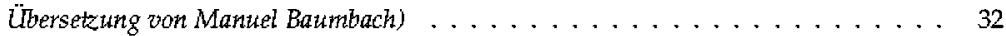

Anmerkungen zur Übersetzung (Manuel Baumbach) . . . . . . . . . . 66

\section{Essays}

Philosophie und religiöse Praxis in De antro Nympharum (Christoph Riedweg) . . . . . . . . . . . . . . . . . . . T7

1. Die philosophische Dimension von Porphyrios' Exegese . . . . . . . . 78

2. Bekräftigung der platonisierenden Attslegung clurch Hinweise auf

Kultisch-Religiöses . . . . . . . . . . . . . . . . 82

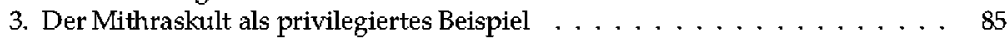

Das Motiv der Höhle in Literatur und Kunst: Porphyrios, De antro

Nympharum (Irmgard Männtein-Robert) . . . . . . . . . . . 97

1. Die Höhle als Symbol des Kosmos . . . . . . . . . . . . . . . . . 101

2. Porphyrios' Abgrenzung vom Mythotopos: Die Höhle als religiöser Raum . 102

3. Die Höhle als Raum der Schwelle tnd des Übergangs:

Mithraskult-Katabaseis . . . . . . . . . . . . . . . . . 105

4. Die Höhle als Heiligtum oder Tempel . . . . . . . . . . 107

5. Die Höhle als Symbol der unsichtbaren kosmischen Kräfte . . . . . . . . . 110

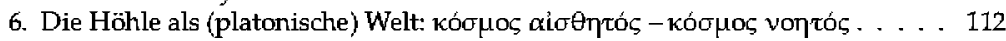

7. Fazit . . . . . . . . . . . . . . . . . . . . . . . . . . 115 


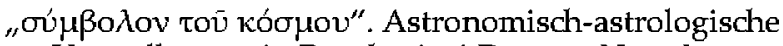

Vorstellungen in Porphyrios' De antro Nympharum (Benjamin Topp) . 117

1. Astronomische Grundvoratssetzungen: Der Lauf der Sontne . . . . . . . 121

2. Der Zadiakus und die zwölf Sternbilder . . . . . . . . . . . . . 123

3. Die Geburt des Kosmos und die Sothis . . . . . . . . . . . . 126

4. Mithras am Sternenhimmel? . . . . . . . . . . . . . . . . 131

5. Nord-Süd-Antagonismus: Die vier kévted . . . . . . . . . . . 135

6. Auf- und Abstieg der Seelen . . . . . . . . . . . . . . . 136

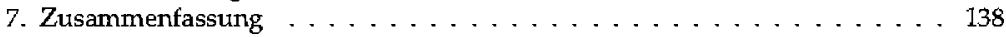

Littérature au troisième degré - Beispiele kreativer Rezeption von

De antro Nympharum (Reinhold F. Glei) . . . . . . . . . . . . 14I

1. Höhleneingänge . . . . . . . . . . . . . . . . 141

2. Tubertus Ocella, Explication de l'antre des nymphes $\ldots \ldots \ldots \ldots \ldots . \ldots 144$

3. Höhlenausgang I . . . . . . . . . . . . . . . . . 150

4. William Blake, The Sea of Time and Space . . . . . . . . . . 151

5. Höhlenatsgang II . . . . . . . . . . . . . . . . . 156

6. Anhang: Francesco Colonna, Hypnerotomachia Poliphili ......... 157

\section{Anhang}

I. Literaturverzeichnis . . . . . . . . . . . . . . 167

1. Abkürzungen . . . . . . . . . . . . . . . . 167

2. Ausgaben, Kommentare und Übersetzungen . . . . . . . . . . . . 167

3. Sekundärliteratur (und Ausgaben anderer Autoren) . . . . . . . . . 168

4. Abbildungsnachweis . . . . . . . . . . . . . . . 173

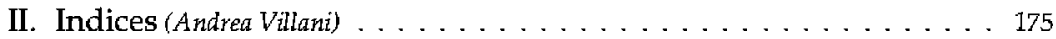

1. Stellenregister (in Auswahl) . . . . . . . . . . . . . . 175

2. Namens- und Sachregister . . . . . . . . . . . . . . . . 179

III. Die Autoren dieses Bandes . . . . . . . . . . . . 187 
A. Einführung 



\title{
Einführung in Autor und Werk*
}

\author{
Matthias Becker
}

\section{Leben des Porphyrios}

Der neuplatonische Philosoph und Philologe Porphyrios (234-301/305 n. Chr.) darf ohne Zweifel zu den großen Universalgelehrten der griechischrömischen Antike gerechnet werden. Dank einiger autobiographischer Einsprengsel ergeben sich zentrale Einblicke in sein Leben aus seinen Werken selbst, v.a. aus der Vita Plotini, die als Einführung zur Edition der Werke seines Lehrmeisters Plotin konzipiert ist. ${ }^{1}$ Diese Einblicke werden durch weitere Quellen ergänzt, unter denen die historisch nicht immer ganz zuverlässige Porphyrios-Vita des Rhetorikers und Neuplatonikers Eunapios $\mathrm{zu}$ nennen ist, der um $400 \mathrm{n}$. Chr. die erste und einzige antike Biographie über Porphyrios verfasste. ${ }^{2}$

Aus dem phönizischen Tyros stammend, ${ }^{3}$ das seit Ende der 190er Jahre n. Chr. römische colonia und Metropole der neuen Provinz Syria Phoenice war, ${ }^{4}$ trug Porphyrios, der in eine "sehr bedeutende" Familie hineinge-

${ }^{*}$ Der biographische Teil der folgenden Einführung in Leben und Werk des Porphyrios stellt eine gekürzte und überarbeitete Fassung von BrCKER 2016, 3-15 dar.

${ }^{1}$ Zum Leben des Porphyrios und zur Chronologisierung seiner Lebensdaten siehe BIDEZ 1913; GoULET 1982; SMITH 1987, 719-722; SMITH 2010; GoULET 2012, 1291-1298; SMITH 2016, 1213-1215. Zu den wichtigsten Testimonien über das Leben des Porphyrios siehe Porph. fr. IT.-43T. SMITH. Die atch im Folgenden nach SMITH nummetierten Fragmente und Testimonien werden zitiert nach SMITH 1993. Einen umf assenden Überblick über Leben, Schriften und Philosophie des Porphyrios bietet der einschlägige Lexikoneintrag im DPhA 5b (2012) P 263, 1289-1468.

${ }^{2}$ Eunap. Vit. soph 4,1-19 GoulET; siehe dazt die deutsche Übers. bei BECKER 2013, 8184 sowie die Kommentierungen bei A. R. Sodano, Porfirio. Vangelo di un pagano. Lettera a Marcella, Contro Boeto, Sull'anima, Sul conosci te stesso; Eunapio. Vita di Porfirio (Mailand 1993) 197-251; M. CrvilETTI, Eunapio di Sardi. Vite di filosofi e sofisti (Mailand 2007) 302-320; BвскBR 2013, 175-207; GouLET 2014, 150-162.

${ }^{3}$ Porph. VPlot. 7,$50 ; 17,6-15 ; 20,91 ; 21,14 ;$ fr. 5T.-6T. Sмгтн; Eunap. Vit. soph. 4,1 GouLBT. Die bei christlichen Autoren überlieferte Tradition, cerzufolge Porphyrios ats Batanea stammte (siehe Porph. fr. 8a-bT. Бмгтн), ist nicht als Herkunftsbezeichnung, sondern als polemische Diffamierung zu verstehen; siehe dazu BвсквR 2016, 116-117 Anm. I.

${ }^{4} \mathrm{~J}$. Nollí, "I Colonia und Socia der Römer". Ein neuer Vorschlag zur Auflösung der Buchstaben,SR' auf den Münzen von Antiocheia bei Pisidien"s, in: C. SchuberT / K. BRoDERSEN (Hg.), Rom und der griechische Osten. Festschrift H. H. Schmitt (Stuttgart 1995) [350370] 357; F. Millar, "Porphyry: Ethnicity, Language, and Alien Wisdom", in: J. BarNBs / 
boren wurde, ${ }^{5}$ zunächst denselben hellenisierten semitischen Namen wie

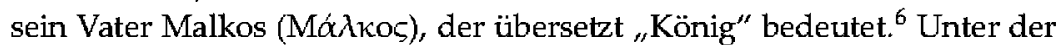

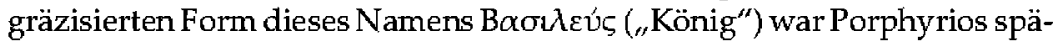
ter in der Schule Plotins bekannt, wie u.a. die Widmung einer Schrift des Amelios, der ein Kommilitone des Porphyrios unter Plotin war, an "Ba-

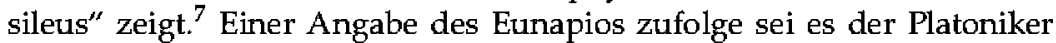
und Philologe Longin gewesen, der den Namen seines Schülers "Malchos" (Mád $\lambda \circ \varsigma$ ) zu "Porphyrios" (wörtlich "der Purpurne" bzw. "mit Purpur

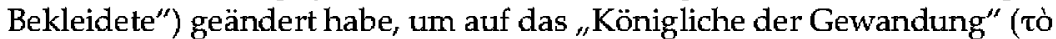

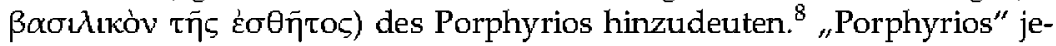
denfalls ist der Name, den er selbst in seinen Schriften immer für sich verwendet. ${ }^{9}$

In einem sicher zuweisbaren Fragment aus dem dritten Buch von Contra Christianos berichtet Porphyrios in einem wörtlichen Zitat davon, dass er "als ganz junger Mann" dem Origenes "begegnet" sei, worunter der christliche Exeget, Theologe und Philosoph zu verstehen ist, nicht der pagane Platoniker gleichen Namens. ${ }^{10}$ In dieser knappen Notiz kann möglicherweise ein Hinweis auf den ersten Studienort des Porphyrios gesehen werden. In Anbetracht des Todesjahres des Christen Origenes, das zwischen 251 und $254 \mathrm{n}$. Chr. angesetzt wird, ${ }_{r}{ }^{11}$ ist zumindest gesichert, dass der 234 n. Chr. geborene Porphyrios vor seinem zwanzigsten Geburtstag

M. Griffin (Hg.), Philosophia togata II. Plato and Aristotle at Rome (Oxford 1997) [241-262] 244-246.

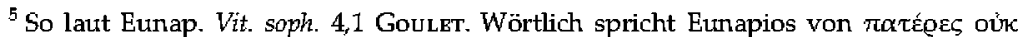

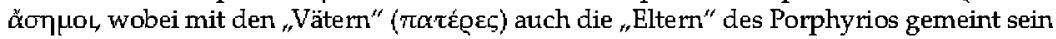
können (Goulet 2014, 150 Anm. 1).

${ }^{6}$ Porph. VPlot. 17,4-15.

${ }^{7}$ Porph. VPlot. 17,1-6; 13-15; Brisson 1982, 74f. s.v. Basileus. Zu Amelios siehe DPhA I (1989) A 136, 160-164, zu Plotin DPhA 5a (2012) P 205, 885-1070. Die Porphyrios gewidmete Schrift trug den Titel Über den Unterschied der Lehren Plotins und des Numenios (Porph. VPlot. $17,4-6)$.

${ }^{8}$ Eunap. Vit. soph. 4,4 Goulet; siehe dazu MänNleIn-RobbrT 2001, 243f.; BвсквR 2013,

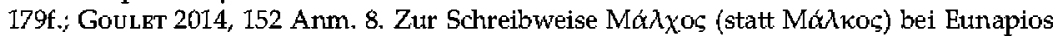
siehe Goulet 2014, $151 \mathrm{Anm}$. 7. Tyros war noch in der Spätantike für seine hochwertige Purpurherstellung bekannt, siehe M. RBinHold, History of Purple as a Status Symbol in Antiquity (Brüssel 1970) 63; vgl. schon Plin. Nat. hist. 5,76; Strabo, Geogr. 16,2,23. Zum kulturgeschichtlichen Hintergrund siehe insgesamt H. BLum, Purpur als Statussymbol in der griechischen Welt (Bonn 1998).

${ }^{9}$ Porph. VPlot. 2,31f.; 4,12; 7,50 u.ö.; zum Namen "Porphyrios" siehe auch GoulET 2012, $1291 \mathrm{f}$

${ }^{10}$ Porph. Chr. fr. 6F. BeckeR = Eus. Hist. eccl. VI 19,5: $\alpha v \delta \rho d s$ [scil. Origenes] $\ddot{\omega} \kappa \alpha \dot{\gamma} \boldsymbol{\omega}$

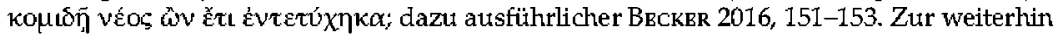
umstrittenen Frage, ob der christliche womöglich mit dem paganen Origetnes identisch sein könnte, siehe B. BäBlER / H.-G. NesselRath (Hg.), Origenes der Christ und Origenes der Platoniker, SERAPHIM 2 (Tübingen 2018).

${ }^{11}$ Vgl. R. Williams, "Origenes/Origenismts", TRE 25 (1995) [397-420] 403; Goulbt 2012, 1292. 
Origenes getroffen haben muss. Wahrscheinlich fand die Begegnung in der nicht allzu weit von Tyros entfernten Stadt Caesarea Maritima gegen Ende der 240er Jahre statt, ${ }^{12}$ wo Origenes seit $231 / 232 \mathrm{n}$. Chr. in einer von ihm gegründeten Schule lehrte, zu der auch eine Bibliothek gehörte. ${ }^{13}$ Dass Porphyrios dort für kurze Zeit, aber nicht als regulärer Schüler Vorlesungen des Origenes gehört hat, ist wahrscheinlich. ${ }^{14}$ Wie Gregor der Wundertäter (um 210-um 270 n. Chr.) in seiner 238 n. Chr . gehaltenen Oratio prosphonetica ac panegyrica in Origenem berichtet, beinhaltete das Curriculum in Caesarea zu Lebzeiten des Porphyrios Dialektik, Physik, Mathematik, Geometrie, Astronomie, Ethik, das Studium paganer Dichter und Philosophen, Theologie sowie die Lektüre und Auslegung der biblischen Schriften. ${ }^{15} \mathrm{Ei}$ nige Zeit nach seiner Zusammenkunft mit Origenes hat Porphyrios in den 250er Jahren bei Longin (um 212-272 n. Chr.) in Athen studiert. ${ }^{16}$ Weitere Lehrer in Athen waren der Mathematiker Demetrios und der Grammatiker Apollonios. ${ }^{17}$ Während der Regierung des Kaisers Gallienus (253-268 n. Chr.) kam Porphyrios 263 n. Chr. in Begleitung eines gewissen Antonius von Rhodos von Griechenland nach Rom, wo er sein Studium bei Plotin (ca. 205-270 n. Chr.) fortsetzte. ${ }^{18}$ Porphyrios selbst war zu diesem Zeitpunkt nach eigenen Angaben 30 Jahre alt, Plotin etwa 59. ${ }^{19}$ Der Wechsel nach Rom markierte für Porphyrios eine "philosophische Umorientierung", ${ }^{20}$ da Longin und Plotin unterschiedliche philosophische Ansätze verfolgten und zwischen ihnen ein gravierender Dissens in der Ideenlehre

\footnotetext{
${ }^{12}$ Dazu und zur Möglichkeit, dass auch Tyros als Ort eines Zusammentreffens in Frage kommt, siehe Becker 2016, 151f. Anm. 26. In Tyros soll Origenes jedenfalls gemäß Hieronymus auch gestorben sein (Vir. illustr. 54: et mortuus est Tyri, in qua urbe et sepultus est, "er ist in Tyros gestorben, der Stadt, in der er auch begraben ist"); vgl. BäBLER 2018, 145 mit Anm. 68.

${ }_{13}$ BÄbLER 2018, 133. Zu dieser Schule des Origenes in Caesarea siehe die Literaturangaben bei MarkschIEs 2007, 73 Anm. 146. Einführend zum intellektuellen und institutionellen Gepräge dieser "christlichen Privatuniversität" (Markschies) in Caesarea siehe H. Kocr, Pronoia und Paideusis. Studien über Origenes und sein Verhältnis zum Platonismus (Berlin / Leipzig 1932) 301-304; MarkschIBs 2007, 72-75. 93-107; B̈̈BLER 2018, 139-148, die auch auf archäologische Gesichtspunkte eingeht.

${ }^{14}$ Siehe dazu Beckrr 2016, 152 Anm. 26.

${ }^{15}$ Greg. Thaum. Pan. or. 7,93-15,183 Crouzbl; dazu K. PIETzndr, Bildung, Elite und Konkurrenz. Heiden und Christen vor der Zeit Constantins (Tübingen 2013) 284-286.

${ }^{16}$ Porph. fr. 15T. Smrth; Eunap. Vit. soph. 4,2-5 Goulet; dazu Männlein-Robert 2001, 237-250; BвCKER 2013, 176-181. Zum Leben und dem nur fragmentarisch erhaltenen Werk Longins siehe MänNLEIN-RokerT 2001 und DPhA 4 (2005) L 63, 116-125.

${ }_{17}$ Porph. fr. 13T.-14T. SMITH; dazu MänNLeIN-Robert 2001, 240. 262-263; GoulEt 2012, 1293. Zu Demetrios siehe überdies DPhA 2 (1994) D 61, 641f.

${ }^{18}$ Porph. VPlot. 4,1-6. Es ist gut möglich, dass Antonius von Rhodos ebenfalls ein ehemaliger Schüler Longins war, siehe Brisson 1982, 73 s.v. Antoine (de Rhodes) und DPhA 1 (1989) A 225, 260.

${ }^{19}$ Porph. VPlot. 4,6-9.

${ }^{20}$ GoulBt 2012, 1293: "the réorientation philosophique”; siehe hierzu Porph. VPlot. 20,92-96 (verba Longini) und BRIsson 1982, 92f.
} 
bestand. ${ }^{21}$ Bis zum Jahre $268 \mathrm{n}$. Chr. studierte Porphyrios in Rom, woraufhin er zu einem Aufenthalt auf Sizilien aufbrach.22

Plotin selbst hatte seinem Schüler diesen Ortswechsel empfohlen, und zwar als Maßnahme gegen suizidale Gedanken, die Porphyrios laut eigener Aussage infolge einer melancholischen Stimmung hegte. ${ }^{23}$ Auf Sizilien angekommen, ging er zu einem gewissen Probus, der sich in der bedeutenden Küstenstadt Lilybaion im äußersten Westen der Insel aufhielt. ${ }^{24}$ Da über Probus, der an der betreffenden Stelle der Vita Plotini nur als "gelehrter bzw. intelligenter" oder "berühmter bzw. namhafter

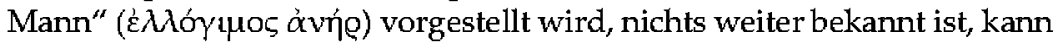

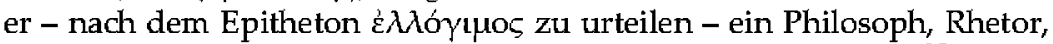
(Rechts-?)Gelehrter oder ein politischer Beamter gewesen sein ${ }^{25}$ wobei sich diese Optionen, vor allem die drei letzteren, nicht gegenseitig ausschließen. Sollte Probus ein Staatsbeamter gewesen sein, wäre dies ein Beleg für die engen Kontakte des Plotin-Zirkels zu politischen Kreisen, die auch aus der Vita Plotini ersichtlich sind. ${ }^{26}$ Aufgrund der Überlieferung, wonach Porphyrios auf Sizilien mehrere Werke verfasst haben soll, ist davon auszugehen, dass er während seines Aufenthaltes zu neuen Kräften kam und seine Gelehrtentätigkeit fortsetzte. ${ }^{27}$ Sein ehemaliger Lehrer Lon-

\footnotetext{
${ }^{21}$ Zu den innerplatonischen Polemiken in den Philosophenschulen des zweiten und dritten Jh.s n.Chr. siehe ausfïthrlich D. O'Mrara, "Polemical Strategies in the Conflict over Plato's Legacy in the Platonist Schools of the Second and Third Centuries", in: I. MännLBinRobert (Hg.), Die Christen als Bedrohung? Text, Kontext und Wirkung von Porphyrios' Contra Christianos (Stuttgart 2017) 19-30.

${ }^{22}$ Porph. VPlot. 6,I-3; zum Sizilienaufenthalt des Porphyrios siehe auch BeCKER 2013, $184 f$.

${ }^{23}$ Porph. VPlot. 11,11-19. Zum Reisen als therapeutischer Maßnahme bei Sttizidalität bzw. schwerer Depressivität in der Antike siehe Becker 2013, 185 mit Artm. 394-395.

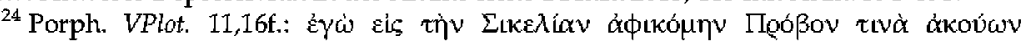

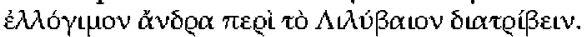

${ }^{25}$ Vgl. dazu Brisson 1982, 108 s.o. Probus sowie DPhA 5b (2012) P 284, 1543. Die PLRE I s.v. "Probus 1", 736 bietet die vorsichtige Vermutung, er sei ein Philosoph gewesen.

${ }^{26}$ Kaiser Gallienus und seine Frau Salonina pflegten nach allem, was Porphyrios suggeriert, ein freundschaftliches Verhältnis zu Plotin, dessen Schulzirkel ihnen persönlich bekannt war (Porph. VPlot. 12,1-3), vgl. Brisson 1982, 75f. s.v. Gallien; O'MrarA 2003, 1316; MänNLEIN-RoBert 2014, 120 Anm. 7. Unter den fünf politisch aktiven Studenten Plotins befanden sich drei Sentatoren namens Orontius (BrIsson 1982, 96f. s.v. Marcellus), Sabinillus (Brisson 1982, 110 s.v. Sabinillus) und Rogatianus (BrIsson 1982, 109 s.v. Rogatianus), siehe Porph. VPlot. 7 und OMgara 2003, 14 (mit Lit.). Nemertios, der Adressat einer Schrift

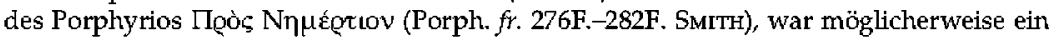
Senator (so PLRE I s.v. "Nemertius", 62I); siehe dazu A. P. JoHNSON, Religion and Identity in Porphyry of Tyre. The Limits of Hellenism in Late Antiguity (Cambridge 2013) 295-296.

${ }^{27}$ Gemäß dem Zeugnis des Ammonios und des Elias sind zwei Werke des Porphyrios

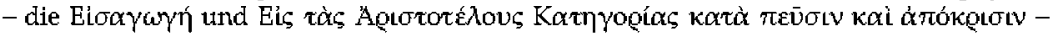
auf Sizilien entstanden, siehe Porph. fr. 28T.-29T. SмIтH sowie Bidbz 1913, 58-60; БмттH 1987, 720. Nach der traditionellen (Fehl-)Interpretation von Ets. Hist. eccl. VI 19,2 soll atch Contra Christianos auf Sizilien entstanden sein; siehe dazu BвCKER 2016, 22-27.
} 
gin schrieb Porphyrios während dieser Zeit einen Brief, in dem er ihn dazu ermunterte, von Sizilien nach Phönizien zu kommen, wo sich Longin zu dieser Zeit aufhielt. ${ }^{28}$ Dieser Tatbestand zeigt, dass der Aufenthaltsort des Porphyrios in platonischen Kreisen bekannt war. Auch seine Kontakte zum Plotin-Zirkel in Rom hielt er aufrecht: So sandte ihm Plotin bis zum Jahre $270 \mathrm{n}$. Chr. eigene Schriften nach Lilybaion. ${ }^{29}$ Wie lange Porphyrios insgesamt auf der Insel blieb, entzieht sich sicherer Kenntnis. Als Plotin, dessen Gesundheitszustand sich nach Abreise des Porphyrios $268 \mathrm{n}$. Chr. kontinuierlich verschlechtert hatte, ${ }^{30}$ im Jahre 270 n. Chr. starb, war Porphyrios jedenfalls immer noch auf Sizilien, wodurch er daran "gehindert wurde, bei Plotin bis zu dessen Tod zu bleiben. " ${ }^{31}$ Zwei Reisen des Porphyrios sind aufgrund von Anspielungen für die Zeit nach $268 \mathrm{n}$. Chr. teils beleg-, teils erschließbar: So geht aus einem Passus in De abstinentia hervor, dass Porphyrios zumindest einige Zeit in Karthago verbrachte, das von Lilybaions Hafen aus gut zu erreichen war. ${ }^{32}$ Aus dem oben erwähnten Brief Longins an Porphyrios ist möglicherweise zu erschließen, dass Porphyrios zwischen 268 und 272/273 n. Chr. nach Tyros reiste. ${ }^{33}$ Diese Reise nach Tyros kann jedoch auch in die Zeit vor $263 \mathrm{n}$. Chr. datiert werden. ${ }^{34}$

Wie lange auch immer Porphyrios sich in Lilybaion aufgehalten haben mag, sicher ist: Er kehrte nach Plotins Tod nach Italien bzw. Rom zurück, wo er von dem Arzt Eustochios über die näheren Todesumstände in Kenntnis gesetzt wurde. ${ }^{35}$ In bereits fortgeschrittenem Alter heiratete Porphyrios Markella, die Witwe eines Freundes, die bereits Mutter von fünf Töchtern und zwei Söhnen war. ${ }^{36}$ Nach zehn Monaten des ehelichen Zusammenlebens trat er eine nicht näher spezifizierte Reise an, die er selbst mit der "Not" bzw. dem "Bedürfnis der Griechen" ( $\tau \bar{\eta} \zeta \tau \bar{\omega} v$ 'E $\lambda \lambda \eta \dot{v} \omega \omega$

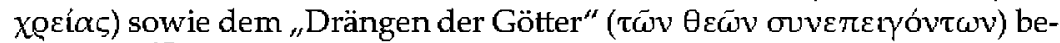
gründete. ${ }^{37}$

\footnotetext{
${ }^{28} \mathrm{Zu}$ dem in Porph. VPlot. 19 zitierten Brief Longins an den auf Sizilien weilenden Porphyrios siehe Männlein-Robert 2001, 150-162. Nach MännLbin-Roвert 2001, 152f. mit Anm. 45 ist es möglich, dass Longin sich zum Zeitpunkt der Abfassung dieses Briefs in Palmyra aufhielt.

${ }_{29}$ Porph. VPlot. 6,1-4.

${ }^{30}$ Porph. VPlot. 2,10-15; zu Krankheit und Tod Plotins siehe Porph. VPlot. 2.

${ }^{31}$ Porph. VPlot. 11,18f;; vgl, attch ebd. 2,31f.

${ }^{32}$ Porph. Abst. III 4.

${ }^{33}$ Verba Longini apud Porph. VPlot. 19,34-36; dazu SMITH 1987, 720.

${ }^{34}$ Siehe dazu Männlein-Roerrt 2001, 160f. mit Anm. 80; Goulet 2012, 1295.

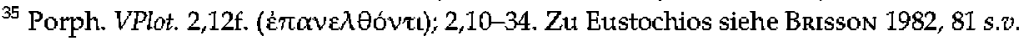
Eustachius sowie $D P h A 3$ (2000) E 162, 378. Von der Rückkehr des Porphyrios nach Rom be-

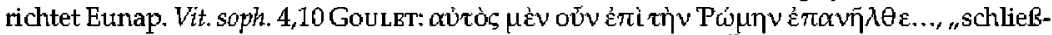
lich kehrte er nach Rom zurück..." (= Porph. fr. IT.,63f. SMITH, Übers. Becker); dazu BвCKER 2013, 196.

${ }^{36}$ Porph. Marc. 1.

${ }^{37}$ Porph. Marc. 4. Einige Forscher verstehen diese Bemerkung als einen Hinweis auf die Beteiligung des Porphyrios an den Vorbereitungen der Diokletianischen Christenverfol-
} 
Außer der Hochzeit mit Markella und der angedeuteten Reise lassen sich aufgrund von Indizien noch folgende Aussagen über die späteren Lebensjahre des Porphyrios machen. Dass er in Rom die Schule Plotins als deren neues und offizielles Oberhaupt fortsetzte bzw. eine eigene Schule gründete, wie in der Forschung bis heute oft zu lesen ist, kann mangels historischer Belege nur schwer bewiesen werden. ${ }^{38}$ Allerdings ist zumindest mit einem inoffiziellen Schülerkreis zu rechnen. ${ }^{39}$ Denn nach allem, was die gelehrsame Aktivität des Porphyrios bis ins Alter vermuten lässt, stand Porphyrios auch nach Plotins Tod mit philosophischen Weggefährten in Kontakt. Als er zu Beginn des 4. Jh.s n. Chr. im Alter von 68 Jahren $^{40}$ Plotins gesammelte Schriften nach Neuner-Gruppen geordnet (Enneaden) edierte und dieser Ausgabe seine $301 \mathrm{n}$. Chr. verfasste Vita Plotini zur Einführung voranstellte, ${ }^{\mathbf{4 1}}$ war er sich jedenfalls der alten Beziehungen zum Plotin-Zirkel sowie seiner eigenen Autorität als Bewahrer des plotinischen Erbes bewusst. ${ }^{42}$ Dies setzt eine Leserschaft bzw. einen Adressatenkreis (in Rom?) voraus, der noch Jahrzehnte nach dem Ableben des Meisters existierte. Was den Tod des Porphyrios betrifft, so überliefert Eunapios ohne Angabe von Quellen die Tradition, dass er in Rom gestorben sei. ${ }^{43} \mathrm{Ge}-$ mäß dem byzantinischen Lexikon $S u d a$ habe er bis in die Regierungszeit Diokletians (284-305 n. Chr.) hinein gelebt. ${ }^{44}$ Demzufolge wird Porphyrios wahrscheinlich zwischen 301 und $305 \mathrm{n}$. Chr. aus dem Leben geschieden sein.

\section{Werkübersicht}

Als Autor hat Porphyrios ein äußerst gelehrtes und vielseitiges Gesamtwerk hinterlassen, das rund 70 Arbeiten umfasst, die allerdings bis auf wenige Ausnahmen entweder nur in Fragmenten überliefert oder ganz verloren sind. Die behandelten Themengebiete, die im Folgenden nur knapp skizziert werden können, umfassen philosophische, philosophiegeschicht-

gung, die 303 n.Chr. einsetzte. Diese Interpretation ist jedoch abwegig (Goulnt 2012, 1296f.; BeCKER 2016, 24-26.465-467 Anm. 15).

${ }^{38}$ Diese Ansicht ist durch das späte Zeugnis der Porphyrios-Vita des Eunapios bedingt, das impliziert, Porphyrios sei im Anschluss an seinen Sizilien-Aufenthalt nach Rom zurückgekehrt und dort bis zu seinem Tod als philosophischer Lehrer tätig gewesen (Eunap. Vit soph . 4,10-18 GouleT = Porph. fr. 1T.,63-106 SMITH).

${ }^{39}$ O'Meara 2003, 15 mit Anm. 11; SMith 2010, 355; Goulbt 2012, $1295 f$.

${ }^{40}$ Porph. VPlot. 23,13f.; Goulet 1982, 210.

${ }^{41}$ I. MÄNNLBIN-RoBERT, ,Biographie, Hagiographie, Autobiographie - Die Vita Plotini des Porphyrios", in: T. Konusch / M. ERLER (Hg.), Metaphysik und Religion. Zur Signatur des spätantiken Denkens (München / Leipzig 2002) 581-609.

${ }^{42}$ Siehe Porph. VPlot. 24,2-5.

${ }^{43}$ Eunap. Vit. soph. 4,18 Goulet.

${ }^{44}$ Suda $\pi 2098=$ Porph. fr. $2 \mathrm{~T}, 3-5$ SMITH. 
liche, philologisch-rhetorische, literarische, ethische, religiöse, naturwissenschaftliche und mathematische Fragen. ${ }^{45} \mathrm{Zu}$ den weitgehend vollständig erhaltenen Werken zählen u.a. die Abhandlungen De abstinentia, in welcher im Zuge einer leidenschaftlichen philosophischen Begründung des Fleischverzichts zu einer vegetarischen Lebensweise aufgerufen wird, das im vorliegenden Band herausgegebene Werk De antro nympharum, mit dem Porphyrios eine philosophische Allegorese der im 13. Gesang der homerischen Odyssee erwähnten Nymphengrotte vorgelegt hat, die Sententiae ad intelligibilia ducentes, worin ethische und spirituelle Anweisungen zur Loslösung der Seele von der materiellen Erfahrungswelt gesammelt sind, die Vita Pythagorae, die als Teil eines mehrbändigen Opus zur Geschichte der Philosophie (Historia philosophica) ${ }^{46}$ Lehre und Wirken des Vorsokratikers Pythagoras ausbreitet, sowie die als Brief an seine Frau stilisierte protreptische Schrift Ad Marcellam, in der Porphyrios werbend dazu aufruft, Philosophie im traditionellen Bezugsrahmen paganer Religiosität zu praktizieren. Darüber hinaus erarbeitete Porphyrios Kommentare zu den logischen Werken des Aristoteles, wobei v.a. seine Isagoge zur Logik des Aristoteles eine besondere Wirkung entfaltete, sowie zu ausgewählten platonischen Dialogen und den Enneaden Plotins.

Neben seinen philosophischen Arbeiten, die auch Fragen der Metaphysik, Seelenlehre, Anthropologie und Ethik berühren, hat Porphyrios einige Werke zu religiösen und religionsphilosophischen Fragestellungen in Angriff genommen. Von besonderer Bedeutung sind in dieser Hinsicht die folgenden Texte: De philosophia ex oraculis haurienda, ${ }^{47}$ worin Porphyrios Orakelsprüche paganer Gottheiten gesammelt und philosophisch kommentiert hat, De simulacris, ${ }^{48}$ wo eine religionsphilosophisch reflektierte Verteidigung von Götterbildern präsentiert wird, sowie die Epistola ad Anebontem, die sich mit einer Kritik der Theurgie befasst. ${ }^{49}$ Während alle diese Texte weitgehend für eine von philosophischer Reflexion durchdrungene Beibehaltung traditioneller paganer Religionspraxis eintreten, ${ }^{50}$ hat Porphyrios in dem 15 Bücher umfassenden Monumentalwerk Contra Christianos auch explizit gegen das Christentum und dessen Heilige Schriften Stel-

\footnotetext{
${ }^{45}$ Siehe dazu den kommentierten Schriftenkatalog bei Goulkt 2012, 1301-1311 sowie den Überblick bei Sмгтн 2016, 1215-1217.

${ }^{46}$ Porph. fr. 193T.-224F. SmITH; zu der auf Kyrill von Alexandria zurückgehenden Nachricht, wonach die Pythagoras-Vita Bestandteil des ersten Buchs der Historia philosophica gewesen sei, siehe Porph. fr. 207T. SMrTH.

${ }^{47}$ Porph. fr. 303F.-350F. SMITH.

${ }^{48}$ Porph. fr. 351F- $360 \mathrm{aF}$. SMITH.

${ }^{49}$ A. R. Sodano (Hg.), Porfirio. Lettera ad Anebo (Neapel 1958). Die Stellung des Porphyrios zur Theurgie im breiteren Kontext des spätantiken Platonismus sowie der Attseinandersetzung mit Jamblich beleuchtet I. TANasBanu-DöBlBr, Theutrgy in Late Antiguity. The Invention of a Ritual Tradition (Göttingen 2013) 45-135.

${ }^{50} \mathrm{Zur}$ Ablehnung von Tieropfern sowie zu kultkritischen Bemerkungen bei Porphyrios siehe allerdings BвCKRR 2016, 323f. 524f. Anm. 3.
} 
lung bezogen.${ }^{51}$ Die schon aus der Plotin-Schule bekannte Kritik an (christlichen) Gnostikern ${ }^{52}$ ist in diesem Werk mit polemischem Impetus auf das Christentum insgesamt ausgeweitet worden. Als Grund dafür kann plausiblerweise angenommen werden, dass Porphyrios nicht nur die politischsoziale Ordnung des Imperium Romanum durch die Christen bedroht sah, sondern auch die althergebrachte polytheistische Religion sowie die Interpretationshoheit über das pagan-philosophische und insbesondere das platonische Erbe, welches zunehmend intellektualisierte und hochgebildete Theologen wie Origenes christlich zu adaptieren und mit der biblischen Theologie zu verschmelzen wussten. ${ }^{53}$

Außer einigen Schriften zu Themen der Astronomie, Natur- und Musikwissenschaft hat Porphyrios schließlich einige philologische Abhandlungen geschrieben, die sich nicht nur mit verschiedenen Problemen der Grammatik und der rhetorischen Stasis-Lehre beschäftigen, sondern schwerpunktmäßig auch mit den homerischen Epen. Das wissenschaftliche Handwerkszeug dazu dürfte sich Porphyrios vornehmlich während seiner Studienzeit in Athen angeeignet haben, zumal sein damaliger Lehrer Longin mit seinen literarisch-rhetorischen Interessen in der Tradition der alexandrinischen Philologie stand und sich selbst als Kommentator und Literaturkritiker hervortat. ${ }^{54}$ Kommentare zu ausgewählten Problemen der Homer-Philologie, insonderheit zur Bedeutung einzelner Wörter und Formulierungen (Quaestiones homericae), ${ }^{55}$ sind hier ebenso anzuführen wie erklärende Texte über den Unterweltfluss Styx (De Styge) ${ }^{56}$ oder über die Philosophie Homers (De Homeri philosophia). ${ }^{57}$ In letzterem dürfte Porphyrios - wie andere Philosophen und Intellektuelle der Kaiserzeit auch - Homer den Rang eines Weisen zugeschrieben haben, dessen Dichtung philosophische Lehren beinhalte. ${ }^{58}$ In diesen Themenkreis gehört

\footnotetext{
${ }^{51}$ BeCKER 2016.

${ }^{52}$ Porph. VPlot. 16.

${ }^{53}$ BвCKER 2016, 32-70, hier bes. 48-70; siehe dazu ferner MänNLEIN-RobBrt 2014.

${ }^{54}$ MänNLein-RobBRT 2001, 251-397.

${ }^{55} \mathrm{H}$. Schrader (Hg.), Porphyrii Quaestionum Homericarum ad Iliadem pertinentitum religuias collegit, disposuit, Fasc. 1. (Leipzig 1880); H. Schrader (Hg.). Porphyrii Quaestionum Homericarum ad Odysseam pertinentizm reliquias collegit, disposudt (Leipzig 1890); J. A. MAcPraIL JR., Porphyry's Homeric Questions on the Iliad. Text, Translation, Commentary (Berlin / Boston 2011).

${ }^{56}$ Porph. fr. 372F.-380F. SмIтH.

${ }^{57}$ Porph. fr. 371T. SMrTH (nur der Titel ist überliefert).

${ }^{58}$ Die Frage nach dem philosophischen Gehalt der homerischen Dichtungen wurde in der Kaiserzeit lebhaft diskutiert und Homer dabei durchaus als Philosoph bzw. Ahrherr der Philosophen sowie als Weiser imaginiert; siehe z.B. Sen. Epist. 88,5; Dio Chrys. Or. 47,5; Max. Tyr. Diss. 26,3-5; A. STückBLERRGRR, Senecas 88. Brief. Über Wert und Unwert der Freien Kïnste. Text-Übersetzung-Kommentar (Heidelberg 1965) 104-106; J. F. Kindstrand, Homer in der Zweiten Sophistik. Studien zu der Homerlektide und dem Homerbild bet Dion von Prusa, Maximos von Tyros und Ailios Aristeides (Uppsala 1973) 124-128. 168-172. 198-203.
} 
auch die im vorliegenden Band präsentierte Schrift De antro nympharum, die ein herausragendes Beispiel der platonischen Homerallegorese darstellt ${ }^{59}$ und die im Folgenden eigens eingeführt wird.

${ }^{59}$ Siehe dazu Lamebrton 1986. 



\title{
Einleitung in die Schrift
}

\author{
Manuel Baumbach
}

\section{Die Nymphengrotte in Homers Odyssee: Kontext und narrative Funktion}

Der 13. Gesang der homerischen Odyssee beginnt mit Schweigen: Die fiktionsinternen Zuhörer sind gebannt ( $k \eta \lambda \eta \theta \mu \bar{\omega} \delta^{\prime}$ है $\sigma \chi 0 v \tau o$, XIII 2) von Odysseus' Erzählungen seiner Irrfahren in den Gesängen 9-12 und rufen sich womöglich gerade die Kalypso-Episode vom Beginn der Apologoi ins Gedächtnis (IX 29f.), auf die Odysseus am Ende des 12. Gesangs mit der rahmenbildenden Bemerkung verwiesen hatte, diese nicht ein zweites Mal berichten zu wollen (XII 451-453). Aus narratologischer Perspektive bereitet die kurze Stille den Übergang von der erzählten Handlung der vergangenen Irrfahrten durch den intradiegetischen Erzähler Odysseus zur teleologischen Handlungsschilderung der kommenden Ereignisse durch den extradiegetischen Erzähler Homer vor: Zu Beginn des 13. Gesangs, genau nach der Hälfte des Epos, nimmt die Handlung im eigentlichen Sinne des Wortes wieder Fahtt auf und bringt Odysseus mit Hilfe der Phaiaken räumlich an sein Ziel, in seine Heimat Ithaka, zurück. Obwohl diese Reise - analog zur sagenhaften Schnelligkeit des Phaiakenschiffes (XIII 81-88) sehr rasch in nur wenigen Versen erzählt wird, ist es gleichwohl die längste Beschreibung einer Seereise in der Odyssee, auf die im unmittelbaren Anschluss die ausführlichste Hafenbeschreibung im Epos folgt, ${ }^{1}$ weshalb der Beginn des 13. Gesangs eine besondere topographische Zuspitzung erfährt. Diese gipfelt in der Ekphrasis einer Nymphengrotte, die in der Nähe des Hafens liegt (XIII 103-112) and in deren Inneres der Erzähler uns in einer Art Zoom-Technik hereinschauen lässt: Nymphen weben an steinernen Webstühlen purpurfarbige Gewänder, dort stehen Mischkrüge und Amphoren, in denen Bienen Honig sammeln, es gibt Quellen und zwei Türen, von denen die eine als Abstieg für die Menschen und die andere als Weg der Götter beschrieben ist.

Der Einblick in diese Grotte kommt zunächst überraschend, da weder die Phaiaken bei ihrer Landung auf Ithaka noch Odysseus nach seinem Erwachen sich für diesen besonderen Ort interessieren - ganz im Gegensatz

\footnotetext{
${ }^{1} \mathrm{Vgl}$. hierzu I. DB Jong, A Narratological Commentary on the Odyssey (Cambridge 2001) 316-318.
} 
zur Nymphengrotte auf der Insel des Helios (XII 316-319), in der Odysseus und seine Gefährten ihr Schiff verstecken -, und auch in Odysseus' kurzer Vorstellung seiner Heimat zu Beginn der Apologoi (IX 19-28) wird die Grotte nicht erwähnt. Gleichwohl hat die Nymphengrotte eine wichtige Funktion auf der Handlungsebene, die sich mit dem Auftritt Athenes ergibt: Denn die Göttin beweist Odysseus unter explizitem Verweis auf die Nymphengrotte, ${ }^{2}$ dass er in seine Heimat zurückgekehrt ist (XIII 344-351), und hilft ihm, die Gastgeschenke, die er von den Phaiaken erhalten hat, ebendort vor möglichen Plünderern zu verstecken (XIII 362-371). Damit wird die Grotte für Odysseus zum Ort des Heimkommens ${ }^{3}$ und sichert als Schatzhöhle nicht nur seinen Reichtum und sein Ansehen - was angesichts des Verprassens seiner Güter durch die Freier nicht unerheblich ist -, sondern bewahrt auch die einzigen materiellen Beweise seines Aufenthalts bei den Phaiaken, deren Insel Poseidon als Strafe für ihre Hilfeleistung gegenüber Odysseus hinter einem Felsmassiv verbirgt und für Menschen unzugänglich macht (XIII 154-183). Die religiöse Bedeutung der Nymphengrotte als wichtiger Kultort auf Ithaka zeigt sich daran, dass Odysseus beabsichtigt,

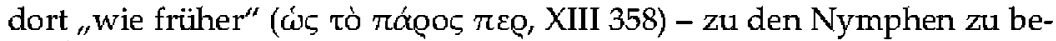
ten. ${ }^{4}$

Vor diesem Hintergrund ist die Nymphengrotte gut in den Handlungszusammenhang des 13. Gesangs und der folgenden Ereignisse eingebunden. Es bleibt jedoch zu klären, warum Homer die Grotte so ausführlich und - das ist der Ausgangspunkt für Porphyrios' Schrift De antro Nympharum - so ,rätselhaft' beschreibt, anstatt sich auf ihre Lokalisierung und eine kurze Erwähnung ihrer Funktionalität und religiösen Bedeutung zu beschränken.

\footnotetext{
${ }^{2}$ Dabei zitiert Athene die Ekphrasis des Erzählers (XIII 347f. = XIII 103f.; XIII $346 \sim$ XIII 102), wodurch die Grotte den textexternen Rezipienten ein zweites Mal vistell vor Augen gestellt und in ihrer Bedeutung hervorgehoben wird. Zur Deutung von De antro Nympharum als "exegetisch umgesetzte Ekphrasis" vgl. den Beitrag von Irmgard Mäntlein-Robert in diesem Band, S. 99.

${ }^{3}$ Zunächst ist Odysseus die Wiedererkenturng seiner eigenen Insel versagt, denn nachdem die Phaiaken ihn kurz vor Morgengrauen schlafend zusammen mit den Gastgeschenken am Hafen des Phorkys abgesetzt haben, erscheint ihm die Insel atfgrund eines von Athene erregten Nebels unvertraut (oủoć $\mu \mathrm{v}$ है $\gamma v \omega$, XIII 187). Er ist ein Fremder in seiner Heimat, und so passt es gut, class Athene, die sich ihm in Gestalt eines jungen Hirten nähert, ihn gleich zweimal als ${ }_{r \prime}$ Fremden" ( $\xi \varepsilon \bar{v} v o c_{,}$XIII 237 u. 248) anspricht.

${ }^{4}$ Die starke Nymphenverehrung auf Ithaka bezettgt auth der Altar für die Nymphen auf dem Weg in die Stadt, auf dem ", alle Wanderer opfern" (XVII 211), und (zahlreiche) religiöse Gebete des Odysseus an die Nymphen erwähnt Eumaios (XVII 240-246), der selbst den Nymphen besondere Verehrung bei der Bereitung von Speisen zukommen lässt, vgl. XIV $435 f$.
} 


\section{Eine zweite (Be-)Deutung: Die Nymphengrotte und die Tradition der Allegorese}

Die Allegorie (í $\dot{\alpha} \lambda \lambda \eta \gamma$ ogí $\alpha)^{5}$ wird in der antiken Rhetorik als ",ausgedehnte Metapher" (continua metaphora) bezeichnet ${ }^{6}$ und zu den Tropen, d.h. zu den Redeweisen gezählt, in denen "die natürliche und ursprüngliche Bedeutung auf eine andere übertragen wird" (vgl. Quint. Inst. or. IX 1,4: sermo a naturali et principali significatione translatus ad aliam). Als Form

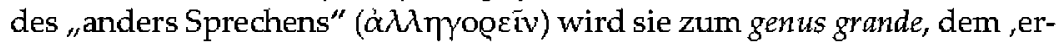
habenen Stil', gezählt und gehört zu den Argumentationstechniken des Redners, der dadurch eine Aussage besonders bildhaft "vor Augen stel-

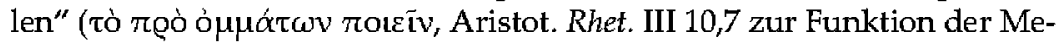
tapher) und dieser allegorisch einen ähnlichen, anderen, zuweilen auch entgegengesetzten Sinn verleihen kann. ${ }^{7}$ Eine Allegorie hat damit immer zwei Bedeutungsebenen, die wörtliche und die allegorische bzw. den sensus litteralis und den sensus allegoricus, ${ }^{8}$ dessen Dekodierung von verschiedenen Faktoren abhängt: Zum einen vom ,Gemachtsein' im aristotelischen

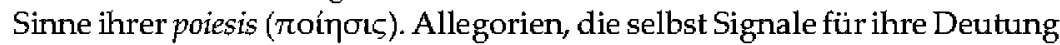
enthalten, sind als allegoriae permixtae apert is von solchen Allegorien zu unterscheiden, bei denen das allegorische Sprechen nicht durch klare, d.h. sinnenthüllende Aussagen durchbrochen wird, sondern implizit vorhanden ist (sog. allegoriae totae), vgl. Quint. Inst. or. VIII 6,47f. ${ }^{9}$ Zum anderen ist der sensus allegoricus eines Textes oder einer Textpassage häufig (aber nicht notwendig) an die Kontexte, in die er eingebunden ist bzw. in die er

\footnotetext{
${ }^{5}$ Der Begriff setzt sich erst ab dem 1. Th. v. Chr. durch und löst únóvoux ab, mit dem das Vorhandensein einer verborgenen Bedeutung in einem Text bezeichthet wurde, so etwa in Platons Staat II 378d3-e1; auf diese Entwicklung verweist Plutarch in De audiendis poetis 4.

${ }^{6} \mathrm{Vgl}$. Quint. Inst. or. IX 2,46 und Cic. Orat. III 38-41. Zur thetorischen Tradition der Allegorie siehe R. HAHN, Die Allegorie in der antiken Rhetorik (Tübingen 1967), zur Begriffsgeschichte A. Havbrkamp (Hg.), Die paradoxe Metapher (Frankfurt/M. 1998); zur antiken Tradition von Allegorie und Allegorese vgl. auch unten Anm. 11.

${ }^{7}$ So Quint. Inst. or. VIII 6,44: $\alpha \lambda \lambda$ nyopla, quam inversionem interpretantur, aut alitud verbis alitud sensu ostendit, aut etiam interim contrarium.

${ }^{8}$ Vor allem in der Bibelexegese wird mit mehrfachem Schriftsinn gearbeitet, und es kommt zu weiteren Ausdifferenzierungen. So postuliert Origenes (Peri Archon IV 2,4) einen dreifachen Sinn: den wörtlichen, historisch-grammatikalischen Sirn (= somatischer Sinn), den allegorischen (= pneumatischen Sinn) und den moralischen (= psychischen) Sinn (vgl. D. Boyarin, "Origen as theorist of allegory: Alexandrian contexts", in: Cofbland / STRUCK 2010, 39-54). Auf den Kirchenvater Augustinus (De utilitate credendi 5) geht der vierfache Schriftsitun zurück, indem er den anagogischen = eschatologischen Sirut hinzufügte $-\mathrm{vgl}$. auch den Augustinus von Dakien zugeschriebenen und bei Nikolaus von Lyra (Comm. in Gal. 4,3) überlieferten Merkvers Littera gesta docet, quid credas allegoria / Moralis quid agas, quo

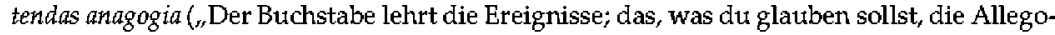
rie; / der moralische Sinn [lehrt], was du tun sollst; wohin du streben sollst, die Anagogie").

${ }_{9}^{9}$ Wegen mangelnder Klarheit wurde diese Form zuweilen auch kritisch gesehen und für Redner eher abgelehunt, vgl. Theon, Prog. 81.
} 
(rhetorisch) gestellt wird, gebunden, insofern sich die Allegorie (wie die Metapher) durch eine (punktuelle) Abweichung von der sie umgebenen ,normalen' Rede auszeichnet, vgl. Aristot. Rhet. III 11,6. ${ }^{10}$ Schlieslich setzt das Erkennen und Entschlüsseln einer Allegorie einen vom Text und seinen Rezipienten geteilten Sprachgebrauch sowie einen gemeinsamen kulturellen Wissenshorizont voraus.

Das Verfahren der allegorischen Auslegung wird mit dem (modernen) Terminus der Allegorese bezeichnet. ${ }^{11}$ Es ist älter als der rhetorische Umgang mit der Allegorie ${ }^{12}$ und auch nicht notwendig mit einer Allegorie verbunden, da die Allegorese einem Text aus rezeptionsästhetischer Perspektive einen verborgenen Sinn, ein ", anders Sprechen", zuschreiben kann, ohne dass dieser produktionsästhetisch (in Form einer Allegorie) mit dem Text verbunden wurde. Das früheste überlieferte Beispiel einer Allegorese findet sich innerhalb der Ilias, wo Patroklos Achill wegen seines andauernden Rückzugs aus dem Kampf vorwirft, dass seine Eltern nicht Thetis und Peleus seien, sondern das Meer und die Steine (XVI 28-35) ${ }^{13}$ - eine allegorische Deutungslinie, die der Homerexeget Metrodoros von Lampsakos (spätes 5. Jh. v. Chr.) fortführte, der die sterblichen Helden der Ilias mit physikalischen Elementen gleichsetzte und die Götter als Bilder menschlicher Organe deutete. ${ }^{14}$

Eine besondere Bedeutung erlangte die Allegorese im Zusammenhang mit der Homerauslegung. Neben dem Versuch des Entschlüsselns von Stellen, die als ,dunkel' empfunden wurden, ${ }^{15}$ konnte sie - wie spätere Al-

\footnotetext{
${ }^{10}$ Dieses Potential verloren haben beispielsweise die so genannten ,toten' bzw. lexikalisierten Metaphern, bei denen die ursprüngliche metaphorische Doppelbedeutung ganz verloren oder weit zurückgetreten ist, z.B. lesen $=$ sammeln, Wolkenkratzer etc.

${ }^{11}$ Vgl. zum Begriff und zur Abgrenzung von der Allegorie W. FreYTAG, , Allegorie, Allegorese" HWRh 1 (1992) 330-393 sowie I. Ramblli/G. LuccheTTA, Allegoria, Bd. 1, L'età classica (Mailand 2004) und J. Whitman, Allegory. The Dynamics of an Ancient and Medieval Technique (Cambridge Mass. 1987) zu antiken Konzepten und Verfahrensweisen. Fallstudien zur Allegorie und Allegorese in griechisch-römischen Texten und ihren Traditionen geben die Sammelbände von G. R. Bors-Stonbs ( $\mathrm{Hg}$ ), Metaphor, Allegory and the Classical Tradition. Ancient Thought and Modern Revisions (Oxford 2003) und Copreand / Struck 2010.

${ }^{12} \mathrm{Vgl}$. Most 2010, 38: „... in the ancient world at least, rhetoric is not the beginning of allegory's story, but the end."

${ }^{13}$ Hierzu siehe G. W. Most, , Die früheste erhaltene griechische Dichterallegorese", $R h M$ 136 (1993) 209-212.

${ }^{14}$ Vgl. N. J. Richardson, "Homeric professors in the age of the sophists", Proceedings of the Cambridge Philological Society 21 (1975) 62-81 und J. HAMMERSTAEDT, "Die Homerallegorese des älteren Metrodor von Lampsakos", ZPE 121 (1998) 28-32. Diese Detutungslinie geht wahrscheirlich auf vorsokratische Überlegungen zur Verbindung von der literarischen, Welt' Homers mit dem Kosmos selbst sowie auf orphische Traditionen zurück, wie sie im Derveni-Papyrus (4. Jh. v. Chr.) fassbar werden (vgl. D. Obernk, sEarly Greek allegory," in: Copeland / STRuck 2010, 15-25).

${ }^{15}$ Das ,verhüllte Sprechen im Sinne der únóvola (vgl. Anm.5) und die dadurch empfundene "Dunkelheit" (obscuritas) wurde hätfig der Dichtung zugewiesen, teils wegen ihres durch Musen verliehenen Inspirationscharakters, teils wegen der besonderen, von der All-
} 
legoresen zu anderen Werken auch - das Ziel verfolgen, kanonisch gewordene Texte, die eine hohe Autorität besaßien, unter Beibehaltung ihres ursprünglichen Wortlauts gegen (religiöse, philosophische, politische) Kritik zu schützen ${ }^{16}$ oder sie mit Hilfe der Allegorese für eigene Vorstellungen zu vereinnahmen und aus ihnen einen Autoritäts- und Traditionsanspruch abzuleiten. ${ }^{17}$ So fassten beispielsweise Stoiker wie Zenon, Kleanthes oder Chrysipp homerische Götter und ihr Wirken als Beschreibungen moralischer Tugenden und kosmischer Kräfte auf und verorteten auf diese Weise eigene philosophische Anschauungen in den Anfängen der griechischen Literatur. $^{18}$

Die häufigsten Allegoresen finden sich im Zusammenhang mit Mythen sowie Offenbarungen und religiösen Schriften, deren tieferen, göttlichen' Hintersinn es zu entschlüsseln galt. Bei Mysterienkulten scheint es zudem die Vorstellung gegeben zu haben, dass Allegorien auf Verrätselung ausgerichtet waren, und das nicht nur, weil in dieser Form das Wissen um den Kult einem Kreis von Eingeweihten vorbehalten blieb, sondern auch, weil man dadurch bestimmte emotionale Wirkungen erzeugen oder unterstützen konnte. So heißt es in der Abhandlung Über den Stil (Peri hermeneias) des Demetrios (die Autorschaft und Datierung ist umstritten, 3. Th. v. Chr.-1. Jh. n. Chr.): "Daher werden auch die Mysterien in Allegorien ausgedrückt zum Zweck der Erschütterung und des Schauderns, denn die Allegorie gleicht dem Dunkel und der Nacht. ${ }^{\prime 19}$ Dabei ist eine Allegorese, die Licht in dieses Dunkel bringt, natürlich keineswegs ausgeschlossen,

tagssprache unterschiedenen sprachlich-stilistischen Gestaltung. So ist die (homerische) Dichtung bei Platon durch úróvola charakterisiert (vgl. Staat II 378d und Lysis 214b), Aischylos wird in Aristophanes' Fröschen als unverständlich karikiert (923-926) und Pindars Werke gelten bereits in der Antike als, dunkel' (vgl. J. T. Ham ILton, Soliciting Darkness. Pindar, Obscurity, and the Classical Tradition, Harvard Studies in Comparative Literature 47 [Cambridge Mass. 2003]) - wobei Pindar seine zahlreichen Metaphern nur selten zu Allegorien ausbaut. Generell zur obscuritas in Dichtung und Rhetorik der Antike siehe M. Fuhrmann, , Obscuritas. Das Problem der Dunkelheit in der rhetorischen und literarästhetischen Theorie der Antike," in: W. Iser (Hg.): Immanente Ästhetik, ästhetische Reflexion. Lyrik als Paradigma der Moderne (München 1966) 47-72.

${ }^{16}$ So zumindest äußert sich Porphyrios über den ,Begründer der Homerallegorese Theagenes von Rhegion (ca. 550 v. Chr.) in den Quaestiones Homericae ad Il. XX 67ff.

${ }^{17}$ Zur Diskussion vgl. H. DörrIE, "Zur Methodik antiker Exegese," ZNTW 65 (1974) 121-138, Long 1992 und J. TATB, "On the History of Allegorism", Classical Quarterly 28 (1934) 105-114; generell zur antiken Homerallegorese und ihren Anfängen sieheF. WeHRLI, Zur Geschichte der allegorischen Interpretation Homers (Basel 1928) und den Sammelband von LAMBERTON / KEANEY 1992.

${ }^{18}$ Zur stoischen Allegorese vgl. P. STrinmbTz, ,Allegorische Deutung und allegorische Dichtung in der Alten Staa”, RhM 129 (1986) 18-30, Long 1992 und G. W. Most, "Cornutus and Stoic Allegoresis: A Preliminary Report", ANRW II 36.3 (1989) 2014-2065 sowie ders. $2010,27-30$.

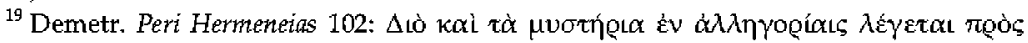

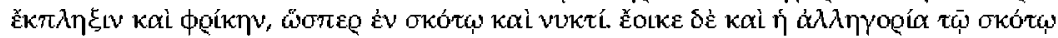

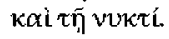


denn sie kann - im Nachgang zur emotionalen Erfahrung des Kultes - die rationale Erkenntnis in denselben befördern. Grundsätzlich ist festzuhalten, dass eine Allegorie nach antiker rhetorischer Tradition zwar nicht zu ,dunkel' sein darf, da sie ansonsten Gefahr läuft, für einen Teil der Rezipienten unklar zu bleiben, ${ }^{20}$ zugleich aber stellen, änigmatische' Allegorien einen besonderen Anreiz für das Chiffrieren von Wissen bzw. ihr Decodieren durch gewitzte Allegoresen dar.

Ein Beispiel für eine rätselhafte Allegorie ist - folgt man Porphyrios' Schrift De antro Nympharum, der einzigen längeren Allegorese einer Homerpassage, die aus der Antike überliefert ist, - die homerische Beschreibung der Nymphengrotte aus dem 13. Gesang der Odyssee:

Am Kopfende des Hafens steht ein langblättriger Ölbaum.
In seiner Nähe befindet sich eine liebliche dämmrige Grotte,
ein Heiligtum der Nymphen, die Naiaden genannt werden.
In ihr stehen steinerne Mischkrüge und Amphoren,
in denen Bienen ihren Honig sammeln,
und sehr hohe Webstühle aus Stein, an denen Nymphen
meerespurpurfarbige Tücher weben, - ein Wunder zu sehen!
Es gibt dort immer-fließendes Wasser, und die Grotte hat zwei Türen:
Die eine führt in Richtung Norden und ist ein Abstieg für die Menschen,
die andere führt in Richtung Süden und ist göttlicher; durch diese
gehen keine Menschen hinein, sondern das ist der Weg der Unsterblichen. ${ }^{21}$

Für Porphyrios und die lange exegetische Tradition dieser homerischen Passage, in die er sich mit Verweisen auf die Platoniker Numenios ( $\$ 10$, $21,34)$ und Kronios $(\$ 2,3,21)$ stellt, ${ }^{22}$ ist der Text in "verrätselter"

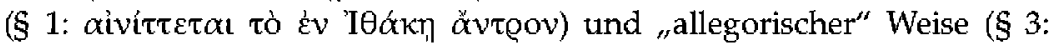

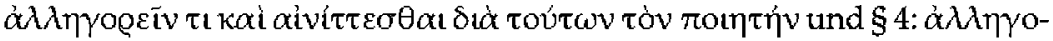

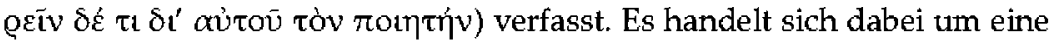
,geschlossene' Allegorie (allegoria tota), da sich weder über den Kontext noch innerhalb der Beschreibung Hinweise auf einen verborgenen Sinn finden. Für Porphyrios und seine Vorgänger ist es eindeutig, dass die allegorische Bedeutung der Nymphengrotte vom Autor intendiett ist und nicht bloß durch die Rezipienten an sie herangetragen wurde. So wird Homer in den Kapiteln 3 und 4 als verfertigendes Stubjekt der Allegorie bzw. des Verrätselns genannt, und Porphyrios macht in seinem Resümee

\footnotetext{
${ }^{20}$ Quint. Inst. or. VIII 6,52: sed allegoria, quae est obscurior, aenigma' dicitur, vitium meao quidem iudicio, si quidem dicere dilucide virtus, guo tamen et poetae utuntur. Zur rhetorischen Kritik an der Allegorie vgl. auch Anm.9.

${ }^{21}$ Hom. Od. XIII 102-112 (Übers. vom Verfasser).

${ }^{22}$ Zur Einordnung des B-Scholions zu Odyssee XIII 103 in die allegorische Tradition vgl. LAMBERTON 1986, 318-324.
} 
(\$36) ganz deutlich, dass die vorgelegte Allegorese die im Text verborgene Weisheit Homers freigelegt hat: $:^{23}$

Man darf aber nun nicht denken, dass Auslegungen dieser Art gezwungen seien und (lediglich) Überzeugungsversuche spitzfindiger Wortkünstler, sondern wentn man die alte Weisheit und die Vernunft Homers in ihrer ganzen Größe und seine grütndliche Kenntnis jeder Tugend in Betracht zieht, dann kann man nicht zurückweisen, dass er im erzählerischen Gewand eines Mythos Bilder von göttlicheren Dingen verrätselt hat. ${ }^{24}$

Bei seiner Deutung der Nymphengrotte bedient sich Porphyrios insofern einer geschickten rhetorischen Strategie, als er Homer nicht nur die Allegorie (und damit das Verrätseln eines bestimmten tieferen Sinns) auktorial zuschreibt, sondern ihn zum ,Interpreten seines eigenen Textes macht', indem er Homer in $\$ 34$ eigene (neuplatonische) Detutungen in den Mund legt. 25

Doch wie gibt sich die homerische Allegorie überhaupt als solche $\mathrm{zu}$ erkennen? Interessant ist der von Kronios übernommene Hinweis, dass

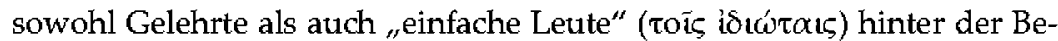
schreibung der Nymphengrotte einen allegorischen Sinn vermuten können (\$ 3). Damit erklärt Porphyrios sowohl die offensichtlichen logischen Brüche in der Beschreibung wie die Bezeichnung der Höhle als zugleich lieblich und dämmrig, das Weben in dunklerer Höhle oder die eigentlich aus der Kultpraxis zu erwartende, aber bei der Nymphengrotte gerade nicht realisierte Ostausrichtung des göttlichen Eingangs als (für einfache Leute erkennbare) Marker eines, anders Sprechens' als auch die fehlende Übereinstimmung der Nymphengrotte mit der ,Realität ${ }^{26}$ oder die philosophischen bzw. religiösen Konnotationen der verwendeten Bilder /

\footnotetext{
${ }^{23}$ Die produktionsästhetische Zuschreibung von Allegorien an Homer, der in ihnen philosophische Ideen formuliert habe, erfolgt besonders prägnant in Heraklits (1.-2. Jh. $\mathrm{n}$. Chr.) Quaestiones Homericae 1.

${ }^{24}$ Porph. Antr. 36.

${ }^{25} \mathrm{Vgl}$. zur rhetorischen Strategie der Suggestion auktorialer Wahrheitsverkündung in De antro Nympharum MrYer 2007, 136-138.

${ }^{26}$ Folgt man Porphyrios, dann war in antiken Geographien keine Übereinstimmung der homerischen Beschreibung mit einer wirklichen Nymphengrotte auf Ithaka erkennbar. Auch die moderne Forschung hat trotz verschiedenster Versuche, die Höhle zu lokalisieren - beispielsweise mit der Marmarospilia (vgl. F. H. StubeinGs, "Ithaca", in: A. J. B. WACB / F. H. Stubeings, A Companion to Homer [London 1962] [398-421] 416) bzw. der sog. Louizos-bzw. Polis-Höhle (hierzu M. Deoud, Ithake. Die Polis-Höhle, Odysseus und die Nymphen [Thessaloniki 2008]), keine überzeugenden Hinweise für ihre Existenz gefunden. Gleichwohl bezeugen die Votivgaben der Polis-Höhle (darunter zwölf bronzene DreifïBe) eine kultische Nutzung von Höhlen atuf Ithaka seit mykenischer Zeit, die Homer und Porphyrios bei ihren Gestaltungen bzw. Deutungen der Nymphengrotte gekannt haben könnten. Vgl. generell zu den Lokalisierungsversuchen der homerischen Odyssee und den methodischen Schwierigkeiten A. WoLf, Homers Reise. Auf den Spuren des Odysseus (Köln 2009) und St. WEsT, "The Transmission of the Text", in: A. Hвubbck / St. WBSt / J. B. HAInsWORTH (Hg.), A commentary on Homer's Odyssey, I: Introduction and Books I-VIII (Oxford 1988) [33-66] 63f. zu Ithaka. Nymphengrotten waren im griechischen Kulturraum weit verbrei-
} 
Symbole, die einem gebildeten Rezipienten auffallen würden. In beiden Fällen kann Porphyrios aus den für ihn wirkungsintentional verankerten Widersprüchen der Beschreibung ${ }^{27}$ ihre Erklärungsbedürftigkeit und damit die Notwendigkeit einer allegorischen Deutung der Nymphengrotte ableiten. Weitere Legitimation gewinnt er durch den Hinweis, dass schon die "Vorfahren" den Text entschlüsseln wollten (\$4) sowie durch das SichEinschreiben in die Tradition der allegorischen Auslegung dieser Stelle innerhalb der platonischen Schule.

Die homerische Nymphengrotte ist damit als Allegorie markiert, doch wie genau soll man sie verstehen? Die antike Allegorese hat viele Deutungsmöglichkeiten der homerischen Allegorien aufgezeigt, ${ }^{28}$ welche jeweils zum Tragen kam, wurde im spannungsreichen und höchst produktiven Streit über die Deutungshoheit der für die Erziehung und Bildung in der Antike wichtigsten Werke, der Epen Homers, immer wieder neu ausgehandelt. Mit Blick auf die Suche nach und Herausbildung von (philosophischen) Wahrheiten kann jede Homerallegorese im foucaultschen Sinn als Diskurs aufgefasst werden, den der Text De antro Nympharum mit Blick auf seine (möglichen) Entstehungskontexte, das intendierte Adressatenpublikum und die philosophische Ausrichtung des Autors Porphyrios kreativ mitgestaltet.

\section{Porphyrios und die neuplatonische ${ }^{29}$ Deutung von De antro Nympharum}

Der ,Sitz im Leben' von De antro Nympharum bzw. seine Stellung im Werk des Porphyrios ${ }^{30}$ ist unklar. Drei verschiedene Kontexte sind denkbar: Es könnte sich um eine alleinstehende Schrift handeln, die in der Tradition der philosophisch-exegetischen Zetemata (lat. quaestiones, vgl. die Bei-

tet, auch bei Homer werden mehrere erwähnt, eine auf der Insel des Helios (XII 317f). Vgl. hierzu auch den Beitrag von Irmgard Männlein-Robert in diesem Band, S. 107-110.

${ }^{27}$ Vgl. hierzu PÉPIN 1966, 251-258.

${ }^{28}$ Vgl. auch Pichler 2006, 32: „Erst dadurch, daß man zwar annimmt, Homer habe Allegorien gedichtet, daß es andrerseits aber keine feste Methode der Interpretation dafür gibt, eben keine objektive Wahrheit, sondern nur das ,Wissen' des einzelnen Deuters ausschlaggebend ist, kann es zu der Vielfalt allegorischer Deutung kommen, wie wir sie in der Antike vorfinden."

${ }^{29}$ Die Bezeichnung Neuplatonismus ist modern und dient - besonders in Abgrenzung zum Mittelplatonismus - der inhaltlichen und methodischen Unterscheidung verschiedener Richtungen der platonischen Philosophie und ihrer Lehrgemeinschaften bzw. Schulen. Zeitlich wird er vom 3. bis zum 5. Jh. n. Chr. angesetzt, zur Ausrichtung der netuplatonischen Schulen vgl. Prabchter 1910, zur geistesgeschichtlichen Einordnung Halfwassen 2004, 11-18.

${ }^{30} \mathrm{Zu}$ Leben und Werk des Porphyrios vgl. GoulEt 2012 und den Beitrag von Matthias Becker in diesem Band, S. 3-11; die Testimonien gibt SMITH 1993. 
spiele bei Gellius in den Noctes Atticae XVIII 2-4) ein einzelnes Problem

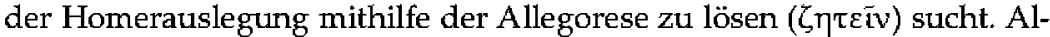
lerdings deutet der elliptische Einstieg in die Schrift mit der indirekten

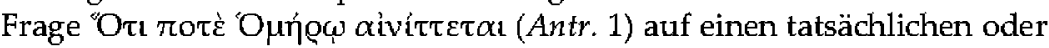
zumindest von den intendierten Rezipienten leicht zu ergänzenden Kontext an, der außerhalb der überlieferten Schrift liegt. Die Formulierung, die Porphyrios gegen Ende seiner Schrift in ausgeführter Weise wieder-

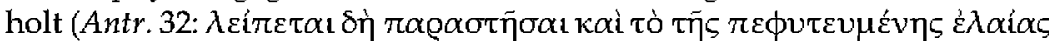

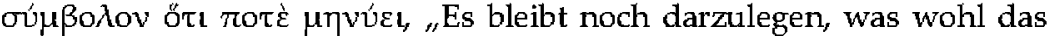
Symbol des gepflanzten Ölbaums anzeigt"), erinnert an die sokratische Gesprächsführung in platonischen Dialogen, die der Platoniker Porphyrios bewusst adaptiert zu haben scheint. ${ }^{31}$ Der elliptische Einstieg in die Schrift würde - ähnlich einer Diatribe - Mündlichkeit suggerieren, die den Lehrer Porphyrios in einem Vortrag vor seinen Schülern inszenieren soll. Eine zweite Möglichkeit wäre die Annahme eines tatsächlichen Werkkontextes, aus dem De antro Nympharum herausgelöst wurde oder nur partiell überliefert ist. Letzteres wäre wahrscheinlicher, da bei einer intentionalen Herauslösung - etwa zum Zweck der Einzelveröffentlichung - der ungewöhnliche elliptische Beginn wohl korrigiert worden wäre. ${ }^{32}$ Schließlich kann nicht ausgeschlossen werden, dass De antro Nympharum als Teil eines größeren Projektes zur Homerallegorese gedacht war, das von Porphyrios nicht weiterverfolgt wurde. In jedem Fall wird das Zetema ganz am Ende der Schrift ebenso als gelöst betrachtet, wie sich Raum für weitere Allegoresen öffnet, die sich anschließen könnten (aber nicht müssen): $\alpha \lambda \lambda \grave{\alpha}$

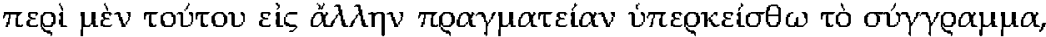

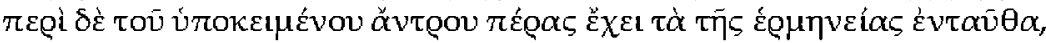
"Aber die Abhandlung hierüber soll einem anderen Werk vorbehalten sein; die an dieser Stelle vorgebrachten Auslegungen der betrachteten (homerischen) Grotte sind hier zu Ende. ${ }^{\prime 33}$

Auch über die Datierung lassen sich nur Vermutungen anstellen, da sich keine textimmanenten Hinweise auf eine Abfassungszeit finden und Versuche, aus den dort geäußerten philosophischen Gedanken in Relation $\mathrm{zu}$ anderen Werken eine relative Chronologie zu erstellen, oder das Werk vor bzw. nach Porphyrios Begegnung mit Plotin anzusetzen, schei-

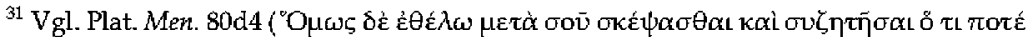

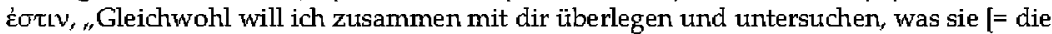
Tugend] wohl ist") und MrYrR 2007, 133 mit weiteren Stellen.

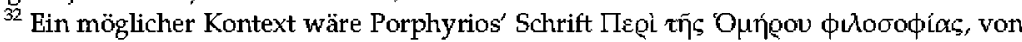
der allerdings nur der Titel im Sucla-Lexikon überliefert ist(Porph. 371T. SMITH), vgl. Christoph Riedweg in diesem Band, S. 78.

${ }^{33}$ Porph. Antr. 36. Vergleiche zur Stelle auch Mgrgr 2007, 135: „Porphyrios selbst kündigt im letzten Satz der Schrift eine weitere Pragmatie an, die letzten Worte von De antro konstatieren das Ende der vorliegenden ẹ́
} 
tern. ${ }^{34}$ Nicht überzeugend sind Hypothesen, die den Text aufgrund von philosophischen "Unausgeglichenheiten" (Alt 1998, 487) oder mangelnder "Einheitlichkeit und Widersprüchlichkeit" der Allegorese (Welt 2009, 26) als Früh- bzw. Jugendwerk des Porphyrios einschätzen. Zum einen ist die Überlieferungslage längerer antiker Allegoresen (zu homerischen Stellen) zu dünn, um die Gestaltung von De antro Nympharum vergleichend als typisch oder untypisch für eine womöglich ,pluralistische ${ }^{\prime 35}$ vielstimmige literarische Form beurteilen zu können, zum anderen ist nicht sicher zu klären, welche Gedanken von Porphyrios selbst stammen und welche er referiert ohne seine Gewährsmänner zu nennen. Im Übrigen suggeriert die Annahme eines nicht stringent platonisch argumentierten Jugendwerkes, dass ein ,erwachsener' Porphyrios (stets) ganzheitlich denken und widerspruchsfrei schreiben würde, was bei Porphyrios - wie Praechter (1910, 122-128) gezeigt hat - nicht der Fall ist.

Zentral für Porphyrios' Philosophie und damit auch für seine Allegorese der homerischen Nymphengrotte ist die spezifisch neuplatonische Auslegung und Ausrichtung des platonischen Denkens; zu ihren Charakteristika ${ }^{36}$ gehören:

- Das Bestreben der Harmonisierung von Platon und Aristoteles, zu der Porphyrios einen entscheidenden Beitrag geleistet hat, da er sowohl platonische als auch aristotelische Schriften kommentierte und die Integration der aristotelischen Kategorien in die platonischen Studien ermöglichte.

- Die Weiterentwicklung der Ontologie Platons. Die Neuplatoniker strukturieren den Bereich des Intelligiblen neu, indem sie drei hierarchisch angeordnete Hypostasen (,Seinsstufen") annehmen, die jeweils auf die darunter liegende, ausstrahlen' bzw. diese, hervorgehen' lassen (sog. Emanation): Am höchsten steht "das Eine" ( (voūs) und "der Seele" ( $\psi \chi \chi \eta)$ ), die wiederum die sinnliche Materie erzeugen kann. ${ }^{38}$ Sitz der platonischen Ideen ist nach diesem Modell "der Geist",

\footnotetext{
${ }^{34}$ Vgl. die Diskussionen bei Buffik̀re 1956, 420; Edwards 1996, 88f.; TurCan 1975, 6264; Simonini 1986, 30f.; Penati Bernardini 1988, 119-121; Alt 1998, 467 u. 487; Maurette 2005, 74-79 und WeLt 2009, 26.

${ }^{35}$ Hierzu siehe PÉPIN 1966, 241-250.

${ }^{36} \mathrm{Vgl}$. ausfiuhrlich J. CoulTER, Literary Microcosm: Theories of Interpretation of the Later Neoplatonists. CSCT 2 (Leiden 1976) 95-126.

${ }^{37}$ Nur indirekte Erkenntnis des obersten Prinzips ( $\tau$ ò $\check{E} v$ ) ist durch Verfahren der Analogie, Metapher und vor allem Negation möglich (sog. apophatische Theologie). Vgl. tumfassend W. BerkRwaLtes. Denken des Einen. Studien zur netuplatonischen Philosophie thd ihrer Wirkungsgeschichte (Frankfurt 2016).

${ }^{38}$ Zur netplatonischen Ontologie und ihrem Verhältris zur sog. Henologie, der die Transzendenz des absoluten Einen als sog. negative Theologie zugrunde liegt, vgl. D. CürsGBN, Henologie und Ontologie. Die metaphysische Prinzipienlehre des späten Netuplatonismus (Würzburg 2007).
} 
der eine dynamische Entität darstellt, die als Derivat "des Einen” zugleich eine Ganzheit ist und die Vielheit der Ideen in sich trägt.

- Die von Plotin proklamierte Identität von Denken und Sein im voū als extreme Form der Selbsterkenntnis, die ein zweifelsfreies Erkennen und Wissen ermöglicht. ${ }^{39}$

- Die synkretistische Tendenz der Inanspruchnahme möglichst vieler philosophischer und religiöser Traditionen (besonders der Orphik und der Lehre des Pythagoras) für platonische Ideen mit dem Ziel des Erkennens eines ,alten, wahren Logos', wie es der Platoniker Kelsos (2. Jh. n. Chr.) in seiner Schrift Alethés lógos formulierte. ${ }^{40}$

- Die Harmonisierung des ,göttlichen' Homer mit Platon, der ihn wegen unwahrer Darstellungen der Götter kritisierte (Rep. II $376 \mathrm{~b}-378 \mathrm{e})^{41}$ und - wie alle Dichtungen - aufgrund ihres wahrheitsfernen mimetischen Status (Rep. X 595a-605c) und des Erregens von Affekten, die die Seele gefährden (Rep. III $387 \mathrm{~b}-\mathrm{d}$ ), ablehnt. Vor allem die Allegorese bot sich als Möglichkeit an, den verborgenen - mit Platons Lehre zu vereinbarenden Sinn zu finden ${ }^{42}$ und Homer "nicht nur als Prototyp des dem Mythos verpflichteten Dichters, sondern auch als Prototyp des dem Logos verpflichteten Philosophen, der sich hinter dem Dichter verbirgt ${ }^{\prime \prime}$, zu deuten. ${ }^{43}$

De antro Nympharum ist eine neuplatonische Allegorese. ${ }^{44}$ Platon selbst wird sieben Mal mit Bezug auf unterschiedliche Werke (Timaios, Politeia, Symposion, Gorgias) namentlich erwähnt $(\$ \S 8,16,22,29,30,31,34)$, was

\footnotetext{
${ }^{39} \mathrm{Vgl}$. HALFWASSEN 2004, 59-64 und K. KREMBR, Die neuplatonische Seinsphilosophie und ihre Wirkung auf Thomas von Aquin (Leiden 1971) 82, zu Plotin: „Der Geist kann daher sowohl als energetisches Prinzip wie als Seinsprinzip angesprochen werden. ... Es ist die Totalität alles Seienden in seiner Ideal-Gestalt, und diese Totalität ist in einer einzigen Form oder Idee, der des Seins aufgehoben. ... Der plotinische Nus wäre nicht nur reines Denken ..., sondern zugleich reines Sein."

${ }^{40}$ Nach Kelsos (ed. BADBR 1940) sei dieser, bei vielen Völkern feststellbare „alte Logos" $(1,14 a)$ auch Platon bekannt gewesen $(6,10)$, der ihm eine besonders eingängige Form verliehen habe.

${ }^{41}$ Hierzu vgl. S. Wrinstock, "Die platonische Homerkritik und ihre Nachwirkung", Philologus 36 (1927) 121-153 und LAMbERTON 1992.

${ }^{42}$ Zum spezifisch netplatonischen Umgang mit Allegorie und Allegorese siehe P. T. STRUCK, "Allegory and ascent in Neoplatonism", in: CoPBLAND / STRUCK 2010, 57-70.

${ }^{43}$ W ELT 2009, 20; vgl. attch (mit Betonung der Homerallegorese des Proklos) PICHLER 2006, [66-72] 71: „Homers Aussagen stehen aber nicht nur für sich. Für die Neuplatoniker hat Homer schon alle wesentlichen Lehren festgelegt und allegorisch dargestellt ... Damit ist das ganze Feld der neuplatonischen, Theologie' abgesteckt. Homers Werke bilden geradezu den theoretischen Hintergrund für die praktischen religiösen und mystischen Handlungen."

44 Vgl. die Analysen von PÉpIN 1966, ALt 1998 und S. ToulousB, sLa lecture allégorique d'Homère chez Porphyre: principes et méthode d'une pratique philosophique", La lecture littéraire. Revue de recherches sur la lecture des textes littéraires 4: L'allégorie (Reims 2000) 25-50. Speziell zu Anlehnungen an Plotins Unsterblichkeitslehre siehe A. Pletsch, Plotins Unsterblichkeitslehre und inre Rezeption bei Porphyrios (Stuttgart 2005) I69-176.
} 
ihn zum wichtigsten Referenzautor neben Homer macht. Das für die neuplatonische Ontologie typische ,Ausstrahlen' des Göttlichen in die jeweils niedere Seinsstufe und von da in die sinnliche Materie wird in $\$ 16$ fassbar, wo bei der Beschreibung der Kastration des Kronos "die göttlichen Teile durch Lust gefesselt und zum Werden herabgeführt werden und in Lust aufgelöst ihre Kräfte aussähen". Die synkretistische Tendenz des Neuplatonismus zeigt sich im Ausgreifen auf ganz unterschiedliche literarische, philosophische, religiöse Traditionen ${ }^{45}$ und Praktiken, die von Zoroaster (Zarathustra) und Mithras ${ }^{46}$ über ägyptische und orphische Lehren, griechische Dichtung (Homer, Hesiod, Sophokles), ${ }^{47}$ Geographie, Astronomie, ${ }^{48}$ verschiedene philosophische Lehren bis zur römischen Festkultur der Saturnalien (\$ 23) reichen. ${ }^{49}$ Dieser breite Bezugshorizont zeigt nicht nur die Gelehrsamkeit des Verfassers, sondern unterstreicht auch die umfassende Gültigkeit der neuplatonischen Lehre im Sinne des ihr zugrunde liegenden, alten und wahren Logos'.

Bei der Allegorese fällt auf, dass die Deutungen im Verlauf der Schrift eigenständiger zu werden scheinen und die platonischen Ansichten eindeutiger formuliert werden; auch die Referenzen auf Platon nehmen in der zweiten Hälfte von De antro Nympharum deutlich zu (s.o.). Eine Erklärung liefert die Anlage der Schrift, die mit der exegetischen Tradition und längeren Referaten (vornehmlich aus Kronios und Numenios) beginnt, ehe eigene Gedanken zum Tragen kommen, mit denen die (neu-)platonische Lehre am Ende telelogisch ausgebreitet wird: Die Darlegung der letzten offenen Frage "was wohl das Symbol des gepflanzten Ölbaums anzeigt" (§32) erfolgt anders als die Erörterungen zuvor ganz ohne Verweise auf die literarische bzw. philosophische Tradition - mit Ausnahme Platons und seines Exegeten Numenios (beide § 34). Und wenn Porphyrios am Ende von $\S 31$ feststellt, dass er nicht beabsichtigt, seine "Abhandlung durch das Erwähnen von Meinungen der alten Philosophen und Theologen (unnötig) zu verlängern", dann ist der methodische Bruch in der Allegorese unverkennbar: Die letzte Frage wird von Porphyrios weitestgehend selbst beantwortet ${ }^{50}$ Diese Beobachtung erklärt auch die vermeintliche Unstimmigkeit in der Deutung der Grotten als Kosmos in $\$ 5$, wo - entgegen der platonischen Lehre - von einem selbst-entstehenden Kosmos die Rede

\footnotetext{
${ }^{45}$ Zur möglichen Auseinandersetzung mit den, Gnostikern' in De antro Nymphartum vgl. Edwards 1996; eine implizite Kritik am Christentum sieht MaUrbTtr 2005, 72-81.

${ }^{46}$ Hierzu siehe TurCan 1975, 62-89, Maurette 2005 und Christoph Riedweg in diesem Band, S. 85-96.

${ }^{47}$ Zur Rolle der Dichtung in De antro Nympharum vgl. MeYBR 2007.

${ }^{48} \mathrm{Vgl}$. den Beitrag von Benjamin Topp in diesem Band, S. 117-139.

${ }^{49}$ Vgl. die Zusammenstellung bei WRLT 2009, 26, Anm. 62.

${ }^{50}$ Vgl. hierzu auch ALt 1998, 487, die allerdings den Widerspruch zu Kapitel 5 als Problem belässt (470-474); ebenso - claran anschließend - WвLт 2009, 26.
} 
ist. ${ }^{51}$ Offensichtlich referiert Porphyrios hier die Meinung vorsokratischer Philosophen, wogegen er in $\$ 32$ die planmäßige Erschaffung des Kosmos durch das vernünftige Wirken des Demiurgen aufruft, wie es Platon im Timaios entworfen hat:

Denn da der Kosmos nicht planlos oder zufällig entstanden ist, sondern das Ergebnis des vernünftigen Plans eines Gottes und einer rationalen Natur ist, wurde der Ölbatm neben das Bild des Kosmos, d.h. neben die Höhle, als ein Symbol der göttlichen Vernunft gepflanzt. ${ }^{52}$

Die zentrale Bedeutung des Ölbatums, der bei Homer die Ortsbeschreibung einleitet und etwas abseits "in der Nähe" der Grotte steht (Od. XIII 102), für die Allegorese der Nymphengrotte wird von Porphyrios mit dem Hinweis unterstrichen, dass er "das (gesamte) Rätsel der Grotte umfasst"

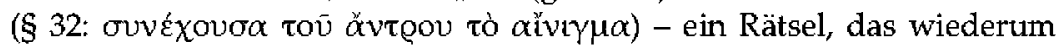
Porphyrios durch seine Deutung lösen kann. Und diese ist letztlich auf eine ganzheitliche Interpretation der Odyssee atusgerichtet, indem in den Schlusskapiteln die Irrfahrten des Odysseus als Bild für die Menschen gesetzt wird, die wie Odysseus ihre Leidenschaften bekämpfen müssen, um ihre (gereinigten) Seelen ganz der Athene, d.h. dem verstandesmäßigen Denken bzw. dem voū ç im netuplatonischen Sinn zuwenden zu können. ${ }^{53}$ Damit schließst die Allegorese mit einer Hinwendung zu dem ethischen Aspekt der Reinigung und des Heils der Seele, mit dem eine paränetische Wirkungsabsicht verbunden zu sein scheint.

Homers Beschreibung der Nymphengrotte mit ihren beiden Türen ist - folgt man Porphyrios - eine Allegorie des Entstehens und Vergehens menschlicher Seelen, die im Leben der sinnlich erfahrbaren materiellen Welt zugewandt sind und - im Bild der gerechten Bienen (\$ 19) - zu ihrer überirdischen, göttlichen Heimat zurückkehren wollen. Zwar erzählt wie Hans Blumenberg in seinen Höhlenausgänge[n] bemerkt - die homerische Allegorie als eine ,Versammlung und Aneinanderreihung von Symbolen' keine Geschichte, ${ }^{54}$ aber die (Re-)kontextualisierung mit der epischen Handlung der Odyssee in Porphyrios' Allegorese verleiht ihr eben diese: „Odysseus wäre die Figur der Seele, die nach ihrer Irrfahrt durch die Welt heimkehrt in das Reich ihrer Herkunft, nach Ithaka."55

So stark Porphyrios' De antro Nympharum in der Forschung zu Homer und zur (antiken) Technik der Allegorese rezipiert wurde, so schwach

\footnotetext{
${ }^{51}$ Eine ausfïhrliche Analyse der Höhle als Motiv und ihrer allegorischen Deutungen gibt Irmgard. Männlein-Robert in diesem Band, S. 97-116.

${ }^{52}$ Porph. Antr. 32.

${ }^{53} \mathrm{Vgl}$. LamberTon 1992, [124-130] 127: „The Odyssey, we are being told, is a poem about the fate of souls, and more specifically, this epic relates the progress of one single soul through the realm of matter ( away."

${ }^{54}$ Vgl. BLUMENBERG 1989, 238.

${ }^{55}$ BLuMbNeERg 1989, 240.
} 
sind die Spuren einer kreativen Rezeption dieses Textes. Zwar findet sich das Motiv der Nymphengrotte häufig in Literatur und Kunst, nicht aber die Allegorese derselben, die von ihrem homerischen Hypotext überlagert wird. ${ }^{56}$ Gleichwohl könnten einzelne Deutungsmuster und Interpretationen aus De antro Nympharum Anstöße für künstlerische Ausgestaltungen gegeben haben, die ganz unabhängig von der homerischen Höhlenmotivik etwa aus der Deutung der Nymphen als Seelen entstanden sind. Ein Beispiel wäre Goethe, der sich im Jahr 1806 ein Exemplar von De antro Nympharum ausgeliehen hatte und die Kenntnis von Porphyrios' Allegorese für die Gestaltung seiner Seelenwanderungsvorstellungen verwendet haben könnte. ${ }^{57}$

\section{Gliederung von De antro Nympharum}

\section{A. Einleitung}

\$1-4 Zitat der homerischen Beschreibung der Nymphengrotte (Od. XIII 102-112); Annahme einer Allegorie aufgrund der rätselhaften bzw. unglaubwürdigen Beschreibungen ( $\$ 2$ u. 4) sowie Auflistung der Fragestellungen und Themenfelder für die Allegorese $(\$ 3)$.

\section{B. Allegorese der homerischen Beschreibung der Nymphengrotte}

\section{\$5-10 Deutung der Grotte}

Unter Rückgriff auf die philosophisch-literarische Tradition wird die Grotte selbst als aus Materie gewordener Kosmos und als Symbol der unsichtbaren Kräfte gedeutet; Stein und Fels sind Symbole der festen Materie, die Feuchtigkeit hingegen Symbol für das Fließen und die Unförmigkeit von Materie (\$ 5). Erklärung des homerischen Paradoxons, dass die Grotte sowohl lieblich als auch dämmrig ist, und Verbindung zur Initiation eines Mysten im Mithraskult (\$6). Die düstere Grotte ist auch ein Symbol der unsichtbaren Kräfte im Kosmos ( $\$ 7$ und 9), Hinweis auf Nymphen bzw. Seelen als Bewohnerinnern der Grotte (\$8). Zusammenfassende Bemerkung, dass Grotten in der

\footnotetext{
${ }^{56}$ Vgl. den Beitrag von Reinhold F. Glei in diesem Band, S. 141-163.

${ }^{57}$ Hierzu siehe G. Colombo, "Goethe und die Seelenwanderung", Goethe Jahrbuch 129 (2012) [39-47] 40. So könnte der Titel des Gedichts (von der Seelenwanderung) Gesang der Geister iuber dem Wasser (1799) von cler Vorstellung der "ïber dem Feuchten schwebenclet

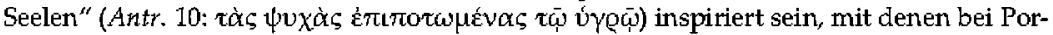
phyrios die Gestalt der Naiaden verbunden ist, die als ,Vorsteherinnen über das Wasser" (\$8) "durch den Hauch der Muse zum göttlichen Gesang aufgezogen" wurden (\$ \&; dort als Zitat aus einem Apollonhymnus). Auch die Feuchtigkeit der Seele durch Wasser (Antr. 10. 11) ist ein zentrales Motiv in Goethes Gedicht ("Des Menschen Seele / Gleichtdem Wasser", If.).
} 
philosophisch-religiösen Tradition sowohl als Symbole für den intelligiblen als auch für den sinnlich wahrnehmbaren Kosmos aufgefasst werden können (\$9). Wegen ihrer zwei Türen, von denen eine für die Menschen ist, kann die homerische Nymphengrotte kein Symbol des intelligiblen Kosmos sein ( $\$ 10$ ).

\section{\$10-14 Deutung der, naiadischen Nymphen'}

Die Nymphen werden zunächst allgemein als Seelen, die zum Werden herabsteigen ( $(10)$ bezeichnet. Bei ihrer Inkarnation müssen sie sich zum Feuchten wenden (§11), sie sind aber zugleich luftig (\$12). Dann Unterscheidung zwischen naiadischen Nymphen, deren Symbole die Kratere und Amphoren sind (\$13), und den Seelen, für die die Webstühle symbolisch stehen, an denen ihnen die Nymphen im Bild des meerespurpurfarbigen Gewandes Fleisch ,annähen', denn "der Körper ist das Gewand der Seele" (\$ 14).

\section{§15-19 Deutung der Bienen und des Honigs}

Referat über verschiedene Bedeutungen des Honigs in orphischer Tradition sowie im Mithraskult, darunter die reinigende und schützende Wirkung ( $\$ 15$ ) sowie seine konservierende Funktion; zudem wird die Überlistung des Kronos in orphischer Tradition durch das Trunkenmachen mit lustbringendem Honig beschrieben und mit dem Ausströmen des Göttlichen in die sinnlich wahrnehmbare Welt verbunden (\$ 16); Deutung der Kratere und Amphoren als Symbole der Quellen (\$ 17) und der Bienen zunächst als Symbol für die Seelen allgemein sowie konkret für Priesterinnen im Demeter- und Mithraskult (\$ 18). Spezifizierung der Bienensymbolik für, gerechte' Seelen, die gottgefällig gelebt haben und zu ihrem Ursprung zurückkehren wollen (\$ 19).

\section{\$20-31 Deutung der beiden Türen}

Hinweis auf die kultische Bedetutung der Grotte im griechischen Kulturraum und auf die zweitürige homerische Grotte mit Betonung der Besonderheit, dass die südliche Tür "der Weg der Götter" ist (\$20). Detutung der Grotte als Symbol des Kosmos mit Blick auf die Gestirne und die beiden (winterlichen und sommerlichen) Wendekreise (\$21); Zuordnung der Planeten zu den Tierkreiszeichen; die Tür, durch die Seelen hinabgehen symbolisiert den nördlich gelegenen Krebs, die andere den südlich gelegenen Steinbock (\$ 22). Die nördlich gelegene Tür (Krebs) ist der Abstieg für die zum Werden gehenden Seelen, die südliche (Steinbock) der Aufstiegsweg der unsterblichen Seelen, die zu den Göttern hinaufsteigen. Vergleich mit dem römischen Saturnalienfest, bei dem die Freiheit der Sklaven mit der Freiheit der Seele in Bezug gesetzt wird (\$ 23); Hinweis auf den ägyptischen Ka- 
lender, der im Sternzeichen des Krebses beginnt und Vergleich mit der Darstellung von Mithras als Sternbild und seiner kultischen Ikonographie, da er "in der rechten Hand die nördlichen Teile und in der linken die südlichen Teile hält" (\$ 24). Zuordnung von Winden zu den Seelen: die zur Entstehung gehenden werden vom kalten Nordwind begleitet und verfestigt, die zum Göttlichen strebenden vom warmen Südwind aufgelöst und leicht gemacht (\$ 25). Zuweisung eines erotischen Wesens an den Nordwind am mythischen Beispiel des Boreas (\$26). Beweis der Heiligkeit von Toren durch Vergleiche mit kultischen Praktiken und mythischen Darstellungen (Pythagoreer, weise Ägypter, Homer) (\$27) und abschließende Nobilitierung der Tore durch den Hinweis auf die homerischen Sonnentore (Od. XXIV 12) und die pythagoreische Verortung der Seelen in der Milchstraße $(\$ 28)$. Zusammenfassung der Ergebnisse und Betonung der Dualität der Natur, die „überall auf der Welt das Doppeltürige zu ihrem Symbol" hat (\$ 29). Deutungen der Seelen als Vorratsgefäße, die unterschiedliche Eigenschaften und Energien sowie Gaben beinhalten ( $\$ 30$ ). Abschluss der Allegorese: „Die eine Tür ist passend für die Götter und die Guten, die andere aber für die Menschen und die Schlechteren" (\$ 31).

\section{Allegorese des Ölbaums}

\$32-35 Klärung einer letzten Frage nach der Funktion des Ölbatums im Eingangsvers der homerischen Beschreibung der Nymphengrotte. Deutung als Symbol für Vernunft und göttliche Weisheit, aus dem der Kosmos planvoll entstanden ist (\$ 32). Die physischen Eigenschaften des Ölbaums spiegeln die (beschriebenen) Wechselfälle der Seele im Kosmos wider; der Ölbatum ist Athene geweiht und damit vernunftdurchwirkt, er ist "der Demiurg, der den Kosmos zusammenhält" (\$ 33). Erweiterung der Allegorese auf die ganze Odyssee: Der Mensch muss seine Leidenschaften bekämpfen und wie Odysseus seinen Besitz in der Höhle ablegen und sich als Bettler von allen irdischen Sinneswahrnehmungen befreien, um sich dem Göttlichen in persona Athenes zuwenden zu können (\$34). Abschließender Verweis auf die Bedeutung des unmittelbaren Kontextes der Nymphengrotte, den "Hafen des Phorkys" (Od. XIII 96), dessen Funktion in einer Erinnerung an die frühere Verfehlung des Odysseus (Blendung des Kyklopen), die ihn zu einem Schutfflehenden macht, der erst dann wirklich frei ist, wenn er die Leiden des irdischen Daseins überwunden hat und, ganz vom Meer entfernt herausgekommen und in Gemeinschaft von solchen Seelen [ist], die die Werke des Meeres und der Materie nicht kennen" (\$35). 


\section{Resümee}

Abschluss der Allegorese mit dem Hinweis, dass die Detutungen nicht vom Verfasser künstlich gesucht und gefunden wurden, sondern von Homer als Allegorie in den Text hineingelegt wurden. Porphyrios hat die "Wahrheiten" aufgedeckt, die der Dichter selbst in seiner alten "Weisheit" und "Vernunft" formuliert hat $(\S 36)$.

\section{Textgestaltung}

Der griechische Text dieser Ausgabe basiert auf Porphyry. The Cave of the Nymphs in the Odyssey. Seminar Classics 609, Arethusa Mongraphs 1 (Buffalo 1969) (= Arethusa-Text). Auf die Erstellung eines Apparats wurde verzichtet, in den Anmerkungen werden einzelne textkritische Entscheidungen $\mathrm{zu}$ folgenden Abweichungen vom Arethusa-Text diskutiert:

\section{Baumbach}

今 4, Z. 10: <...>

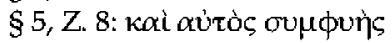

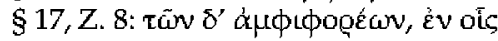

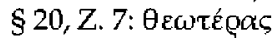

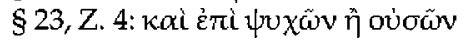

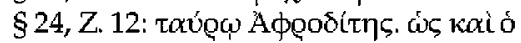

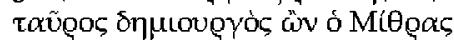

\section{Arethusa-Text}

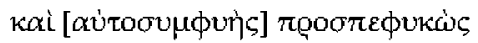

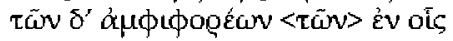

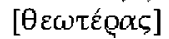

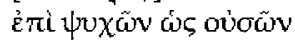

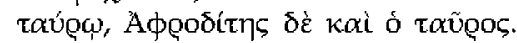

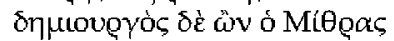

Jede dieser Textvarianten ist im griechischen Text durch einen Asteriskos $\left.{ }^{*}\right)$ markiert. 

B. Text, Übersetzung und Anmerkungen 


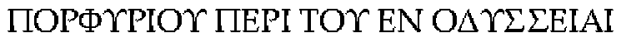

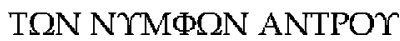

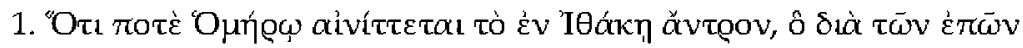

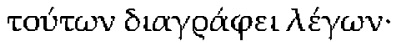

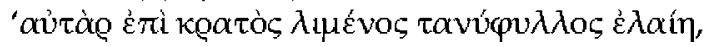

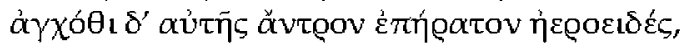

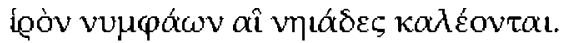

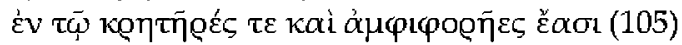

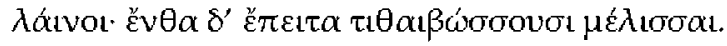

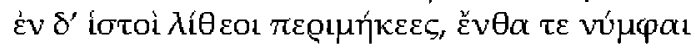

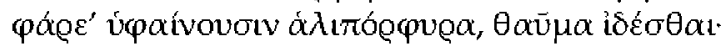

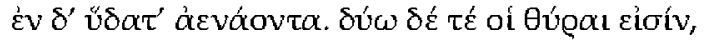

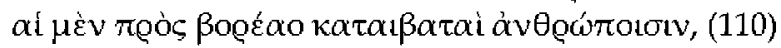

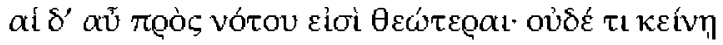

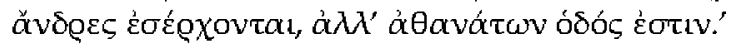

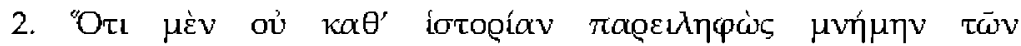

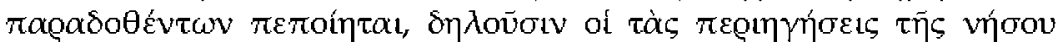

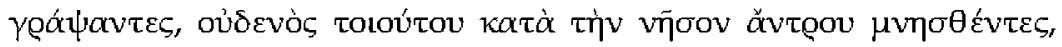

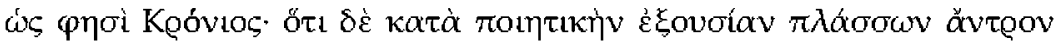

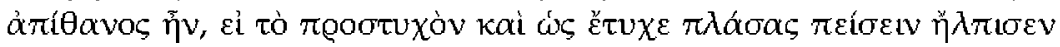

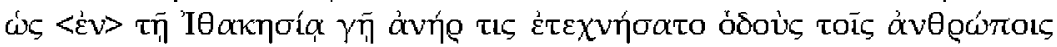

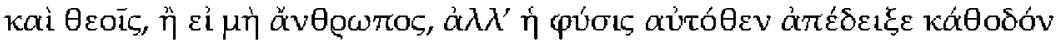

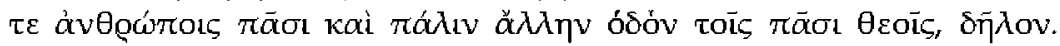

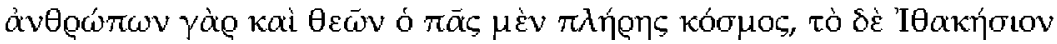

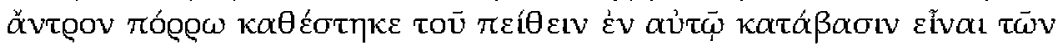

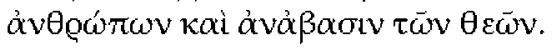

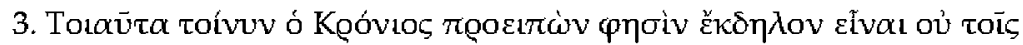

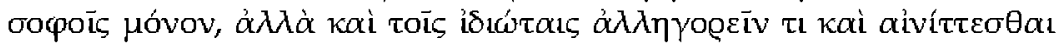

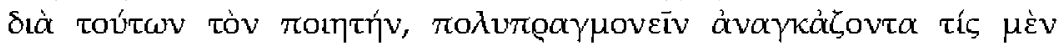

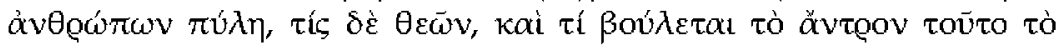

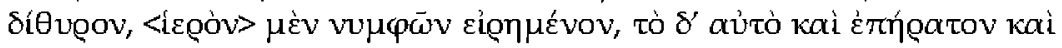

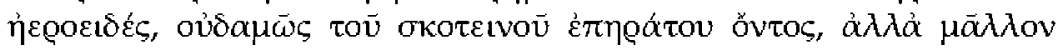


Porphyrios, Über die Nymphengrotte in der Odyssee ${ }^{1}$

1. [Es ist zu untersuchen], ${ }^{2}$ was Homer in verrätselter Form mit der Grotte auf Ithaka sagen will, die er in diesen Versen so beschreibt: "Am Kopfende des Hafens steht ein langblättriger Ölbaum. In seiner Nähe befindet sich eine liebliche dämmrige Grotte, ein Heiligtum der Nymphen, die Naiaden genannt werden. In ihr stehen steinerne Mischkrüge und Amphoren, in denen Bienen ihren Honig sammeln, und sehr hohe Webstiuhle aus Stein, an denen Nymphen meerespurpurfarbige Tücher weben, - ein Wunder zu sehen! Es gibt dort immer-fließendes Wasser, und die Grotte hat zwei

Türen:

Die eine führt in Richtung Norden und ist ein Abstieg für die Menschen, die andere führt in Richtung Süden und ist göttlicher; durch diese gehen keine Menschen hinein, sondern das ist der Weg der Unsterblichen." 3

2. Dass Homer nicht unter Rückgriff auf wirkliche Kunde die zitierten Dinge erwähnt hat, beweisen Verfasser von geographischen Beschreibungen ${ }^{4}$ der Insel, die, wie Kronios ${ }^{5}$ sagt, keine solche Grotte auf der Insel erwähnen. Zugleich ist es klar, dass er auch als Dichter einer Grotte in seiner poetischen Freiheit unglaubwürdig erscheinen würde, wenn er gehofft hätte, durch eine zufällige und beliebige Gestaltung glaubhaft machen zu können, dass auf Ithaka irgendjemand künstlich Wege für Menschen und Götter angelegt hat, oder - wenn es kein Mensch war dass die Natur dort ganz von selbst nicht nur einen hinabführenden Weg für alle Menschen, sondern auch noch einen anderen Weg für alle Götter aufgezeigt hat. Freilich ist der ganze Kosmos voll von Menschen und Göttern, aber was die Grotte auf Ithaka betrifft, so ist es kaum glaubwürdig dass es in ihr einen Weg hinab für die Menschen und einen Weg hinauf für die Götter gibt.

3. Im Anschluss an diese Vorbemerkungen sagt Kronios, dass es nicht nur für die Gebildeten, sondern auch für die einfachen Leute überaus deutlich sei, dass der Dichter durch diese Worte irgendwie allegorisch und verrätselt spricht, und [uns] dadurch zwingt, begierig danach zu forschen, welche Tür für die Menschen und welche für die Götter ist, und was wohl die doppeltürige Grotte bedeutet, die Nymphenheiligtum genannt wird und sowohl lieblich als auch dämmrig ist, da ja die Dunkelheit auf keine Weise lieblich, sondern viel eher furchteinflößend 


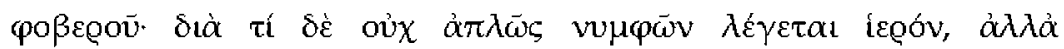

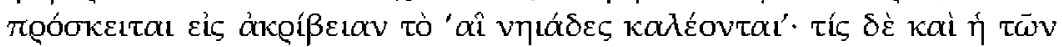

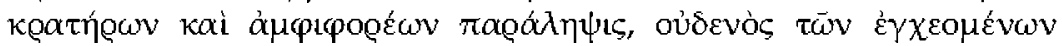

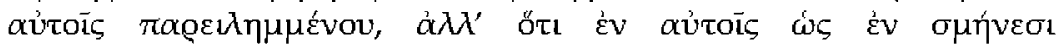

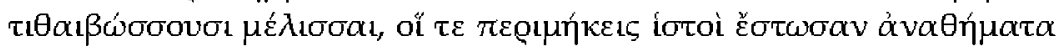

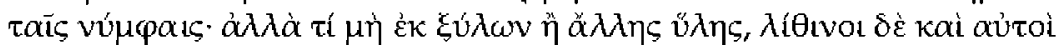

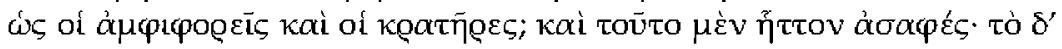

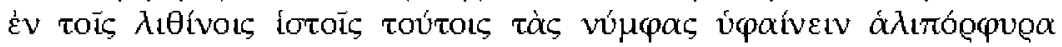

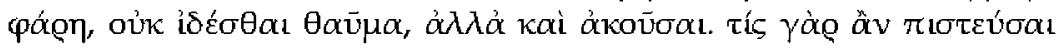

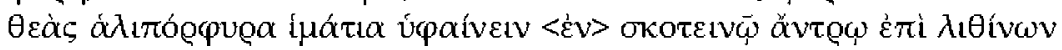

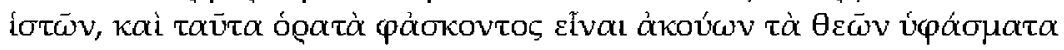

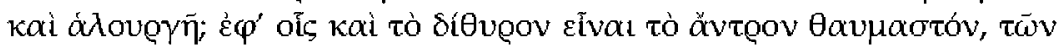

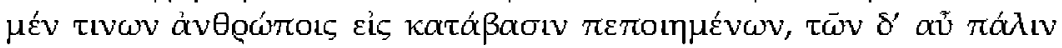

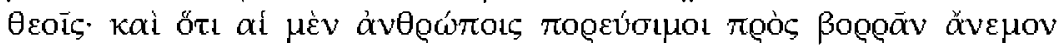

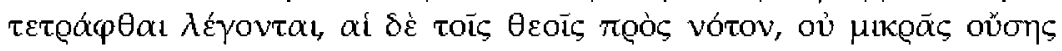

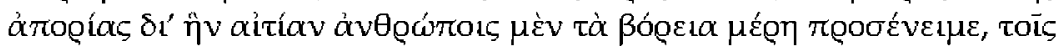

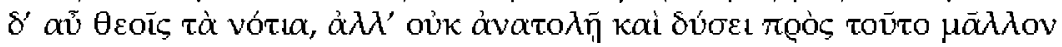

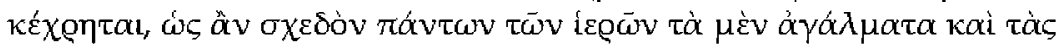

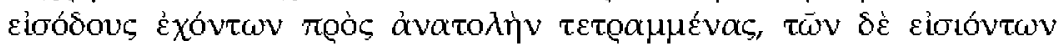

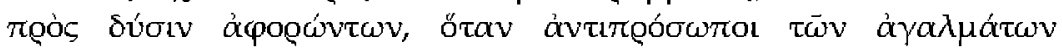

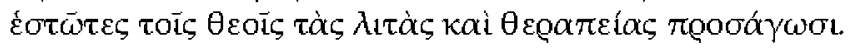

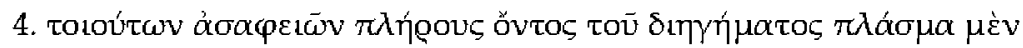

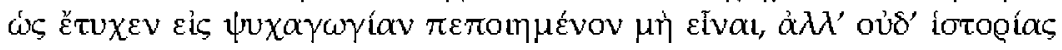

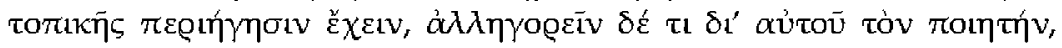

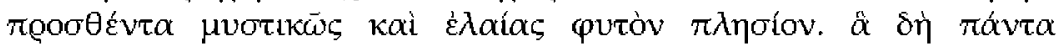

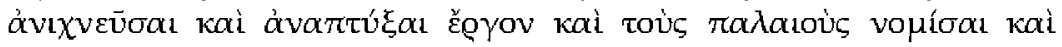

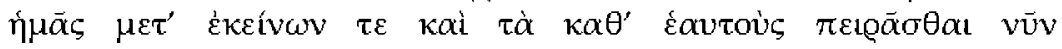
àveveí

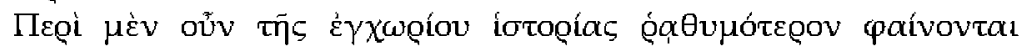

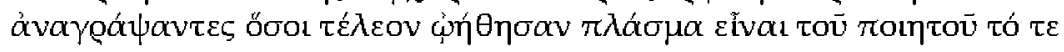

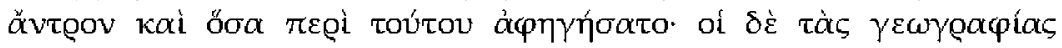

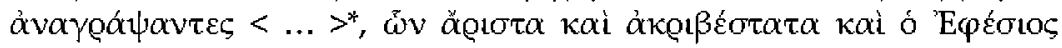

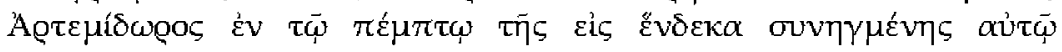

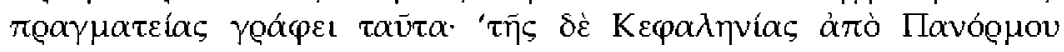


ist. ${ }^{6}$ Und warum wird die Grotte nicht einfach ,Heiligtum der Nymphen' genannt, sondern noch speziell hinzugefügt, dass sie "Naiaden genannt werden"7? Was bedeutet die Hinzunahme der Mischkrüge und Amphoren, über deren hineingegossenen Inhalt nichts berichtet wird, außer dass in ihnen Bienen wie in Bienenstöcken Honig sammeln? Die überaus großen Webstühle dürften wohl Weihgaben für die Nymphen sein. Aber warum sind sie nicht aus Holz oder anderem Material, sondern ebenfalls aus Stein wie die Amphoren und Mischkrüge? Und dies ist noch der weniger unklare Teil (der Beschreibung). Dass aber an diesen steinernen Webstühlen die Nymphen meerespurpurfarbige Tücher weben, ist nicht nur ,ein Wunder zu sehen', sondern auch ein Wunder zu hören. Denn wer könnte wohl glauben, dass Göttinnen meerespurpurfarbige Mäntel in einer dunklen Grotte auf steinernen Webstühlen weben, zumal wenn er jemanden sagen hört, dass diese von den Göttinnen gewebten Gegenstände sichtbar und purpurn sind? Zusätzlich dazu ist es verwunderlich, dass die Grotte zweitürig ist, wobei eine Tür für die Menschen zum Herabgehen gemacht ist, die andere wiederum für die Götter. Es ist auch erstaunlich, dass gesagt wird, dass die für die Menschen gangbare Tür nach Norden gewandt ist, die für die Götter aber nach Süden. Denn es ist völlig unklar, warum Homer die nördlichen Teile den Menschen und die südlichen den Göttern zugeteilt hat, anstatt hierfür eher den Osten und den Westen zu nehmen, da ja wohl mehr oder weniger alle Tempel ihre Götterstatuen und Eingänge nach Osten ausgerichtet haben, ${ }^{8}$ und die Hineingehenden nach Westen blicken, wenn sie den Statuen gegenüberstehen und den Göttern ihre Bitten und Verehrungen entgegenbringen.

4. Da nun die Darstellung voll von derartigen unklaren Dingen ist, könne sie (laut Kronios) nicht eine freie, zum Zweck der Unterhaltung gemachte Erfindung sein und genauso wenig die Beschreibung eines realen Ortes enthalten, sondern der Dichter spreche durch sie etwas allegorisch an, wobei er auf mystische Weise noch einen Ölbaum in ihre Nähe gesetzt habe. Bereits unsere Vorfahren hätten es für nötig befunden, all diesen Dingen nachzuspüren und sie zu entschlüsseln, und nun sei es an uns, mit ihrer Hilfe und durch unsere eigenen Möglichkeiten $\mathrm{zu}$ versuchen, eine Erklärung zu finden. 9

Diejenigen nun scheinen (mir) sehr leichtfertig über die Beschaffenheit des Ortes geschrieben zu haben, die glauben, dass die Grotte und alles, was er über sie erzählt hat, vollständig eine Erfindung des Dichters sei. Verfasser von geographischen Abhandlungen aber <glauben das nicht>;10 am besten und genauesten von ihnen ist Artemidor von Ephesos, der im fünften Buch seiner elf Bücher umfassenden Abhand- 


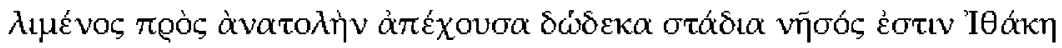

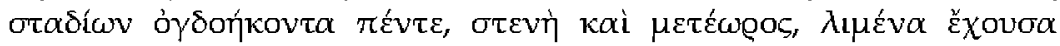

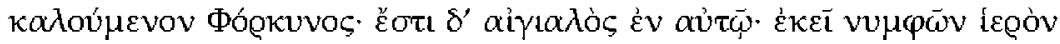

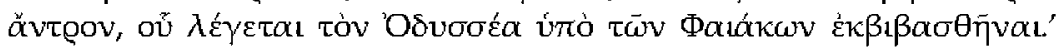

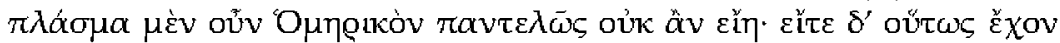

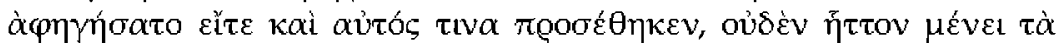

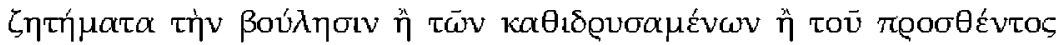

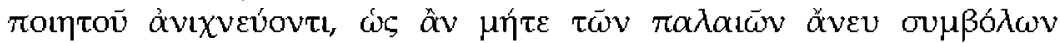

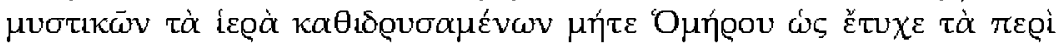

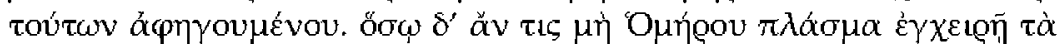

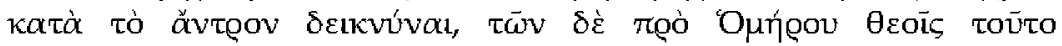

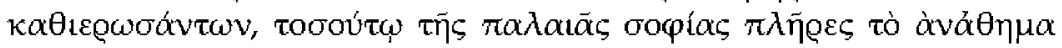

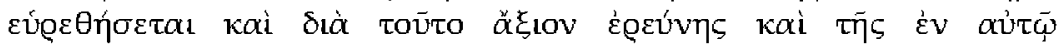

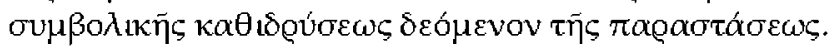

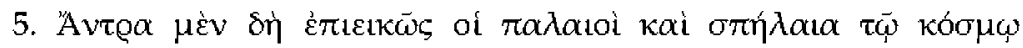

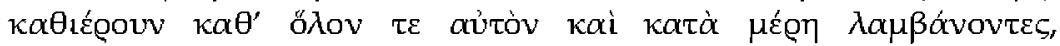

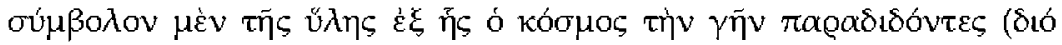

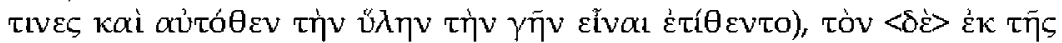

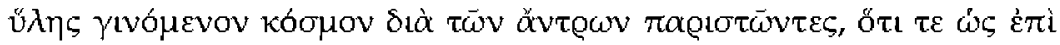

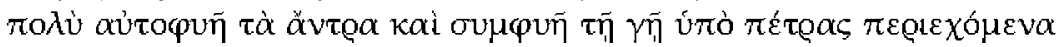

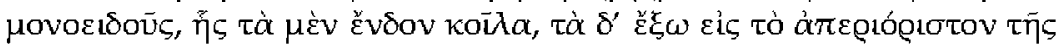
ү̄̄

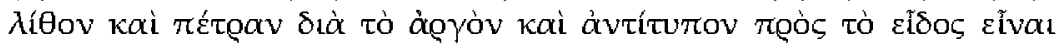

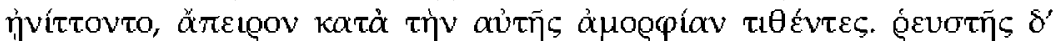

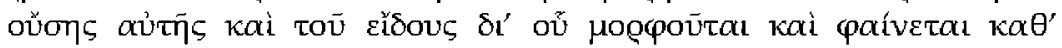

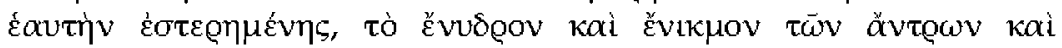

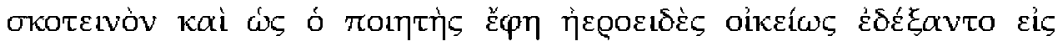

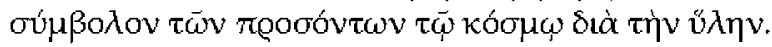

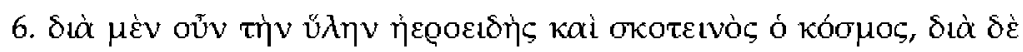

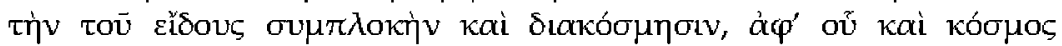

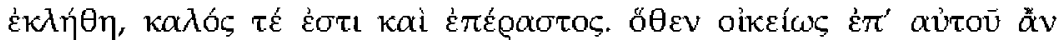

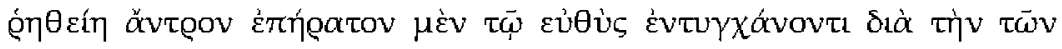


lung folgendes schreibt: "Zwölf Stadien ${ }^{11}$ östlich vom Hafen Panormus auf Kephallenia liegt die Insel Ithaka. Sie ist 85 Stadien lang, schmal und gebirgig, ihr Hafen ist der sogenannte Hafen des Phorkys. In diesem gibt es einen Strand; dort ist eine heilige Nymphengrotte, wo Odysseus von den Phaiaken an Land gebracht worden sein soll. ${ }^{\prime \prime 2}$ Es dürfte sich also bei der homerischen Erzählung nicht gänzlich um eine Erfindung handeln. Aber unabhängig davon, ob Homer es nun so beschrieb, wie es war, oder ob er selbst etwas hinzufügte, bleiben die (genannten) Fragen für denjenigen, der die Intention entweder der Aufstellenden oder des hinzufügenden Dichters aufspüren will. Denn weder dürften unsere Vorfahren die Tempel ohne mystische Symbole aufgestellt haben noch hat Homer zufällig dieses über sie erzählt. Je mehr man zu zeigen versucht, dass die Grotte und ihre Gegenstände keine Erfindung Homers sind, weil schon die Menschen vor Homer diese den Göttern geweiht hatten, desto erfüllter von alter Weisheit wird sich das Weihgeschenk ${ }^{13}$ erweisen. Und aus eben diesen Gründen ist die Grotte einer genauen Untersuchung wert und sie bedarf einer Erklärung der in ihr gemachten symbolischen Weihung.

5. Unsere Vorfahren weihten dem Kosmos in angemessener Weise Grotten und Höhlen, wobei sie ihn sowohl mit Blick auf seine Ganzheit als auch auf seine Teile erfassten. Dabei lehrten sie, dass die Erde ein Symbol der Materie sei, aus der der Kosmos besteht - weswegen einige kurzerhand die Materie mit Erde gleichsetzten ${ }^{14}$-, und sie stellten den aus der Materie gewordenen Kosmos durch Grotten dar, weil Grotten zumeist von selbst entstehen, mit der Erde verbunden und rings von einem einzigen Felsen umschlossen sind, dessen Inneres hohl ist und dessen Äußeres sich in die Unbegrenztheit der Erde erstreckt. Der Kosmos ist (ihrer Meinung nach) ${ }^{15}$ von selbst entstanden und zwar mit der Materie zusammen, die unsere Vorfahren wegen ihrer unbeweglichen und harten Form verrätselt als Stein oder Felsen beschrieben und aufgrund ihrer Unförmigkeit als unbegrenzt ansahen. Und weil die Materie selbst flüssig ist und ihr für sich selbst keine Form zukommt, durch die sie Gestalt annimmt und sichtbar wird, nahmen sie passenderweise die Feuchtigkeit und die Nässe der Grotten sowie ihre Dunkelheit und - wie der Dichter sagt - ,das Düstere ${ }^{16}$ als Symbole der Eigenschaften, die dem Kosmos wegen der Materie zukommen.

6. Aufgrund seiner Materie ist der Kosmos einerseits düster und dunkel, andererseits aber ist er wegen der Verbindung mit der Form und der Ordnung, nach der er auch benannt ist, schön und lieblich. Vor diesem Hintergrund dürfte wohl passend von ihm gesagt werden, dass er eine Grotte ist, die aufgrund ihrer Teilhabe an den Formen einerseits 


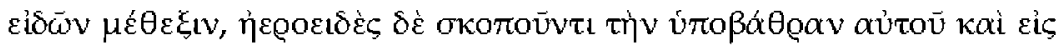

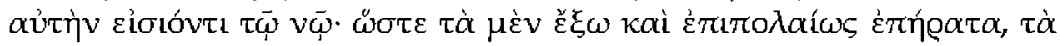

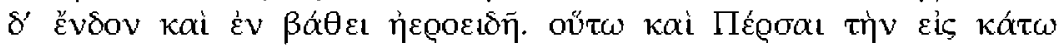

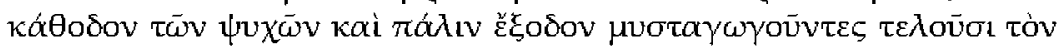

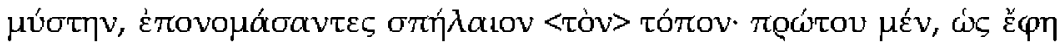

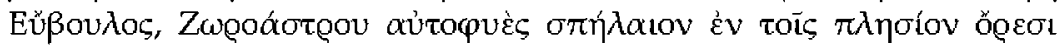

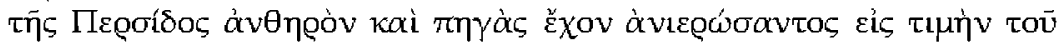

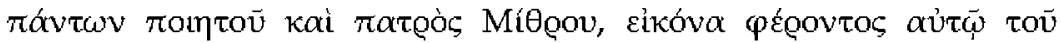

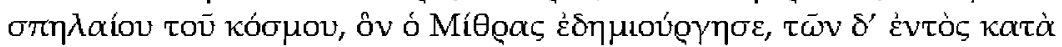

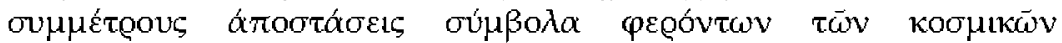

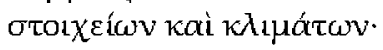

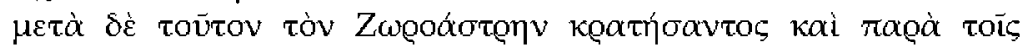

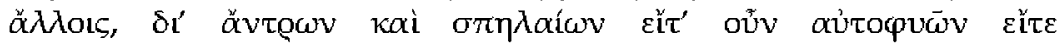

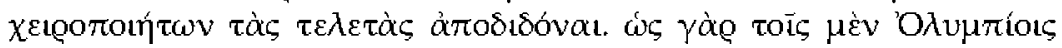

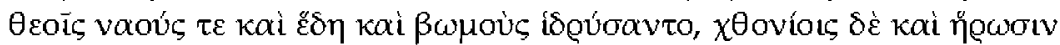

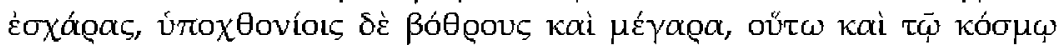

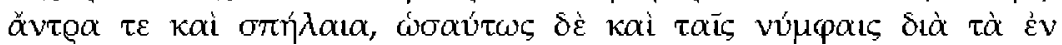

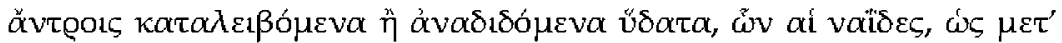

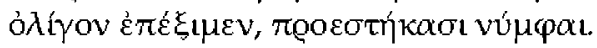

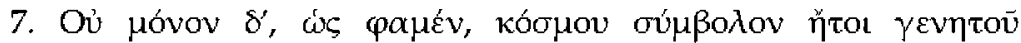

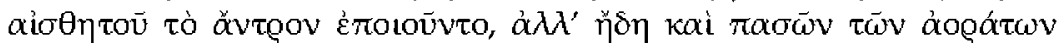

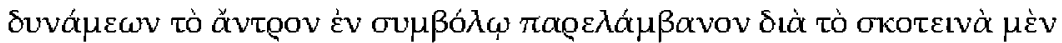

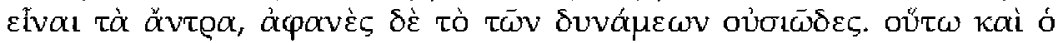

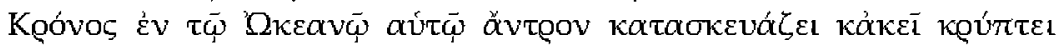

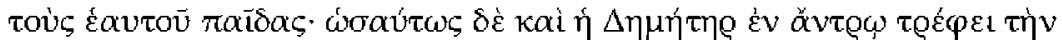

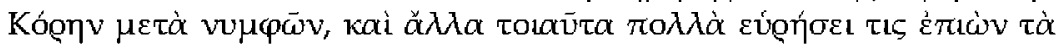
$\tau \bar{\omega} v \theta \varepsilon \sigma \lambda \hat{\gamma} \gamma \omega v$.

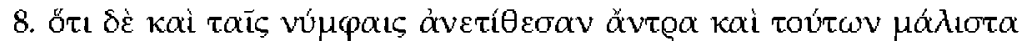

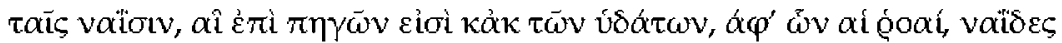

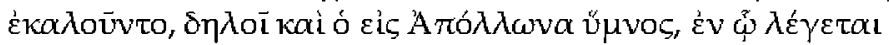

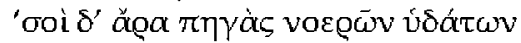

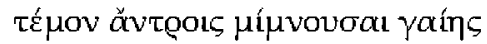

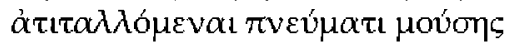

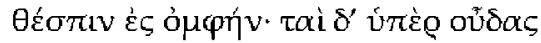

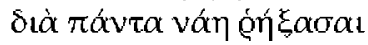

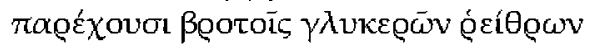

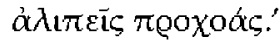


denjenigen, der sie gerade betritt, lieblich vorkommt, andererseits für den, der nach ihrem Untergrund forscht und mit dem Intellekt in sie eindringt, düster ist. Folglich ist ihr Äußeres und Oberflächliches liebenswert, ihr Inneres aber und Tieferliegendes düster. Ganz ähnlich halten es die Perser, die einen Mysten einweihen, indem sie ihn auf dem Weg der Seelen hinab und wieder hinaus führen, und diesen Ort ,Höhle' nennen. ${ }^{17}$ Zuerst hat nämlich, wie Eubulos ${ }^{18}$ berichtet, Zoroaster ${ }^{19}$ eine natürlich entstandene Höhle mit Blumen und Quellen, die sich in den nahegelegenen Bergen der Persis befand, zu Ehren des Mithras, ${ }^{20}$,des Schöpfers und Vaters von allen', ${ }^{21}$ geweiht, wobei die Höhle für ihn das Bild des Kosmos, den Mithras erschaffen hatte, ${ }^{22}$ darstellte und ihre Inhalte in wohlproportionierten Abständen die kosmischen Elemente und Himmelszonen symbolisierten.

In Zoroasters Nachfolge hat sich auch bei den anderen (Völkern) der Brauch etabliert, Mysterien in Höhlen und Grotten - seien sie natürlich entstanden oder künstlich geschaffen - durchzuführen. Denn so, wie sie für die olympischen Götter Tempel, Götterbilder und Altäre, für irdische Gottheiten und Heroen Opferstellen und für unterirdische Götter Gruben und Erdlöcher errichteten, so schufen sie für den Kosmos Grotten und Höhlen. Selbiges taten sie auch für die Nymphen wegen der in den Grotten herabrinnenden oder emporsprudelnden Wasser, denen, wie ich gleich zeigen werde, die naiadischen Nymphen vorstehen.

7. Unsere Vorfahren machten die Grotte nicht nur, wie gesagt, zu einem Symbol des Kosmos, das heißt eines sinnlich wahrnehmbaren Gewordenen, sondern sie machten sie auch zu einem Symbol aller unsichtbaren Kräfte, ${ }^{23}$ weil Grotten dunkel sind und weil die Essenz dieser Kräfte unsichtbar ist. Daher bereitet auch Kronos für sich eine Höhle im Okeanos und verbirgt dort seine Kinder ${ }^{24}$ und ebenso zieht Demeter zusammen mit Nymphen die Persephone in einer Höhle groß. ${ }^{25}$ Und man wird noch viele weitere solche Beispiele finden, wenn man die Werke der Theologen ${ }^{26}$ konsultiert.

8. Dass unsere Vorfahren aber auch den Nymphen Grotten weihten und zwar besonders den Naiaden, die den Quellen vorstehen und die nach den Wassern, aus denen die Ströme entstehen, Naiaden genannt wurden, das zeigt auch der Hymnus an Apoll, in dem es heißt:

"Dir schnitten [Nymphen], die in Grotten wohnen, Quellen von vernunfthaftem Wasser aus dem Boden, und sie wurden durch den Hauch der Muse zum göttlichen Gesang aufgezogen. Die Quellen brechen über der Erde durch alle Ströme hervor, und sie bereiten den Menschen einen niemals aufhörenden Zufluss an erquicklichem. Nass." 27 


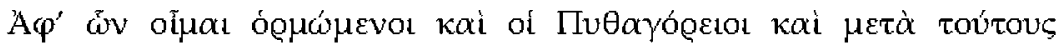

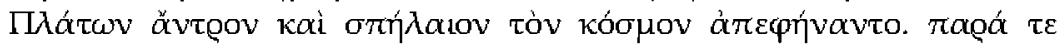

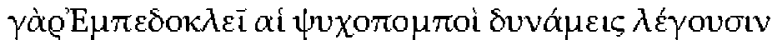

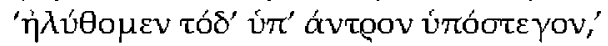

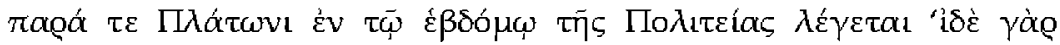

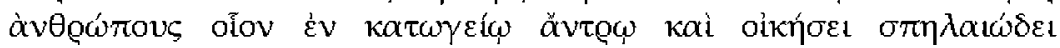

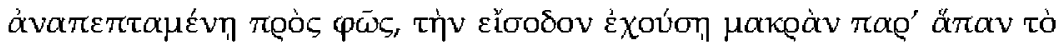

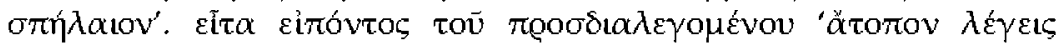

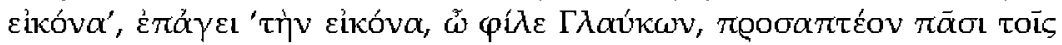

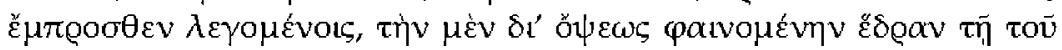

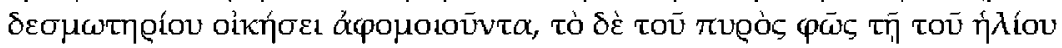
$\delta v \vee o ́ \mu \varepsilon \iota^{\prime}$.

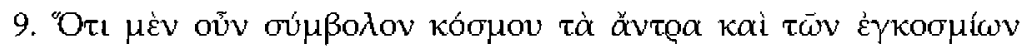

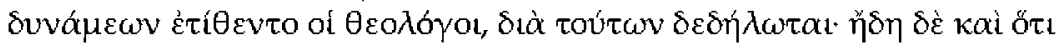

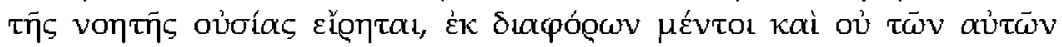

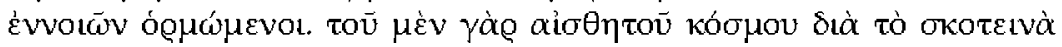

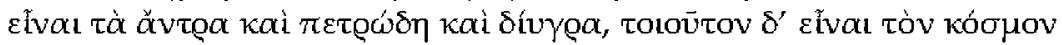

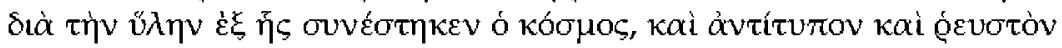

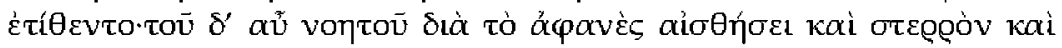

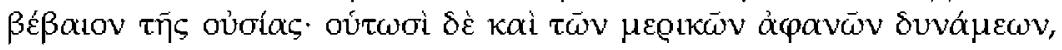

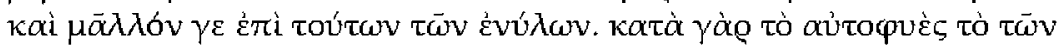

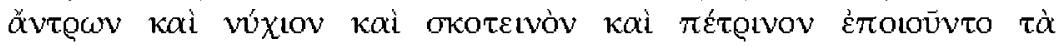

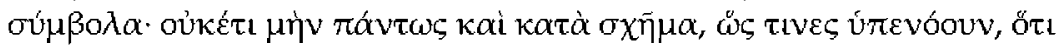

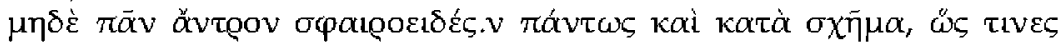

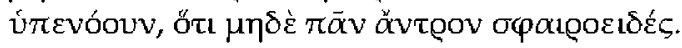

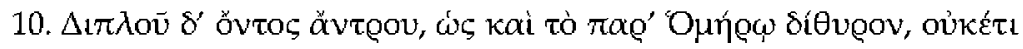

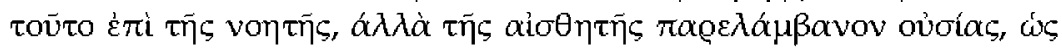

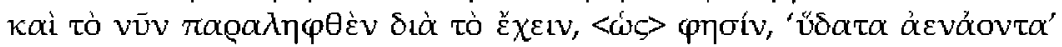

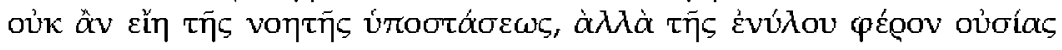

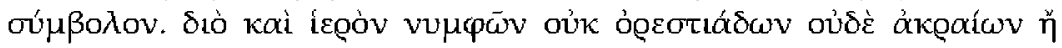

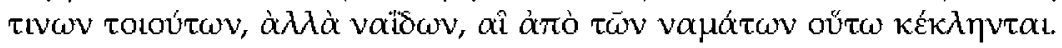

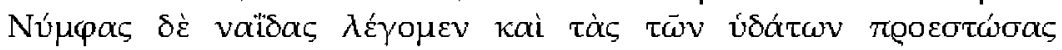


Davon beeinflusst haben, wie ich glaube, die Pythagoreer ${ }^{28}$ und nach ihnen auch Platon den Kosmos als Grotte bzw. Höhle dargestellt. Denn bei Empedokles sagen die seelengeleitenden Kräfte:

"Wir sind hinunter in diese bedachte Grotte gekommen. "29

Und bei Platon heißt es im siebten Buch der Politeia: „Stell dir Menschen wie in einer unterirdischen Grotte und einer höhlenartigen Behausung vor, die einen zum Licht geöffneten Eingang hat, der die Breite der ganzen Höhle einnimmt." Und als dann der Dialogpartner sagt: "Du erzählst ein sonderbares Bild" setzt er (=Sokrates) hinzu:

„Dieses Bild, mein lieber Glaukon, muss du mit allem früher Gesagten verbinden, indem $d u$ den durch Wahrnehmung sichtbaren Wohnsitz mit dem Haus des Gefängnisses gleichsetzt und das Licht des Feuers in ihm mit der Kraft der Sonne."30

9. Anhand dieser Beispiele ist deutlich geworden, dass die Theologen die Grotten als ein Symbol des Kosmos und der kosmischen Kräfte auffassten. Es wurde auch schon festgestellt, dass sie die Grotten für ein Symbol des intelligiblen Seins hielten, wobei sie das freilich aus verschiedenen und nicht denselben Erwägungen heraus angingen. Denn einerseits fassten sie Grotten als ein Symbol des sinnlich wahrnehmbaren Kosmos auf, weil Grotten schattig, felsig und feucht seien, und sie nahmen an, dass der Kosmos wegen der Materie, aus der er zusammengesetzt ist, ebenso beschaffen sei, d.h. sowohl fest als auch fließend. Andererseits fassten sie die Grotten als ein Symbol des intelligiblen Kosmos auf, weil er für die Wahrnehmung unsichtbar ist, und wegen der Härte und Festigkeit seiner Essenz. Entsprechend seien die Grotten auch ein Symbol der partikulären unsichtbaren und besonders der an Materie gebundenen Kräfte. Sie schufen die Symbole wegen des natürlichen Entstehens der Grotten sowie ihrer Dunkelheit, Schatten- und Felsenhaftigkeit, jedoch nicht gänzlich, wie einige vermutet haben, wegen der Form der Grotten, da nicht jede Grotte kugelförmig ist.

10. Da nun eine Grotte eine doppelte Natur hat, so wie auch die bei Homer doppeltürig ist, nahmen sie diese nicht als Symbol des intelligiblen, sondern des sinnlich wahrnehmbaren Seins. Entsprechend dürfte die hier betrachtete Grotte kein Symbol des intelligiblen Stoffes sein, da sie "immer-fließendes Wasser ${ }^{\prime 31}$ hat, sondern ein Symbol des in der Materie befindlichen Seins.32 Daher ist die Grotte auch kein Heiligtum der Berg- oder Gipfelnymphen oder irgendwelcher anderer Nymphen von dieser Art, sondern ein Heiligtum der Naiaden, die ihren Namen von den fließenden Wassern haben. Während wir im engeren Sinne die den Wassern vorstehenden Kräfte ,naiadische Nymphen' 


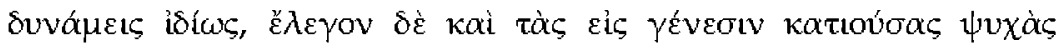

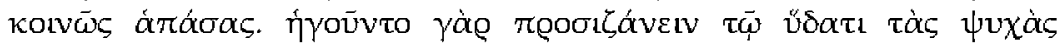

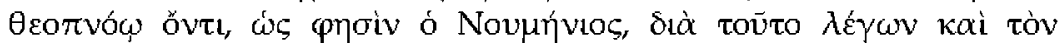

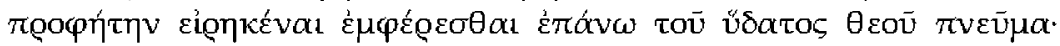

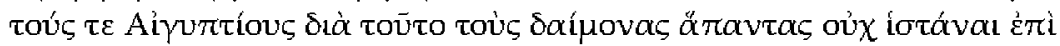

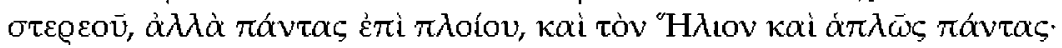

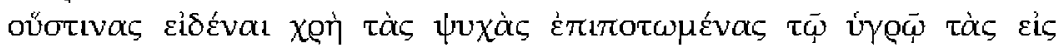

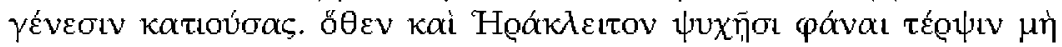

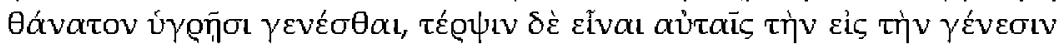

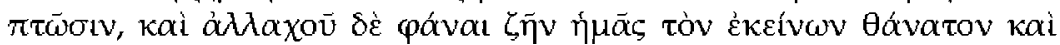

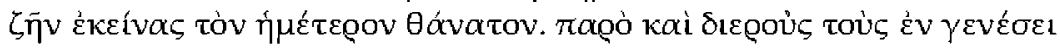

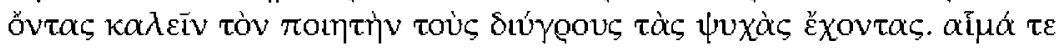

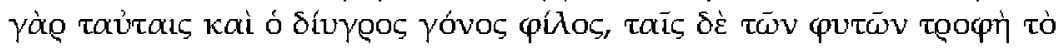
ưowe.

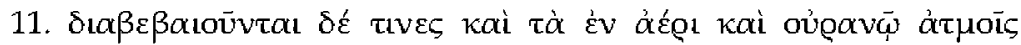

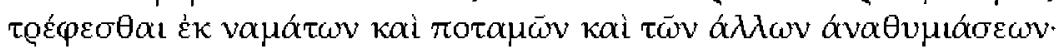

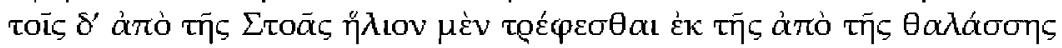

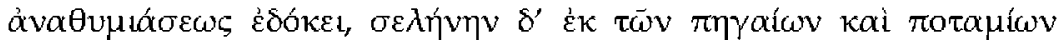

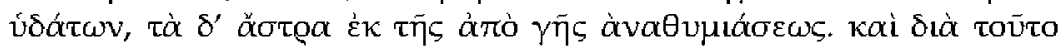

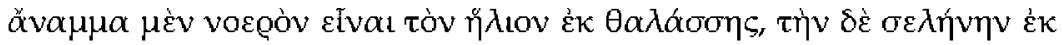

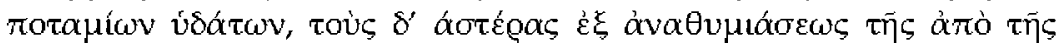

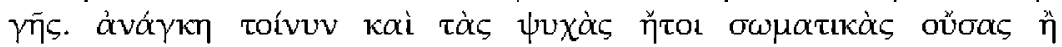

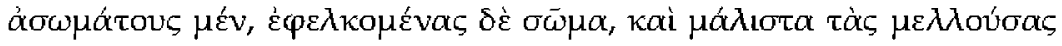

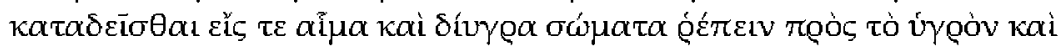

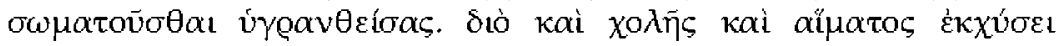

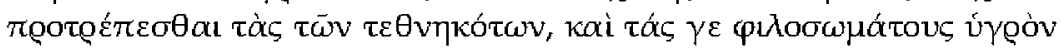

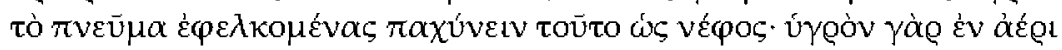

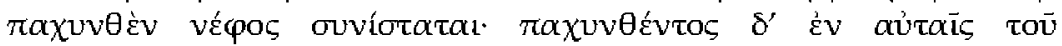

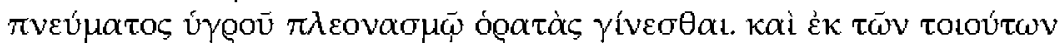

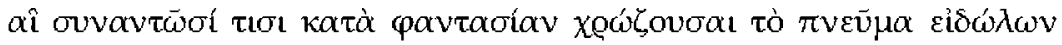

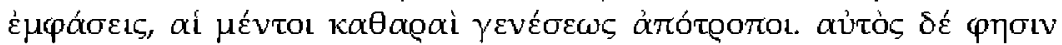

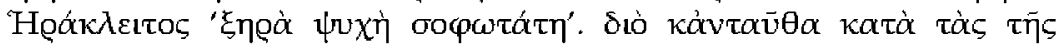

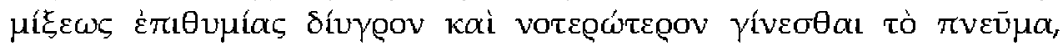


nennen, bezeichneten sie (= die Theologen) generell auch alle zur Geburt hinabsteigenden Seelen in dieser Weise. Sie glaubten nämlich, dass die Seelen deswegen beim Wasser sitzen, weil es ,gottdurchweht' ist, wie Numenios berichtet, der sagt, dass deswegen auch der Prophet gesagt habe, ,dass der Hauch Gottes oberhalb des Wassers schwebe' ${ }^{33}$ Auch die Ägypter würden deswegen all ihre Gottheiten nicht auf etwas Festes stellen, sondern auf eine Barke; dies gelte sowohl für die Sonne als auch generell für alle [Gottheiten]; diese (= die Ägypter) wissen notwendigerweise, dass die Seelen über dem Feuchten schweben, wenn sie zum Werden hinabgehen. Deswegen bemerke auch Heraklit, ,dass es für die Seelen ein Vergnügen und nicht der Tod ist, feucht zu werden', ${ }^{34}$ da der Fall in das Werden für die Seelen ein Vergnügen sei. Und an anderer Stelle sagt Heraklit [laut Numenios], dass wir ihren und sie unseren Tod leben' ${ }^{35}$ Daher bezeichne der Dichter die im Werden befindlichen Lebe-wesen auch als ,nass', weil sie feuchte Seelen hätten. ${ }^{36}$ Und während für diese Blut und feuchtes Entstehen angenehm ist, ist das Wasser die Nahrung für die pflanzlichen Seelen.

11. Manche behaupten fest, dass auch die Dinge, die sich in der Luft und im Himmel befinden, durch den Dunst aus Quellen, Flüssen und anderen Arten der Verdunstung ernährt werden. Die Stoiker glaubten, dass die Sonne aus der vom Meer aufsteigenden Verdunstung ernährt würde, der Mond von den Quell- und Flusswassern und die Sterne von der aus der Erde hervorgehenden Verdampfung. Deswegen sei die Sonne eine angezündete, vernunfthafte und aus dem Meer genährte Masse, wohingegen der Mond aus Flusswassern und die Sterne aus der von der Erde hervorgehenden Verdampfung genährt würden. Daraus folgt notwendigerweise, dass auch die Seelen - seien sie nun körperlich oder nicht-körperlich, aber an einen Körper angebunden - und besonders die Seelen, die im Begriff sind, (an Körper) angebunden zu werden, sich in das Blut und in die feuchten Körper zum Feuchten hinwenden und im befeuchteten Zustand körperlich werden. Und deswegen würden sich die Seelen der Toten dem Ausguss von Galle und Blut zuwenden ${ }^{37}$ und die körperliebenden Seelen einen feuchten Hauch mit sich ziehen und diesen wie einen Nebel verdichten, denn Feuchtes, das in der Luft verdichtet wird, bildet Nebel. Wenn nun der Hauch in den Seelen verdichtet wird, würden sie durch den Überfluss an Feuchtigkeit sichtbar. Von den Seelen dieser Art treten einige den Menschen in der Imagination als Erscheinungen von Bildern entgegen, indem sie ihren Hauch färben. Die reinen Seelen sind jedoch vom Werden abgewandt, und Heraklit selbst sagt: "Die trockene Seele ist die weiseste." Deswegen werde der Hauch auch hier (bei uns) während der Begierde 


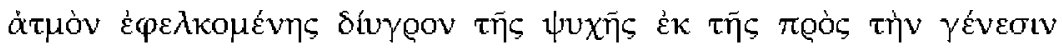

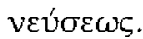

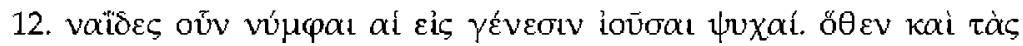

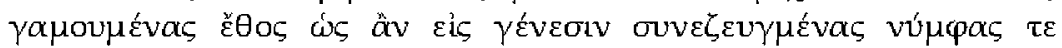

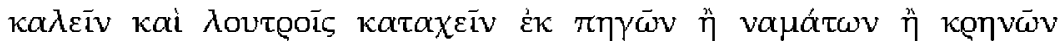

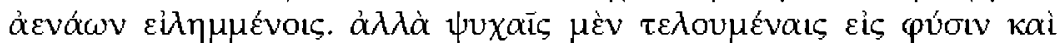

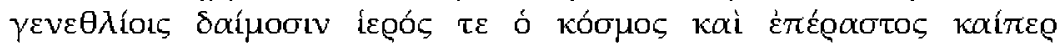

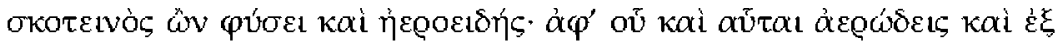

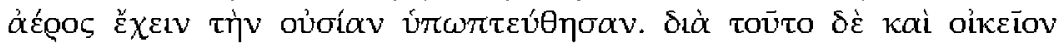

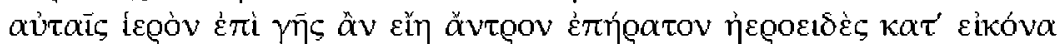

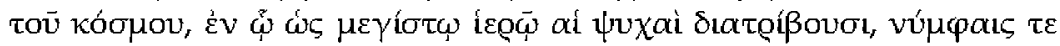

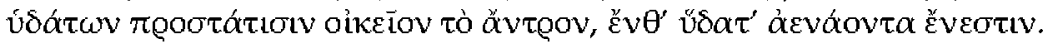

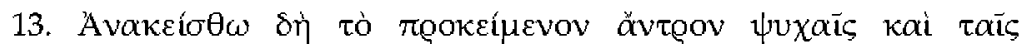

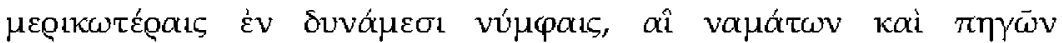

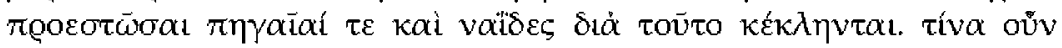

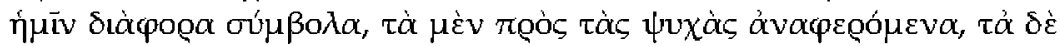

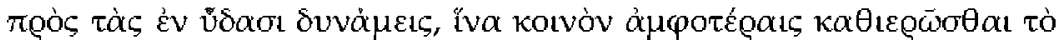

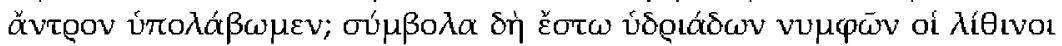

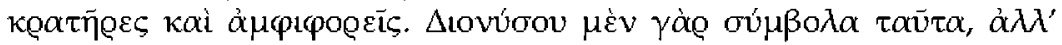

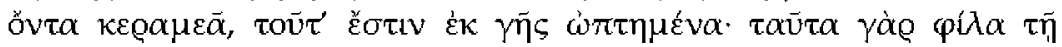

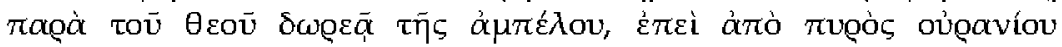

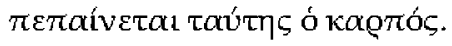

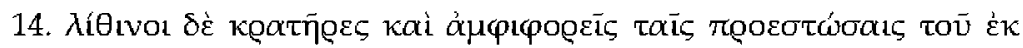

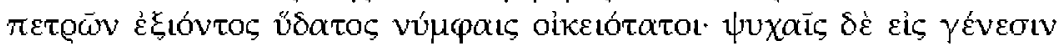

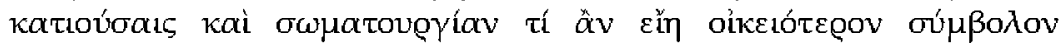

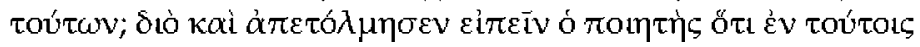

' $\varphi \alpha ́ \varrho \varepsilon$ ' v́

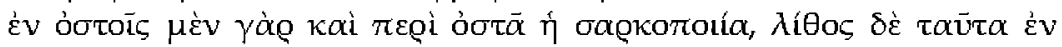

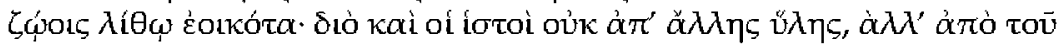

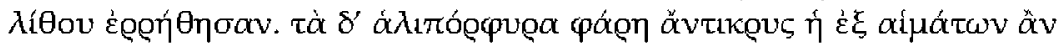

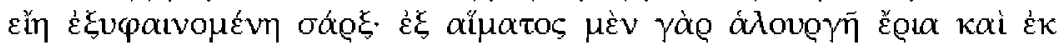

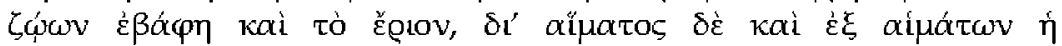


nach sexueller Vereinigung nass und feuchter, da die Seele den feuchten Hauch aufgrund ihrer zum Werden gerichteten Neigung mit sich führt.

12. Naiadische Nymphen sind also die Seelen, die zum Werden gehen. Daher stammt auch der Brauch, Bräute, die ja zum Zweck der Zeugung verheiratet werden, Nymphen zu nennen und mit Wasser zu begießen, das aus Quellen, Flüssen oder immer-fließenden Brunnen genommen ist. Aber für Seelen, die in die Natur eingeweiht werden, und für die Gottheiten, die über die Geburt walten, ${ }^{39}$ ist der Kosmos sowohl heilig als auch lieblich, ${ }^{40}$ obwohl er seiner Natur nach finster und dämmrig ist. Deshalb wurde vermutet, dass auch diese Seelen luftig seien und dass sie ihre Essenz aus der Luft hätten. Hieraus folgt, dass eine liebliche, dämmrige und nach dem Bild des Kosmos geschaffene Grotte, in der die Seelen wie in einem überaus großen Tempel wohnen, ein für sie passendes Heiligtum auf der Erde sein dürfte; und für die Nymphen als Vorsteherinnen des Wassers dürfte eine Grotte angemessen sein, in der immer-fließendes Wasser ist.

13. So soll also die hier zu untersuchende Grotte (den) Seelen und den kraft ihrer Fähigkeiten spezielleren Nymphen geweiht sein, (nämlich den Nymphen), die den Strömen und Quellen vorstehen und deswegen Quellnymphen und Naiaden genannt werden. Welche sind nun für uns die unterschiedlichen Symbole, die sich einerseits auf die Seelen beziehen und andererseits auf die Kräfte im Wasser, so dass wir folgern können, dass die Grotte beiden geweiht ist? Als Symbole der Wassernymphen sollen die steinernen Kratere und Amphoren gelten. Sie sind nämlich Symbole des Dionysos, aber (nur) dann, wenn sie aus Ton, d.h. aus Erde gebrannt sind. Denn in dieser Form sind sie dem von Dionysos stammenden Geschenk des Weinstocks willkommen, weil deren Frucht vom himmlischen Feuer reif gemacht wird.

14. Die steinernen Kratere und Amphoren sind dagegen überaus passend für die Nymphen, die dem aus Felsen herausfließenden Wasser vorstehen. Was aber dürfte für Seelen, die zum Werden und zur Erschaffung von Körpern herabsteigen, ein passenderes Symbol sein als diese [steinernen Webstiuhle]? Daher konnte der Dichter auch ganz unverblümt sagen, dass die Nymphen auf ihnen "meerespurpurfarbige Gewänder weben, - ein Wunder zu sehen". ${ }^{41}$ Denn die Fleischbildung findet an den Knochen und um die Knochen herum statt, und der Stein steht für die Knochen in den Lebewesen, weil sie dem Stein ähnlich sind. Daher heißt es auch, dass die Webstühle aus Stein und nicht aus anderem Material gemacht sind. Und die meerespurpurfarbigen Gewänder dürften nun offenbar das aus Blut gewobene Fleisch sein. Denn purpurne Wolle ist aus Blut gemacht, und die Wolle wurde (durch Blut) 


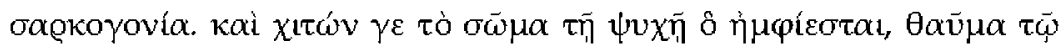

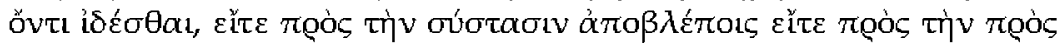

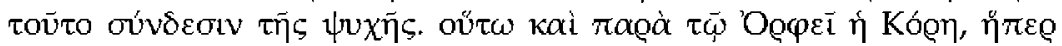

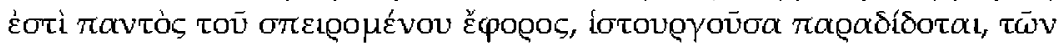

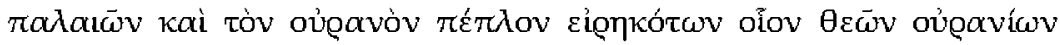

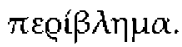

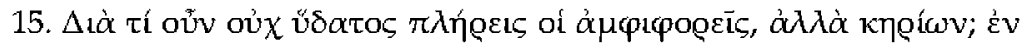

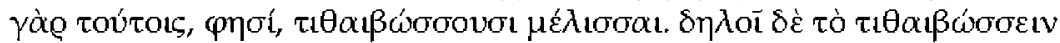

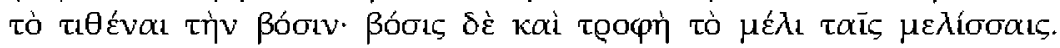

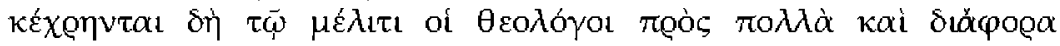

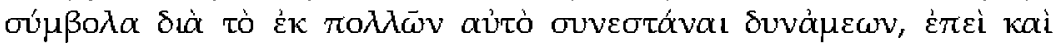

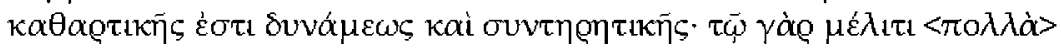

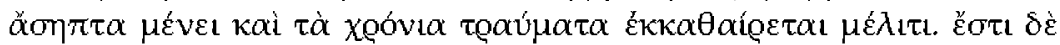

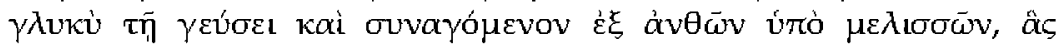

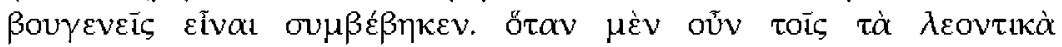

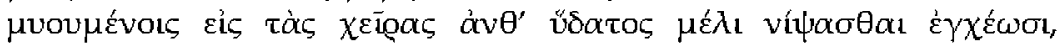

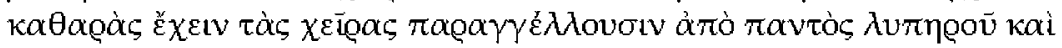

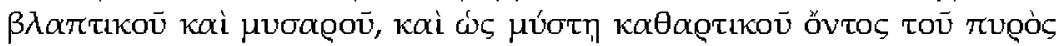

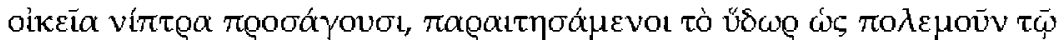

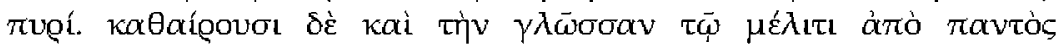
$\grave{\alpha} \mu \alpha \varrho \tau \omega \lambda$ v.

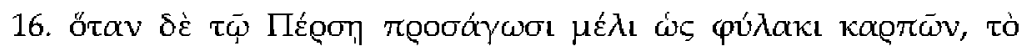

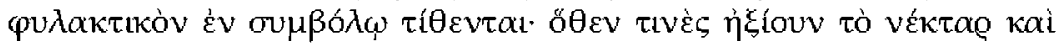

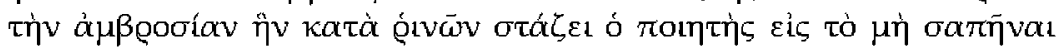

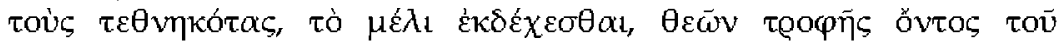

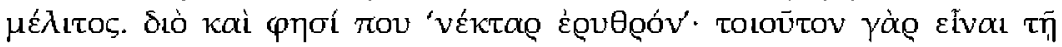

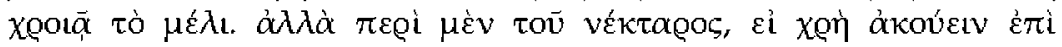

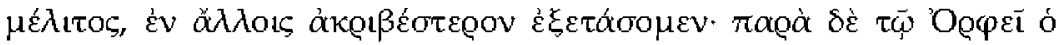

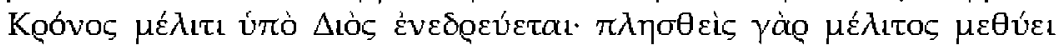

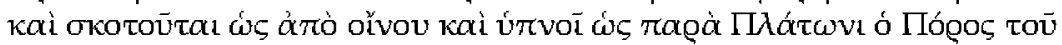

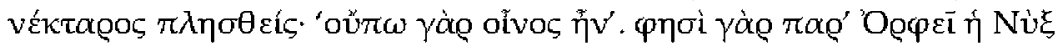

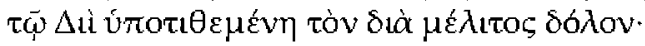

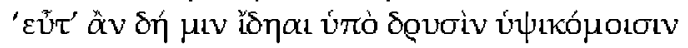


von Lebewesen gefärbt; durch Blut und aus Blut entsteht aber auch das Fleisch. Und der Körper ist das Gewand der Seele, ${ }^{42}$ das sie umgibt. In der Tat ,ein Wunder zu sehen', ob man nun die Zusammensetzung betrachtet oder die Anbindung der Seele an den Körper. So wird auch bei Orpheus die Kore, die Aufseherin über alles, was gesät wird, als webend dargestellt, ${ }^{43}$ wobei unsere Vorfahren auch den Himmel ein Gewand nannten, so als ob er eine Bedeckung für die himmlischen Götter wäre.

15. Aber warum sind die Amphoren nicht voll von Wasser, sondern voll von Honigwaben? In den Amphoren nämlich, sagt Homer, "sammeln Bienen Honig".44 Offenbar hat (das Verb) „Honig sammeln' die Bedeutung ,Futter bereitstellen', denn der Honig ist Futter und Nahrung für die Bienen. Die Theologen nun gebrauchen den Honig für viele unterschiedliche Symbole, weil er aus vielen Kräften zusammengesetzt ist und weil er sowohl eine reinigende als auch eine schützende Wirkung hat. Denn Honig bewahrt vieles vor Fäulnis, und langwierige Wunden werden mit Honig gereinigt. Er ist süß im Geschmack und wird von Bienen, die durch Bugonie ${ }^{45}$ entstanden sind, gesammelt. Wenn man nun Leuten, die sich in den Grad der Löwen ${ }^{46}$ einweihen lassen, anstelle von Wasser Honig in die Hände gießt, damit sie sich waschen, dann sollen sie ihre Hände rein halten von allem, was Schmerz, Schaden und Befleckung verursacht. Und weil Feuer eine reinigende Wirkung auf den Mysten ausübt, geben sie ihm passendes Waschzeug, wobei sie Wasser als ein dem Feuer feindliches Element zurückweisen. Sie reinigen mit Honig aber auch die Zunge von jeder Schuld.

16. Wenn sie aber dem Perser ${ }^{47}$ als Hüter der Früchte Honig zuführen, dann nehmen sie seine schützende Kraft als Symbol. ${ }^{48}$ Daher glaubten einige, dass der Nektar und die Ambrosia, die der Dichter / Homer zum Zweck des Nicht-verfaulen-Lassens der Toten in ihre Nasenlöcher tröpfeln lässt, ${ }^{49}$ als Honig verstanden werden müsse, weil Honig die Nahrung der Götter ist. Daher (meinen sie,) spricht Homer auch irgendwo vom ,roten Nektar' ${ }^{50}$ denn eine solche Farbe habe der Honig. Aber ob der Nektar (tatsächlich) als Honig zu verstehen ist, werden wir an anderer Stelle genauer untersuchen. Bei Orpheus lockt Zeus den Kronos jedenfalls mit Honig in eine Falle: Denn von Honig gesättigt ist Kronos so trunken und benebelt wie von Wein, und er schläft wie Platons Poros, der vom Nektar gesättigt war, "denn es gab noch keinen Wein". ${ }^{51}$ Bei Orpheus sagt die Nacht, als sie Zeus zur List mit dem Honig rät:

„S Sobald du ihn unter den hochbelaubten Eichen erblickst, 


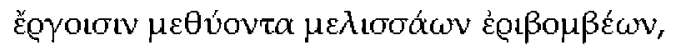

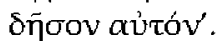

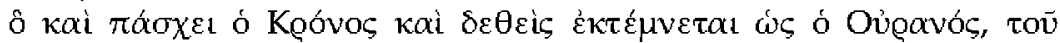

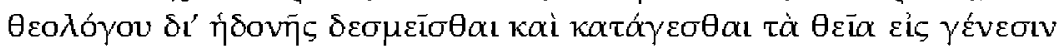

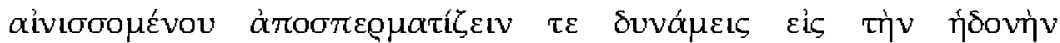

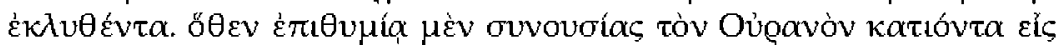
Г̄̄

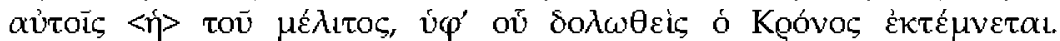

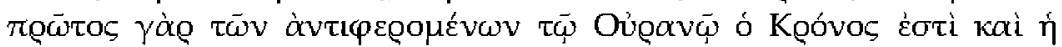

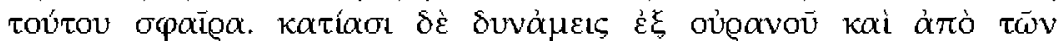

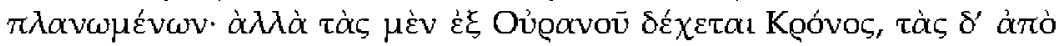

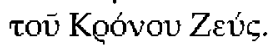

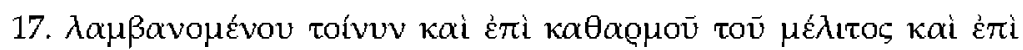

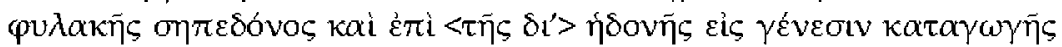

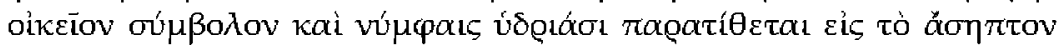

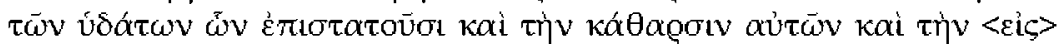

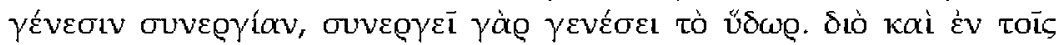

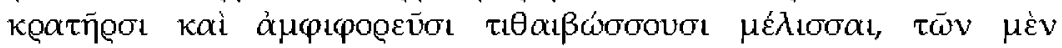

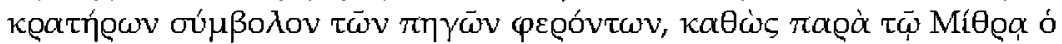
кอa $\tau \bar{\omega} v \pi \eta \gamma \bar{\omega} v$ ả @uvó $\mu \varepsilon \theta \alpha$.

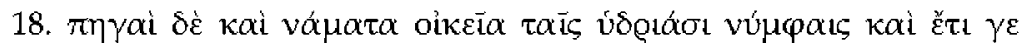

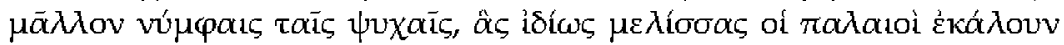

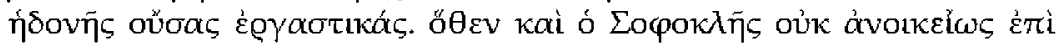
$\tau \bar{\omega} v \psi \psi \chi \chi \bar{\omega} v \varepsilon \varepsilon \varphi \eta$

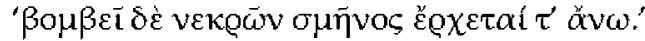

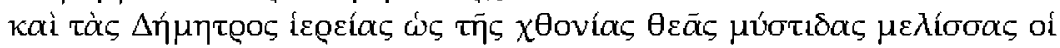

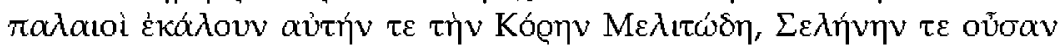

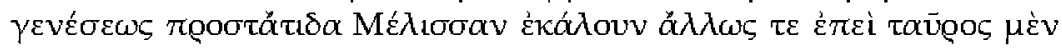

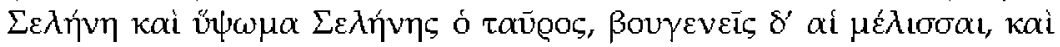

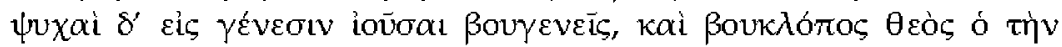

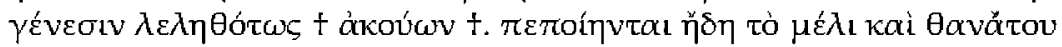
oú $\mu \beta 0 \lambda$ ov (

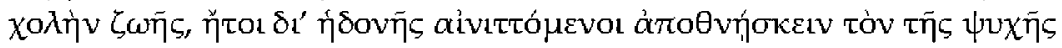

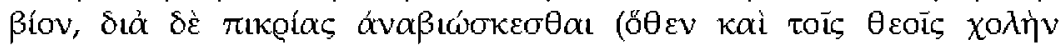


trunken durch die Werke der laut brummenden Bienen, ${ }^{52}$ fessle ihn."

So geschieht es: Kronos wird gefesselt und wie Uranos kastriert, womit der Theologe verrätselt sagt, dass die göttlichen Teile durch Lust gefesselt und zum Werden herabgeführt werden und in Lust aufgelöst ihre Kräfte aussähen. So hat (auch) Kronos den Uranos kastriert, als er in seiner Begierde nach sexueller Vereinigung zur Erde herabstieg. ${ }^{53}$ Für sie (= die Theologen) ist das Verlangen nach Honig dasselbe wie die Lust an sexueller Vereinigung, durch das Kronos getäuscht und kastriert wurde. Denn Kronos ist zusammen mit seiner Sphäre ${ }^{54}$ der erste von denen, die sich dem Uranos entgegenbewegen. Kräfte gehen nun sowohl vom Himmel als auch von den Planeten ${ }^{55}$ aus, aber Kronos nimmt sie sich von Uranos und Zeus von Kronos.

17. Da Honig zur Reinigung, zum Schutz vor Fäulnis und zur Herabführung zum Werden durch Lust genommen wird, ist er auch ein passendes Symbol für die Wassernymphen mit Blick auf das unverderbliche Wasser, dem sie vorstehen, sowie auf ihre reinigende Kraft und ihre Mitwirkung bei dem Werden, denn Wasser wirkt bei dem Werden mit. Daher sammeln die Bienen ihren Honig auch in ,Krateren und Amphoren', wobei die Kratere das Symbol der Quellen sind so wie im Mithraskult, wo der Krater anstelle der Quelle aufgestellt ist; und auch die Amphoren, in denen wir das Wasser aus den Quellen schöpfen, sind ein Symbol der Quellen. ${ }^{56}$

18. Quellen und Ströme sind passend für Wassernymphen und besonders für solche Nymphen, die Seelen sind. Diese bezeichneten unsere Vorfahren speziell als ,Bienen', weil sie Hervorbringer von Lust sind. Daher hat auch Sophokles nicht unpassend über die Seelen gesagt:

"Es summt der Schwarm der Toten und steigt herauf. ${ }^{\text {57 }}$

Und sie nannten die Priesterinnen der Demeter als Mystinnen der irdischen Göttin ,Bienen', und Persephone selbst bezeichneten sie als "honigartig'. Auch den Mond, den Vorsteher des Werdens, nannten sie 'Biene', vor allem deswegen, weil der Mond (auch) Stier ist, und der Stier die Erhöhung des Mondes ist, ${ }^{58}$ und die Bienen kuhgeboren sind; ebenso sind die Seelen, die zum Werden gehen, rindergeboren, und der Gott, der das Werden im Verborgenen + hört,+ 59 heißt ,Rinderstehler'. Den Honig machten sie zu einem Symbol des Todes (und opferten deshalb den chthonischen Göttern Honigspenden). Und die Galle machten sie zu einem Symbol des Lebens, wodurch sie entweder andeuten, dass das Leben der Seele durch Lust sterbe, aber durch Bitterkeit wieder entstehe - daher opferten sie auch den Göttern Galle -, 


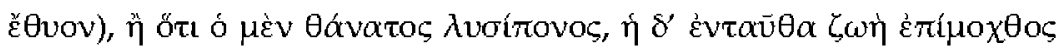
кaì тıқ@á.

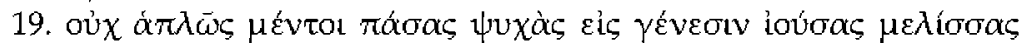

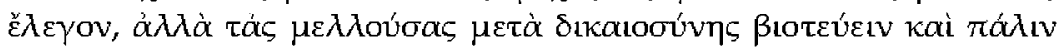

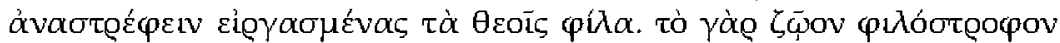

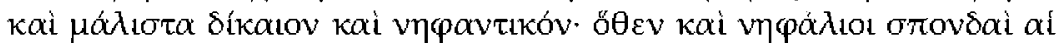

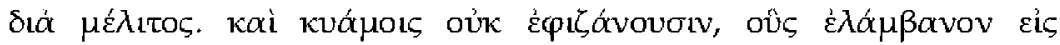

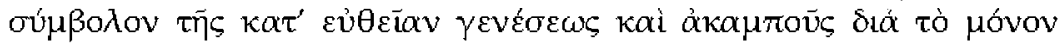

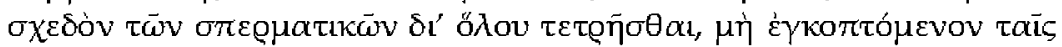

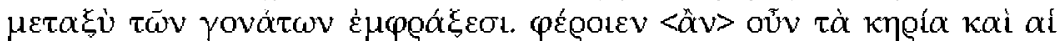

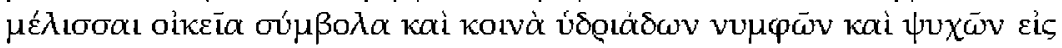

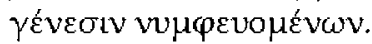

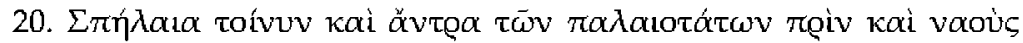

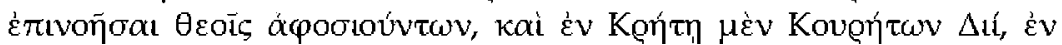

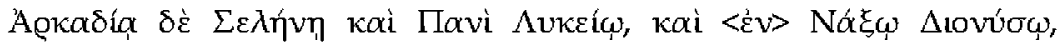

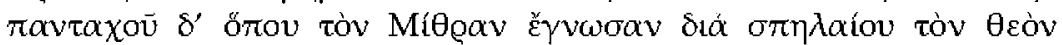

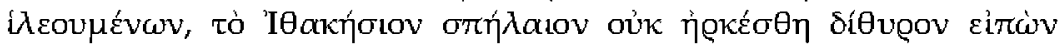

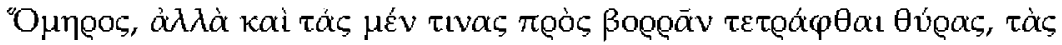

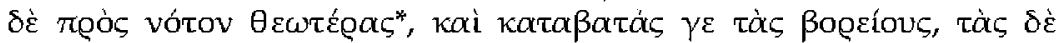

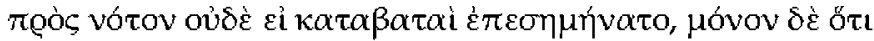

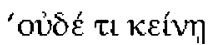

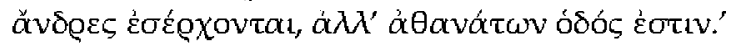

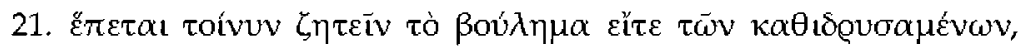

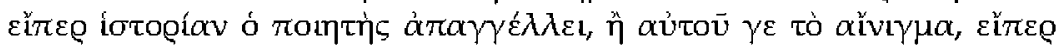

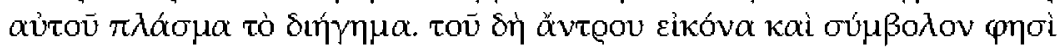

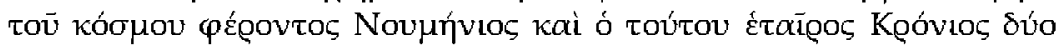

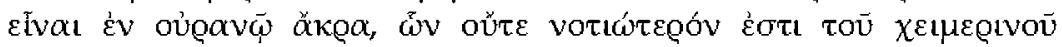

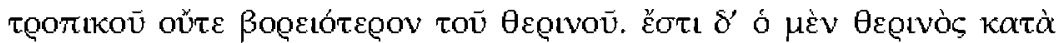

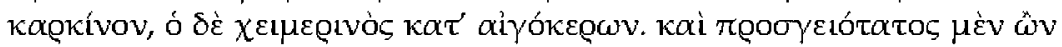

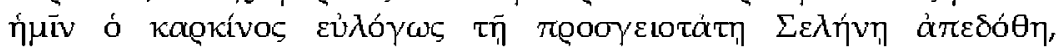

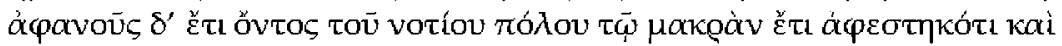

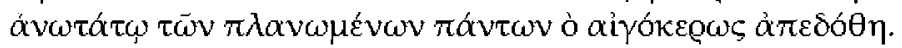


oder dass der Tod vom Leid erlöst, das Leben hier auf der Erde aber sehr mühevoll und bitter ist.

19. Sie nannten aber nicht pauschal alle Seelen, die zum Werden gehen, „Bienen', sondern nur solche, die in Gerechtigkeit leben und wieder hinaufsteigen würden, nachdem sie den Göttern angenehme Werke vollbracht haben. Dieses Lebewesen (= die Biene) liebt es nämlich, zu ihrem Ursprung zurückzukehren, und ist besonders gerecht und ,nüchtern' (= rein). Daher werden auch die mit Honig gemachten Trankopfer ,nüchtern' genannt. Die Bienen setzen sich nicht auf Bohnen, die sie als Symbol eines geraden und nicht gebogenen Werdens ansahen, weil Bohnen beinahe die einzigen keimenden Substanzen sind, die ganz durchbohrt und nicht inmitten durch Knoten gehemmt werden. ${ }^{60}$ Honigwaben und Bienen dürften folglich passende und gemeinsame Symbole der Wassernymphen und der Seelen sein, die als Bräute zum Werden gehen.

20. Ganz früher, noch bevor man Tempel kannte, weihte man den Göttern Höhlen und Grotten: auf Kreta weihte man Zeus die Grotte der Kureten, ${ }^{61}$ in Arkadien gab es eine Grotte für Selene und Pan Lykeios, ${ }^{62}$ auf Naxos eine für Dionysos, und überall dort, wo man den Mithras verehrte, suchte man den Gott durch eine Höhle gnädig zu stimmen. Homer genügte es nicht, die Grotte auf Ithaka zweitürig zu nennen, sondern er sagt, dass die eine Tür nach Norden, die göttlichere Tür aber nach Süden gerichtet ist, und dass die nördliche Tür ein Abstieg ist; bei der nach Süden gerichteten Tür macht er dagegen nicht deutlich, ob man durch sie herabsteigen kann, sondern er sagt lediglich:

„durch sie gehen keine Menschen hinein, sondern das ist der Weg der Götter. ${ }^{\star x 63}$

21. Es bleibt nun die Absicht entweder derer zu untersuchen, die die Grotte errichtet haben, falls der Dichter historisch gesichertes Wissen beschreibt, oder die Intention seiner Verrätselung, falls die Erzählung seine Erfindung ist. Weil die Grotte Bild und Symbol des Kosmos ist, sagen Numenios und sein Schüler Kronios, ${ }^{64}$ dass es im Himmel zwei Extreme gibt: den winterlichen Wendekreis im äußersten Süden und den sommerlichen Wendekreis im äußersten Norden. Der sommerliche Wendekreis liegt im Sternbild des Krebses, der winterliche in dem des Steinbocks. Und weil der Krebs uns (= der Erde) am nächsten liegt, wurde er mit gutem Grund dem der Erde am nächsten gelegenen Mond zugeschrieben; dagegen wurde der Steinbock, weil der Südpol (für uns) noch unsichtbar ist, dem ganz weit entfernten und höchsten von allen Planeten ${ }^{65}$ zugeschrieben. 


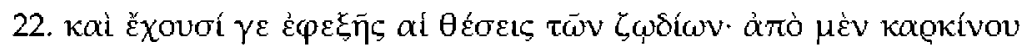

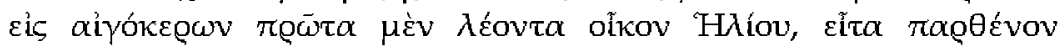

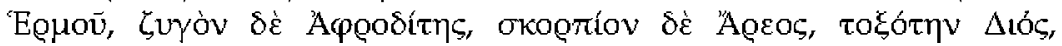

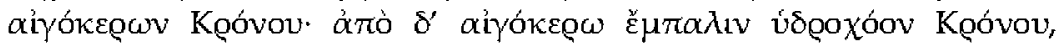

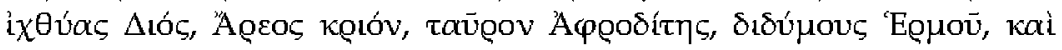

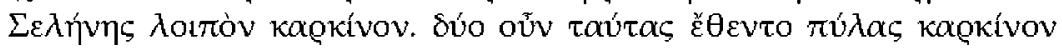

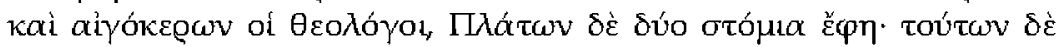

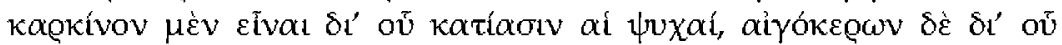

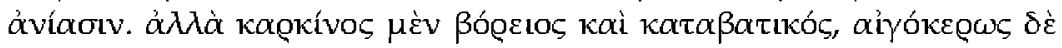
vótıos кai ảvaßatıkós.

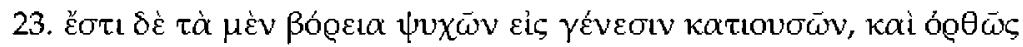

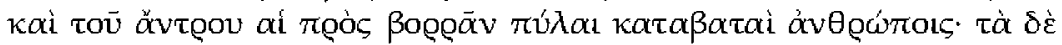

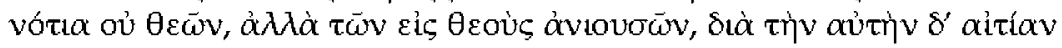

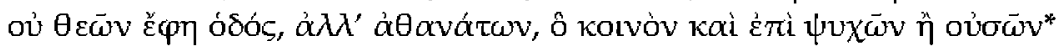

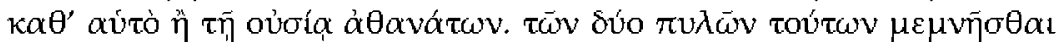

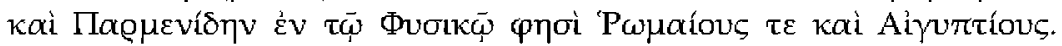

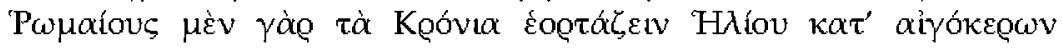

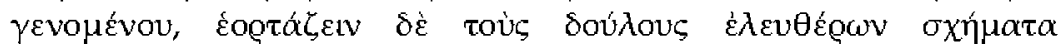

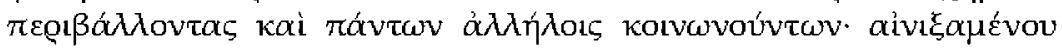

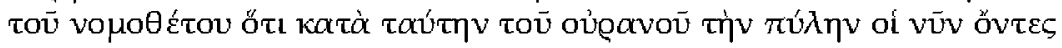

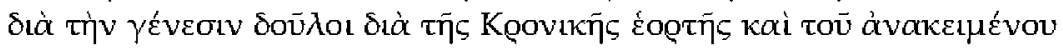

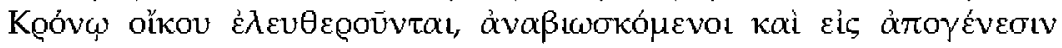

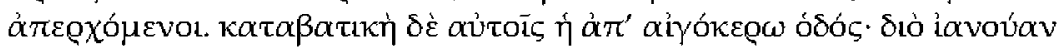

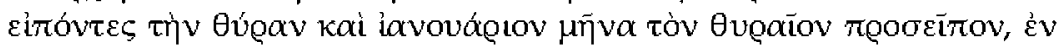

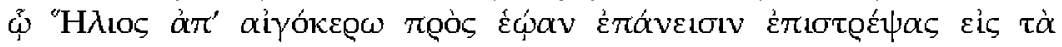
ßópela.

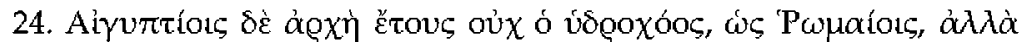
каркívo

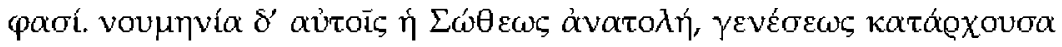


22. Der Reihe nach gibt es folgende Positionen der Tierkreiszeichen: In der Richtung vom Krebs bis zum Steinbock findet sich an erster Stelle der Löwe als das Haus der Sonne. ${ }^{66}$ Es folgt die Jungfrau als das Haus des Merkur, dann die Waage als das Haus der Venus, dann der Skorpion als das Haus des Mars, der Schütze als das Haus des Jupiter und der Steinbock als das Haus des Saturn. Vom Steinbock zurüick liegt der Wassermann als das Haus des Saturn, dann folgen die Fische als das Haus des Jupiter, der Widder als das Haus des Mars, der Stier als das Haus der Venus, die Zwillinge als das Haus des Merkur und schließlich der Krebs als das Haus des Mondes. Die Theologen betrachteten diese beiden Zeichen, Krebs und Steinbock, als Türen, wogegen Platon sie zwei Öffnungen nannte. ${ }^{67}$ Von diesen sei der Krebs die Tür, durch die die Seelen hinabgehen, der Steinbock aber die, durch die sie hinaufgehen. Der Krebs liegt nördlich und ist zum Hinabsteigen geeignet, der Steinbock dagegen südlich und ist zum Hinaufsteigen geeignet.

23. Die nördlichen Gegenden sind der Ort für die Seelen, die zum Werden hinabsteigen, und richtig sind auch die nördlich gelegenen Türen der Grotte Abstiege für die Menschen. Die südlichen Gegenden sind kein Ort für die Götter, sondern für die Seelen, die zu den Göttern hinaufsteigen. Aus eben diesem Grund sagt Homer auch nicht "Weg der Götter", sondern "Weg der Unsterblichen", was ein gemeinsamer Begriff (für Götter und) für Seelen ist, die entweder aus sich selbst oder in ihrer Essenz unsterblich sind. Diese beiden Türen soll auch Parmenides in seiner Physik erwähnt haben, ${ }^{68}$ und auch die Römer und die Ägypter sollen sie kennen. Denn die Römer feiern die Saturnalien, ${ }^{69}$ wenn die Sonne im Steinbock steht, und die Sklaven feiern das Fest der Saturnalien, indem sie sich die Kleidung von Freien umwerfen, und alle machen miteinander gemeinsame Sache. Der Begründer dieses Brauches deutete damit an, dass diejenigen, die jetzt aufgrund ihrer Geburt Sklaven sind, durch diese Himmelstür vermittels des Saturnalienfestes und (unter dem Einfluss) des dem Saturn zugeschriebenen Hauses ${ }^{70}$ befreit werden, indem sie wieder zum Leben kommen und zum Werden aus dem Leben gehen. Für sie ist der Weg vom Steinbock aus herabsteigbar. Und weil sie die Tür ianua nannten, nannten die Römer auch den (das Jahr) eröffnenden Monat ,Januar', in dem die Sonne vom Steinbock her wieder zum Osten zurückkehrt, nachdem sie sich zu den nördlichen Zeichen ${ }^{71}$ gewendet hat.

24. Bei den Ägyptern steht am Anfang des Jahres nicht wie bei den Römern der Wassermann, sondern der Krebs. In der Nähe des Krebses befindet sich nämlich die Sothis, die die Griechen Hundsstern nennen. ${ }^{72}$ 


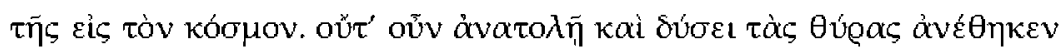

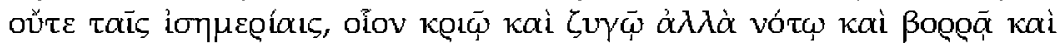

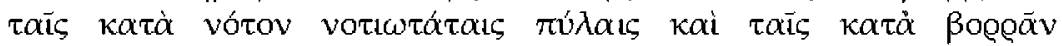

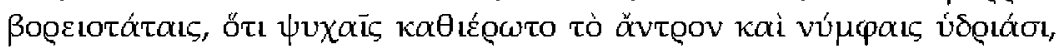

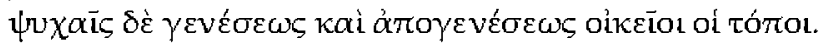

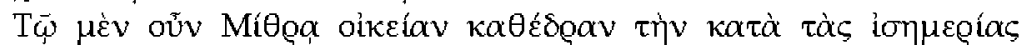

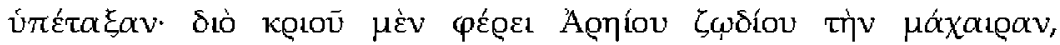

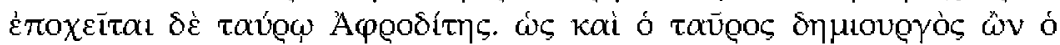

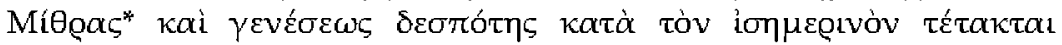

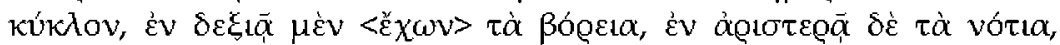

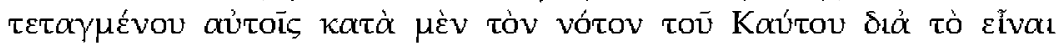

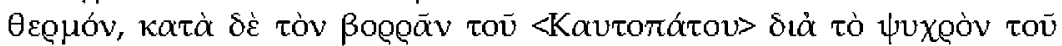
ảvéruov.

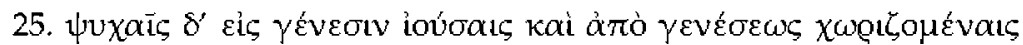

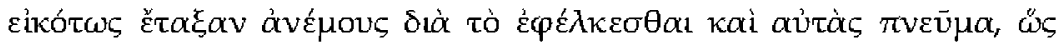

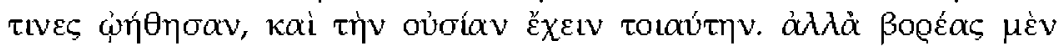

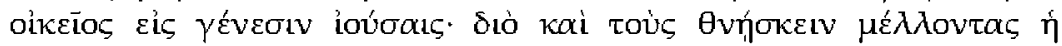

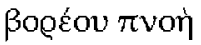

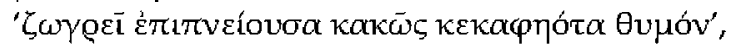

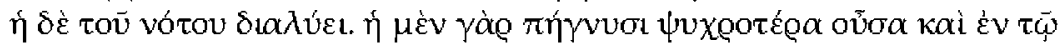

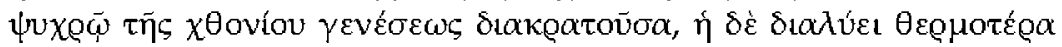

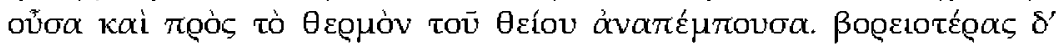

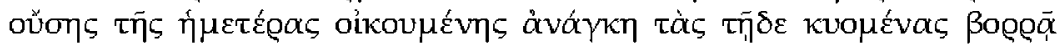

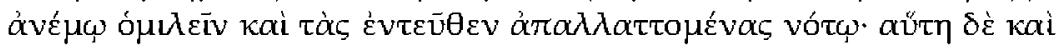

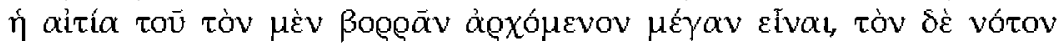

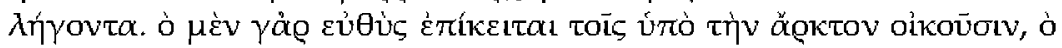

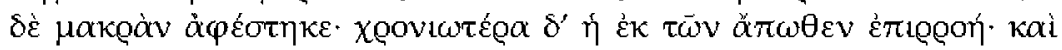

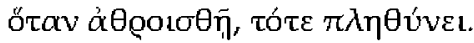

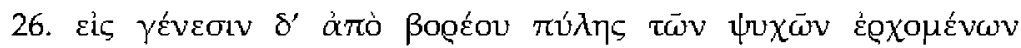

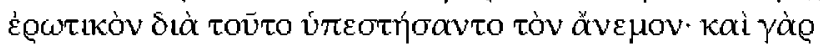

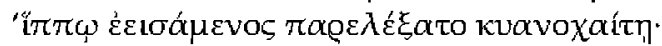

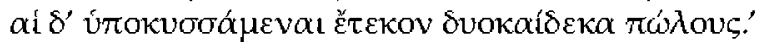


Sein Aufgang, der den Beginn der zum Kosmos führenden Entstehung markiert, ist für die Ägypter der Neumond. Entsprechend hat Homer die Türen weder dem Osten oder Westen noch der Tag- und Nachtgleiche, also dem Widder und der Waage, zugewiesen, sondern dem Süden und dem Norden mit den nach Süden gelegenen südlichsten und den nach Norden gelegenen nördlichsten Himmelstoren, weil die Grotte Seelen und Wassernymphen geweiht war; und (eben) diese Orte sind für Seelen mit Blick auf ihr Werden und Vergehen geeignet.

Dem Mithras haben sie den Ort der Tag- und Nachtgleiche als passenden Sitz gegeben. Deswegen trägt er das Schwert des Widders, das Zeichen des Mars, und er reitet auf dem Stier der Venus..$^{73}$ Wie der Stier so ist auch Mithras als Demiurg und Herrscher über das Werden ${ }^{74}$ entlang des Kreises der Tag- und Nachtgleiche gesetzt, wobei er in der rechten Hand die nördlichen Teile und in der linken die südlichen Teile hält. Im Süden haben sie Kautes aufgestellt wegen der Hitze und im Norden den Kautopates wegen der Kälte des Windes. ${ }^{75}$

25. Den Seelen, die zur Entstehung gehen und von der Entstehung weggehen, ordnen sie in passender Weise Winde $z u$, weil auch die Seelen einen Hauch atmen, wie manche glaubten, und eine ähnliche Essenz haben. Aber der Nordwind ist für die Seelen passend, die zur Entstehung gehen, denn der Hauch des Nordwindes belebt die Seelen, die im Begriff sind, zu sterben, „indem er in die sehr erschöpfte Seele hineinbläst ${ }^{\prime \prime},{ }^{76}$ der Hauch des Südwindes hingegen löst sie auf. Denn der Nordwind verfestigt die Seele, weil er kälter ist, und er herrscht mit der Kälte über das irdische Werden; der Südwind aber löst sie auf, weil er wärmer ist, und schickt sie zur Wärme des Göttlichen empor. Weil der von uns bewohnte Teil der Welt aber weiter im Norden liegt, sind die Seelen, die hier ausgetragen werden, notwendigerweise mit dem Nordwind vertraut, wogegen die Seelen, die sich von hier entfernen, mit dem Südwind vertraut sind. Dies ist auch die Ursache dafür, dass der Nordwind an seinem Anfang und der Südwind an seinem Ende stark ist: Denn der Nordwind legt sich sofort auf die Menschen, die unterhalb des Bären ${ }^{77}$ wohnen, der Südwind ist dagegen weit (von ihnen) entfernt. Und der von entlegeneren Gebieten kommende Zustrom dauert länger; er nimmt vor allem dann zu, wenn er sich sammelt.

26. Weil die Seelen aber von der nördlichen Tür aus zur Entstehung gehen, hat man angenommen, dass der Nordwind ein erotisches Wesen hat. Denn Boreas

"begattete sie in Gestalt eines schwarzhaarigen Pferdes; sie aber wurden trächtig und gebaren zwölf Fohlen." ${ }^{478}$ 


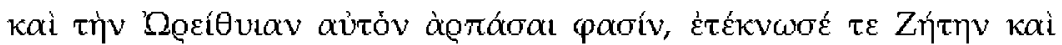

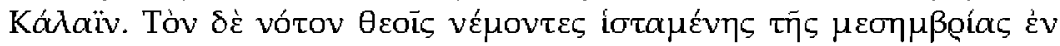

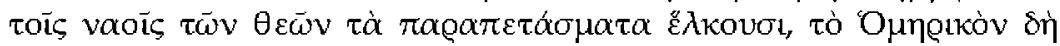

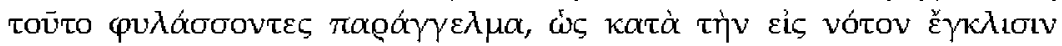

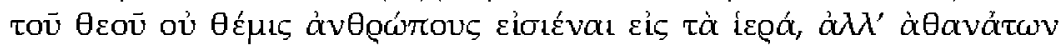
óoóc żotıv.

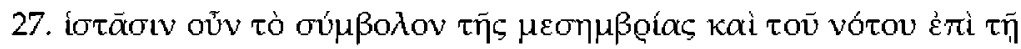

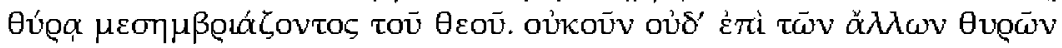

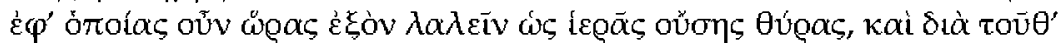

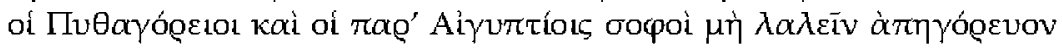

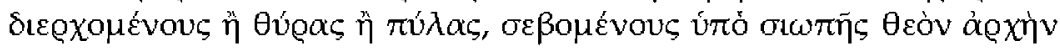

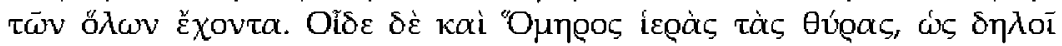

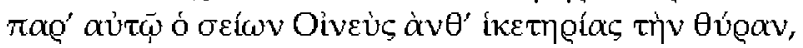

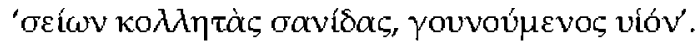

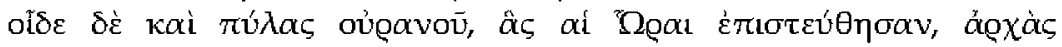

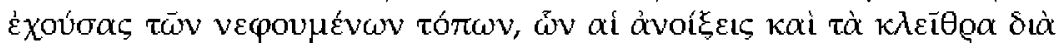
veৎp̄iv,

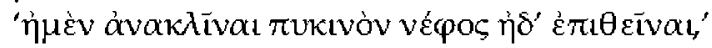

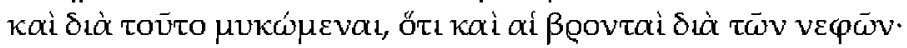

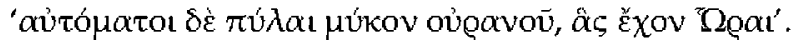

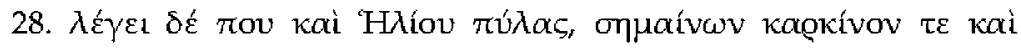

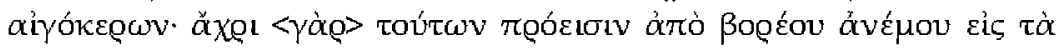

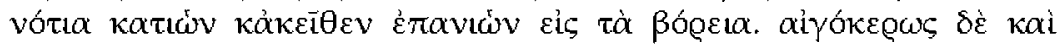

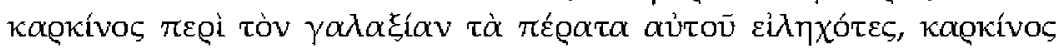

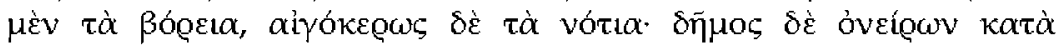

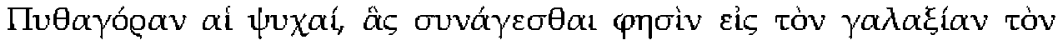

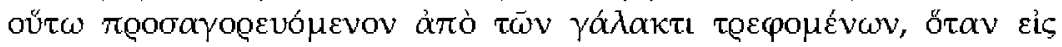

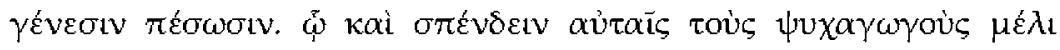

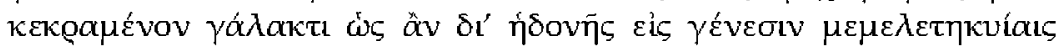

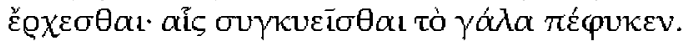

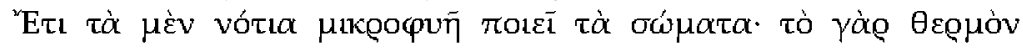

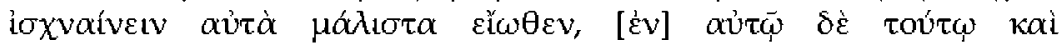

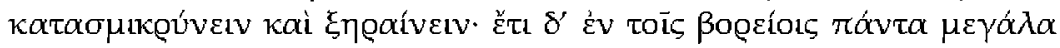


Und man sagt, dass Boreas die (Nymphe) Oreithyia ${ }^{79}$ geraubt habe, und er zeugte Zetes und Kalais. Weil die Menschen nun den Süden den Göttern zuteilen, ziehen sie, wenn es Mittag ist, in den Tempeln der Götter die Vorhänge $\mathbf{z u}$, wobei sie die homerische Vorschrift beachten, dass es nicht rechtens ist, dass die Menschen die Tempel während der Neigung der Sonne nach Süden betreten; dies ist vielmehr der Weg der Unsterblichen.

27. Wenn der Gott (= die Sonne) im Zenit steht, bringen sie also das Symbol des Mittags und des Südens an der Tür an. Und weil die Tür heilig ist, ist es auch zu keiner Zeit erlaubt, an anderen (Tempel-)Türen zu sprechen. Daher haben die Pythagoreer und die Weisen bei den Ägyptern verboten zu sprechen, wenn man Tore oder Türen durchschreitet, um schweigend den Gott als den Anfang aller Dinge zu verehren. Auch Homer kennt die Türen als heilig, wie bei ihm Oineus deutlich macht, der anstelle einer Bitte an der Tür rüttelt:

"Indem er die fest verbundenen Türen schüttelte, flehte er seinen Sohn an." $" 80$

Homer kennt auch die Tore des Himmels, die den Horen anvertraut wurden; diese Tore sind der Ursprung der nebligen Gefilde, deren Öffnung und Verriegelung durch die Wolken erfolgt,

"um den dichten Nebel sowohl herauszulassen als auch, um ihn zu verschließen. ${ }^{\prime \prime} 81$

Und deswegen ,brüllen' die Wolken (bei Homer), weil auch der Donner durch die Wolken ensteht:

"Von selbst brüllten die Tore des Himmels, die die Horen hielten." 82

28. Homer spricht auch irgendwo von den "Toren der Sonne",83 womit er Krebs und Steinbock meint. ${ }^{84}$ Denn bis zu diesen schreitet die Sonne voran, indem sie vom Nordwind $z \mathbf{u}$ den südlichen Gefilden herabsteigt und von dort (wiederum) zum Norden aufsteigt. Steinbock und Krebs markieren im Bereich der Milchstraße deren Enden, der Krebs den Norden, der Steinbock den Süden. Die Seelen sind nach Pythagoras ein ,Volk der Träume', ${ }^{85}$ die sich, wie er sagt, in der Milchstraße versammeln, die so nach den durch Milch genährten Seelen, wenn sie in das Werden fallen, benannt ist. Deswegen bringen Leute, die Seelen beschwören, ihnen auch mit Milch gemischten Honig als Opfergabe, weil sie daran gewöhnt seien, durch Lust zur Entstehung gehen. Zusammen mit ihrer Empfängnis entsteht natürlicherweise die Milch.

Ferner bringen die südlichen Gefilde kleinwüchsige Körper hervor, denn die Hitze lässt sie für gewöhnlich stark verdorren, so dass sie kleiner werden und ausgemergelt sind. Im Norden sind alle Körper 


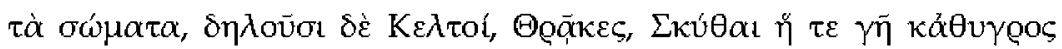

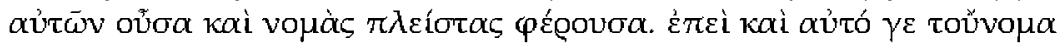

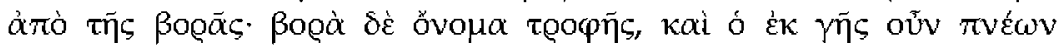

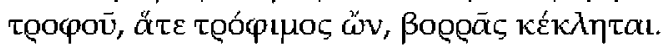

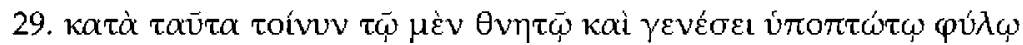

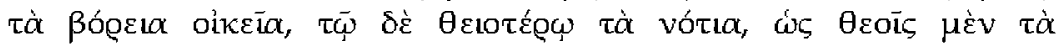

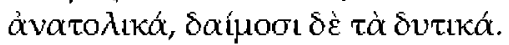

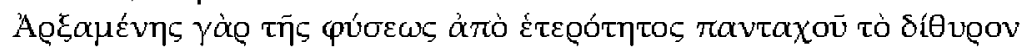

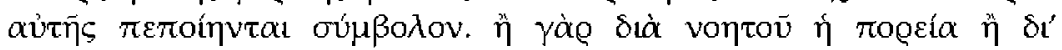

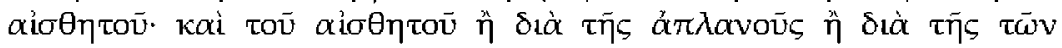

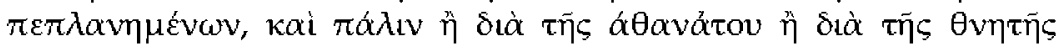

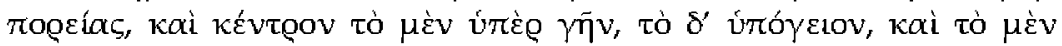

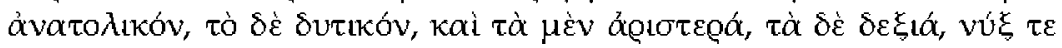
кà

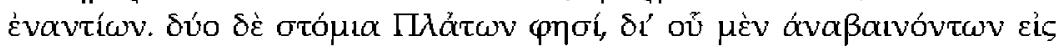

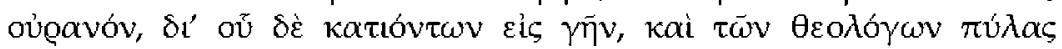

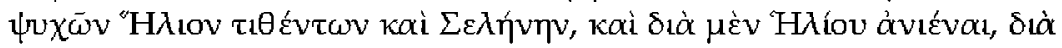

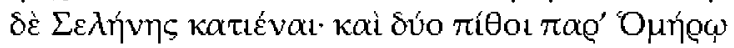

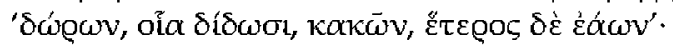

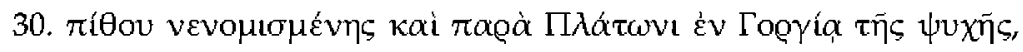

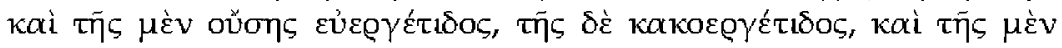

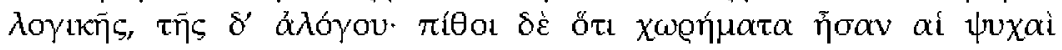

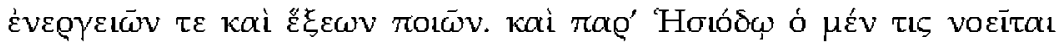

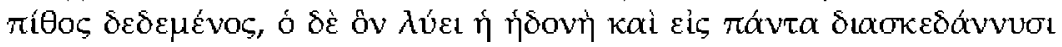

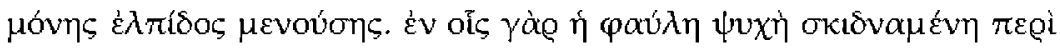

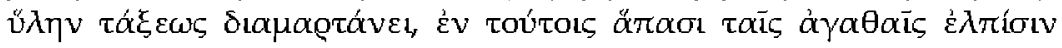

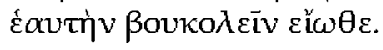

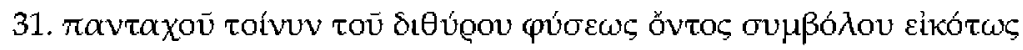

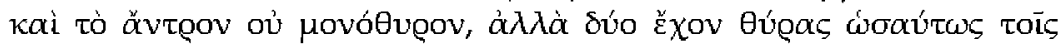

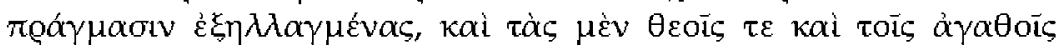

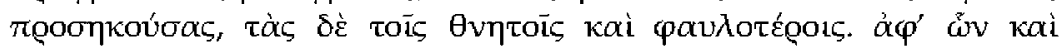


groß, was man an den Kelten, Thrakern und Skythen sehen kann, deren Land sehr feucht ist und viele Weiden hat. Daher ist auch der Name ,Boreas' selbst abgeleitet von dem Wort ,Bora', das eine Bezeichnung für Ernährung ist. Und der Wind, der von einem so ernährenden Land weht, wird ,Borras' genannt, weil er nährend ist.

29. Insofern also sind die nördlichen Regionen passend für das, was von sterblicher Abstammung ist und der Entstehung unterliegt, die südlichen hingegen für das, was von göttlicher(-er) ${ }^{86}$ Abstammung ist, so wie die östlichen Gegenden für Götter und die westlichen für Dämonen angemessen sind.

Weil die Natur ja ihren Anfang aus der Verschiedenartigkeit genommen hatte, hat man überall auf der Welt das Doppeltürige zu ihrem Symbol gemacht. Denn das Fortschreiten erfolgt entweder durch das Intelligible oder das Wahrnehmbare. Im letzten Fall geschieht es entweder auf einem unveränderlichen $W g^{87}$ oder auf dem der Planeten und wiederum auf einem unsterblichen oder einem sterblichen Weg. ${ }^{88}$ Es gibt einen Kardinalpunkt ${ }^{89}$ über der Erde und einen unter der Erde, der eine liegt östlich, der andere westlich. Entsprechend sind die einen Regionen links und die anderen rechts gelegen, und es gibt Nacht und Tag. Deswegen ist , die Harmonie durch Gegensätze gespannt ${ }^{\prime 90}$ und schießt durch Gegensätze ihre Pfeile ab. Platon sagt, dass es zwei Öffnungen gibt: Durch die eine würden die Seelen zum Himmel aufsteigen, durch die andere zur Erde hinabgehen; ${ }^{91}$ und die Theologen setzen die Sonne und den Mond als Tore der Seele fest, wobei die Seelen durch die Sonne aufsteigen und durch den Mond herabsteigen würden. Und bei Homer gibt es zwei Vorratsgefäße "deren eines die schlechten Gaben, die er zuteilt, enthält, deren anderes die guten".92

30. Auch in Platons Gorgias wird die Seele für ein Vorratsgefäß gehalten, und die eine Seele tue Gutes, die andere Böses, und die eine sei rational, die andere aber irrational. ${ }^{93}$ Seelen werden mit Vorratsgefäßen verglichen, weil sie Behälter für bestimmte Energien und Eigenschaften sind. Und bei Hesiod wird das eine Vorratsgefäß als geschlossen vorgestellt, das andere als eines, das die Lust offfnet und seinen Inhalt in alle Richtungen verstreut, wobei nur die Hoffnung (darin) bleibt. ${ }^{94}$ Denn wo eine schlechte Seele sich über die Materie zerstreut und die Ordnung verfehlt, pflegt sie sich selbst durch gute Hoffnungen zu täuschen.

31. Wenn also überall in der Welt ein doppelter Eingang ein Symbol der Natur ist, dann ist es auch passend, dass die (homerische) Grotte nicht eintürig ist, sondern zwei Türen hat, die sich ebenso wie die Dinge in der Wirklichkeit voneinander unterscheiden. Die eine Tür ist passend für die Götter und die Guten, die andere aber für die Menschen und die 


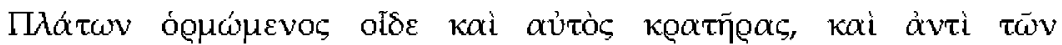

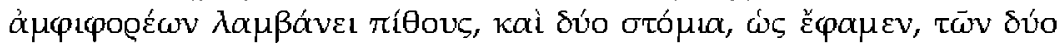

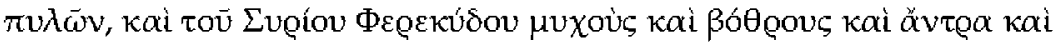

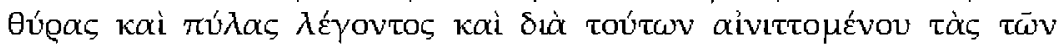

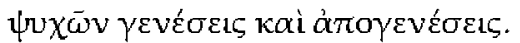

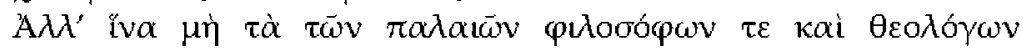

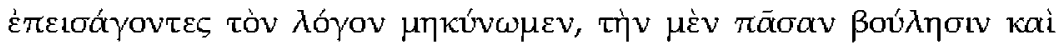

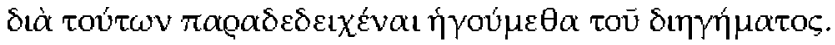

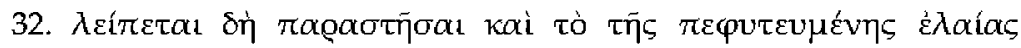

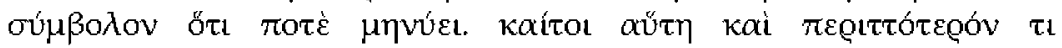

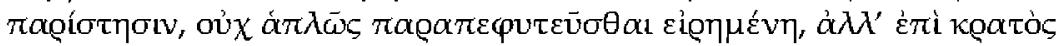

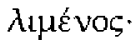

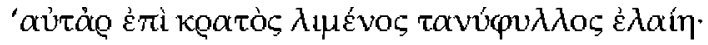

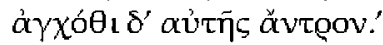

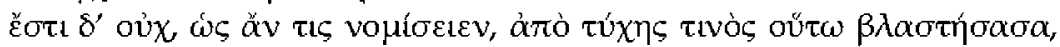

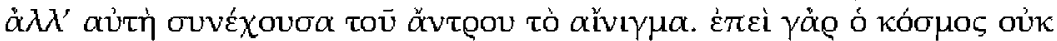

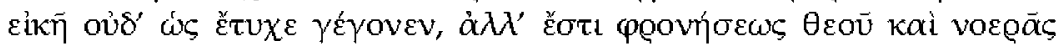

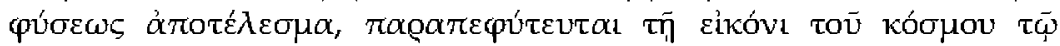

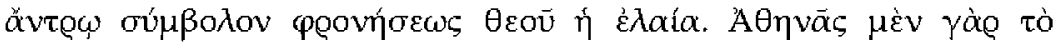

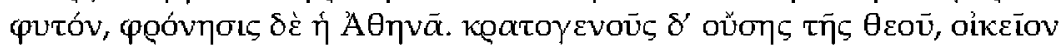

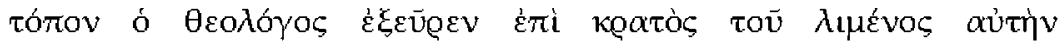

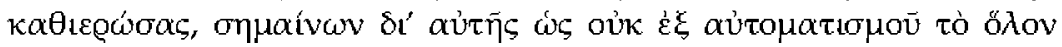

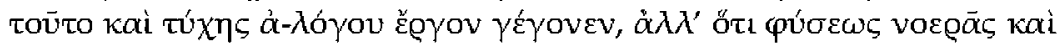

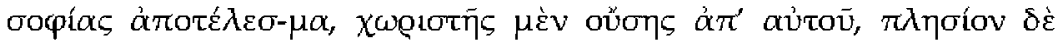

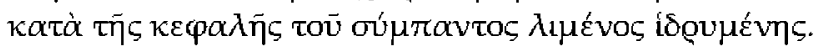

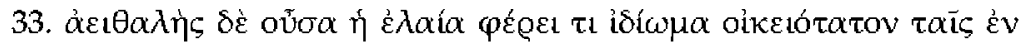

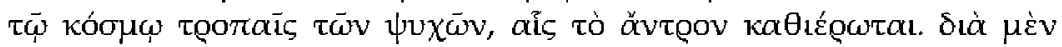

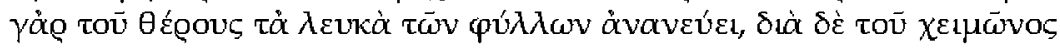

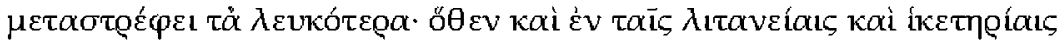

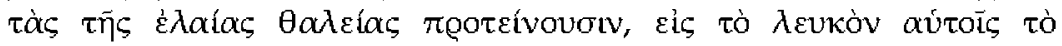

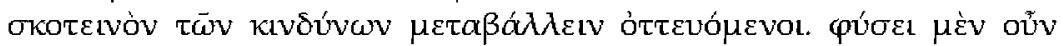

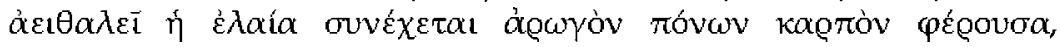

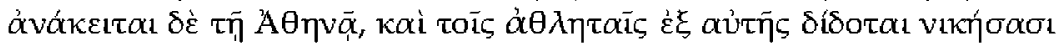


Schlechteren. Von diesen Überlegungen ausgehend kennt auch Platon selbst Kratere und nimmt Vorratsgefäße anstelle von Amphoren, ${ }^{95}$ und wie wir ausgeführt haben - setzt zwei Öffnungen anstelle der beiden Tore, wobei auch Pherekydes von Syros ${ }^{96}$ von Verstecken, Gruben, Grotten, Türen und Toren spricht und dadurch das Werden der Seelen und ihr Vergehen verrätselt.

Aber um nicht unsere Abhandlung durch das Erwähnen von Meinungen der alten Philosophen und Theologen (unnötig) zu verlängern, glauben wir, dass wir hiermit die ganze Intention der (homerischen) Erzählung dargestellt haben.

32. Es bleibt noch darzulegen, was wohl das Symbol des gepflanzten Ölbaums anzeigt. Doch wohl etwas sehr Außerordentliches, weil von ihm nicht einfach gesagt ist, dass er in der Nähe (der Grotte) gepflanzt ist, sondern am Kopfende des Hafens:

"Am Kopfende des Hafens steht ein langblättriger Ölbaum.

In dessen Nähe befindet sich eine Grotte ..."97

Der Ölbaum ist aber nicht, wie man vermuten könnte, gewissermaßen zufällig so gewachsen, sondern er umfasst das (gesamte) Rätsel der Grotte. Denn da der Kosmos nicht planlos oder zufällig entstanden ist, sondern das Ergebnis des vernünftigen Plans eines Gottes und einer rationalen Natur ist, wurde der Ölbaum neben das Bild des Kosmos, d.h. neben die Höhle, als ein Symbol der göttlichen Vernunft gepflanzt. Der Ölbaum ist nämlich das Gewächs der Athene, und Athene ist (die Verkörperung der) Vernunft. Und weil Athene eine kopfgeborene Gottheit ist, hat der Theologe den passenden Platz gefunden, als er den Ölbaum am ,Kopfende des Hafens' weihte; durch den Ölbaum zeigt er an, dass dieser ganze (Kosmos) nicht von allein entstanden oder das Werk eines irrationalen Zufalls ist, sondern dass er das Ergebnis einer rationalen Natur und einer (göttlichen) Weisheit ist, die (in Form des Ölbaums) zwar von ihr (= der natürlich gewachsenen Grotte) getrennt ist, aber in der Nähe der Grotte am Kopfende des ganzen Hafens platziert ist.

33. Weil der Ölbaum aber immergrün ist, hat er eine Eigentümlichkeit, die perfekt zu den Wechselfällen der Seelen im Kosmos, denen die Grotte gewidmet ist, passt. Im Sommer wendet er die weißen Teile seiner Blätter nach oben, im Winter kehrt er die weißeren Teile dagegen nach unten um. Daher streckt man auch bei Gebeten und Bittflehen die Blüten des Ölbaums vor, weil man für sich erhofft, dass das Dunkel der Gefahren in ein Leuchten umschlägt. ${ }^{98}$ Mit seiner immergrünen Natur trägt der Ölbaum eine bei Mühen hilfreiche Frucht. Er ist Athene geweiht, aus ihm wird den siegreichen Athleten der Kranz 


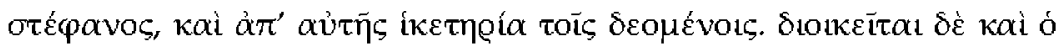

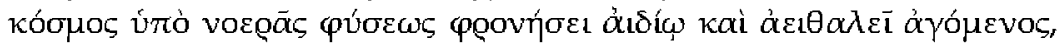

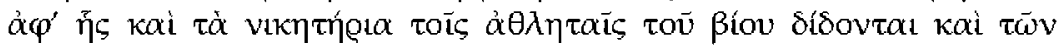

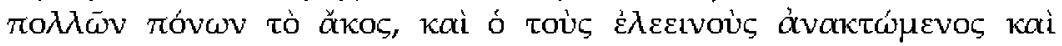

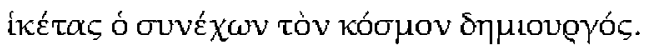

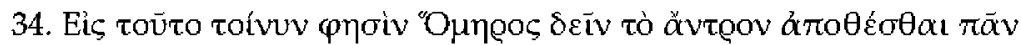

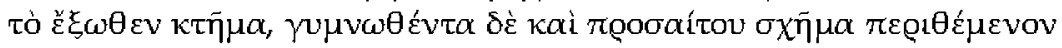

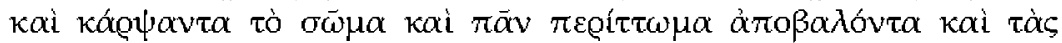

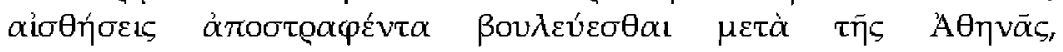

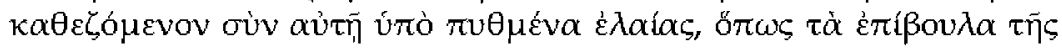

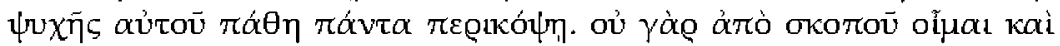

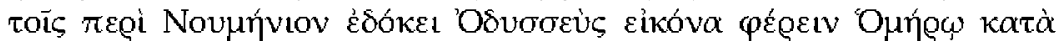

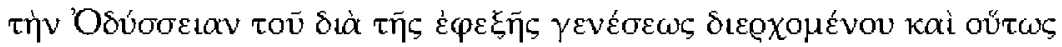

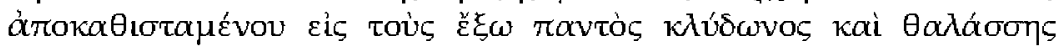

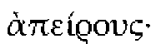

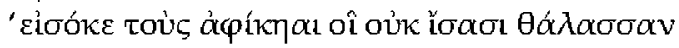

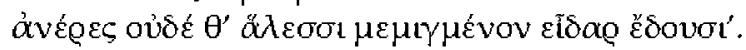

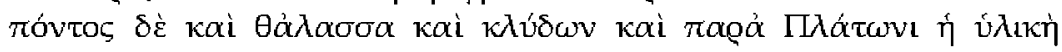
бúotaois.

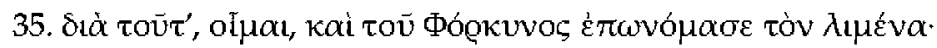

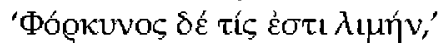

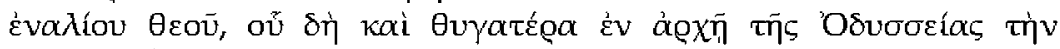

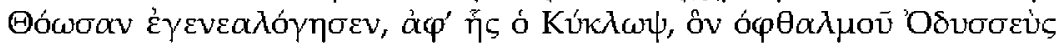

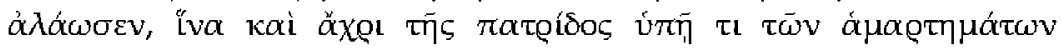

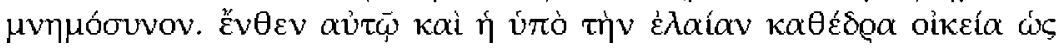

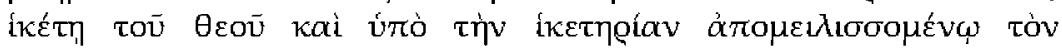

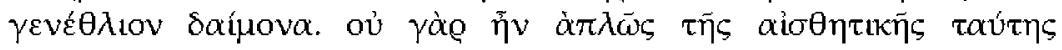

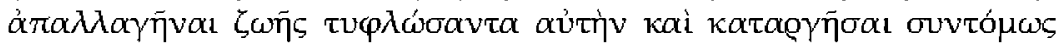

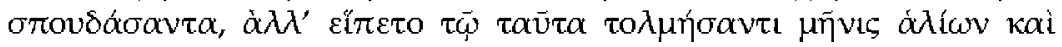

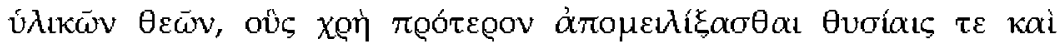

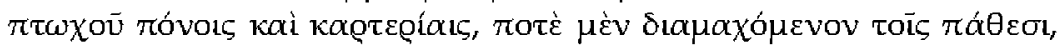

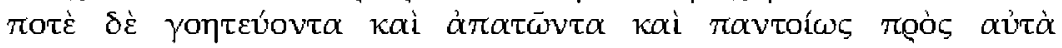

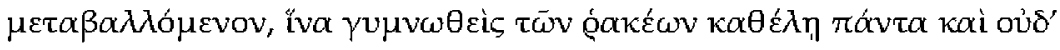

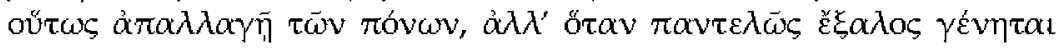


gewunden und von ihm erhalten die Schutzflehenden ihre Bittzweige. Aber auch der Kosmos wird von einer rationalen Natur durchwaltet und von einer ewigen und immer-blühenden Vernunft geführt, von der auch den Athleten des Lebens die Siegespreise und die Heilung von ihren vielen Mühen gegeben werden. Und der, der den Bemitleidenswerten und Bittflehenden aufhilft, ist der Demiurg, der den Kosmos zusammenhält.

34. In dieser Grotte, sagt Homer, muss jeder ätuerliche Besitz abgelegt werden: Nackt, in der Haltung eines Bettlers, am Körper geschlagen, von allem Überflüssigen entledigt und abgewandt von den Sinneswahrnehmungen muss man mit Athene, mit der man unten am Stamm des Olivenbaumes zusammensitzt, darüber beraten, wie man all die Affekte, die der Seele nachstellen, ausmerzen kann. Nicht ohne Grund haben, wie ich glaube, Numenios und seine Schüler geglaubt, dass Odysseus in Homers Odyssee das Abbild eines durch die aufeinanderfolgenden Stadien des Werdens gehenden Menschen ist, der auf diese Weise zu denen zurückkommt, die fern von jedem Wogenschwall wohnen und das grenzenlose Meer nicht kennen:

"Bis du zu denen kommst, die das Meer nicht kennen -

Männer, die kein mit Salz vermischtes Essen essen."

Auch bei Platon bezeichnen Meerestiefe, Meer und Wogenschwall den Zustand der Materie.

35. Deswegen, glaube ich, hat Homer den Hafen auch ,Hafen des Phorkys' genannt:

„Es ist der Hafen des Phorkys," 100

eines Meergottes, als dessen Tochter zu Beginn der Odyssee Thoosa angeführt wird. ${ }^{101}$ Von Thoosa stammt der Kyklop ab, dessen Augenlicht Odysseus geraubt hat, damit ihm bis zu seiner Heimat eine (ständige) Erinnerung an seine Verfehlungen blieb. Daher ist für ihn auch der Sitz unterhalb des Ölbaums passend, so wie für einen Schutzflehenden des Gottes und für einen, der seinen Geburtsdämon unter dem Bittzweig zu besänftigen sucht. Denn es ist nicht einfach, sich von diesem sinnlich wahrnehmbaren Leben $z u$ befreien, indem man es blendet und danach strebt, es schnell zu zerstören; vielmehr folgte dem, der solches wagte, der Zorn der Götter des Meeres und der Materie. Diese Götter muss er erst durch Opfer sowie durch die Mühen und Entsagungen eines Bettlers besänftigen, indem er mal seinen Leidenschaften widersteht, mal ihnen schmeichelt und sie täuscht und sich ihnen gegenüber in manigfacher Weise verwandelt, damit er von den Lumpen entkleidet jede Leidenschaft niederreiße und selbst so (noch) nicht von den Mühen befreit werde, sondern (erst dann,) wenn er ganz vom Meer entfernt 


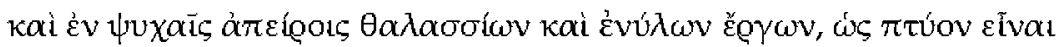

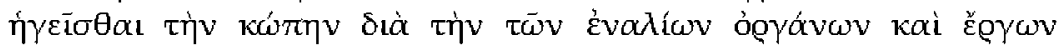

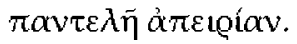

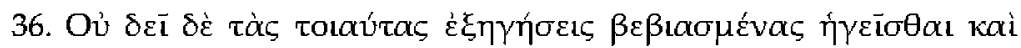

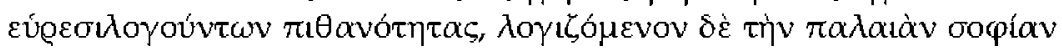

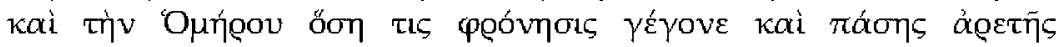

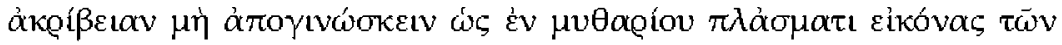

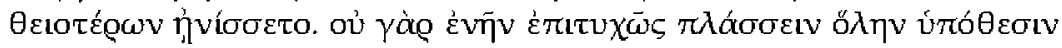

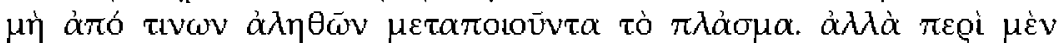

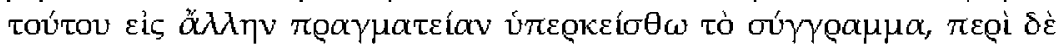

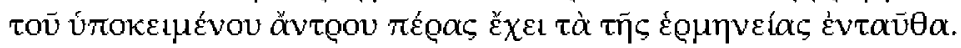


herausgekommen und in Gemeinschaft von solchen Seelen sei, die die Werke des Meeres und der Materie nicht kennen, und er aufgrund seiner völligen Unerfahrenheit in nautischen Werkzeugen und der Seefahrerei sein Ruder für eine Kornschaufel hielte. ${ }^{102}$

36. Man darf aber nun nicht denken, dass Auslegungen dieser Art gezwungen seien und (lediglich) Überzeugungsversuche spitzfindiger Wortkünstler, sondern wenn man die alte Weisheit und die Vernunft Homers in ihrer ganzen Größe und seine gründliche Kenntnis jeder Tugend in Betracht zieht, dann kann man nicht zurückweisen, dass er im erzählerischen Gewand eines Mythos Bilder von göttlicheren Dingen verrätselt hat. Denn es wäre (Homer) nicht möglich gewesen, die ganze Darstellung plausibel zu halten, wenn er sie nicht auf der Basis von gewissen Wahrheiten gestaltet hätte. Aber die Abhandlung hierüber soll einem anderen Werk vorbehalten sein; die an dieser Stelle vorgebrachten Auslegungen der betrachteten (homerischen) Grotte sind hier zu Ende. 


\section{Anmerkungen zur Übersetzung}

* Der Asteriskos im griechischen Text bezieht sich auf die Liste der Textvarianten am Ende der Einleitung.

1 Der griechische Text folgt dem Arethusa-Text. Zu Abweichungen vgl. die Einleitung in die Schrift, oben S. 29.

2 Der Beginn des Textes ist grammatisch schwierig, weil "O $\mathrm{OL}$ eine indirekte Frage einleitet, hier jedoch ein übergeordneter Satz fehlt. Möglicherweise ist dies ein Hinweis darauf, dass die Schrift aus einer längeren Abhandlung zu homerischen Fragen bzw. Allegorien stammt (vgl. zum Werkkontext die Einleitung in die Schrift, oben S. 20-21).

3 Homer, Od. XIII 102-112. Die Beschreibung der Nymphengrotte wird in der Odyssee bei der Landung des Phaiakenschiffes im Hafen des Phorkys auf der Insel Ithaka gegeben, wo die Phaiaken den schlafenden Odysseus zusammen mit zahlreichen Gastgeschenken absetzen. Die Verse 102-104 werden wenig später von Athene wiederholt, als sie Odysseus am Strand vor der Höhle erscheint tund ihm erklärt, wo er sich befindet (XIII 346-348). Dort wird auch deutlich, dass die Grotte für Odysseus ein wichtiger Kultort ist, an dem er den Nymphen schon oft geopfert hat (XIII 349-360).

4 Die Periegese (periégesis) gehörte neben der Periplus-Literatur mit ihren Seefahrtsoder Küstenbeschreibungen und dem auf Anaximander (frühes 6. Jh. v. Chr.) und Hekataios von Milet (ca. 560-480 v. Chr.) zurückgehenden, mit Karten versehenen, Wegen um die Welt (periodoi gés) zur geographischen Fachschriftstellerei. Sie konnte in Prosa ocler Poesie (vgl. Dionysios von Alexandria, 2. Jh. n. Chr.) verfasst werden und enthielt neben rein geographischen Beschreibungen von Ländern und Kultstätten auch Exkurse zur Kultur, Mythos und Geschichte eines Ortes.

5 Das Werk des Kronios, den Porphyrios in De antro Nympharum mehrfach erwähnt $(\$ \S 2,3,21)$, ist bis auf einen Werktitel (De regeneratione $=\ddot{U}$ ber die Wiedergeburt) und wenige Hinweise auf Kommentare (u.a. zu Platons Staat und. Timaios) vollständig verloren. Folgt man Porphyrios, der ihn in Kapitel 21 als Schüler des Numenios (von Apameia) bezeichnet, lebte Krotrios um die Mitte des 2. Jh.s th. Chr. Porphyrios nennt ihn und Numenios wechselweise Platoniker - die Werke beider Autoren wurden in Plotins Schule gelesen (VPlot. 14,10-14) - und. Pythagoreer (Euseb. Hist. eccl. VI 19,8). Wahrscheinlich ging es Kronios ähnlich wie Numenios und später atch Plotin darum, pythagoreische Prinzipien in den platortischen Werken zu erkennen und Teile der pythagoreischen Lehre aus Platon zu rekonstruieren; für diese „pythagoreisierenden Platoniker" (M. FrRDE, "Numenius", ANRW II.36.2 [1987] [1034-1075] 1047) war die Seelenlehre, die bei der Allegorese der Nymphengrotte eine zentrale Rolle spielt, ein wichtiges Thema. Zu Kronios vgl. J. Dillon, The Middle Platonists. 80 B.C. to A.D. 220 (London 21996) 379f.; WHITTAKER 1994 und MänNLEINRoBBrT 2018.

6 Zur Bedeutung der Dunkelheit der Höhle aus ritueller Sicht als Schwelle des Übergangs bzw. der katábasis (Hinabstieg, Gang in die Unterwelt) vgl. Irmgard Männlein-Robert in diesem Band, S. 105-I07.

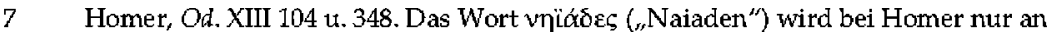
diesen beiden Stellen sowie in XIII 356 und jeweils in Bezug auf die Nymphengrotte verwendet. Das verwandte v $\eta$ ïs findet sich ebenfalls nur an drei Stellen der home-

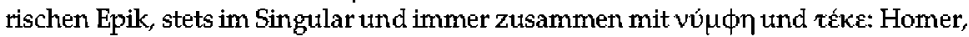
II. VI 22, XIV 444 u. XX 384. Naiaden sind "Quell- bzw. Wassernymphen", die als Naturgottheiten zumeist im Freien (Hainen, Quellen, Grotten) verehrt wurden. Die 
Unterscheidung verschiedener Nymphenarten ist bei Homer bereits angelegt, vgl. II. XX 8f. und Od. VI $123 \mathrm{f}$.

Die Ostaustichtung der Tempel in Richtung der atfgehenden Sonne ist für griechisch-römische aber auch ägyptische und orientalische Tempelbauten gängig. Es gibt jedoch durchaus -z.T. topographisch bedingte - Ausnahment wie cen Apollontempel zu Bassai (Nord-Süd-Richtung), der allerdings einen nach Osten ausgerichteten Zugang zum Adyton hat.

9 Das Referat aus Kronios endet, und Porphyrios beginnt seine Allegorese, wobei er sich gleich zu Beginn von Kronios absetzt und dessen Position, dass es keine geographischen Quellen für die Existenz der Grotte gibt (vgl. \$2) mit dem Zitat aus Artemidor (s.u. Anm. 12) widerlegt.

10 Hier fehlt ein finites Verb; aus dem Kontext wird deutlich, dass die Geographen, die die Insel und die Grotte beschrieben haben, in ihrem reflektierten Urteil über die homerische Beschreibung von den zuvor genannten, leichtfertigeren' Schrei-

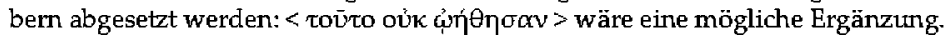
Antikes Längenmaß; ein Stadion umfasste $600 \mathrm{FuB}$, was regional leicht unterschiedlich gemessen wurde und ca. 160-190 Metern entsprach.

12 Porphyrios zitiert diese Stelle aus den 11 Bücher umfassenden Geographúmena Artemidors (Geograph ats dem späten 2. bzw. frühen 1. Th. v. Chr.; fr. 55 STIEHLE), in denen nach Art der Periplus-Literatur (s. Anm. 4) topographische und geschichtliche Informationen über Länder und Inseln des Mittelmeerraums versammelt waren.

Vgl. zur Konnotation von $\alpha \dot{\alpha} \alpha \dot{\theta} \eta \mu \alpha$ als , heiliges Bild" tud zur semantischen Nähe zu $\alpha \gamma \alpha \lambda \mu \alpha$ ( ${ }_{s}$ Götterbild, Weihgeschenk") bei Porphyrios Irmgard Märnleirt-Robert in diesem Band, S. 99 mit Anm. 17.

14 Diese Position vertrat unter den Vorsokratikern Xenophanes aus Kolophon (ca. 570-

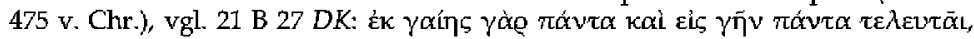
"Denn aus Erde ist alles, und zur Erde wird alles am Ende". Vgl. auch Simonini 1986, 95-97.

Hier referiert Porphyrios offensichtlich weiter die Ansicht der vorsokratischen Philosophen, denn in Kapitel 32 wird deutlich, dass er selbst eine platonische Sichtweise von dem "durch göttliche Weisheit erschaffenen Kosmos" vertritt.

16 Vgl. Homer, Od. XIII 103.

17 Zum Ritus der symbolischen Seelenführung im Mithraskult und seiner Entstehung vgl. Gordon 2001.

18 Platoniker ats dem 3. Th. th. Chr., mit dessen Schriften, zut denen ein mehrbätıdiges Werk über die Mithrasmysterien (vgl. Porphyrios, De abst. 4.16.8f.) gehōrte, Porphyrios bestens vertratut war, vgl. Porph. VPlot. 15. Zur platonischen Färbutng des Werkes von Eubulos vgl. Turcan 1975, 23-43.

19 Altiranischer Religionsstifter und Priester (gr. Zöroástrēs). Zur späteren Aufnahme der Mithrasverehrung in den Zarathustrakult und zu dessen Stilisierung als Begründer des Mithraskultes vgl. MerkeleAch 1994, 9-22 und den Mithras-Hymntts (Yašt 10). Zur Verbreitung von Zarathustras Lehre und ps.-zarathustrischer Literatur in der griechisch-römischen Kultur vgl. M. L. WBST, "The Classical World", in: M. Stausberg / Y. S.-D. Vevaina (Hg.), The Wiley Blackwell Companion to Zoroastrianism (Chichester 2015) 437-450.

20 Ursprünglich eine altpersische Gottheit, für die es seit dem 2. Jh. v. Chr. im giechisch-römischen Sprachraum einen eigenen, weit verbreiteten Mysterienkult gab. Mithras soll als Stiertöter eine neue kosmische Ordnung etabliert haben und wurde als Sonnengott (sol invictus) verehrt. Zu den Höhlen als Kultorten des Mithras vgl. Clauss 2012, 48-64. 
An Platons Tímaios 28c3-e4 ( te Formulierung, die Porphyrios wohl aus Eubulos (s. Anm. 18) übernommen hat, vgl. Alt 1998, 470 und Christoph Riedweg in diesem Band, S. 87, Anm. 62.

Mit Mithras als Demiurg ist nach Materie und Form (Idee) auch das dritte Prinzip der aus dem platonischen Timaios abgeleiteten mittelplatonischen Prinzipienlehre eingeführt, vgl. Christoph Riedweg in diesem Band, S. 78-79.

Vgl. hierzu Irmgard Märnleirt-Robert in diesem Band, S. 110-112.

In Hesiods Theogonie (459-462) verschluckt Kronos seine Kinder aus Angst vor Umsturz und Stukzession; in gleicher Absicht hatte zuvor Uratos seine Kinder ,in der

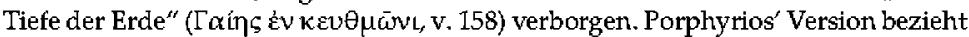
sich wohl auf einen orphischen Mythos, vgl. Orphic. fr. $79 \mathrm{~F}$ III Bernabé und SimoNINI 1986, 164-I66.

Das Erziehen von Gottheiten in Höhlen ist häufig und dient zumeist dem Schutz vor Nachstellungen. So wird Zeus nach seiner Geburt von seiner Mutter Rhea in einer Höhle auf Kreta vor Kronos versteckt (vgl. Hesiod, Theogonie 479-484), und Zeus selbst lässt den aus seinem Schenkel geborenen Dionysos in einer Höhle von Nymphen erziehen. Im orphischen Zeus-Mythos wird die jungfräuliche Persephone von ihrer Mutter Demeter erzogen (vgl. Orphic. fr. 279 F III und 209 F I) und aus Furcht vor Freiern in einer Höhle verborgen; gleichwohl dringt Zets in Gestalt eines Drachen in die Höhle ein und zeugt mit Persephone den (Dionysos-)Zagreus. In Nonnos' Version dieses Mythos wird auch ein steinemer Webstuhl erwähnt, der sich in der Höhle befunden haben soll (Nonnos, Dionysiaka VI 133).

Porphyrios verweist im Folgenden häufig allgemein atf "Theologen", ohne seine Referenzen zu konkretisieren. Wahrscheinlich handelt es sich dabei um Verfasser von orphischen Schriften. Bei "dem Theologen" $(\$ 16)$ handelt es sich dagegen um Orpheus selbst, der in den Kapiteln 14 und 16 insgesamt dreimal namentlich erwähnt wird. Auch Homer wurde als, Künder göttlicher Wahurheiten' von Neutplatonikern, besonders von Proklos, als "Theologe" bezeichnet und dadurch in seiner Autorität gestärkt, vgl. LAMberTon 1986, 22 und PICHLBR 2006, 67-71.

Der Kontext der Verse sowie die Entstehungszeit und Autorschaft dieses Hymnos sind unbekannt, vgl. PLG III, 684 BERGK.

Die Verbreitung der Lehre des Naturphilosophen Pythagoras (ca. $570-480$ v. Chr.), über den Porphyrios eine eigene Biographie verfasst hat, erfolgte über die Mitglieder der sog. pythagoreischen Schule, auf deren Lehrmeinung Porphyrios hier generell verweist. Zum Einfluss der pythagoreischen Lehre auf die platonische Philosophie und zu ihrer Bedeutung im Netuplatonismus vgl. oben, Attm. 5.

Das Zitat stammt aus den Katharmoi ("Reirigungen") des Vorsokratikers Empedokles (ca. 490-430 v.Chr.), in denen das erzählende Ich als gefallener Daimon atttritt und von dem Abstieg (seiner Seele) und der Ankunft in einer Höhle spricht (fr. 31 B $120 \mathrm{DK}$ ), die ähnlich wie Homers Nymphengrotte eine allegorische Auscleututng erlaubt. Vgl. hierzu auch Irmgard Mätnlein-Robert in diesem Band, S. 113. Porphyrios zitiert den Beginu des Höhlengleichrisses (Platon, Politeia 514a2-517b4, mit Auslassungen). Er setzt dabei die Bekanntheit der Stelle bei seinen Rezipienten voraus, so dass er die weiteren Überlegungen Platons zum Aufstieg der Seele zur Gegend der Erkenntnis nicht weiter zitieren muss (vgl. dagegen ALt 1998, 471f).

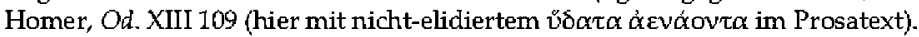
$\mathrm{Zu}$ dieser Symbolik und ihrem platonischen Substrat vgl. Christoph Riedweg in diesem Band, S. 79-80.

33 Vgl. Gen. 1,2:

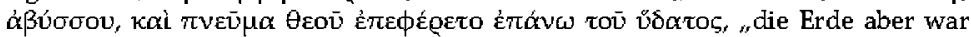
wüst und wirr, Finsternis lag über der Urflut und. Gottes Geist schwebte über dem Wasser" (Einheitsübersetzung). Von hier an ist der Rest von Kapitel 10 ein Referat aus Numenios. 
34 Der vorsokratische Philosoph Heraklit aus Ephesos (6./5. Jh. v. Chr.) ging davon aus, dass der Kosmos von einem umfassenden Logos ( $\lambda$ ófos) geleitet würde; der materielle Grundstoff des Kosmos und zugleich seine reinste Form ist das Fetter, das als kosmisches Feuer mit der Seele gleichgesetzt wird. Jeder Mensch besitzt eine feurige Seele, die stirbt, wenn das Fetuer (= Leben) erlischt und sie zu Wasser wird, zugleich aber - und das ist der Hintergrund der von Numenios zitierten Stelle $(f r$. 22 B $77 D K$ ) - kann sie aus dem Wasser wieder neu entstehen, wenn dieses (unter Einwirkung von Feuer) verdunstet.

35 Vgl. Heraklit, fr. 22 B 62 DK. Numenios scheint das Fragment in orphisch-pythagoreischer Weise zu interpretieren, wonach der Körper das Grab der Seele ist und erst der Tod des Menschen ihre Rückkehr ins Leben ermöglicht (vgl. zur Seelenwanderungslehre in Orphik und Pythagoreismus J. G. Kalogrrakos, Seele und Unsterblichkeit. Untersuchungen zur Vorsokratik bis Empedokdes. BzA 52 [Stuttgart / Leipzig 1996] 144-149). Das Heraklitfragment selbst lässt sich dagegen nicht nur als Aussage über die Einheit der für die herakliteische Philosophie typischen Gegensätze lesen (vgl. hierzu Simonini 1986, 122f), curch die alles in Dynamik, im Fluss bleibt ( $\pi \alpha v \tau \alpha$ èei), sondern auch als Beschreibung von Heroen, die in ihrem menschlichen Leben sterblich sind und erst nach dem ,Tod' unsterblich werden, vgl. hierzu T. M. Rokinson, Heraclitus. Fragments (Toronto / London 1987) 124f. Weitere Interpretationen des Heraklitfragments bei M. Marchovich, Heraclitus. Greek Text with a Short Commentary (Merida 1967) 240f. und KAHN 1979, 216-220.

Hier spielt Numenios wohl auf Homer, Od. VI 201 an, wo Nausikaa ihre Mägde beim Anblick des gestrandeten Odysseus mit den Worten beruhigt, dass es kei-

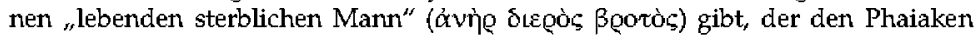
Feindschaft bringen kann. Während dıegó von "lebendig" gebraucht ist (und sonst nur noch ein weiteres Mal, in Od. LX 43, in der Bedeutung , lebhaft, rasch" vorkommt), liest Numenios offensichtlich die nachhomerische Bedeutung "nass" in die Wendung hinein. Eine weitere Abweichung von der Homerstelle ergibt sich durch die direkt folgende Gegenüberstellung der ,nassen', blutgenährten Seelen mit denen der Pflanzen, die nahelegt, dass Numenios die bei Homer noch speziell auf Menschen bezogene Aussagekraft auf alle Lebewesen erweitert.

37 Flüssige Opferspenden für Götter und Verstorbene sind in rituellen Kontexten seit Homer belegt, mit Blick auf Seelen von Menschen und den Kontext der Odyssee am prägnantesten in der nekyia im 11. Gesang, 23-50. Nach einer Spende für alle Toten aus vermischtem Honig. Wein und Wasser tötet Odyssetus Schafe und lockt mit ihrem Blut die Seelen Verstorbener an. Porphyrios kommt in $\$ 18$ nochmals auf die Spende von Galle für die Götter und in $\$ \S 19 \mathrm{t} .28$ atf ,mit Honig gemachte Trankopfer zurück.

38 Häufig zitiertes Heraklitfragment ( $f r .22$ B $118 \mathrm{DK}$ ). Porphytios gibt eine verkürzte

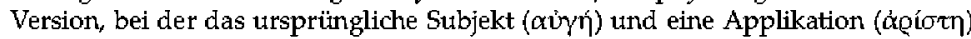

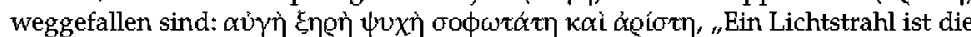
trockene Seele, die weisteste und beste". Zur Überlieferung, Konstruktion und Deutungsmöglichkeiten des Fragments vgl. KAHN 1979, 245-254.

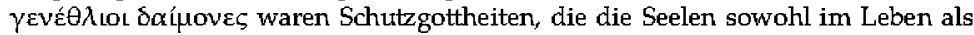
auch nach dem Tod eines Menschen begleiten. Die Vorstellung ist alt (vgl. Pindar, Olympie XIII 106); sie wird bei Platon im Zusammenhang mit der Seelenwanderung und der Frage nach der Unsterblichkeit der Seele diskutiert, vgl. Phaidon 107d6108 c5. Porphyrios kommt auf sie nochmals in Kapitel 35 zurück. Vgl. Christoph Riedweg in diesem Band, S. 78-79.

41 Homer, Od. XIII 108.

42 Häufig verwendete Metapher, die zuerst bei Empedokles in einem Fragment aus den Katharmoi (31 B 126 DK) belegt ist; zu weiteren Belegen vgl. A. KвHL, s, Gewand 
(der Seele)", RAC 10 (1978) 945-1025 und - mit Blick auf seine Verwendung bei Porphyrios und in der platonischen Tradition-SIMONINI 1986, 149-152. Ein direkter Bezug auf Empedokles liegt nahe mit Blick auf $\S 8$, wo Porphyrios eine weitere Stelle aus den Katharmoi zitiert hat (vgl. Anm. 29).

Die webende Persephone wird im Zusammenhang mit Demeters Versuch, sie vor Freiern in einer Höhle zu verstecken, erwähnt (vgl. Nonnos, Dionysiaka VI 103-154). Auf die Erzählung, in der atch ein steinemer Webstuhl vorkommt (v. 133), wurde von Porphyrios bereits in $\$ 7$ verwiesen (vgl. Anm. 25). Zur orphischen Vorstellung eines Himmelsgewands vgl. Orph hymn. 19, I6 und generell Sim ONINI 1986, 152-155. Homer, Od. XIII 106. Das Verb $\tau \iota \theta \alpha \iota \beta \omega \sigma \sigma \sigma \omega$ fühtt das Anlegen von Honigwaben mit und scheint den ganzen Vorgang des Sammelns und Bereitstellen des Honigs als Futter zu beschreiben. Letzteres wird durch das etymologisierende Spiel tò

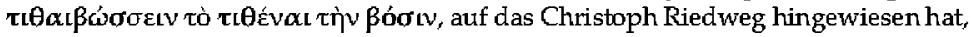
pointiert unterstrichen.

45 Als Bugonie wird das Entstehen eines neuen Bienenvolkes aus dem Kadaver eines Stieres bezeichnet. Literarisch vielfach beschrieben und wohl seit Demokrit bezeugt (68 B 27a DK) ist die Bugonie nicht nur ein Naturphänomen, sondern auch ein Symbol für die Reinkarnation, die Porphyrios in Kapitel 19 beschreibt. Einen Bezug zu Orpheus stellt Vergil im Aristaeus-Epyllion der Georgica (IV 453-527) her; zur poetologischen Funktion der Bugorie vgl. M. Baumbach, "Quae mox ventura trahantur. Eine poetologische Lektüre der Proteusfigur im Vergleich von Homers Odyssee, Goethes Faust II und Vergils Georgica", in: M. Baumbach / W. PollbichTn bR (Hg.) Innovation aus Tradition. Literaturwissenschaftliche Perspektioen der Vergilforschung (Trier 2013) 205-229.

46 Der Mithraskult kennt sieben Intiationsgrade: 1. Corax (Rabe), 2. Nymphus (Brätttigam), 3. Miles (Soldat), 4. Leo (Löwe), 5. Perses (Perser), 6. Heliodromus (Sonnenläufer), 7. Pater(Vater), vgl. Clauss 2012. Die Grade standen in Beziehung zu den sieben Planeten, die als Symbole für die Seelenreise angesehen wurden.

Der Perser ist der 5. Weihegrad der Initiationsriten im Mithraskult, vgl. Anm. 46. Als Hüter der Vegetation hat er im Mithraskult die Attribute Hecke, Pflug und Sichel. Zur Symbolik der kosmischen Elemente vgl. Christoph Riedweg in diesem Band, S. $87-88$

49 Vgl. Homer, Il. XIX 38f. Auf Bitten des um Patroklos trauernden Achill tröpfelt Thetis dem Leichnam Nektar und. Ambrosia in die Nase, um ihn unversehrt zu halten.

50 Homer, Od. V 93. Der Kontext ist Hermes' Besuch bei Kalypso, die ihn mit Nektar uthd Ambrosia bewirtet.

51 Vgl. Platon, Symp. 203b5-6. Poros ist der Sohn der Metis (Klugheit) und verkörpert Findigkeit und Reichtum. Im Symposion wird er von Diotima als Vater des Eros genannt, den er zusammen mit Penia (der Verkörperung der Armut) im Rausch gezeugt hat.

52 Orphic. fr. 187 F II Bernakê. Vgl. hierzu Christoph Riedweg in diesem Band, 5. 85-86, Artm. 55.

53 So im Sukzessionsmythos von Hesiods Theogonie 173-182.

54 Gemeint ist die Planetensphäre; Porphyrios referiert hier die wohl von den Orphikern vorgenommene allegorische Deutung der mythischen Erzählung mit Blick auf das Verständnis der Himmelssphären, auf die er später in $\$ \$ 21$ u. 22 noch ausführlicher eingeht. Kronos steht für den Saturn.

55 In der Antike zählte man sieben Planeten: Jupiter, Mars, Merkur, Saturn, Venus sowie die Sonne und den Mond. Vgl. zur unterschiedlichen Planetenreihenfolge in antiken Planetenmodellen Nbugrbaubr 1975, 690-693, und speziell bei Porphyrios Benjamin Topp in diesem Band, S. 121-126.

56 Amphoren waren in der Regel nicht für das Schöpfen von Wasser vorgesehen, sondern waren ein Aufbewahrungsort für Öl oder Wein. Es gibt allerdings eine Reihe 
von literarischen, ikonographischen und inschriftlichen Zeugnissen, in denen Wasser in Amphoren geschöpft und transportiert wurde, vgl. z.B. IG I ${ }^{3} 256,4-13$ für die Quelle Halykos bei Louparda in der Nähe von Athen. Eine Hinzufügung von $\langle\tau \bar{\omega} v\rangle$ (vgl. den Arethusa-Text) im Sinne von "the amphoras are symbols of the vessels in which we draw water from springs" (A rethutsa-Text, 19) ist daher unnötig. Sophokles, fr. 879 .

58 Hier wird vor allem auf den Platz des Mondes im Sternzeichen ,Stier verwiesen, in dem er astronomisch betrachtet besonders wirksam ist; vgl. auch Benjamin Topp in diesem Band, S. 129f. Zugleich wird die Engführung vor Mond und Stier im Mithraskult mitgeführt.

Überliefert ist ákoú $\omega v$, was semantisch schwierig ist. Da Mithras den Stier in einer Höhle opfert, um aus diesem Opfer die Welt zu erneuern und Entstehung zu bewirken, könnte der Stierstehler eine ähnliche Intention haben - vgl. dxvakisuvv (WESTERINK) - oder Porphyrios betont die, Aufhebung des Werdens, wie Christoph Riedweg in diesem Band (S. 92-93) mit àvaıpōvv vorschlägt. Zu weiteren Konjekturen vgl. Sim ONini 1986, $179 \mathrm{f}$.

60 Porphyrios referiert hier weiter die Meinung der Theologen. Interessanterweise üben sich die Bienen mit Blick auf das Bohnensymbol in gleichsam pythagoreischer Enthaltsamkeit allerdings mit einer anderen Begründung: Galt die Bohne den Pythagoreern im Zusammenhang mit der Wiedergeburtslehre als tabu, da sie beseelt war (vgl. Orphic. fr. $291 \mathrm{KERN}$ ), so meidet die Biene (als Symbol der gerechten Seele) die Bohne, weil die Biene keine direkte Reirkamation verkörpert, sondern den Kreislauf der Inkarnation durch einen Aufenthalt an ihrem Ursprung unterbricht (vgl. hierzu ALt 1986, 477).

61 Erdgeborene Diener der Rhea, die deren Sohn Zeus als Kind in der Höhle von Dikte auf Kreta bewacht und vor Kronos beschützt haben sollen. Zu den zahlreichen Belegen für diesen Mythos vgl. Simonini 1986, 186f.

Eine solche kultische Gemeinschaft von Pan und Selene ist sonst nicht bezeugt; Porphyrios greift wohl auf die seit hellenistischer Zeit bezeugte Liebesgeschichte dieser beiden Gottheiten zurück, vgl. die Belege bei Simonini 1986, 187f. Zu den zahlreichen Höhlen, die Pan und den Nymphen geweiht sind vgl. Ustinova 2009, 55-68 und Irmgard Männlein-Robert in diesem Band, S. 108-110.

63 Homer, Od. XIII 111f.

64 Das lange Referat aus Numenios endet in Kapitel 24. Es ist unklar, welche Teile von Kronios stammen. Die Ausführungen des Numenios waren ausführlicher, wie aus Parallelüberliefertungen bei Proklos und Macrobitts detutlich wird, vgl. Numenios fr. 34,3f. u. fr. 35.

65 Gemeint ist der Satum, der schon nach antiken Berechuntungen als am weitesten von der Erde entfernt angesehen wurde, vgl. Ввск 1988, 4-8.

66 Zu der Vorstellung und dem Konzept der Planetenhäuser in cler Antike vgl. Benjamin Topp in diesem Band, S. 124-126.

67 Ein Verweis auf den Seelenwanderungsmythos von Er in der Politeia X 614b1-621b7.

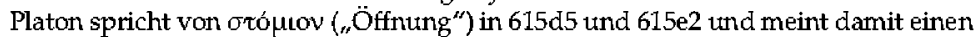
Ort im Jenseits, durch den die Seelen an die Orte ihrer Bestimmung geführt werden. Die von Numenios angeführte Lokalisierung in der Himmelssphäre ist eine spätere, wohl neuplatonische Umdeutung (vgl. ALt 1998, 478).

68 Anspielung auf das fragmentarisch erhaltene Lehrgedicht Peri physeôs („Über die Natur ${ }^{\prime \prime}$ ) des vorsokratischen Philosophen Parmenides aus Elea (6/5. Jh. v. Chr.). Der genaute Kontext, in dem der Hinweis auf die zwei Türen bei Parmenides steht ( fr. 28 B I DK), ist unklar; im erhaltenen Proömium, das in der Metapher der Himmelsreise den Weg zur Wahrheit und die Initiation des Dichters enthält, wird von einer "Tür

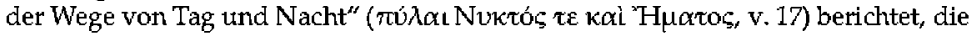


von der Göttin Dike auf- und zugeschlossen wird, die damit die Abfolge von Tag und Nacht regelt.

69 Das mehrtägige römische Saturnalienfest wurde im Dezember zu Ehren des Gottes Saturn gefeiert; zentrales Element war das temporäre Außer-Kraft-Setzen von gesellschaftlichen Konventionen - Sklaven und Herren tatschten ihre Rollen - in Erinnerung an die aetas aurea unter der Herrschaft Saturns.

70 Gemeint ist der Steitbock. In der Atssage schwingt eine zeitliche Komponente mit, da die Befreiung (symbolisch) im Verlauf des Saturnalienfestes erfolgt, das während der Phase, in der die Sonne im Steinbock steht, gefeiert wird.

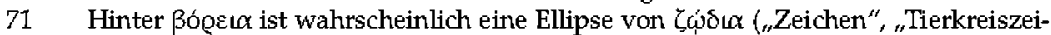
chen") anzunehmen. Die Sonne, die am Jahresbeginn vom südlich gelegenen Steinbock zu ihrem ,Startpurkt' im Widder (= Osten) zurückschreitet, muss sich erst dem Norden zuwenden und zu den nördlichen Zeichen, insbesondere zum Krebs, aufsteigen, ehe sie in den Osten gelangt, der mit dem Sonnenaufgang konnotiert ist. Sothis war eine ägyptische Fruchtbarkeits- und zugleich Totengöttin, die man im Griechischen als Sirius oder Hundsstern bezeichnete; ihr Erscheinen wurcle mit clen heißen Sommertagen (= Hundstagen) verbunden.

73 Der in V überlieferte Text ist gut verständlich: Aphrodite ist die Hausherrin des Sternbildes Stier, das sich neben dem Widder befindet, dessen Schwert Mithras trägt. Die Figur des Mithras wäre demnach zwischen Stier und Widder zu denken und ebendort befindet sich das Sternbild des Perseus, mit dem Mithras assoziiert zu sein scheint, vgl. Benjamin Topp in diesem Band, S. 131-133. Die Annahme ei-

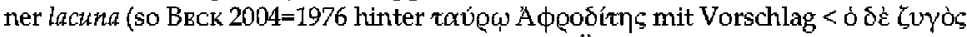

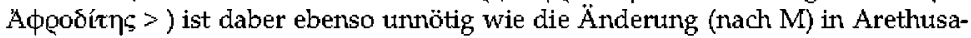

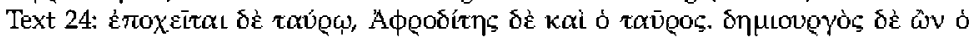
Mïpas ... Zur Diskussion siehe auch Christoph Riedweg in diesem Band, S. 94-95,

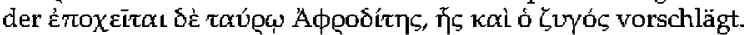

74 Die Mithras-Passage ist wohl ein Zusatz von Porphyrios zu den ägyptischen Vorstellungen. Die Beschreibung der Epitheta ist eng an die Kultikonographie des Gottes angelehnt (vgl. CAM PBELL 1968, 54-56), der astrologisch eingeordnet wird: Venus ist die ,Hausherrin' ihres Nachthauses Stier, in dem sich die von Porphyrios vorgestellte Mithrasfigur am Himmel bewegt.

75 Zur ikonographischen Verbindung von Mithras mit Kautes und Kautopates auf antiken Reliefs und in Mithräen vgl. Simonini 1986, 205-207 und Christoph Riedweg in diesem Band, S. IIf.

76 Homer, Ilias V 698 über den durch einen Lanzenwurf seines Gegners Tepolemos schwer verletzten Sarpedon, dem das Wehen des Nordwindes Erfrischung bringt.

77 Also unter dem Stembild des Bären, d.h. im Norden.

78 Homer, Ilias $X X$ 224f. Das Zitat stammt aus der Rede des Aeneas vor seinem Zweikampf mit Achill. Aeneas verweist auf die Bedeutung und das Alter seines Geschlechts, das sich auf den Zeussohn Dardanos und dessen Sohn Erichthonios zurückführt. Letzterer war der reichste Mann auf Erden, der 3000 Stuten besaß, die der Norwind Boreas so reizvoll fand, dass er in Gestalt eines Rosses einige von ihnen begattete und 12 Fohlen zeugte, die besonders leichtfüßig und schnell waren. Den Eros des Boreas erwähnt auch der Lyriker Ibykus (PMG 286).

Oreithyia (wörtl. "die im Gebirge Stürmende") war die Tochter des attischen Königs Erechtheus, die Boreas nach Thrakien entführt haben soll. Ihre Söhne Kalais und Zetes nahmen am Argonautenzug teil (vgl. Apoll. Rhod. I 211-218). In Platons Phaidros erinnert sich Phaidros an prominenter Stelle - auf dem Weg zur Platane am Fluss nissos - an den Mythos vom Raub der Oreithyia (Phaedr. 229b-230a), was in der Platonexegese u.a. durch den Neuplatoniker Hermias von Alexandria (5. Jh. n. Chr.) zu allegorischen Ausdeutungen geführt hat. 
80 Homer, Thias IX 583. Das Zitat stammt aus der Rede des Phönix an Achill, der ihn durch das Negativbeispiel des Meleagros zur Rückkehr in die Schlacht bewegen möchte. Meleagros, der Sohn des Königs von Kalydon, Oinetts, hatte sich ats Zorn aus dem Kampf zurückgezogen und wurde u.a. von seinem Vater - vergeblich zum Wiedereintritt in die Schlacht gebeten. Das Rütteln an der verschlossenen Tür ist der symbolische Versuch des verzweifelten Vaters, den trägen und durch Worte nicht zu bewegenden Sohn aufzuritteln.

81 Das Zitat aus Homers Thas V 751 beschreibt die Fahrt der Hera mit ihrem Wagen zu Zeus zum Olymp, wo sie ihn bittet, den Griechen gegen Ares und die Trojaner zu helfen. Die Hïter des Himmelstores sind die Horen, die Göttinnen der Jahreszeiten. Der Iteratvers (Horner, Itias V 749 u. VIII 393 ) beschreibt jeweils die Fahrt der Hera

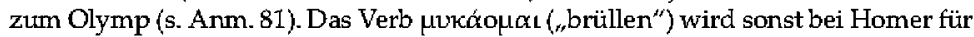
Stiere oder für das Geräusch von Lanzenwürfen auf Tore (IIias XII 460) oder Schilde (Ilias XX260) verwendet.

Homer, Od. XXIV 12. Hermes geleitet die Seelen der getöteten Freier in die Unterwelt.

84 Wie die Parallelüberlieferung zu Numenios zeigt, nimmt Porphyrios hier sein in den Kapiteln 21-24 begonnenes Referat aus Numenios wieder auf, vgl. ALT 1998, 478-479.

85 Porphyrios folgt hier Numenios' Auslegung (fr. 34) des Pythagoras, der den Bereich der Milchstraße ,Hades' genannt haben soll (vgl. Proklos, In Plat. Remp., 2, 128,26130,14 KroLL). Die Seelen würden im Tierkreiszeichen des Krebses zum Werden herabsteigen und im Steinbock nach ihrer Entkörperung wieder in den Bereich des Göttlichen aufsteigen. Die Milch ist in Assoziation mit der Milchstraße daher einerseits die Nahrung für die neugeborenen (= reinkarnierten) Seelen und andererseits eine geeignete Spende für die ,toten' Seelen (vgl. hierzu auch Anm. 37 und generell zur Stelle Simonin I 1986, 216-222).

Der Komparativ könnte auf die Seelen verweisen (vgl. ALt 1998, 481), ist aber wahr-

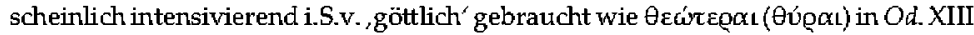
111.

87 Gemeint ist der Weg durch die Sphäre der Fixsterne.

88 Womöglich eine Anspielung auf den unterhalb der göttlichen Gestirne befindlichen und im platonischen Timaios von den ,Hilfsdemiurgen' geschaffenen Bereich, vgl. Christoph Riedweg in diesem Band, S. 80-81.

89 Vermutlich sind die astrologischen Kardinalpunkte gemeint, d.h. die Schnittpunkte von Horizont und Ortsmeridian mit der Ekliptik ats Sicht des irclischen Beobachters, vgl. Benjamin Topp in diesem Band, S. 135-136.

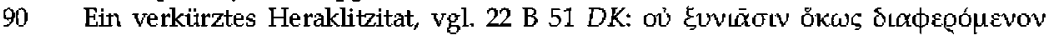

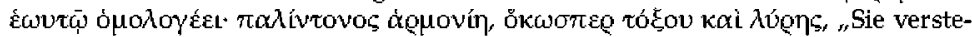
hen nicht, wie es auseinander getragen mit sich selbst im Situ zusammetı geht ge-

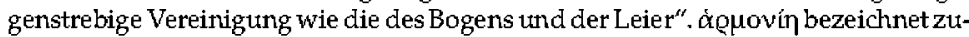
nächst konkret die ${ }_{s}$ Fügutng ${ }^{\prime \prime}$, Verbindung ${ }^{\prime}$ der einzelnen Bestandteile von Bogen bzw. Leier in dem Situne, dass bei beiden die Enden in entgegengesetzte Richtungen streben und durch eine Saite bzw. eine Saiten-haltende Querstrebe (verbunden werden). Zugleich wirken in der Anwendung gegenspielige Kräfte, da die Leier erst erklingt und der Bogen erst einen Pfeil schiesst, wenn die Saite in die entgegengesetzte (zugleich von der haltenden Hand gedachten) Richtung gespannt wird. Die platonische Bedeutung "Harmonie“ im Sinne des Zusammenklangs (von Hohem und Tiefem) ergibt sich aus der Deutung des Fragments im Symposion $187 \mathrm{~b}$ im Kontext der Betrachtung von Musik. Zur herakliteischen Annahme der Einheit von Gegensätzen vgl. auch \$10 mit Anm. 35, allgemein zur Überlieferung und Deutung des Heraklitfragments siehe KAHN 195-200. 
Homer, Ilias XXIV 528. Achill zu Priamos, der um die Auslösung seines getöteten Sohnes Hektor bittet. Achill verweist auf das den Menschen durch Zeus zugeteilte wechselhafte Schicksal. Die $\pi \dot{i} \theta$ oL, die symbolisch die guten bzw. schlechten Lebensumstände enthalten, sind eigentlich große Vorratsgefäße für Lebensmittel (Öl, Getreide). Ein analoger Dualismus (,wahr' und, falsch') findet sich im Bild der beiden Tratmtore in Od. XIX 562f.

93 Vgl. Platon, Gorgias 493a-494a. Sokrates bertft sich für diese Vorstellutng auf einetr

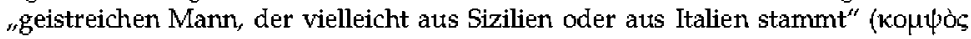

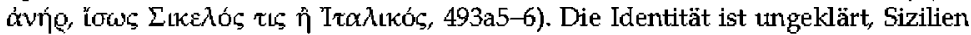
könnte auf Empedokles verweisen, Italien auf einen Orphiker oder Pythagoreer, vielleicht Philolaos, vgl.J. DaLfen, Platon. Gorgias. Übersetzung und Kommentar (Göttingen 2004) 369. Die folgenden Vergleiche der zügellosen, uneinsichtigen Seele mit einem Sieb (493b7-c2) und der beiden Männer, die gut gefüllte bzw. löchrige Vorratsgefäße haben (493d5-494a5) sind als Allegorien auf die rationale bzw. irrationale Seele zu verstehen, vgl. Olympiodors Kommentare ad loc.

94 Anspielung auf den Pandora-Mythosin Hesiods Erga (90-104; hier 96), wo Zeus den Menschen zur Strafe für Prometheus' Feuderdiebstahl die Pandora erschaffen lässt und mit einem Vorratsgefäß voller Krankheiten und Übel zu Epimetheus sendet. Als Pandora den Deckel des Gefäßes öffnet, fliegen alle Übel heraus und verbreiten sich unter den Menschen, nur die Hoffnung bleibt zurück.

95 Vgl. Platon, Timaios 41d4, wo von der Herstellung der geistigen Seele im Mischkrug (Krater) die Rede ist.

96 Pherekydes aus Syros (6. Jh. v. Chr.) war ein Kosmologe und Mythograph. Sein Hauptwerk Mit Sieben Schlupfwinkeln (Heptámychos) ist nur äußerst fragmentarisch bezeugt. Der Kontext der Stelle bei Pherekydes ist unklar.

97 Homer, Od. XIII 102f.

98 Vgl. zur rituellen Bedeutung des Olivenbaums und der Verwendung seiner Blätter im Mithraskult Simonini 1986, 236-239.

99 Homer, Od. XI 122f. Das Zitat stammt aus Teiresias' Prophezeiung der Heimreise des Odysseus in der nekyiia. Es verweist zugleich proleptisch auf sein in der Odyssee selbst nicht mehr geschildertes Schicksal nach der Heimkehr nach Ithaka und der Tötung der Freier. Die Erwähnung des salzlosen Essens deutet auf nomadische Völker, Pausanias (I 12) verweist im Zusammenhang mit dieser Stelle auf die Bewohner der Landschaft Epirus, die Epiroten. Mit der prophezeihten Reise verbinden sich die Aufforderung an Odysseus, sich mit Poseidon zu versöhnen, und die Ankündigung seines Todes im hohen Alter.

100 Homer, Od. XIII 96.

101 Thoosa wird als Tochter des Phorkis und Geliebte des Poseidon, die den Kyklopert gebar, in der Rede des Zeus an Athene zu Beginn der Odyssee (I 71-73) bei der Beratung der Götter über die Heimkehr des Odysseus erwähnt. Es ist auffällig, dass Poseidon von Porphyrios wie schon zuvor bei der Prophezeihung des Teiresias (vgl. Antm. 99) nicht erwähnt wird, obschon er bei Homer die zentrale Figur ist, die das Geschehen bestimmt.

102 Vgl. die Prophezeihung des Teiresias an Odysseus in Od. XI 122-134 u. Anm. 99. Mit dem Verweis auf den Bettler und die Prüfung der Leidenschaften ruft Porphyrios für einen Moment den Fortgang der Odyssee auf - die Verw andlung des Odysseus in einen Bettler durch Athene (Od. XIII 429-438) und die anschließende Prüfung seiner Standfestigkeit während der Demütigungen durch die Freier -, der für die allegorische Deutung der Nymphengrotte jedoch nur begrenzten Wert hat; vgl. H. BuvMENBERG, Quellen, Ströme, Eisberge. Über Metaphern. Aus dem Nachlaß des berühmten Philosophen (Berlin 2012). 
C. Essays 



\title{
Philosophie und religiöse Praxis in De antro Nympharum
}

\author{
Christoph Riedweg
}

Die Schrift De antro Nympharum ist für Porphyrios' intellektuelles Profil höchst aufschlussreich. Auf der einen Seite begegnen wir darin - bei einem Longin-Schüler wenig überraschend - dem kompetenten Philologen, der um die Eigentümlichkeiten eines poetischen Textes weiß und dessen Os-

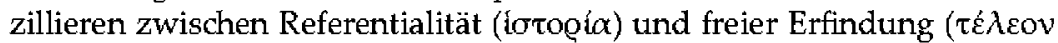
$\pi \lambda \alpha ́ \alpha \sigma \alpha \alpha$ ) im Anschluss an andere Interpreten feinsinnig auslotet. ${ }^{1}$ Auf der anderen Seite gilt Porphyrios' Hauptinteresse evidentermaßen der, symbolischen' Ausdeutung der Homerverse auf philosophische Lehren, doch werden zur Bestätigung der vorgeschlagenen Interpretationen jeweils mit größter Selbstverständlichkeit Beispiele aus der gelebten Kultpraxis eingeflochten. Man geht, auch auf dem Hintergrund der leider nur sehr fragmentarisch erhaltenen Schrift De philosophia ex oraculis haurienda (Пęi $\tau \bar{\eta} \bar{\zeta}$

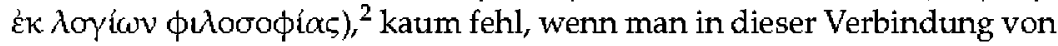
Religion und Philosophie, wie sie sich ebenfalls in dem vermutlich von Porphyrios selbst geprägten Begriff $\theta \varepsilon o \sigma o \phi i \alpha ~ s p i e g e l t,{ }^{3}$ geradezu die Signatur seines Denkens sieht. ${ }^{4}$

\footnotetext{
${ }^{1}$ S. dazu und zu Porphyrios' Hermeneutik auch die Einleitung in die Schrift, S. 20-26; zu möglichen Bezügen zu Porphytios' antichristlicher Polemik Penati Bernardini 1988, $118 f$.

${ }^{2}$ Ährlich in der Ausrichtung auch die ebenfalls nutr fragmentarisch erhaltene Schrift Пeol $\dot{\alpha} \gamma \alpha \lambda \mu \alpha \dot{\alpha} \omega v$; vgl. M. Gabrible / F. Maltomins, Porfirio. Sui Simulacri (Milano 2012).

${ }^{3}$ Vgl. u.a. Eus. Praep. ev. IV 6,3 (= Einleitung zu Philos. ex orac. haur. 1, fr. 303F. SMrTH) [...]

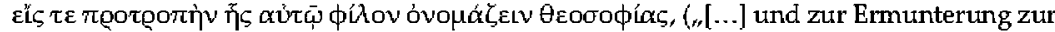
"Theosophie - so beliebt es ihm sie zu nennen"); CASTBLletTr 2006, 121 Anm. 319; ToulousB

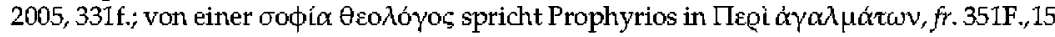
Бмгтн.

${ }^{4} \mathrm{Ob}$ dies generell oder lediglich für eine gewisse Zeit seines Schaffens gilt, lässt sich angesichts der fragmentarischen Überlieferung und der weitgehenden Unsicherheit über die zeitliche Abfolge seiner Werke kaum entscheiden; vgl. etwa zur Orakelphilosophie Riedweg 2005, 167f.; allgemein SAFFREY / SBGonds 2012, xxxvii: "Pour finir, nous voudrions insister sur le fait que la recherche dans le domaine de la philosophie religieuse a été une constante de la vie de Porphyre après son passage dans l'école de Plotin" (sie plädieren daher mit G. FowDEN, "Late Antique Paganism reasoned and revealed”, Journal of Roman Studies 71 [1981] 178-182 für eine Datierung der Orakelphilosophie ${ }_{s}$ at milieu de tous ces traités de spiritualité dans les deux ou trois dernières décennies de la vie de Porphyre": xxxviii); für eine Spätdatierung von De antro sprechen sich BufFìkr 1956, $420-425$ (unter Verweis auf
} 


\section{Die philosophische Dimension von Porphyrios' Exegese}

Während wir in den erhaltenen Fragmenten der Orakelphilosophie aufgrund der apologetischen Selektionskriterien unserer Hauptquelle, Eusebios' von Caesarea, über die rituellen Anweisungen der Orakel sehr viel, über deren philosophische Auslegung dagegen kaum etwas erfahren, lassen sich aus den zusammenhängenden Ausführungen zu Od. XIII 102-112 Porphyrios' philosophische Überzeugungen vergleichsweise gut rekonstruieren. (Dass unser Traktat wie die ebenfalls auf einer Studie des pythagoreisierenden Platonikers Kronios aufbauende Abhandlung De Styge ${ }^{5}$ sehr wohl einem größeren Werk - warum nicht der verlorenen Schrift Пe९i

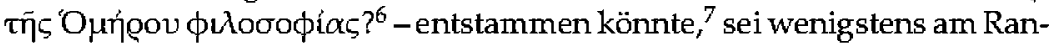
de erwähnt.) Leitend ist dabei das platonische Weltbild: die Höhle steht für

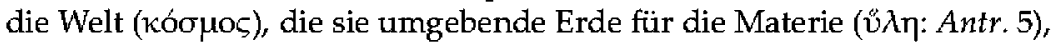
aus der die Welt als „sinnlich wahrnehmbares Gewordenes” (7) entstanden ist; ${ }^{8}$ Höhle und Welt berühren sich u.a. darin, dass die Höhlen zumeist

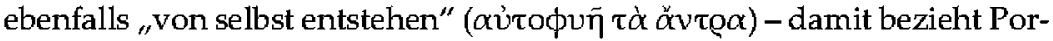
phyrios indirekt wohl auch in der Streitfrage, ob die Weltentstehung des platonischen Timaios wörtlich zu verstehen sei oder nicht, zugunsten der zweiten Lösung Stellung; ${ }^{9}$ in der Erde als mit feucht-dunklem Stein und

die Lektüre der Kommentare des Kronios und Numenios in Plotins Schule) und PвnAti BeRNARDINI 1988, 119-121 aus (im Hinblick auf Parallelen mit Ad Marcellam und die - thach Ad Anebonem - wieder positivere Haltung gegenüber theurgischen Praktiken); auf einer problematischen Detutung von Etts. Hist. eccl. VI 19,2 bertht die Annahme von MAUR ETTE 2005, 74, Porphyrios habe De antro zusammen mit Adv. Christianos um 270-271 in Sizilien verfasst (vgl. zur Eusebiosstelle RIBDWBG 2005, 152-154).

${ }^{5}$ Vgl. Kronios, fr. 8 (= De Styge, fr. 372F. SMITH $=f r .1$ CAstBlLbTti $)$ und fr. 9 LbEMANs $(=$ De antro 2); allgemein zt Kronios WHITTAKER 1994.; zt der atsschließlich in Exzerpten bei Stobaios erhaltenen Schrift De Styge CASTBLlBTtr 2006.

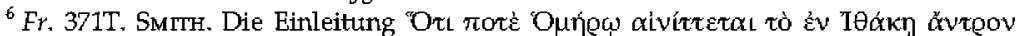

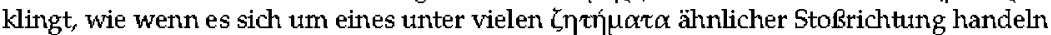
würde (zum Vergleich sei auf Inhaltsverzeichnisse von Werken wie Eusebios' Praeparatio evangelica oder Makarios Magnes' Apokritikos verwiesen). S. im übrigen auch die Einleitung in die Schrift, S. 20-21, und Irmgard Mätnlein-Robert in diesem Band, S. 97-98.

${ }^{7}$ Anders CAstblletti 2006, 36-38. 83-88.

${ }^{8} \mathrm{Vgl}$. zu diesem Assoziationsgeflecht auch Julians Auslegung des Attis-Mythos in In

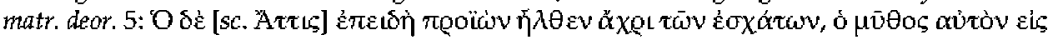

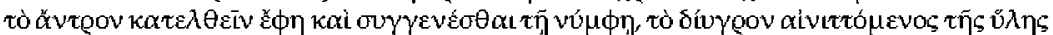
$\kappa \tau \lambda$. (,Als dieser [sc. Attis] bei seinem Hervortreten bis zu den ätßßersten [sc. Bereichen] gelangt war, ging er in die Höhle hinunter und vereinigte sich mit der Nymphe, wie der My thos unter verrätselter Anspielung auf die Feuchtigkeit der Materie berichtet"); TurCAN 1975, 106; Penati Bernardini 1988, 123.

${ }^{9}$ Vgl. dazu u.a. M. Baltes, "Гéyovev (Platon, Tim. 28 B 7). Ist die Welt real entstanden oder nicht?", in:Ders., $\triangle$ IANOHMATA. Kleine Schriften zu Platon und zum Platonismus, h.g.v. A. Hüffmeier / M.-L. Lakmann / M. Vorwerk. Beiträge zur Altertumskunde 123 (Stuttgart / Leipzig 1999) 303-325 (= K. A. Algra / P. W. van dBR Horst / D. T. RunLA [Hg.], Polyhistor. 
Fels assoziiertem "Symbol” erkennt Porphyrios wichtige Eigenschaften

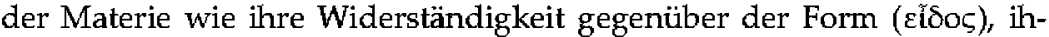
re dauernde Veränderung and prinzipielle Formlosigkeit. ${ }^{10}$ Durch die Verbindung mit und Ausschmückung durch die Form ist die Welt frei-

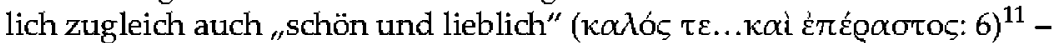
was laut Porphyrios die überraschende Doppelbezeichnung der Höhle als

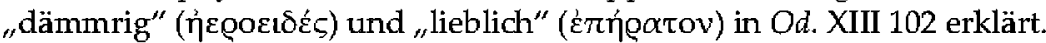
Sind damit zwei der drei aus dem Timaios abgeleiteten Prinzipien des kaiserzeitlichen Platonismus benannt (Materie und Idee), folgt das dritte, der Demiurg, eingebettet in einen Verweis auf Mithras (weiterhin 6), auf den später eingegangen werden soll. ${ }^{12}$

In diesem Verweis klingt überdies das philosophische Kernthema der

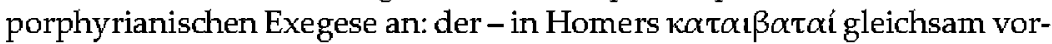

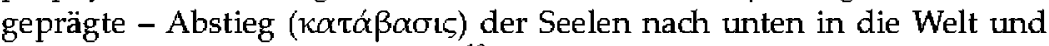

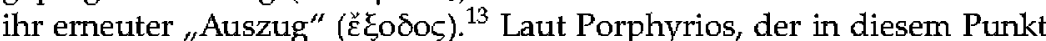
Numenios folgt ( $f r .30$ des Places), ${ }^{14}$ werden unter den nach dem "Nass" (vá $\mu \alpha \tau \alpha$ ) benannten Wassernymphen, den Naiaden, traditionell die "zum Werden hinabsteigenden Seelen" verstanden (10): Sie "sitzen beim göttlich inspirierten Wasser", aus dem sie - in Analogie zu den Gestirnen, die nach stoischer Auffassung aus Ausdünstungen des Meeres, der Quellen, Flüsse und der Erde "genährt werden" - die Körper an sich ziehen, dem Werden zugeneigt wie sie eben sind (11). ${ }^{15}$ Für die inkarnierten Seelen indes wird der Kosmos zum größten Heiligtum (12) - ein Gedanke, der nicht nur die cotvì Ěvvoua des Göttlichen aus der Naturbetrachtung, ${ }^{16}$ sondern wohl auch die heilende Wirkung der Gestirnsbetrachtung gemäß Platons

Studies in the History and Historiography of Ancient Philosophy presented to J. Mansfield on His Sixtieth Birthday. Philosophia Antiqua 72 [Leiden 1996] 76-96).

${ }^{10} \mathrm{Vgl}$. auch 9; Buffière 1956, 428; ausführlich zur ṽ $\lambda \eta$ in De antro Simonini 1986, 97-101.

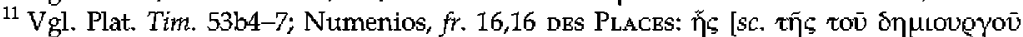

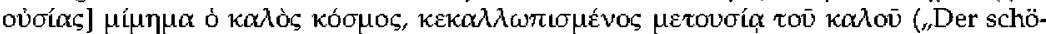
ne Kosmos ist ein Abbild von ihm [sc. dem Sein des Demiurgen], verschönert durch die Teilhabe am Schönen"); Turcan 1975, 80; MaUretTB 2005, 66.

${ }^{12}$ S. unten, S. 80-82 und 95 mit Anm. 102. Zur platonischen Dreiprinzipienlehre vgl. u.a. Ch. RigdwbG, Ps.-Justin (Markell von Ankyra?), Ad Graecos de vera religione (bisher "Cohortatio ad Graecos"). Einleitung und Kommentar. Schweizerische Beiträge zur Altertumswissenschaft 25/1-2 (Basel 1994) 246-250.

${ }^{13}$ Das Wort žzoðo $\zeta$ auch in Sent. ad intellig. duc. 29,14 LAMERRZ; vgl. im übrigen das Graf-

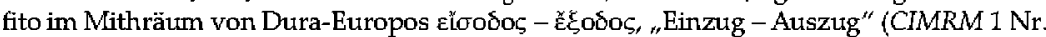
66; vgl. VermasEREN / vaN EsSEN 1965, 197).

${ }^{14} \mathrm{Vgl}$. dazu jetzt auch F. Jourdan, "Traditions bibliques et traditions égyptiennes au service d'une exégèse du mythe d'Er: Numénius et l'allégorie d'Homère dans le fragment 30 des Places", Les Êtudes philosophiques 153 (2015) 431-452, ferner Simonini 1986, 115f.; allgemein zum Verhältnis von $D e$ antro zu Numenios ebenfalls unten Anm. 102.

${ }^{15} \mathrm{Vgl}$. Sent. ad intellig. duc. 29,10-13 LAMBBRz; allgemein SimoninI 1986, 122-130.

${ }^{16}$ Vgl. u.a. Ch. RIEDwbG, ${ }_{s}$ Mit Stoa und Platon gegen die Christen: Philosophische Argumentationsstrukturen in Julians Contra Galilaeos", in: Th. FuHRER / M. ERLER (Hg), Zur 
Timaios aufruft. ${ }^{17}$ In den "steinernen Mischkrügen und Amphoren" wiederum erkennt Porphyrios die Knochen der sich ausbildenden Körper, in den "meer-purpurnen Tüchern" das „aus Blut gewobene Fleisch", das die Seele bekleidet (14). Und wenn Bienen in den steinernen Gefäßen ihre "Honigwaben anlegen”, dann wird damit angedeutet, dass das Göttliche auf-

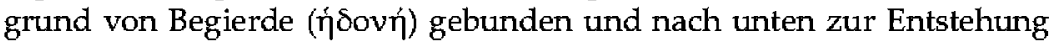
geführt wird (16). ${ }^{18}$ Soviel zur Inkarnation der Seelen.

Unter diesen werden im Hinblick auf ihre ethische Vollkommenheit die als "Bienen" bezeichneten Seelen hervorgehoben, die sich dadurch auszeichnen, dass sie das von Mühsal und Bitterkeit gezeichnete Dasein hienieden ${ }^{19}$ "in Gerechtigkeit leben" und "nachdem sie den Göttern angenehme Werke vollbracht haben", "wieder zurückkehren" ( $\pi \alpha \dot{\lambda} \lambda \mathrm{tv}$

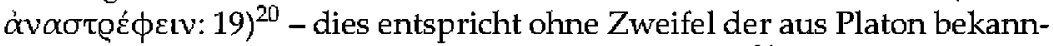
ten höchsten Reinkarnationsstufe eines Philosophen. ${ }^{21}$

Die Nord- und Südtore der Höhle werden auf den - mit der Sommersonnenwende identifizierten - Ort des Abstiegs in die Welt und den - mit der Wintersonnenwende in eins gesetzten - Punkt des Wiederaufsteigens und der Rückkehr der Seelen zu den Göttern ausgedeutet (21-24, im Anschluss an Numenios, fr. 31 des Places). Mithras als "Demiurg und Herrscher über das Werden" werden dagegen sinnigerweise die Frühlings- und Herbstäquinoktien als Mitte zwischen diesen beiden zugewiesen (24). Porphyrios entfaltet seine philosophische Ontologie weiter durch die Unterscheidung zwischen dem Sterblichen, das dem Werden unterworfen ist, und "dem Göttlicheren" im Menschen - eine Unterscheidung, die Porphyrios auf theologischer Ebene mit der Differenzierung zwischen den Dämonen und den Göttern assoziiert (29). Vor allem aber klingt bei der Auslegung der beiden Tore auch die grundlegende platonische Dichotomie zwischen dem Intelligiblen und dem sinnlich Wahrnehmbaren an, wobei letzteres - in enger Anlehnung an den Timaios - weiter unterteilt wird in die Fixstern- und die Planetensphäre sowie in unsterblich (alle Gestirne) und

Rezeption der hellenistischen Philosophie in der Spätantike. Philosophie der Antike 9 (Stuttgart 1999) [55-81] 65-70.

${ }^{17}$ Vgl. Plat. Tim. 89e-90d; zur Entwicklung des Gedankens der Welt als Tempel Gottes allgemein Simonini 1986, 144-146.

${ }^{18}$ Vgl. auch 18: „[sie deuten an,] dass das Leben der Seele durch Lust sterbe, aber durch Bitterkeit wieder entstehe"; außerdem v. 10f. der Inschrift von S. Prisca: dulc(i)a sunt fi(cata) avium (s)ed cura gubernat / pi(e) r(e)b(u)s renatum dulcibus atgue creatum (,Süß sind die mit Feigen gemästeten Lebern der Vögel, doch die Sorge/Sorgfalt lenkt den auf fromme Weise durch süße Dinge Wiedergeborenen und Erschaffenen") mit den Erläuterungen von VBRMASERBN / VAN EsSBN 1965, 206-211.

${ }^{19}$ Vgl. 18 (dazu unten mit Anm. 44).

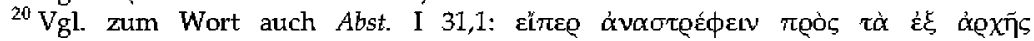

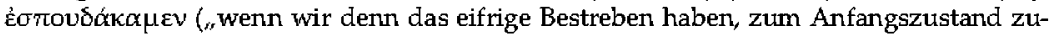
rückzukehren").

${ }^{21}$ Vgl. u.a. Phaedr. 248d2-4 und 248e5-249a4; Phaed. 114b-c. 
sterblich (ebenfalls 29; mit letzterem dürfte auf das, was sich unterhalb der Gestime befindet und durch die göttlichen 'Hilfsdemiurgen' geschaffen wird, ${ }^{22}$ angespielt werden).

Der am Kopf des Hafens ganz nahe bei der Höhle aufragende Ölbatum schließlich signalisiert als Attribut der Göttin Athene, dass der Kosmos nicht planlos und automatisch entstanden ist, sondern das Ergebnis göttli-

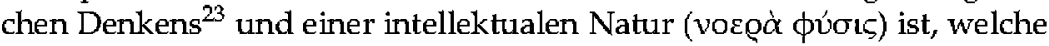
die Welt in Ewigkeit durchwirkt und ordnet (32f.). An dieser Stelle lenkt Porphyrios den Blick über die eingangs zitierten Verse hinaus und vertieft seine ethische Anthropologie durch Einbezug der Episode Od. XIII 361371, wo Odysseus auf Rat der Athene die von den Phaiaken erhaltenen Geschenke im Innern der Höhle deponiert: Porphyrios deutet diesen Vorgang als Aufforderung, sich aller äußeren Güter und Sinne zu entledigen und als Bettler den Schutz der Athene zu suchen, um, von ihr beraten, den unausweichlichen Zorn der Götter des Meeres und der Materie durch Opfer und Entsagungen zu beschwichtigen, bevor man zu den reinen, von allem Materiellen unbefleckten Seelen aufzusteigen vermag (34f.). ${ }^{24}$

Kurz, was Porphyrios in Homers Beschreibung der Nymphengrotte findet, ist das menschliche Drama des Abstiegs der Seele in die Welt, ihrer Inkarnation und leidvollen Existenz auf der Erde, aber auch der Möglichkeit ihrer Rückkehr zur göttlichen Existenz durch ein konsequent tugendhaftes Leben. ${ }^{25}$ Oder wie er es selbst prägnant formuliert hat: "...] die Wechselfail-

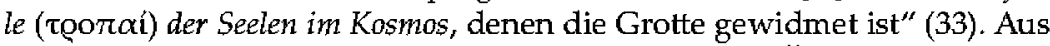
philosophischer Perspektive fällt dabei eine Lücke auf: Über die Spitze der platonischen Onto-Theologie wird - anders als in der Orakelphilosophie ${ }^{26}$ kaum etwas gesagt, selbst der Demiurg Mithras scheint höchstens auf der

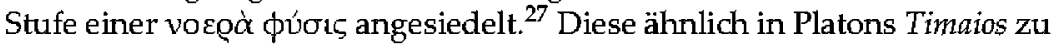

\footnotetext{
${ }^{22}$ Vgl. die Rede des Demiurgen an diese Götter in Tim. 41a-d.

${ }^{23}$ Vgl. auch Plat. Tim. 30b6-c1. 34a8f. 44c7.

${ }^{24} \mathrm{Vgl}$.zu diesem mitbestimmten Riten und Regelth verbundenen Weg auch Porph. Abst.

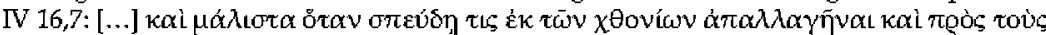

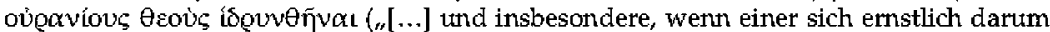
bemüht, sich von den irdischen Dingen zt entfernen tund Wohnstatt bei den himmlischen Göttern zu nehmen"); allgemein zu dieser Stelle ebenfalls Simonini 1986, 249.

${ }^{25}$ Vgl. u.a. Porph. Philos. ex orac. haur. 3, fr. 346F.,23-28 SMITH: nam deus quidem, utpote omnium pater, nullius indiget; sed nobis est bene, cum eum per iustitiam et castitatem aliasque virtutes adoramus, ipsam vitam precem ad ipsum facientes per imitationem et inguisitionem de ipso, inguisitio enim purgat, [...] imitatio deificat affectionem ad ipsum operando (,denn Gott zumindest, als Vater aller Dinge, bedarf nichts; doch für uns ist es gut, ihn mit Gerechtigkeit, Züchtigkeit und den übrigen Tugenden zu verehren, indem wir das Leben selbst durch Nachahmung und. Erforschung seines Wesens zu einem Gebet an ihn machen. Denn die Erforschung reinigt, [...] die Nachahmung vergöttlicht, indem sie [sc. unsere] Liebe $\mathrm{zu} \mathrm{ihm}$ bewirkt'); Toulouse 2005, 336-340; schon Plat. Phaedr. 248e3-5 und Tim. 42a-b. 90bo-c5 etc. Zur Betonung des ethischen Aspekts im Mithraskult vgl. unten bei Anm. 69.

${ }^{26} \mathrm{Vgl}$. fr. 325F. SMITH.

${ }^{27} \mathrm{Vgl} .32$ und 33.
} 
beobachtende ${ }^{28}$ Lücke ist hier offenkundig durch die zu interpretierenden Verse vorgegeben: Dass Höhlen an sich wegen ihrer Unzugänglichkeit für den Sehsinn sowie aufgrund ihrer Festigkeit und Beständigkeit durchaus

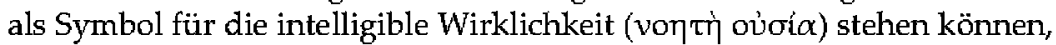
klingt in Kapitel 9 zwar an, doch wird diese Deutung für die Nymphengrotte vor allem deswegen als nicht zutreffend ausgeschlossen, weil Homers "immer-fließende Wasser" nur als Symbol des "in der Materie befindlichen Seins" zu begreifen seien (10). Porphyrios berücksichtigt daher in De antro die ontologische Pyramide lediglich vom höchsten Gewordenen an - d.h. dem (nach platonischer Auffassung ewigen) Kosmos, unter Einschluss der darin wirkenden unsichtbaren Mächte, zu denen auch der Demiurg zu zählen sein dürfte ${ }^{29}$ - bis hinunter zu den materiehaften niedrigen Gottheiten. Dass wir letzteren in der Form von Reinigungs- und Abwendungsopfern, aber auch durch Askese Tribut zahlen müssen $(35),{ }^{30}$ betont Porphyrios genauso in der Orakelphilosophie. ${ }^{31}$

\section{Bekräftigung der platonisierenden Auslegung durch Hinweise auf Kultisch-Religiöses}

Es ist nun sehr interessant, zu beobachten, wie Porphyrios in De antro in dieses philosophische Argumentationsgerüst regelmäßig Stützbalken aus Mythen, Riten und Kulten einbaut. Während Kronios im Zusammenhang mit der Nord-Süd-Orientierung der Höhleneingänge auf die traditionelle Ost-West-Ausrichtung der Tempel (mit Eingang im Osten) verweist und aus diesem Widerspruch auf die Notwendigkeit einer allegorischen Deutung schlieBt (3), rekurriert Porphyrios auf Kultisch-Religiöses ausnahmslos als positives Zeugnis für seine Darlegungen. Diese bejahende Haltung überrascht umso weniger, als Porphyrios durchaus bereit ist, damit zu rechnen, dass es sich um eine wahrheitsgetreue Beschreibung einer Grotte auf Ithaka durch Homer handeln könnte. ${ }^{32}$ Falls dies zutreffe, so Porphyrios, hätten die Menschen, die die Höhle vor der Zeit Homers den Göttern geweiht hätten, dieses Heiligtum zweifellos unter Verwendung "mystischer Symbole" errichtet - als "Weihgeschenk", welches "von alter Weis-

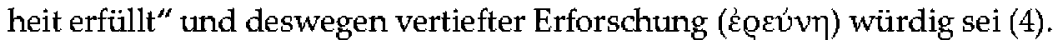

\footnotetext{
${ }^{28}$ Vgl. Ch. RigDwbG, "Anti-Christian Polemics and Pagan Onto-Theology", in: S. RebeNICH / H.-U. WibMrR (Hg.), Brill's Companion to Julian the Apostate (Leiden, im Druck).

${ }^{29}$ Simonini 1986, 106f. denkt in erster Linie an die platonischen Ideen.

${ }^{30} \mathrm{Vgl}$. dazu auch Penati Bernardini 1988, $120 \mathrm{f}$.

${ }^{31} \mathrm{Vgl}$. fr. 326F. SMITH; auch fr. 324F. SMITH (Unterscheidung der Reinigungsopfer für dent Körper und für die Seele, zu letzteren vgl. fr. 304F. SMITH); zur Bandbreite der zu verehrenden Gottheiten, von den hypochthonischen bis zu den himmlischen, vgl. auch fr. 314F.315F. SMrTH.

${ }^{32} \mathrm{Vgl} . \S 4$ und $\S 21$.
} 
Die prinzipielle Gleichrangigkeit religiöser und philosophischer Weisheit wird damit von Beginn an deklariert, und entsprechend eng sind die beiden Bereiche in Porphyrios' Exegese miteinander verknüpft. Schon gleich am Anfang seiner eigenen Auslegung beruft er sich für die Identifikation der Höhle mit dem Kosmos nicht etwa auf die Philosophie, sondern auf die nach seiner Darstellung seit alters übliche Weihe von Höhlen und Grotten an die Welt als ganze oder an einzelne ihrer Teile (5). Diese Praxis, von der auch die entsprechenden Vorstellungen der Pythagoreer und des Empedokles sowie Platons Höhlengleichnis hergeleitet werden, ${ }^{33}$ ordnet er wenig später in eine Gesamtschau der griechisch-römischen Kultausübung ein: Wie man für die Olympischen Götter Tempel, Götterstatuen und Altäre geweiht habe, für chthonische Götter und Heroen Opferherde sowie für die unterirdischen Gottheiten Opfergruben und -gräben, so auch für den Kosmos Höhlen und Grotten (6). ${ }^{34}$

Die Ausweitung des Symbolgehalts der Höhle vom Kosmos auf "alle unsichtbaren Kräfte", die im Innern des Kosmos wirken, ${ }^{35}$ wird über die Analogie des Dunklen und Unsichtbaren hinaus durch den Verweis auf - orphische? - Mythen ${ }^{36}$ gestützt, in denen Höhlen eine Rolle spielen: So soll sich etwa Kronos im Okeanos eine Höhle errichtet und dort seine eigenen Kinder versteckt haben, während Demeter Kore zusammen mit den Nymphen, denen allgemein im religiösen Alltag Grotten häufig geweiht worden seien, ${ }^{37}$ in einer Höhle ernährte (7). Die Bedeutung des Feuchten für das "Festbinden” der Seelen ${ }^{38}$ in Blut und feuchten Körpern wiederum wird durch das - sonst so nicht bezeugte - Ritual der Totenbeschwörung als Beleg abgesichert, bei dem Galle ( $\chi \circ \lambda \eta$ ) und Blut ausgegossen werde, um die Seelen der Verstorbenen anzulocken (11). ${ }^{39}$ Porphyrios gibt in diesem Zusammenhang auch eine quasi-wissenschaftliche Erklärung, wie es durch Verfeuchtung und nebelartige Verdichtung solcher „körperliebender" Seelen zu Erscheinungen von Gespenstern bei den Menschen

\footnotetext{
${ }^{33}$ Vgl. 8; dazu Simonini 1986, 109-112; Irmgard Mäntnlein-Robert in diesem Band, S. 112116. Dass die philosophische Doxographie hier über das Religiöse erfolgt tund diesem also gewissermaßen nachgeordnet ist, verdient Beachtung.

${ }^{34}$ In Antr. 20 kommt eine zeitliche Dimension in Porphyrios' Betrachtung hinzu: Die Weihung von Grotten und Höhlen wird in die Urzeit verlegt, "noch bevor man Tempel für Götter auch nur ausgedacht" habe (als Beispiele werclen die Zetssgrotte der Koureten auf Kreta, die Grotten für Selene und Pan Lykeios in Arkadien, außerdem eine Höhle für Dionysos auf Naxos sowie die Mithräen erwähnt; dazu Simonini 1986, 186-189).

${ }^{35} \mathrm{Vgl} .9$.

${ }^{36}$ S. dazu auch unten Anm. 55, ferner Irmgard Männlein-Robert in diesem Band, S. 110112.

${ }^{37} \mathrm{Vgl} .8$; allgemein zu den (Nymphen-)Grotten in antiker Literatur und Kunst Irmgard Männlein-Robert in diesem Band.

${ }^{39}$ Vgl. dazu Simonini 1986, $163 \mathrm{f}$.

${ }^{39} \mathrm{Vgl}$. dazu Simonini 1986, 130-134.
} 
kommen könne (11);0 außerdem leitet er von der Bezeichnung, Naiaden' für die sich inkarnierenden Seelen den Namen vú $\mu \phi \alpha ı$ für Bräute $a b$, die beim Hochzeitsritual dementsprechend mit Quellwasser übergossen würden (12). ${ }^{\mathbf{4 1}}$ Auf chthonische Rituale verweist er im Rahmen seiner Ausfüh-

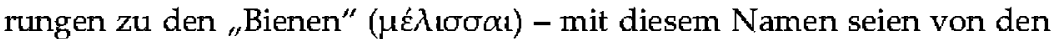
Alten ebenfalls die Priesterinnen der Demeter qua chthonischer Göttin bezeichnet worden $-{ }^{42}$ welche die homerische Nymphengrotte beleben: In der Verwendung von Honig für Opfer an die Unterirdischen ${ }^{43}$ sieht Porphyrios bestätigt, dass Honig auch Symbol für den Tod der Seele bei der Inkarnation sei, während er das Opfern von Galle an die Götter mit dem über die Bitterkeit des mühsamen Erdenlebens zu erlangenden ${ }^{44}$ _ „Wiederaufleben" der Seele im Tod assoziiert (18).

Weitere punktuelle Hinweise auf Kultisches, die der außerordentlich belesene Autor ohne erkennbare Systematik, wenn auch mit offensichtlicher Sympathie für den Pythagoreismus, ${ }^{45}$ in seine Argumentation einflieBen lässt, betreffen:

- die botanische Besonderheit der (im Pythagoreismus tabuisierten) Bohnen (19) ${ }^{46}$

- das pythagoreisch-ägyptische Verbot, beim Durchschreiten von Türen und Toren $z u$ reden $(27)^{47}$

- die Verwendung von Trankopfern aus Honig und Milch bei Seelenbeschwörungen (unter Verweis auf Pythagoras' Erklärung der Träume als Seelen, die sich in der Milchstraße versammeln) (28) ${ }^{48}$

- die "nüchternen [d.h. nicht mit Wein vermischten] Trankopfer durch Honig" $(19)^{49}$

\footnotetext{
${ }^{40}$ Für Porphyrios' Interesse an diesen Fragen vgl. Abst. IV 17,7; s. allgemein zu dieser Stelle auch Simanini 1986, 134-138.

${ }^{41} \mathrm{Vgl}$. Schol. in Hom. Il. XXIII 142a und in Eur. Phoen. 347 etc.; SImoninI 1986, 114f.

${ }^{42}$ Dazu Simonini 1986, 169-172.

${ }^{43} \mathrm{Vgl}$. auch 19 und 28.

${ }^{44}$ Dieser Aspekt begegnet auch in cer Versinschrift des Mithräums von S. Prisca in Rom v. 12: nubila per ritum ducatis tempora cuncti (, Wolkenverhangene Zeiten sollt ihr alle mit Hilfe des Ritus verbringen"; vgl. dazu VERMASBREN / VAN ESSEN 1965, 211-213).

${ }^{45}$ Zur Orphik s. unten Anm. 55.

${ }^{46}$ Vgl. dazu Simonini 1986, 183-186; RigDweg 2007, 95-97.

${ }^{47}$ In dieser Form m.W. sonst ticht belegt; vgl. in anderem Zusammenhang lambl. Protr.

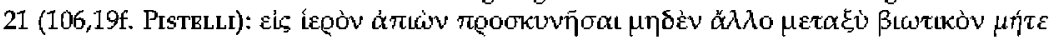

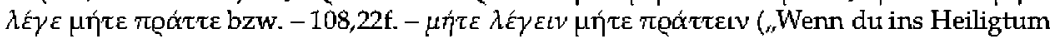
weggehst, um anzubeten, dann sage oder tue in der Zwischenzeit nichts anderes, was mit dem [sc. alltäglichen] Leben zu tun hat" ${ }^{\prime \prime}$; allgemein für die Bedeutung des Schweigens im

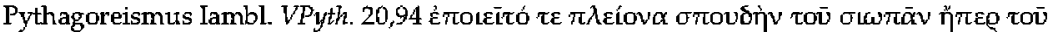
$\lambda \alpha \lambda \varepsilon \bar{w}$ etc. ( ${ }_{r}$ Er bemühte sich viel mehr um das Schweigen als um das Reden $\left.{ }^{\prime \prime}\right) ;$ SimoninI 1986, $213 \mathrm{f}$.

${ }^{48}$ In Anlehnung an Numenios, fr. 35,23-31 des Placbs; vgl. auch Simonini 1986, 216-222.

${ }^{49} \mathrm{Vgl}$. Abst. II 2,3 und die alten Scholien zu Soph. Oed. Col. 100 víфuv dólvolc (mit Philohistor FGrHist 328 F 12 und Polemon, fr. 42a PRELLER).
} 
- die Verwendung von Olivenblättern bei Bitt- und Flehzeremonien: deren hellere Unterseite gebe der Hoffnung auf einen Glücksumschwung Ausdruck (33) ${ }^{50}$

- die genannten Beschwichtigungsopfer an die materieverhafteten Gottheiten (35) $)^{51}$

- das Ziehen der Vorhänge in den Tempeln am Mittag als Signal, dass, wenn die Sonne im Süden steht, den Menschen der Zugang zum Tempel verwehrt sei (26)

- die an der Wintersonnenwende gefeierten römischen Saturnalien ( $\tau \dot{x}$ Koóvi $\alpha$ ) als Sinnbild für die Befreiung der im Körper versklavten Seelen $(23) .^{52}$

\section{Der Mithraskult als privilegiertes Beispiel}

Bereits diese Hinweise machen De antro zu einer Fundgrube für alle, die an antiker "lived religion ${ }^{\mu 53}$ interessiert sind, erlauben sie doch wertvolle Einblicke, wie einer der führenden Denker der Kaiserzeit Religion erlebt und in eine aus seiner Sicht sinnvolle Lebens- und Weltdeutung integriert. ${ }^{54}$ Überdies liefert die Schrift atuch für Fragmente orphischer Mythologie wichtige Belege. ${ }^{55}$ Was Porphyrios' Exegese der Nymphengrotte aus

\footnotetext{
${ }^{50} \mathrm{Vgl}$. SimONini 1986, 236-239.

${ }^{51} \mathrm{~S}$. oben bei Anm. 31.

$52=$ Numenios, fr. 31,28-36 des Placbs.

${ }^{53} \mathrm{Vgl}$. zum Konzept R. RAJA / J. RÜPKE, ,A Appropriating Religion: Methodological Issues in Testing the Lived Ancient Religion Approach", Religion in the Roman Empire 1,1 (2015) [1119] 12f.; J. RüPKE, "The Connected Reader as a Window into Lived Ancient Religion: A Case Study of Ovid's Libri fastorum", Religion in the Roman Empire 1,1 (2015) [95-113] 95f.

${ }^{54} \mathrm{Vgl}$. im Hirblick auf die Angaben zum Mithraskult attch BвCK 2006, 45; ,The Neoplatonic model of religion, apart from its own intrinsic interest, is important because it shows us how the contemporary intelligentsia constructed the mysteries"; s. allgemein auch R. HIRSCH-LuIPOLD, "Die religiös-philosophische Literatur der frühen Kaiserzeit und das Neue Testament", in: Ders. / H. Görgemanns / M. Albrecht (Hg.), Religiöse Philosophie und philosophische Religion der frühen Kaiserzeit. Literaturgeschichtliche Perspektiven. Ratio Religionis Studien I. / STAC 51 (Tübingen 2009) [117-146] 129f. (\$ 4.1 "Gelebte religiöse Tradition als Anstoß und Gegenstand philosophischen Nachdenkens" im kaiserzeitlichen Platonismus).

${ }^{55}$ Der Name des Orpheus wird in De antro dreimal erwähnt: einmal in 14 und zweimal in 16. In 14 (= Orphic. fr. 286 F I Brrnabé) wird Orpheus' Darstellung der Kore, der Porphyrios die Rolle der "Aufseherin (č́pooos) über alles, was gesät wird" (vgl. auch Пrò

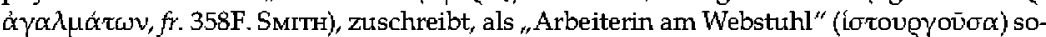
wohl mikrokosmisch (Verbindung der Seele mit dem Körper als deren Gewarld) wie makrokosmisch ausgelegt (Himmel als Peplos, der von den Alten sozusagen als Umhang der himmlischen Götter bezeichnet wurde). In 16 (= Orphic. fr. 187 F II; 220 F; 222 F; 225 F V BeRNABB́) erfahren wir davon, dass "bei Orpheus" Zeus dem Kronos mit Honig nachstellt (wie Wein macht dieser ihn betrunken und schläfrig) und dass es die Nacht war, die dem Zeus die "List durch Honig" geraten hatte: Mit dieser List, welche die Fesselung und Entmannung des Kronos ermöglichte, habe "der Theologe" (d. h. wohl Orpheus) die Rolle der
} 
religionswissenschaftlicher Perspektive aber vollends singulär macht, sind die z.T. ausgesprochen detaillierten Informationen über den Mithraskult. ${ }^{56}$ Dieser ist zwar archäologisch hervorragend dokumentiert - und neue Funde ergänzen laufend das Bild -, doch in der antiken Literatur gibt es vergleichsweise wenige und überwiegend der christlichen Polemik entstammende Zeugnisse. De antro ist daher als eine der wichtigsten literarischen Primärquellen zu betrachten und wird nicht erst in der neueren Forschung mit gutem Grund als "gateway into the Mithraic mysteries" benutzt. ${ }^{57}$

Lust für die Fesselung und Herabführung des Göttlichen ins Werden angedeutet, ferner, dass dieses (sc. das Göttliche), in die Lust hinein aufgelöst, Kräfte ejakuliere; die aus Hesiod geläufige Entmannung des Uranos wird in diesem Zusammenhang ebenfalls genannt und die Abfolge Uranos-Kronos-Zeus zusätzlich aus der Anordnung der Gestime belegt. Einiges spricht dafür, dass auch die beiden Beispiele für Höhlen in Mythen der ,Theologen' in De antro 7 auf Orpheus zurückgehen; vgl. zu Demeters Aufziehen der Kore in einer Höhle Orphic. fr. 279 F III Bernabê, ferner 209 F I, und dass Orpheus' Mythos vom Umgang des Kronos mit seinen Kindern von Hesiod abgewichen hat, wird in Orphic. fr. $214 \mathrm{~F}$

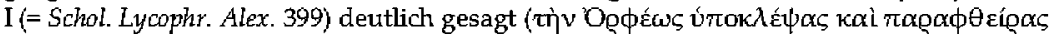
Өeoyovíav; insofem können die von Bernabé unter Orphic. fr. 214f. gesammelten Beispiele für das - hesiodeische - Verschlingen der Kinder wohl kaum als orphisch betrachtet werden; vgl. auch SIMONINI 1986, 164).

${ }^{56}$ TuRCan 1975, 69 spricht zu Recht von einem "parti pris mithriaciste" von De antro; ähnlich Mauretre 2005, 64: "Mithraism is one of the protagonists of Porphyry's De antro nympharum" (nicht zutreffend. freilich seine Angabe, Mithras und Platon wïrden gleich oft namentlich erwähnt in dieser Schrift [das Verhältnis lautet vielmehr 5:8 zugunsten Platons]).

${ }^{57}$ Brск 2006, 16. 34. 41. 84. 102 (vgl. schon Ders. 2004, 333, nach der Erwähnung seines Artikels 2004=1976: ,Almost thirty years later I still consider De antro 6 and 24 the most important fragments of text concerning the Mithraic mysteries"); die Stellen aus De antro haben aber auch bei andern Forschem seit langem große Atfmerksamkeit gefunden, vgl, u.a. die Arbeiten von VBRMASERBN / VAN EssEn 1965; TuRCAN 1975; Gordon 1996=1976; MbRKELBACH 1984; GoRdon 1996=1988; MAURETTE 2005 und jetzt ebenfalls BREMMER 2014. Athders dagegen Gordon 2012, der im Anschluss an Forscher wie F. Cumont, Textes et monuments figurés relatifs atax mystères de Mithra (Bruxelles 1896-1899) und. Clauss 2012 (vgl. Bвck 2006, 16-25) allgemein die archäologische gegenüber der literarischen Überlieferung privilegiert (vgl. 965f.) und von einer kaum zu harmontsierenden Diversität der Mithraskulte ausgeht (vgl. 983 "Eine Standardisierung der Ritualvorgänge u. deren Interpretationen hatte keinen Stellenwert u. wäre sowieso unmöglich gewesen, weil jede M.-Gruppierung nach den Vorstellungen des jeweiligen Vorstehers [...] agierte" usw. 994. 1007: "die Anhänger zogen eine interessante, aber lose, pluriforme Theologie einer, korrekten" vor"; vgl. zu dieser typisch ,postmodernen' Tendenz Beck 2006, 39 und 52f.; anders u.a. Burkert 1990, 46): Er schenkt De antro im Rahmen seiner Rekonstruktion des Mithraskults keine Beachtung. Nach seiner Ansicht dürfen die Angaben der Platoniker generell "nicht zu sehr verallgemeinert werden", wofür er als Beispiel die Hinweise zur Verwendung von Honig bei der Löwen-Weihe (De antro 15) anführt, die nach seiner Auffassung "wahrscheinlich nutur das Ritual einer einzigen Gemeinde" spiegeln (990); anders dagegen noch Ders. 2001, 298; vgl. allgemein jetzt auch Chalupa 2008, 198, der treffend von einer Tendenz in der theueren Forschung spricht, "to minimize the intellectual capacities of Mithraic initiates and operate with a view of a relatively simple mystery cult with little elaborate ideology". Auch wenn Gordon 2012 die Heterogenität der Mithraskulte tendenziell überzeichnet, ist ihm jedenfalls zuzustimmen, wenn er ähnlich wie u.a. schon Bвск 2006, 44 im Hinblick auf 
Die Hinweise auf die Mithrasweihen sind über die ganze Schrift verteilt $(6 ; 15 ; 17 ; 18 ; 20 ; 24)$. Deren singuläre Häufung erklärt sich wohl zum einen mit der Bedeutung, die der Höhle als Modell für die Mithräen zukommt, und zum andern allgemein mit der Popularität dieses Kultes im 2. und 3. Jh. n. Chr. ${ }^{58}$ Erstmals fällt der Name Mithras im Zusammenhang mit der Weihe von Höhlen an den Kosmos, wobei Porphyrios den Kern seiner philosophischen Exegese, die Lehre von der (Re-)Inkarnation der Seelen, über diese persischen Mysterien einführt (6): „So weihen auch die Perser, wenn sie in das Geheimnis des Hinabsteigens der Seele und ihres erneuten Ausstiegs einführen, ${ }^{59}$ den Mysten, indem sie den Ort [sc. der Weihe] "Höhle' nennen". Als aĭtıov dafür wird im Anschluss an Eubulos, ${ }^{60} \mathrm{der}$ laut Abst. IV 16,2 eine mehrbändige "Geschichte über Mithras" geschrieben hat, Zoroaster erwähnt: Dieser habe eine "von selbst [d.h. natïrlich] entstandene" ${ }^{\prime \prime}$, mit Blumen ${ }^{61}$ und Quellen versehene Grotte in den an Persien angrenzenden Bergen zu Ehren Mithras", des "Schöpfers und Vaters

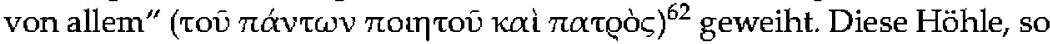
Porphyrios weiter - und damit spricht er, der sehr wohl in die Mithrasmysterien wie in viele andere Kulte eingeweiht gewesen sein könnte, ${ }^{63}$ jetzt gewiss ganz allgemein von den Mithräen $-{ }^{64}$ trage das Abbild des Kosmos,

die platonischen Quellen schreibt, dass „ihr Hauptinteresse nicht auf reiner Überlieferung, sondern der Verwendbarkeit der Fakten für ihre eigene Argumentationslinie" lag (993).

${ }^{58}$ Nicht auszuschließen ist, dass Porphyrios mit der auffälligen Privilegierung des Mithraskultes auch eine antichristliche Nebenabsicht verfolgt; vgl. MAuRETTE 2005, passim, der zu Recht darauf hinweist, dass die christliche Polemik gegen die Mithrasweihen schon bei Justin beginnt und auf die - als teuflische Imitation verurteilten - Ähnlichkeiten mit christlichen Ritualen zielt (77f.).

${ }^{59}$ Dass dies auch einen lehrhaften Teil einschließt, scheint mir pace Bвck 2006, 41f. unzweifelhaft ("teaching" und "enacting" schließen sich nicht gegenseitig aus, sondern ergänzen sich in Mysterienweihen, wie dann auch Bвск 43 konzediert); vgl. Ch. RiвDwbG, Mysterienterminologie bei Platon, Philon und Klemens von Alexandrien. Untersuchungen zur

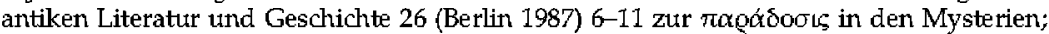
BURKERT 1990, 58-74; TURCAN 1982, $207 \mathrm{f}$.

${ }^{6}$ Vil Vgl. zu Eubulos Simonini 1986, 101-103 und Patillon / Segonds 1995, xxxv-xxxvi; Brisson 2000, 249 setzt ihn mit dem athenischen Platoniker aus der Zeit Plotins gleich.

${ }^{61} \mathrm{Vgl}$. dazu Turcan 1975, 68 : "qui [sc. l'antre fleuri] donc attirait les abeilles, quoique Porphyre ne retienne d'abord de ce détail qu'une correspondance philosophiquement significative avec l' ̇̇rṇ̨́arov d'Homère. ${ }^{\prime \prime}$

${ }^{62}$ In unverkennbarer Anlehnung an Plat. Tim. 28c3; "Vater" auch bei Iul. Symp. 38; vgl. auch Merkelbach 1984, 232; Simonini 1986, 103f; Maurette 2005, 65.

${ }^{63}$ Vorsichtiger MAURETTE 2005, 67f. im Hinblick auf De antro 17: ,We cannot say if he had read all these details in Eubutus since his works are lost, but considering that in the third century Mithraism had its peak of popularity, and that Porphyry lived in Rome where there was a proved abundance of Mithraea, it is not preposterous to venture the hypothesis that he had actually been inside a Mithraeum."

${ }^{64} \mathrm{Vgl}$. zur Bedeutung dieser Stelle auch Sfameni Gasparro 1979, 317f.; MaurbtTB 2005, 66: "The passage ends with what could be considered as an accurate description of an actual Mithraeum" usw; Веск 2006, 17: "De antro 6 is actually the sole explicit testimony 
den Mithras erschaffen habe, wobei die Dinge im Innern in wohlpropor-

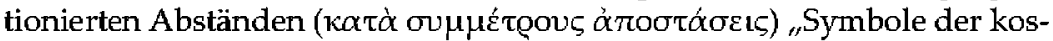
mischen Elemente und Himmelszonen" trügen. Damit wird deutlich ausgesprochen, was an sich auch aufgrund der Ikonographie und der archäologischen Funde unzweifelhaft ist: Mit den über die Mithräen verstreuten Sternen und Tierkreiszeichen sollte das mythische Hauptgeschehen, die Tötung des Stiers durch Mithras, ${ }^{65}$ offenkundig in das große Weltganze eingeordnet werden; ${ }^{66}$ visuelle Spezialeffekte, mit denen u.a. die Abfolge von Tag und Nacht sowie der Jahreszeiten evoziert wurden, verstärkten dabei offenkundig die kosmologische Dimension der Zeremonie. ${ }^{67}$

Das zweite Streiflicht auf den Mithraskult lässt Porphyrios im Zusammenhang mit dem symbolischen Gehalt des Honigs fallen, dessen doppelte Funktion er betont: Der Honig vermöge sowohl zu reinigen wie auch zu konservieren (15). Im Hinblick auf die kathartische Eigenschaft deutet er das rituelle Ausgießen von Honig statt Wasser in die Hände der Initianden bei der Einweihung in den Löwengrad ${ }^{68}$ als Weisung, "die Hände von allem, was Schmerz, Schaden und Abscheu verursacht, rein zu halten $^{\prime \prime}$. Zu dieser ethischen Deutung ${ }^{69}$ fügt er eine rituelle hinzu: Da für diesen Weihegrad das Element des Feuers als reinigender Kraft charakteris-

from antiquity as to the intent of Mithraism's mysteries and the means by which that intent was realized. Porphyry, moreover, was an intelligent and well-placed. theoretician of contemporary religion, with access to predecessors' studies, now lost"; 23: "The intent of the mithraeum's symbolism may or may not be what Porphyry says it is, but at least we are listening to a contemporary of the Mysteries making the inference, and there is a good chance that he is drawing (albeit at second. hand) on sources within the Mysteries"; allgemein zur Zuverlässigkeit von Porphyrios' Angaben ebd. 45 und 85-87; anders u.a. TurCan 2000, 93f.: "La difficulté majeure tient au fait que les premiers [sc. les monuments mithriaques proprement dits (inscrits ou figurés)] ne concordent pas toujours avec les seconds [sc. les témoignages de la tradition littéraire sur le culte persique], qui sont indirects et de seconde main, puisqu'ils ne procèdent pas d'authentiques mithriastes pratiquants. C'est le cas des textes de Porphyre qui réinterprète des données putsées dans les ouvrages d'Eubule et de Pallas [...], mais par l'intermédiaire le plus souvent (semble-t-il) du Néopythagoricien Numérius d'Apamée qui les expliquait à sa façon. Il s'agit d'exégèses philosophiques qui risquent d'avoir faussé, pour ne pas dire dénaturé les indications de base" (vgl. auch unten Anm. 102).

${ }^{65}$ Zur Deutung dieses Mythologems als „Rettung" vgl. Burkert 1990, $94 \mathrm{f}$.

${ }^{66} \mathrm{Vgl}$. dazu auch Burkert 1990, 70f;; Gordon 1996=1976, 120. 126-128 und ders. 1996=1988, 50-55; Beck 2006, 30-39 und 102-107; Alvar 2008, 94; Gordon 2012, 984f;; Clauss 2012, 55f. 83-88.

${ }^{67}$ Vgl. GoRdon 2012, 978; Clauss 2012, 116-123.

${ }^{68}$ Interessant in diesem Zusammenhang die Inschrift aus Steklen (Bulgarien) CIMRM 2 Nr. 2269: ... / leo / Melichrisus usw. Vgl. auch Gordon 1996=1988, 69 und 2001, 298 (ders. 2012,990 versucht dagegen wenig überzeugend, den Wert von Porphyrios' Zeugnis dadurch herunterzuspielen, dass er es auf ein isoliertes Einzelritual einer bestimmten Gemeinde beziehen möchte: vgl. oben Anm. 57).

${ }^{69} \mathrm{Vgl}$. dazu und allgemein zu den s, moral values in mithraism" Alvar 2009, 192-203. 
tisch sei, ${ }^{70}$ würden spezifische Waschungen (virtea $)^{71}$ und nicht das dem Feuer feindliche Wasser verwendet; im übrigen werde auch die Zunge mit Honig von jeder Verfehlung gereinigt (weiterhin 15). Die zweite natürliche Eigenschaft des Honigs, sein Konservierungsvermögen, sieht Porphyrios im Ritus darin abgebildet, dass "man dem "Perser' als Hüter der Feldfrüchte Honig zuführt" (16). ${ }^{72}$ Zwar fällt der Name Mithras an dieser Stelle nicht, doch genügt der Hinweis auf die Löwenweihe und den ,Perser', um die genannten Rituale religionsgeschichtlich einzuordnen: ${ }^{73}$ Mit leo wird nach Rabe (corax), nymphus und miles der vierte Weihegrad der Mithrasmysterien bezeichnet, dessen Bedeutung als erste vollkommene Stufe der Einweihung ${ }^{74}$ über welche wohl nur die wenigsten hinausgelangt sind, allein schon daraus zu entnehmen ist, dass er dem Planeten Jupiter zugeordnet ist (die tieferen Stufen werden - aufsteigend - mit Merkur, Venus und Mars assoziiert). Die für diese Stufe kennzeichnende Verpflichtung auf ein ethisch gutes Leben, auf die auch der wohl ebenfalls in die Mithrasmysterien eingeweihte Kaiser Julian einmal anspielt, ${ }^{75}$ fügt sich zum Hinweis

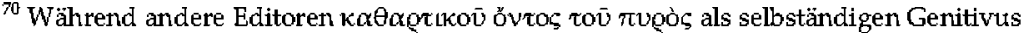
absolutus verstehen (s. SIMoNINI 1986, 157), ziehen sie die Herausgeber des ArethusaTextes m. E. zu Recht zu $\mu$ úom (vgl. die Übersetzung „and since he is an initiate of fire, which has a cathartic effect" usw.); vgl. Tert. Adv. Marc. I 13,5: aridae et ardentis naturae sacramenta leones mithrae philosophantur (, Die heiligen Lehren der trockenen und giühenden Natur ergrïnden die ,Löwen' des Mithras"; dazu TURCAN 2000, 135-138 und GorDon 2012, 1002 mit weiterer Literatur); Vermaseren / van Essen 1965, 226-232; CHALuPA 2008, 186; auch Iul. In matr. deor. 7 verbindet den Löwen mit dem Fetuer; allgemein zur Ptivilegierung des Feuers gegenüber allen anderen Elementen bei den Persern Firm. Mat. Err. prof. rel. V 1.

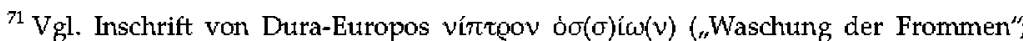
CIMRM I Nr. 68; dazu GoRDon 2001, 298f.).

${ }^{72} \mathrm{Vgl}$. TurCan 1975, 70f. Diese Rolle des ,Persers' spiegelt sich an seinen ikonographischen Attributen Hacke, Pflug und Sichel; vgl. Simonins 1986, 159f.; Clauss 2012, 129.

${ }^{73} \mathrm{Vgl}$. u.a. auch die bildliche Darstellung der sieben Grade im Mithräum von S. Prisca in Rom: VBRMASEREN / vAN EsSEN 1965, 155-160 und 167-172; allgemein MAURETTE 2005, 67; Chalupa 2008; Bremmer 2014, 132-138; Clauss 2012, 124f. glaubt, dass die Weihegrade Priester bezeichneten (in leichtem Widerspruch dazu erklärt ders. 13I wohl richtig, dass die Bezeichnungen ,Vater" und "Priester" [sacerdos] austauschbar waren).

${ }^{74} \mathrm{Vgl}$. auch Gordon 2012, 982.

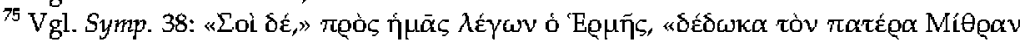

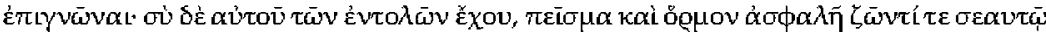

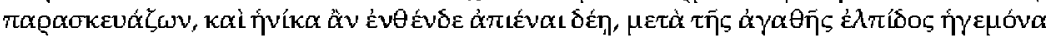

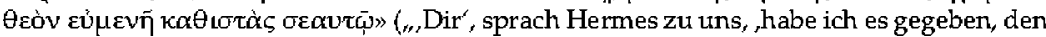
Vater Mithras zu erkennen. Du aber halte Dich an seine Gebote: Du verschaffst Dir [sc. damit] zu Lebzeiten ein Haltetat und einen sicheren Ankerplatz, und went du von hier weggehen musst, machst Du Dir zusammen mit der guten Hoffnung den Gott zu einem wohlgesonnenen Führer"); zu Julians Mithrasverehrung auch In reg. sol. 4I; zu skeptisch zu Julians Verhältnis zum Mithraskult TurCan 1975, 105-128; vgl. auch P. AtHanassiadi, "A contribution to Mithraic theology: the Emperor Julian's Hymn to King Helios", Journal of Theological Studies, N.S. 28,2 (1977) 360-371; A. MastrocinquB, Des mystères de Mithra aux mystères de Jésus. Potsdamer altertumswissenschaftliche Beiträge 26 (Stuttgart 2009) 21-23.
} 
in Kapitel 19, dass nur diejenigen der Seelen „Bienen“ genannt würden, welche dazu bestimmt seien, gerecht zu leben und den Göttern gefällige Taten zu vollbringen - ob die Unterscheidung zwischen allen ins Werden hinabsteigenden Seelen, die laut 10 allgemein "Nymphen" genannt werden, und den ethisch herausragenden Bienen vielleicht auch auf die Grade nymphus und leo übertragbar ist? Jedenfalls vertritt Porphyrios in einem anderen wichtigen Zeugnis die Auffassung, dass gerade durch die Tatsache, dass in den Mithrasmysterien Namen aus dem Tierbereich für die Weihegrade verwendet würden, die Metempsychose „angezeigt ${ }^{\prime \prime}$ werde ( $\left.\varepsilon^{\prime} \mu \phi \alpha i ́ v \varepsilon v v\right):{ }^{76}$ In rätselhafter Anspielung auf unsere Gemeinschaft mit den Lebewesen hätten die Perser die Gewohnheit, uns durch Tiere zu bezeichnen, so dass diejenigen, welche als Mysten an den Geheimriten selbst teilhätten, "Löwen" genannt würden - eine klare Bestätigung, dass erst die leones im eigentlichen Sinn als Mithraseingeweihte betrachtet wurden -, die Frauen aber als "Hyänen" ${ }^{77}$ die Diener jedoch als "Raben". Das gilt, aus dem lückenhaften folgenden Satz des Porphyrios zu schließen, ebenso zumindest für die höchste der drei über den leones stehenden Stufen "Per-

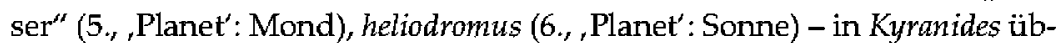
rigens die Bezeichnung eines indischen Vogels ${ }^{78}$ - und pater (7., Planet: Saturn): Die Väter scheinen "Adler" und „Falken" ${ }^{\prime 79}$ genannt worden zu sein. Ein weiteres interessantes Kultdetail wird an dieser Stelle genannt: „Wer den Löwengrad empfängt, dem werden verschiedenartige Gestalten von Tieren umgelegt" (Abst. IV 16,3), was nach mantelartigen Verkleidungen und Überwürfen klingt. ${ }^{80}$ Während diese Tiere offenbar von den Mithrasanhängern traditionellerweise auf die Tierkreiszeichen bezogen wurden, zitiert Porphyrios den Verfasser eines Werks Über Mithras, Pallas, ${ }^{81}$ für die - von Porphyrios offensichtlich geteilte - Meinung, dass damit vielmehr auf die Reinkarnation der menschlichen Seelen in verschiedenartigen Leibern angespielt werde (IV 16,4f.). ${ }^{82}$

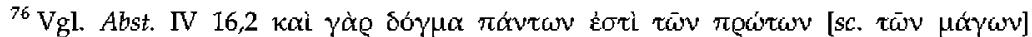

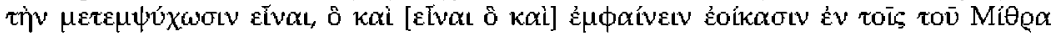

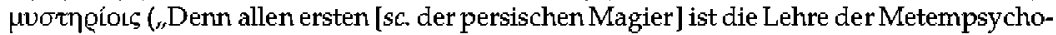
se eigentümlich, die sich, wie es scheint, atch in den Mysterien des Mithras manifestiert"); zur eschatologischen Bedeutung des Mithras vgl. Iul. Symp. 38 (vorhergehende Atum.).

${ }^{77}$ Die Mithrasmysterien scheinen generell Männern vorbehalten gewesen zu sein; vgl. GORDON 2012, 983f;; BREMMER 2014, I31f.

${ }^{78} 3,15$.

${ }^{79}$ Oder war letzteres vielleicht die Bezeichnung der Perser? In Abst. III 5 wird zwischen Adler (Zeus) und Falke (Apollon; zus. mit Krähe) unterschieden.

${ }^{80} \mathrm{Vgl}$. zu den Tieren, „die mit großer Regelmäßigkeit bei der Stiertötung anwesend sind" (Rabe, Hund, Skorpion, Schlange, z.T. auch der Löwe), Clauss 2012, 966 .

${ }^{81}$ Vgl. dazu Patillan / Segonds 1995, xxxvi-xxxvii.

${ }^{82}$ Dazu steht in einem gewissen Widerspruch, dass Porphyrios nach Augustinus' Angaben in De regressu animae anders als Platon die Reinkamation von Menschen in Tieren in Abrede gestellt haben soll (Regr. anim., fr. 300F. Sмгтн).
} 
Die weiteren expliziten und impliziten Hinweise auf Mithras sind zwar eher punktueller Natur, aber nicht minder aufschlussreich für eine platonisierende Innenansicht des Kults. So erfahren wir zum einen, dass in den Mithrasweihen der Mischkrug symbolisch für die Quelle steht (17) ${ }^{83}$ - schon die ,Urgrotte' des Zoroaster, die zum Vorbild für alle späteren Kultorte des Mithras wurde (wie Porphyrios in 20 nochmals wiederholt), war mit Quellen ausgestattet (6), wobei der Zusammenhang hier freilich spezifisch an die Nektarquelle erinnert, welche laut einer Versinschrift von S. Prisca in Rom die Zwillinge Kautes und Kautopates nährte und allgemein wohl denjenigen, die davon kosteten, Unsterblichkeit versprach. ${ }^{84}$

Vor allem aber klingt in De antro 18 das zentrale Mythologem des Mithraskults, der Rinderdiebstahl und die Tötung des Stiers, zumindest an: Die ebenfalls auf den Mond angewandte Bezeichnung „Biene“ veranlasst Porphyrios zu einer Kette von Assoziationen, welche vom Mond ( $\Sigma \varepsilon \lambda \eta \dot{v \eta}$ ) als "Vorsteher des Werdens" ${ }^{\prime \prime 5}$ ausgeht, diese gemäß verbreiteter Ikonographie mit dem Stier verbindet ${ }^{86}$ und den Stier dann als "Erhöhung" $(v i \psi \omega \mu \alpha)$ des Mondes bezeichnet, was nicht nur astronomisch-astrologisch

\footnotetext{
${ }^{89} \mathrm{Vgl}$. TuRCAN 1975, 68; Clauss 2012, 72-74; allgemein zur Fülle der mit Wasser verbundenen Assoziationen Simonini 1986, 166-168.

${ }^{84} \mathrm{Vgl}$.S. Prisca v. 4: fons concluse petris qui geminos aluisti nectare fratres ("Oh Du im Felsen eingeschlossene Quelle, die Du die Zwillingsbrüder mit Nektar nährtest") mit den Erläuterungen von VBRMASBREN / VAN ESSBN 1965, 193-200; ferner v. IOf. (s. oben Anm. 18).

${ }^{85} \mathrm{Vgl}$. dazu auch die Ausführungen von Num. fr. 31 DEs PLACEs $=$ De antro 21f. (der Mond wird mit dem Krebs assoziiert, durch das Krebstor aber steigen die Seelen auf die Erde, während sie durch den Steinbock wieder hinatsgehen); allgemein für die Fruchtbar-

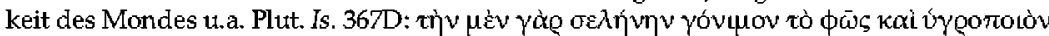

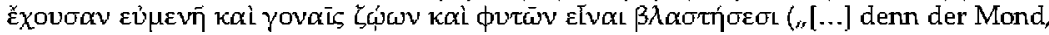
der ein zeugungsfähiges und feucht machendes Licht hat, sei förderlich für Erzeugung von Lebewesen und Wuchs von Pflanzen"). Bis zum Mond reicht nach gängigem philosophi-

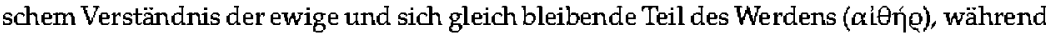
darunter die dauernde Veränderung herrscht (vgl. Iambl. Theol. arithm. 34 DE FALCo); der Mond wirkt dabei als Bindeglied: Er schmückt Julian zufolge die Materie mit Ideen und nimmt ihr so das Tierische und Ungeordnete (In reg. sol. 32); nach einer bestimmten Schule der Platoniker wohnen die Seelen entweder im Mond oder in der Luft darunter und von dort steigen sie herunter (Iambl. De anima, fr. 26, 54,11-13 Finamore $/$ Dillon $=$ Stob. $1,49,39,378,14-16$ W ACHSMUTH).

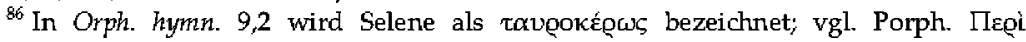

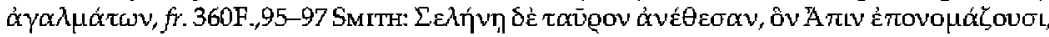

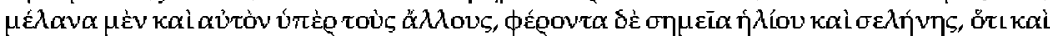

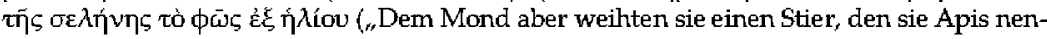
nen: schwarz auch er, mehr als die anderen; er trägt die Zeichen von Sonne tnd Mond, weil auch das Licht des Mondes von der Sonne [sc. kommt]'); auch Heliodor, Aethiog. X 28,1:

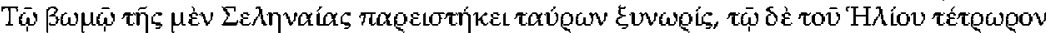

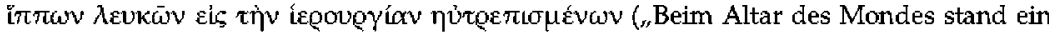
Zweigespann von Stieren, bei dem der Sonne ein Viergespann von Schimmeln, die für das heilige Handeln [gemeintist das Opfer] hergerichtet waren"; ähnlich Kyranides 1,10,81; zum Stiergespanu der Selene vgl, „Selene/Luna", LIMC VII 1, 706.711f.).
} 
zu verstehen ist ${ }_{r}^{87}$ sondern gewiss auch auf das Stieropfer des Mithras verweist - tatsächlich spielt der Mond bei den Opferdarstellung eine fundamentale Rolle. Zuweilen ist eine Mondsichel auf dem Rücken des Stiers eingraviert, bzw. er reist auf einer mondförmigen Barke, ${ }^{88}$ oder der Stier selbst bzw. seine Hörner formen sich zur Mondsichel, wobei Luna nicht selten am rechten Bildrand ins Geschehen einbezogen ist. ${ }^{89}$ Der Gedanke, dass aus diesem Stier Leben entsteht, wird im traditionellen Bildprogramm oft dadurch angedeutet, dass sein Schwanz zu einer Ähre wird. ${ }^{90}$ Porphyrios dagegen fügt an dieser Stelle als Beispiel solcher Fruchtbarkeit aus dem Tod die - uns heute vor allem durch Vergil bekannte - Bugonie der Bienen an, wobei im nächsten Atemzug gleich auch die "Seelen, die zum Werden gehen", als "rindergeborene" (Bovүeveīs) bezeichnet werden: Daraus darf gewiss auf einen engen Bezug des Reinkarnationszyklus zum mithräischen Hauptmythologem geschlossen werden.

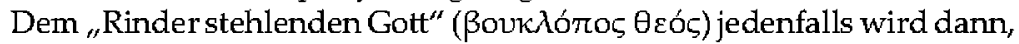
wie es scheint, nicht nur die Inkarnation, sondern ebenfalls die heimliche Aufhebung des Werdens zugeschrieben (weiterhin 18): Falls die hier vorgeschlagene Emendation $\alpha$ vaœ $\dot{\alpha} \kappa o u ́ \omega v^{91}$ sowie die traditionelle Deutung der Stelle auf Mithras zutrifft, ${ }^{92}$

\footnotetext{
${ }^{87} \mathrm{Zu}$ den astronomisch-astrologischen Vorstellungen in De antro vgl. Benjamin Topp in diesem Band.

${ }^{88}$ Vgl. TurCan 1975, 73-75; Simonini 1986, 176.

${ }^{89}$ Vgl. u.a. CIMRM 1 Nr. $368=$ Fig. 106 (s. Abb. 1 auf der folgenden Seite) und Nr. 1400 = Fig. 360; dem Mond korrespondiert auf der Gegenseite (welche vom Bild her betrachtet eigentlich die höherwertige rechte ist) die Sonne. S. auch BrCK 2006, 194-200; CLAuss 2012, 8If.

${ }^{90}$ Auf römischen Darstellungen gilt dies auch für das Blut, welches aus der Stelle des Schwerteinstichs hervortritt; vgl. MERKELBACH 1984, 316f. (Abb. 66f.); VBRMASBREN / vaN EssEN 1965, 218; Clauss 2012, 80-88.

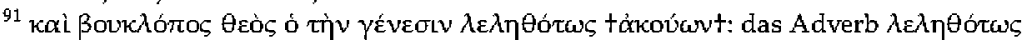
dürfte an dieser Stelle auf die ,diebische' Seite des Gottes zielen, wobei diese entweder die Entstehung oder die Aufhebung des Werdens betreffen kann; da bereits Selene in der Funktion der "Vorsteherin des Werdens" genannt war, halte ich eine Anspielung auf de-

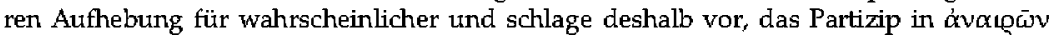

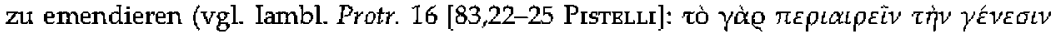

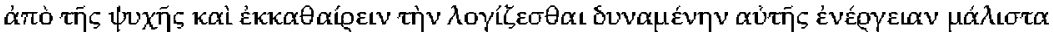

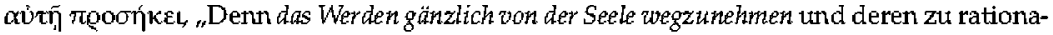
lem Denken befähigte Kraft zu reinigen kommt ihr [sc. der Philosophie] am meisten $z u^{\prime \prime}$ ). Für weitere Emendationsvorschläge (darunter besonders erwägenswert Turcans $\dot{\alpha} \pi \alpha ́ \gamma \omega v$ : TurCan 1975, 75-77) vgl. Simonini 1986, 179f. und MaURETTE 2005, 71f.; allgemein zu dieser Stelle auch Alvar 2009, 104f.

${ }^{92}$ Mir scheint diese auf dem Hintergrutnd des im folgenden aus Firmicus Maternus zitierten Verses sowie ikonographischer Darstellungen des den Stier auf den Schultern tragenden bzw, in eine Höhle wegfühtrenden Mithras (vgl. v. 7 der Inschrift von S. Prisca in Rom: hunc quem aurkebs hutheris portazit more ituencum, "[...] diesen Stier, den er mit [seinen] goldenen Schultern in der rechten Art trug" mit den Erläuterungen von VBRMASRREN / VAN EsSEN 1965, 200-202 und SIMONINI 1986, 179f.; außerdem ClAuss 2012, 75-78) pace M. J. Edwards, "Porphyry and the Cattle-Stealing God“, Hermes 121, I (1993) I22-125
} 


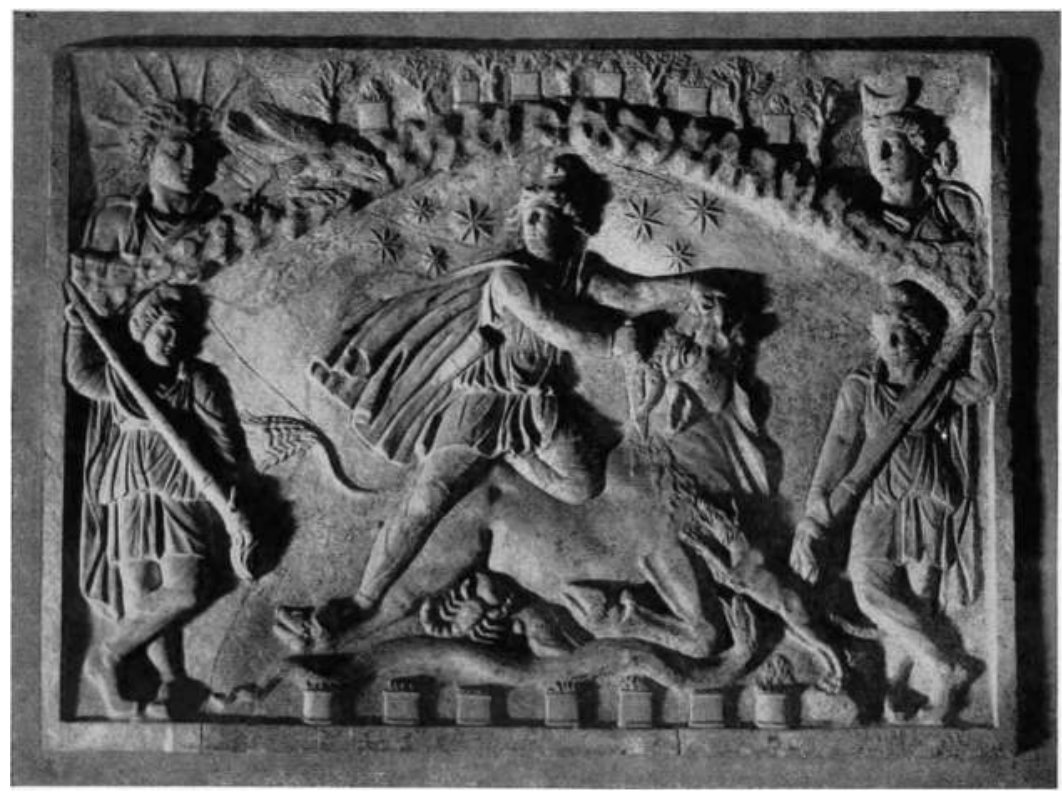

Abb. 1: Rinderdiebstahl und Tötung des Stiers durch Mithras, aus: CIMRM 1, Nr. $368=$ Fig. 106

dürfte damit Mithras' Beitrag zu der in der Orakelphilosophie als Ziel ge-

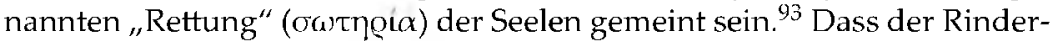
bzw. Stierdiebstahl zum ,Geheimnis' der Mithrasweihe gehört, bestätigt im übrigen der bei Firmicus Maternus überlieferte Vers, der am ehesten am Ende der Weihe oder im Rückblick auf dieselbe gesprochen worden

weiterhin gerechtfertigt (zwar ist es richtig, dass man beim Rinderdiebstahl zunächst viel eher an Hermes oder an Herakles denkt; doch abgesehen von evidenten Berührungen zwischen Mithras und I Ierakles [vgl. u.a. VERMASEREN / vaN EsSEN 1965, 204-206 usw.] hat z11mindest der Einwand, dass Firmicus Maternus mehr als ein halbes Jahrhundert jünger ist als Porphyrios, kein Gewicht, da er in diesem Punkt unmöglich von Porphyrios abhängen kann, und ob Porphyrios „never elsewhere refers to him [sc. Mithras] without naming him" [EDwARDs 1993, 124], kann angesichts der äußerst lückenhaften Überlieferung zwar nur bedingt nachgeprüt werden, doch gibt es eindeutige Gegenbeispiele: vg1. u.a. die leicht zu identifizierenden Angaben in 15f., ferner oben Anm. 44; zu mithräischen Elementen in den Ausführungen zu den Winden [De antro 25] SIMONini 1986, 207f.; heikel dagegen die Inanspruchnahme von De antro 29 für den Mithraskult durch R. BECK, "Ritual, Myth, Doctrine, and Initiation in the Mysteries of Mithras: New Evidence from a Cult Vessel", in: Вғск 2004, [55-92] (= Journal of Roman Studies 90 [2000] 145-180) 78-81.

${ }^{93}$ Auf diese zielt Porphyrios auch mit Philos. ex orac. haur, vgl. fr. 304F. Sмiтh. Für Mithras' Bedeutung für die Rettung der Seelen vgl. unten Anm. 103; allgemein zur Höhle als Symbol "del mistero della salvezza" in der heidnisch-christlichen Auseinandersetzung Penati Bernardini 1988, $122 \mathrm{f}$. 


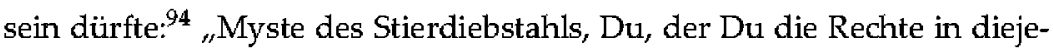

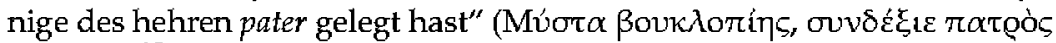
$\dot{\alpha} \gamma \alpha \boldsymbol{v} \mathrm{v}) .{ }^{95}$

Eine solche Doppelfunktion des Mithras wird in De antro 24 mit dessen astronomisch-astrologischer Lokalisierung zwischen dem "Nordtor" des Abstiegs im Krebs und dem "Südtor" des Steinbocks, durch das die Seelen nach oben zurückkehren, signalisiert. Zwar ist der Text an dieser Stelle erneut leicht verderbt, ${ }^{96}$ doch der zentrale Punkt, dass Mithras gewissermaßen als Mittler seinen Sitz an den beiden Tag-und-Nacht-Gleichen im Frühling und im Herbst hat, wird im ersten, einheitlich überlieferten Satz eindeutig festgehalten. Zur Begründung verweist Porphyrios auf die Ikonographie: ${ }^{97}$ Mithras trage aus diesem Grund das Opfermesser des dem Mars zugehörigen Tierkreiszeichens Widder und reite auf einem Stier der Aphrodite - an dieser Stelle folgt in den Manuskripten die tautologische Fortsetzung "wie auch der Stier". Beck (2004=1976) hat zu Recht darauf hingewiesen, dass vielmehr eine Anspielung auf das wenige Zeilen zuvor dem Tierkreiszeichen der Waage ( $\zeta \circlearrowright \gamma^{\prime}$ 's) zugeordnete Herbstäquinoktium zu erwarten wäre. ${ }^{98}$ Anstelle seiner freilich etwas umständlichen Lösung

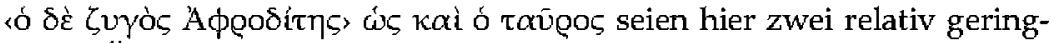
fügige Änderungen vorgeschlagen: 1) die Emendation von $\omega \zeta$ in $\eta \eta^{\circ} \zeta$, und

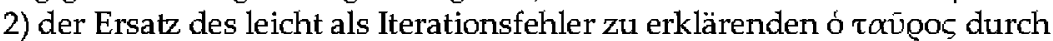

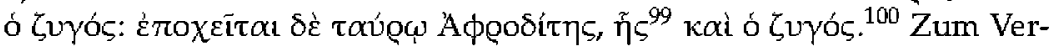
gleich kann u.a. auf Sext. Emp. Adv. math. V 34 verwiesen werden: Agews

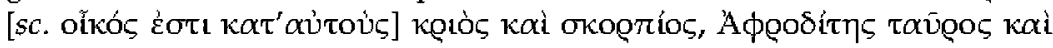

\footnotetext{
${ }^{94}$ Vgl. auch Alvar 2008, 100; anders Gondon 2012, 980 (,Begrü:Bungsformel“). Vgl. im übrigen auch Comm. Instr. I 13: Insuper et furem adhuc depingitis esse, / cum, si deus esset. utigue non furto vivebat. / Terrenus utigue fuit et monstruosa natura / vertebat quae boves alienos semper in antris, / sicut et Cacus Vulcani filitus ille ("Überdies malt ihr ihn Euch ja atch als Dieb aus, / obwohl er, wenn er ein Gott wäre, keinesfalls von Diebstahl lebte. / Jedenfalls war er ein Erdenkind und ein monströses Wesen, das fremde Rinder stets in seine Höhlen umlenkte, / wie auch Cacus, jener Sohn des Vulcanus").

${ }^{95}$ Err. prof. rel. V 2; dazu auch TuRCAN 1982, 208f.; Merkelbach 1984, 107; Clauss 2012, 101. 144 .

${ }^{96} \mathrm{Vgl}$. zu den bisherigen Emendationsversuchen Simonini 1986, 202.

${ }^{97}$ Vgl. auch TurCan 1975, 83-88; SIMONINI 1986, 202f.; laut GoRdon 2012, $989 f$. gibt es für die Verbindung zwischen Mithras und der Herbst-Tag-und-Nacht-Gleiche "anscheinend keine archäologischen Befunde im organisierten Kult"; ders. 2001, 294 beruft sich freilich auf unsere Stelle, um den Bezug des Mithraskults zum Datum des iranischen MithrakanaFests zu belegen.

${ }^{98} \mathrm{Vgl}$. auch MAURETTE 2005, 68.

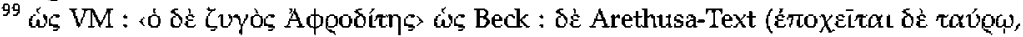

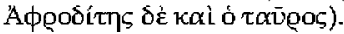

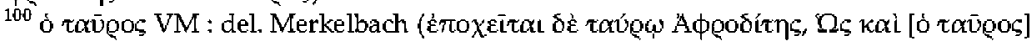

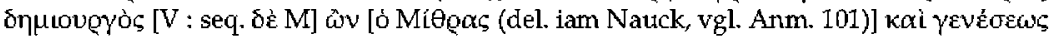

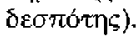




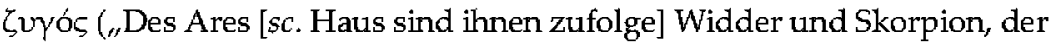
Aphrodite Stier und Waage").

An diesem Äquinoktial-Kreis wacht Mithras ${ }^{101}$ als "Demiurg und Herr-

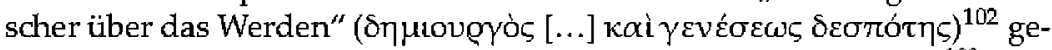
nauso über den Abstieg wie über den Wiederaufstieg der Seelen. ${ }^{103}$ Porphyrios denkt wohl weiterhin auch an bildliche Darstellungen, wenn er in Auslegung dieser Mittelposition anschließend hinzufügt, dass Mithras in der - in der Antike grundsätzlich als höherwertig betrachteten - "rechten Hand die nördlichen Teile und in der linken die südlichen Teile hält", wobei man „im Süden [...] Kautes wegen der Hitze, und im Norden den $<$ Kautopates $>104$ wegen der Kälte des Windes" aufgestellt habe. Auf Reliefs der Geburt des Mithras aus dem Felsen und der Stiertötung sind oft zwei Fackelträger mit phrygischer Mütze zu finden, die Mithras flankieren und in der Tat "due aspetti complementari" (Simonini 1986) des Gottes darzustellen scheinen, wobei der eine mit gehobener (Kautes), der andere mit gesenkter Fackel dargestellt wird (Kautopates) und ihre kosmologische Dimension auf der Stele aus dem Mithräum bei Heddernheim durch

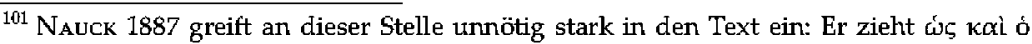

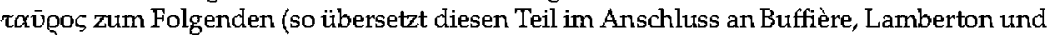
Speidel auch Simonini 1986, 69 "Poiché Mitra, come il Toro, è demiurgo" usw.), wobei

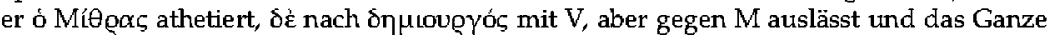

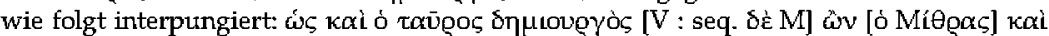

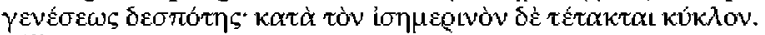

${ }^{102} \mathrm{Vgl}$. dazu Simonin 1986, 203 ",come si è notato, Mitra, demiurgó è linguaggio platonico che tradisce una ellenizzazione della teologia mitraica [... ]; ma tale quadro si armonizza con l'iconografia di Mitra tauroctono, posto al centro di ogni mitreo e, simbolicamente, dell'intero universo, dove esercita la sua azione demiurgica [...] sui rilievi Mitra compare a volte come kosmokratōr, signore e animatore del cosmo, simboleggiato da una sfera che egli tiene in mano" usw. Die bei Simonini zu beobachtende Tendenz, diese Detutung im Anschluss an TurCan 1975 (vgl. u.a. 88 "Numénitus revu ou répété par Porphyre"; ähnlich ders. 2000, 93f. [oben Anm. 64] und 145) atsschließlich auf Numenios zurückzuführen, scheint mir allerdings problematisch; es dürfte sich vielmehr um ,zeitgeistige Vorstellun- $^{\prime}$ gen handeln, die allgemein in dieser vom Platonismus durchdrungenen Zeit in der Luft lagen.

${ }^{103}$ Zur Rolle des Mithras für die ,Erlösung der Seelen vgl. u.a. die Inschrift im Mithrätum von S. Prisca in Rom v. 14 (et nos) servasti (?) eternali (?) sanguine fuso (". [...] (und uns) hast Du errettet (?) durch das vergossene ewige (?) Blut" ) mit den Erlätuterungen von VBRMASEREN / VAN EsSEN 1965, 217-221 (die Lesung ist freilich z.T. unsicher, vgl. S. PANCIBRA, "I materiale epigrafico dallo scavo del mitreo de S. Stefano Rotondo (con tu addendtum stul verso terminante ...sanguine fuso "', in: BIANCHI 1979, [87-126] 103-105 Anm. **, SFAM ENI GASPARRo 1979, 327f. Anm. 85 [übertrieben GoRDon 2012, 977 "nur sangtine fuso ist sicher"]); außerdem schon Tert. De praescr. haer. 40: imaginem resurrectionis inducit [sc. diabolus] (,Ein Abbild der Auferstehung führt er [sc. der Teufel, im Rahmen seiner Imitation der heiligen Lehren in den Mithrasmysterien] vor").

${ }^{104}$ Coni. Arethusa-Text : $k \alpha \tau^{\prime}$ éké́vov V2.
} 
die Hinzufügung eines auf einer Weltkugel aufsitzenden Adlers sowie des Okeanos unterstrichen wird. ${ }^{105}$

Es ist geradezu emblematisch, wie sich in diesem Passus aus Porphyrios' De antro astronomisch-astrologische Vorstellungen mit Mythen, Riten, ikonographischen Darstellungen und philosophischen Konzepten zu einem Gesamtbild kosmologischer Dimension fügen. So befremdlich uns eine solche Gemengelage heute anmuten mag: In weitgehender Übereinstimmung mit der platonischen Anthropologie wird auf diese Weise das menschliche Leben, mit seinem Kreislauf von Inkarnation und Befreiung durch den Tod, in ein großes Ganzes eingebettet. Es erfährt damit auf philosophischer ebenso wie auf religiöser Ebene Sinn und Ziel.

${ }^{105}$ CIMRM 2, 1127; vgl. auch die at tsführlichen Erlätterungen ad loc. von SIMONini 1986, 206f.; Gordon 1996=1976, 128 und 1996=1988, 55f.; R. BECK, ${ }_{s}$ Cautes and Cautopates: Some Astronomical Considerations", in: BEcK 2004, 133-149 (= Journal of Mithraic Studiles 2 [1977] 1-17) und ders. 2006, 107-112 und 212-214; MauretTB 2005, 69f; Clauss 2012, 93-95. 


\title{
Das Motiv der Höhle ${ }^{1}$ in Literatur und Kunst: Porphyrios, De antro ${ }^{2}$ Nympharum
}

\author{
Irmgard Männlein-Robert
}

In seiner Schrift De antro Nympharum ${ }^{3}$ legt der Platoniker und Religionsphilosoph Porphyrios eine eindrucksvolle und komplexe Kommentierung der Nymphengrotte aus Homers Odyssee (XIII 102-112) vor. ${ }^{4}$ Es ist zu vermuten, dass es sich bei De antro nicht um eine eigenständige Schrift, sondern um einen umfangreichen Passus aus einem größeren Kontext handelt. ${ }^{5}$ Enge thematische und methodische Zusammenhänge mit weiteren (fragmentarisch überlieferten) Schriften des Porphyrios, wie etwa De philosophia ex oraculis haurienda, De imaginibus, De Styge, aber auch zu De abstinentia oder Sententiae, sind deutlich erkennbar, ohne dass eine genaue

\footnotetext{
${ }^{1}$ Im Deutschen wurde bis in die Mitte ces 20. Jh.s hinein keine wirkliche inhaltliche Unterscheidung zwischen den Begriffen ,Höhle' und ,Grotte' gemacht, was sich auch in der älteren Forschungsliteratur zu De antro Nympharum zeigt. Seither hat sich eine gewisse begriffliche Differetzierung durchgesetzt, die ,Höhle' als natürlichen und, Grotte als künstlich geschaffenen Hohlraum versteht, dazu siehe H. Trim MвL, Höhlenkunde. Die Wissenschaft: Sammlung naturwissenschaftlicher und mathematischer Monographien 126 (Braunschweig 1968). Im Folgenden wird mit Blick auf den Titel der Schrift der schlichtweg etablierte Über die Nymphengrotte beibehalten, ansonsten aber für das bei Porphyrios fokus-

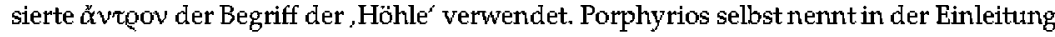
seiner Schrift die bereits bei Kronios diskutierte Aporie, ob die Höhle der Nymphen bei Homer nun von Menschen geschaffen oder natürlich sei ( $\$ 2$ und 6), tendiert aber selbst offenbar mehr dazu, die Höhle als naturgegeben und nicht als (reine) Erfindung Homers anzusehen, siehe $\$ 4$.

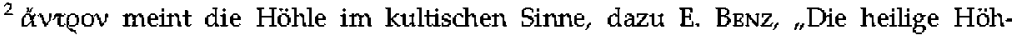
le in der alten Christenheit tund in der östlich-orthodoxen Kirche", Eranos-jb 22 (1953) [365-432] 431 und v.a. 384. Homer verwendet (nur in der Odyssee) övvteov (Od. IX 216.218.235.236.298.312.407; XIII 103.347.363; XX 21; XXIV 6); vgl, dagegen Platon, der in seinem Höhlengleichnis (Rep. VII 514a3.515a8.539e3 u.a.) gezielt nicht ăvtęov, sondern

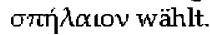

${ }^{3}$ Hier zitiert nach der Attsgabe von Latra Simonitui (Simonini 1986).

${ }^{4}$ Zu diesem Kommentar als Metatext sowie zu dessen Rezeption selbst siehe den Beitrag von Reinhold Glei in diesem Band, v.a. S. 142-143.

${ }^{5}$ Das legen z.B. bereits der Eingang der Schrift mit ŏ $\tau$ (\$ 1) sowie der fehlende Abschluss (\$ 36) nahe. Christoph Riedweg (siehe seinen Beitrag in diesem Band, S. 78 mit Anm. 6) deutet als möglichen größeren Kontext die nur dem Titel nach überlieferte Schrift

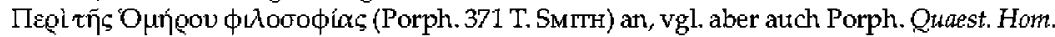

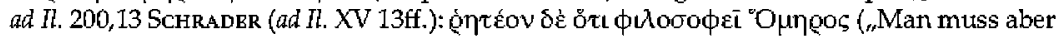
sagen, dass Homer Philosoph ist"), dazu LamberTon 1986, 113 mit Anm. 98.
} 
Datierung von De antro Nympharum bislang möglich oder eine vorgeschlagene allgemein akzeptiert worden wäre. ${ }^{6}$ Diese Schrift enthält den einzigen überlieferten zusammenhängenden allegorischen Kommentar eines Homerpassus ${ }^{7}$ und erweist sich überdies als ergiebige Fundgrube für religionsphilosophische resp. theosophische, ${ }^{8}$ aber auch religionspraktische Informationen aus der Spätantike. Zunächst in Anlehnung an den allegorischen Homerkommentar des pythagoreisierenden Platonikers Kronios (wohl 2. Jh. n. Chr.), den er in dieser Schrift (De antro 21) als Étaīoos (Schüler) des Numenios bezeichnet und damit wohl vor allem auf eine enge doktrinale Übereinstimmung beider Philosophen verweist, ${ }^{9}$ referiert Porphyrios einige ältere allegorische Interpretationen, ${ }^{10}$ denen er nicht immer zustimmt und die er an geeigneter Stelle dann auch korrigiert. ${ }^{11}$ Mit Blick auf die auch von Porphyrios gewählte allegorische Methode zeigt sich freilich, dass er hier keine einheitliche Linie verfolgt, sondern dass es sich vielmehr - wohl angesichts des thematisierten Pluralismus der ,Symbole ${ }^{\prime}$ - um einen Pluralismus auch der allegorischen Erklärungsansätze handelt (so mit Jean Pépin). ${ }^{12}$ Porphyrios legt also mit De antro Nympharum eine allegorische Interpretation der bei Homer ( $O d$. XIII 102-112) beschriebenen Nymphengrotte vor und erläutert in wissenschaftlich anmutender Weise, dass diese ein poetisch verschlüsseltes Bild sei, das die Einkörperung von Seelen in Körper sowie den umgekehrten Prozess basierend auf platonischen Prämissen beschreibe. Dabei formuliert er im Eingang einen Problemaufriss für die zunächst rätselhafte Schilderung dieser Höhle bei Homer. Er bezeichnet deren Deutung als "nicht geringe Aporia" (De antro $3^{13}$ ) und benennt die im Folgenden zur Beantwortung stehenden Fragen

${ }^{6}$ Zur Datierung siehe ALt 1998, 467 und den Beitrag von Christoph Riedweg in diesem Band, S. 77-78 Anm. 4 (mit Tendenz zur Datierung in die letzten Jahrzehnte von Porphyrios' Leben).

${ }^{7}$ Castelletti 2006, 21.

${ }^{8}$ Zum Begriff $\theta$ coøoфía, $\theta \varepsilon o ́ \sigma o \emptyset o \varsigma$, der wohl auf Porphyrios selbst zurückgeht, siehe CAstBlletTi 2006, $212 \mathrm{mit}$ Anm. 319.

${ }^{9}$ Siehe ausführlicher zu Kronios WhITTAKER 1994.

${ }^{10}$ Möglicherweise verfasste auch der Mittelplatoniker Maximos von Tyros einen allegorischen, platonisierenden Kommentar zu Homer (dazu z.B. M. B. Trapp, „Philosophical Sermons: 'The "Dialexeis' of Maximus of Tyre", ANRW II.34.3 (1997) [1945-1976] 1971f.; ders., "Maximos von Tyros (1)", DNP 7 (1999) 1074f.; J. L. Lópbz Cruces / J. CAMpos DarocA, Máximo de Tiro. Disertaciones filosóficas. Introducción general, traducción y notas, Bd. 2 [Madrid 2005] 343), siehe dessen Interpretation des Odysseus als Verkörperung innerweltlicher platortischer ápetr (Max. Tyr. Diss. 26,4.6.9), dazu I. Männlein-RoberT, „Maximos von Tyros", in: Ch. HoRn / Ch. RIEDWBg / D. WYRWA (Hg.), Philosophie der Kaiserzeit und der Spätantike. Grundriss der Geschichte der Philosophie. Die Philosophie der Artike 5 (voraussichtlich Basel 2018).

${ }^{11}$ Porph. De antro 2-4 = T. 9 Legmans; zu Kronios siehe Männlein-Robert 2018.

${ }^{12}$ PépIN 1966, 241f. Ähnlich Müri 1976, 33.

${ }^{13}$ Hier weicht die Übersetzung von der im Band gedruckten ab, damit der für Porphyrios methodisch so widhtige Begriff ,A poria zum Ausdruck kommt. 
als $\zeta \eta \tau \eta \mu \alpha \tau \alpha$ (\$ 4). Porphyrios tritt hier als Philosoph, als philosophischer Exeget Homers auf, in dessen Text es uralte Weisheit (бoфía) zu enträtseln gilt. Dabei bedient er sich etablierter, wohl in Alexandria wurzelnder, philologischer Methoden der Homerkommentierung, die er sicherlich bei seinem langjährigen Athener Lehrer, dem Philologen und Platoniker Longin, von Grund auf gelernt und eingeübt hat, ${ }^{14}$ und wendet diese hier auf seine religionsphilosophische Allegorese der Nymphengrotte bei Homer an. Überhaupt steht er mit seiner intensiven Homerwürdigung in der Tradition Longins und anderer Mittelplatoniker, die neben Homerstudien auch eine Rehabilitierung Homers mit Blick auf Platon und seine Schriften angestrengt haben. ${ }^{15}$ Zugleich erinnert Porphyrios' Auslegung dieses auch bei Homer statisch beschriebenen Bildes der Höhle, ihrer Lage und ihrer Ausstattung, an eine exegetisch umgesetzte Ekphrasis, da sämtliche bei Homer genannten Details etwa des Aussehens, der Eigenheiten und Qualitäten dieser Höhle aufgegriffen und erläutert werden. ${ }^{16}$ Der im exegetischen Duktus dieser Schrift aufscheinende, gleichsam ekphrastische Habitus des Porphyrios wird dadurch bestätigt, dass er die Nymphenhöhle ausdrücklich als heiliges, Göttern geweihtes ,Heiligtum' $(\dot{\alpha} v a ́ \theta \eta \mu \alpha)^{17}$ voll alter Weisheit ( $\sigma \circ \phi i ́ \alpha$ ) bezeichnet, denn bereits vor Homers Zeiten hätten, so Porphyrios, Menschen diese Höhle den Göttern geweiht (ebd. 4). Es handelt sich bei De antro Nympharum nicht nur um eine philosophisch motivierte und philologisch durchgeführte Abhandlung über einen rätselhaften Passus bei Homer, sondern auch um die allegorische Deutung eines göttlichen, Gottheiten geweihten bildlichen Ortes, so dass wir, ähnlich wie in der Schrift Пв@i ó $\gamma \alpha \lambda \mu \alpha \dot{\alpha} \tau \omega v$, in der Schreibhaltung des Autors Por-

\footnotetext{
${ }^{14}$ Siehe Männlbin-Robert 2001 und dies., "Philosophie als Philologie? Der Platoniker Longin und seine Kritiker", int: Ch. RIBDwBG (Hg.), PHILOSOPHIA in der Konkurrenz von Schulen, Wissenschaften und Religionen. Zur Pluralisierung des Philosophiebegriffs in Kaiserzeit und Spätantike. Akten der 17. Tagung der Karl und Gertrud Abel-Stiftung vom 16.-17. Oktober 2014 in Zürich (Boston / Berlin 2017) 161-178.

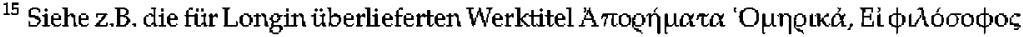

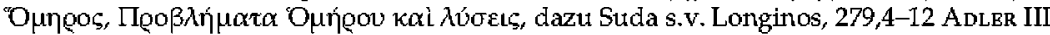
$=f r$. I MäNNLEIN-ROBERT.

${ }^{16}$ Dazu Marzillo 2013, 231. Siehe auch die kaiserzeitlichen, im Rhetorikunterricht verwendeten Progymnasmata mit expliziten Anleitungen zum Erstellen von Ekphraseis, dazu jetzt R. WвеE, Ekphrasis, Imagination and Persuasion in Ancient Rhetorical Theory and Practice (London / New York 2016). Vgl. Campbell 1968, 55, der Porphyrios' De antro für die Beschreibung eines zeitgenössischen Mithräums hält.

${ }^{17}$ Die Bedeutung von $\alpha v \alpha \theta \eta \eta \alpha$ konvergiert hier weitgehend mit der von $\alpha \gamma \alpha \lambda \mu \alpha$ : Die Nymphengrotte ist damit als den Göttern geweiht, als Schmuck und Gabe für die Götter

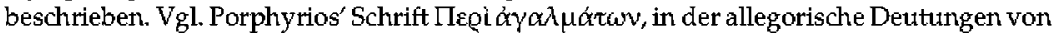
Götterbildern vorgenommen werden. Im Eingang macht Porphyrios dort deutlich, dass man $\alpha \gamma \gamma \alpha \dot{\alpha} \lambda \mu \alpha \tau \alpha$ wie Bücher lesen und interpretieren müsse (De imaginibus 351F.,408,14 24 SMITH); bei Plotin werden etwa atch die in Tempel eingeschriebenen Hieroglyphen als

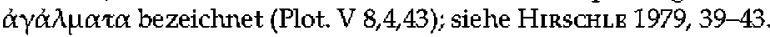


phyrios hier einen gewissen Offenbarungsgestus konstatieren können. ${ }^{18}$ Das Ziel seiner Exegese ist, wie er deutlich sagt ( $\$ 4)$, das Verstehen dieses göttlichen Bildes voll ,alter Weisheit' sowie - wie auch in der Schrift Пe@i $\dot{\alpha} \gamma \alpha \lambda \mu \alpha \dot{\tau} \tau \omega \mathrm{v}$ - die durch die Deutung von göttlichen Zeichen intendierte "Vergegenwärtigung des Göttlichen". ${ }^{19}$ Die in der neueren Forschung vielfach vorgenommene Suche nach platonischem Gedankengut in engerem Sinne, die Frage, wieso hier manche der referierten Erklärungsversuche nicht immer wirklich mit platonischen Lehren übereinstimmen, liegt m.E. in der klaren und betonten Konzentration des Porphyrios auf die, Sophia der Alten' begründet. Mit den $\pi \alpha \lambda \alpha ı{ }^{20}{ }^{20}$ die bereits vor Homer diese Höhle den Göttern geweiht hätten, führt Porphyrios nun weise Männer einer nicht näher präzisierten Vorzeit an, in deren Tradition bereits Homer stehe. Somit wird Homer als eine spätere historische Stufe dieser uralten Weisheit kenntlich, so dass dessen Schilderung der Nymphengrotte zwar klar in der Tradition dieser Weisheit zu sehen ist, gleichwohl freilich, da vor-philosophisch, hermeneutische Schwierigkeiten hervorruft, die der Philosoph Porphyrios nun zu lösen beabsichtigt. Interessanterweise gilt hier - streng genommen - nicht das alte, begrifflich freilich erst bei Porphyrios selbst verbatim belegte, ${ }^{21}$ wohl in Alexandria wurzelnde Exegese-

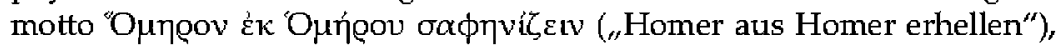
das von den philologisch geschulten kaiserzeitlichen und spätantiken Exegeten Platons längst auf die Kommentierung der Platonschriften übertragen worden war. ${ }^{22}$ Vielmehr lässt sich mit Blick auf Porphyrios' De antro

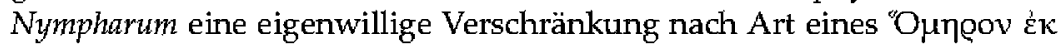
$\Pi \lambda \alpha ́ \tau \omega v o \zeta$ im weiteren Sinne konstatieren. In jedem Falle geht es Porphyrios darum zu zeigen, dass die Geltung der Sophia, wie sie sich bei Homer mehr oder weniger artikuliert, alt oder besser: überzeitlich ist und daher größten Respekt verdient. ${ }^{23}$ In diesem Kontext verweist Porphyrios nach-

\footnotetext{
${ }^{18}$ Siehe De imaginibus 351 F. SMITH. Diesen, vielleicht habituellen, priesterlichen Gestus bescheinigtihm auch Plotin, siehe Porph. VPlot. 15,4-6, wenn er ihn als, Hierophanten' bezeichnet. Passend in diesem Kontext ist Porphyrios' eigene Bemerkung in Marc. 16: Hóvos

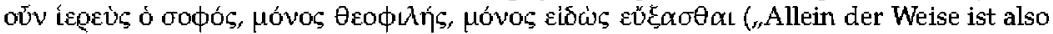
ein Priester, allein er ist von Gott geliebt, allein er versteht zu beten ${ }^{\prime \prime}$ ).

${ }^{19}$ So mit Cromb 1970, 155f.; zum Interesse an ,barbarischer' oder alter Sophia siehe Kronios (T. 4 Leemans); dazu M. Frede, „Kronios”, DNP 6 (1999) [863f.] 864; ERLER 2001.

${ }^{20}$ Zur Wortwahl vgl. Longin, der in seiner Exegese des Timaios-Kommentares fein säuberlich verschiedene Adjektive mit der Bedeutung ,alt' unterscheidet, dazu MäNnLBINROBBRT 2001, $449 f$.

${ }^{21}$ Porph. Quaest. Hom. ad Il, 297,16 Schrader; analog dazu ist das bei Galen erkennbare Prinzip Hippocratem ex Hippocrate, z.B. Gal. De comate secundum Hippocratem 1,5 (CMG V 9,2, 182,23-26).

${ }^{22}$ Die Praxis, schwierige Homerstellen durch Zuthilfenahme ähnlicher, gleicher oder konträrer Stellen aus Homer zu erklären, ist freilich älter; sie basiert wohl auf der entsprechenden forensischen Praxis der Attischen Redner, dazu Ch. SCHÄUbliN, "Homerum ex Homero", MH 24 (1977) [221-227] 224-226.

${ }^{23}$ ERLER 2001.
} 
drücklich darauf, dass die weisen Alten (dieser nicht näher benannten Vorzeit) ihre heiligen Stätten - also auch Höhlen - stets mit mystischen Symbolen ausgestattet hätten $(\S 4)$, die es nun, soweit bei Homer greifbar, zu deuten gilt. Klar wird hier die Fokussierung des Porphyrios auf religiöse Gehalte des homerischen Höhlenbildes erkennbar.

Im Folgenden sollen Motivtraditionen der Höhle aus der Literatur, Religion und Philosophie der Griechen vorgestellt werden, auf die Porphyrios in seiner Schrift anspielt: Insbesondere in den Kapiteln 5 bis 8 klingen in De antro einschlägige Topoi der Höhle an. Es wird dabei deutlich, dass das Motiv der Höhle, das in der antiken Literatur reich vertreten ist, von Porphyrios in recht eigenwilliger, fokussierter Interpretation vorgestellt wird. Der Platoniker Porphyrios demonstriert nämlich in seiner allegorischen Auslegung der homerischen Nymphenhöhle eine durchaus, exklusive' exegetische und somit programmatische Haltung. Im Folgenden sollen anhand von Porphyrios' Exegese der homerischen Nymphenhöhle die von ihm fokussierten Höhlenbilder und -konzepte in den Blick genommen werden. Soweit das möglich ist, wird dabei auch auf Darstellungen von Höhlen resp. Nymphengrotten in der antiken bildenden Kunst verwiesen.

\section{Die Höhle als Symbol des Kosmos}

Entsprechend der von ihm hier gewählten allegorischen Exegese erläutert Porphyrios die homerische Höhle zunächst als Symbol für den Kosmos und verweist dafür auf den Usus der Alten, Höhlen als ganze oder in ihren Teilen dem Kosmos zu weihen (De antro 5) ${ }^{24}$ Die Höhle gilt ihm dabei zunächst als (re-präsentierendes) Symbol ( $\left.\sigma^{\prime} \mu \beta \circ \lambda \circ v\right)$ der Welt überhatupt. ${ }^{25}$ Die Höhle ist demnach eine verrätselte und zu entschlüisselnde Repräsentation oder Bild des Kosmos - Welt, Himmel und Erde sowie den Kreislauf der Seelenwanderung gleichermaßen umfassend. Porphyrios erklärt zuerst unter Berufung auf die $\pi \alpha \lambda \alpha$ o im - im phsikalischen Sinne - die Höhle als Symbol der Materie, aus welcher der Kosmos besteht. Dabei wird eine Gleichsetzung von Erde und Materie nach dem Vorbild des Xenophanes kenntlich. ${ }^{26}$ Die Erde, also die Höhle, erscheint dabei - wie bereits

\footnotetext{
${ }^{24} \mathrm{Zu}$ dieser Vorstellung sowie zu den spirituellen Implikationen siehe SIMONINI 1986, 94f.; siehe ebenso später bei Prokl. In Tim. I, 333,26-334,1 DirHL; siehe auch Prokl. In Remp. II, 31,4-7 KROLL.

${ }^{25}$ Siehe Croms 1970, 146-148 und v.a. 156-158 zum (nicht einheitlichen) SymbolVerständnis bei Porphyrios. Eine Historisierung des dann auch allegorischen SymbolonBegriffes und die damit einhergehende Mystifizierung von dessen Deutung und Bedeutung bietet MürI 1976, 30f.

${ }^{26}$ Xenophanes, fr. 21 A 36. B 27 DK. Ausführliche Belege bei Simonini 1986, 95-97.
} 
bei Pherekydes, ${ }^{27}$ den Porphyrios später (ebd. 31) auch explizit nennt $-^{28}$ als Konkretisierung eines basalen Grundprinzips der Welt, das im Mittelplatonismus als erstes Prinzip resp.

Im Folgenden leitet Porphyrios über zur Erklärung der in Homers Text

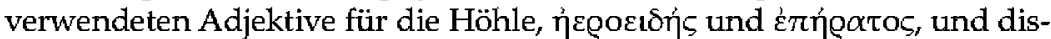
kutiert die mit diesen Begrifflichkeiten einhergehende Ambiguität derselben ( $\$ \S 5$ f.). Obgleich die Höhle also, wie auch der Kosmos, aufgrund ihrer

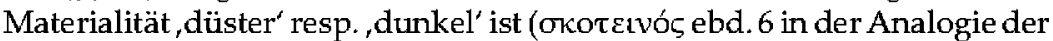
Höhle zum Kosmos), ist sie zugleich auch aufgrund der sich in ihr manifestierenden Verbindung von Materie und ordnunggebender Form ,liebenswert'. Hier (\$ 6) unterscheidet Porphyrios den Eindruck, den die Höhle auf normale Betrachter macht, die sie betreten - ihnen erscheint sie lieblich, während sie denjenigen, welche nach ihrer Ursache forschen, die also tiefer als der Augenschein der Phänomenwelt dringen wollen, ,düster' erscheint. In klarer Abgrenzung von philosophischen Laien, die diese Höhle dem Augenschein nach beurteilen, hebt Porphyrios den tiefer gehenden Blick der Philosophen davon ab, die nicht mit den Augen, sondern mit ihrem Intellekt ( $\tau \bar{\omega} \vee \bar{\omega}, \S 6)$ die Höhle betrachten. Porphyrios formuliert also gleich zu Beginn seiner Abhandlung über die homerische Nymphengrotte eine philosophisch basierte Differenzierung der beiden grundsätzlich möglichen Sichtweisen auf diese Höhle und markiert somit klar deren basale Ambiguität. Auffällig ist in diesem Kontext, dass Porphyrios nicht auf andere Höhlen(-Bilder) verweist, die in der homerischen Odyssee vorkommen: So bleiben etwa Kalypsos reizvolle Höhle (Hom. Od. V 55-74; vgl. IX 30) oder aber die Höhle des Kyklopen Polyphem (ebd. LX 182f. 216f.) unerwähnt ${ }^{30}$ Daran wird deutlich, dass es ihm nicht vorrangig um das Motiv der Höhle als solches oder gar um den Mythotopos ,Höhle' geht, sondern um den (konkreten) Topos der homerischen Nymphenhöhle auf Ithaka als Raum und Projektionsfläche für seine (religions-)philosophische Exegese.

\section{Porphyrios' Abgrenzung vom Mythotopos: Die Höhle als religiöser Raum}

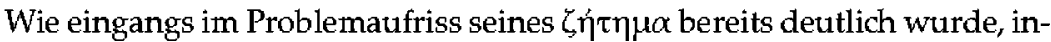
tendiert Porphyrios eine philosophische Analyse ${ }^{31}$ der homerischen Nym-

\footnotetext{
${ }^{27}$ Schibli 1990, 21-27, v.a. 24.

${ }^{28}$ Pherekydes, fr. 7 A 10 DK, siehe Simonini 1986, $96 \mathrm{f}$.

${ }^{29}$ Ausführlich zur philosophischen, mittel- und neuplatonischen Bewertung der $ั \lambda_{\eta} /$ Materie siehe Simonini 1986, 98-101.

${ }^{30} \mathrm{Vgl}$. auch das Bild der Höhle im Fledermausgleichnis Od. XXIV 6-9

${ }^{31}$ So mit R. Lambirton, "Sweet Honey in the Rock: Pleasure, Embodiment, and Metaphor in Late-Antique Platonism”, in: J. I. Portbr (Hg.), Constructions of the Classical Body (Ann Arbor 1999) [314-326] 318.
} 
phengrotte, die für ihn ein ,Symbolon' uralter Sophia ist, die sich bei Homer artikuliert. Es geht ihm nicht um den vordergründig-phänomenalen Augenschein dieser Höhle, sondern um die intellektuelle Erfassung und Deutung der mit der Höhle gebotenen Zeichen. Das wird deutlich, etwa wenn er (\$ 6) den, liebenswerten' Charakter der Höhle auf ihre Teilhabe an den Ideen zurückführt und somit einmal mehr $^{32}$ basierend auf mittelplatonischen Prämissen klar platonisch (hier prinzipientheoretisch) argumentiert. Seine exegetische Fokussierung zeigt sich nicht zuletzt in seiner Erklärung der als ,düster' beschriebenen homerischen Nymphengrotte, da er die Dunkelheit als Symbol des Kosmos resp. seiner Eigenschaften als Materie herausstellt. Porphyrios stellt nun die Höhle in einen erklärt religiösen, sogar mystischen Zusammenhang, da er auf den bei den Persern ${ }^{33}$ (offenbar damals noch) gepflegten Usus verweist, Mysten in einer als Höhle bezeichneten Lokalität herunter- und wieder hinauf zu führen (in Analogie zum Eingang der Seele in den Körper und ihrem Verlassen desselben). ${ }^{34}$ Dieser rituelle Usus wird auf Zoroaster zurückgeführt, als Gewährsmann für dieses Faktum verweist Porphyrios auf den Platoniker Eubulos, einen Zeitgenossen Longins und Plotins, der als Diadochos Inhaber eines der kaiserlich subventionierten Lehrstühle in Athen war. ${ }^{35}$ Nicht zuletzt der unmittelbar (\$ 6) anschließende Verweis auf Zoroaster und den durch ihn initiierten Usus, zu Ehren des Gottes Mithras in Höhlen symbolträchtige Arrangements von Dingen vorzunehmen, kurz: Höhlen im Mithraskult in ihrer Funktion als Symbola des Kosmos zu sehen, ist bedeutsam. Porphyrios verschiebt nämlich so seine allegorische Interpretation der Höhle als Symbol des Kosmos nun über die Erwähnung von dunklen Höhlen in Mysterienkulten dezidiert in den religiösen Bereich.

Höhlen, die im Mithraskult eine über das Atmosphärische hinausgehende, vielmehr auf dem Stifterkult beruhende mythische Fundierung hatten, dürften m.E. Porphyrios, der mindestens fünf Jahre seines Lebens in Rom verbrachte, ${ }^{36}$ wohlbekannt gewesen sein. Im ganzen römischen Reich wie in Rom selbst waren seit dem 1. Jh. etliche Mithraskulthöhlen (speluncae) verbreitet, die - meist künstliche Höhlen - als Orte der Kultausübung

\footnotetext{
${ }^{32}$ Vgl. § 5f. zur Materie.

${ }^{33}$ Die Perser gelten den kaiserzeitlichen und spätantiken Platonikern (ähnlich wie die Chaldäer, Mager, Inder, Ägypter) als würdige Ethnie, die im Besitz uralter Weisheit ist; sie

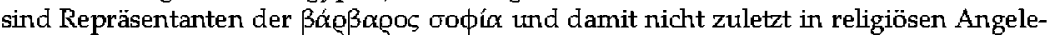
genheiten autoritativ, siehe ERLER 2001, 321f.

${ }^{34}$ De antro 6. Ausführlicher zum Ritual siehe GoRdon 2001.

${ }^{35}$ Siehe auch Porph. Abst. IV 16,2, wo Eubulos als Autor einer Mithrasgeschichte genannt ist; zu Eubulos siehe SimONINI 1986, 101-103; Brisson 2000; vermutlich handelt es sich dabei um den Platoniker, mit dem auch der Lehrer des Porphyrios, Longin, korrespondiert, dazu MäNNLEIN-ROBERT 2001, $187 \mathrm{f}$.

${ }^{36}$ Siehe Goulet 2012, 1293-1295.
} 
dienten. ${ }^{37}$ Wenn Porphyrios tatsächlich selbst in die Mithrasmysterien eingeweiht war, ${ }^{38}$ wusste er sicher, dass mithräische Höhlen basierend auf orientalischem Sternglatuben auch die Himmelssymbolik (und den Zodiakus) aufnahmen, ${ }^{39}$ die in De antro nicht nur mit Blick auf die Allegorese der Höhle als Symbol des Kosmos (s.o.), sondern auch für die folgenden astrologischen Ausführungen des Porphyrios eine wichtige Rolle spielt. ${ }^{40}$ In diesem Zusammenhang sei auf das unterirdische Hypogäum des Aurelius in der Via Manzoni in Rom aus dem 1. Jh. n. Chr. verwiesen: Dieses enthält ein Fresco, das nach Valérie Daniel und Marzillo (zumindest im unteren Bildteil des Frescos) als ikonische Umsetzung der homerischen Nymphengrotte interpretiert werden kann. ${ }^{41}$ Aber auch das Mithräum der ,Sieben Sphären' in Ostia scheint weitestgehend auf die von Porphyrios gebotene Beschreibung (vor allem aus $\$ 24$ ) zu passen. ${ }^{42}$

Die hier in Kapitel 6 formulierte Deutung der lieblich-dunklen Höhle als Symbol des Kosmos und der Welt ist der erste Schritt in Porphyrios' eigener religionsphilosophischer Allegorese des homerischen Bildes, wie er das wenig vorher angekündigt hatte (\$4). In ausschließlicher Konzentration zunächst auf die physikalische, dann die religiöse Deutung dieses Symbolons präsentiert der Philosoph seine Interpretation des Homertextes - die nahe liegenden Analogien und Motivparallelen hinsichtlich anderer mythischer Höhlen bei Homer oder aus der literarischen Tradition ${ }^{43}$ blendet Porphyrios hier aus.

Vor diesem Hintergrund zeichnet sich nun eine bestimmte exegetische Perspektive ab: Es geht Porphyrios weniger um eine umfassende Deutung des homerischen Passus mithilfe vergleichbarer Darstellungen bei Homer (im Sinne eines Homerum ex Homero), sondern um die demons-

\footnotetext{
${ }^{37}$ Siehe De antro 20. Zu Mithrashöhlen siehe Boyancé 1960; Clauss 2012, 48-64; weitere Literatur bei EgBLHAAF-GAISBR / RüPKB 2000, 169 mit Anm. 39. Zu den etwa in Rom bekannten Mithräen, z.B. unter San Clemente, Santa Prisca, unter den Caracalla-Thermen, beim Circus Maximus oder unter dem Palazzo Barberini siehe ausführlich I. Della Portblla, Subterranean Rome (Köln 2000); siehe auch MAURETTE 2005, 68. 76.

${ }^{38}$ Das vermutet Christoph Riedweg, wohl aufgrund des Detailwissens des Porphyrios über diesen Mysterienkult, siehe den Beitrag von Christoph Riedweg in ciesem Band, S. 87 mit Anm. 63.

${ }^{39}$ Zum Mithräum als ,kosmischem Bild‘ siehe Brck 1994, 103. 108. Zu den kosmischen Zeichen in den bekannten Mithräen siehe CIMRM I Nr. 75 (= Fig. 26). 810 (Fig. 218); II Nr. 1137 (= Fig. 296). 1292 (Fig. 340). Siehe den Beitrag von Benjamin Topp in diesem Band, S. $131-133$.

${ }^{40}$ EgrlhaAf-Gaiser / RüpKe 2000, 170. Zur Bedeutung dieses Passus aus De antro als singulärem literarischen Beleg für den sonst fast ausschließlich archäologisch erschließbaren Mithraskult siehe z.B. SfAMENI GASPARro 1979, 317f. und v.a. BвCK 2006, 17.

${ }^{41} \mathrm{Abb}$. bei Marzillo 2013, 229. Siehe V. Danibl, "Une fresque du viale Manzoni expliquée par un texte de Porphyre", Revue Belge de Philologie et d'Fistoire 3 (1924) 703-711; Marzillo 2013, 228-230.

${ }^{42}$ Dazu siehe Bвск 1994, 106-109.

${ }^{43}$ Siehe Ustinova 2009, 184-217.
} 
trative Inanspruchnahme eines alten Exemplums - der Beschreibung der Nymphengrotte in der Odyssee Homers - für eine Homer noch vorgängige, sogar überzeitliche Sophia. Das Bild der Höhle wird mittels platonischer (inklusive pythagoreischer) Prämissen, Vorstellungen und Konzepten dechiffriert und im Kontext der Exegese zu einem religionsphilosophischen ,Schaubild' gemacht.

\section{Die Höhle als Raum der Schwelle und des Übergangs: Mithraskult - Katabaseis}

Die Dunkelheit der natürlichen wie der künstlichen Höhle, die im Kontext von Mysterienritualen etwa des Mithras eindrïckliche psychologische Effekte hervorruft, ist für Porphyrios im Kontext seiner allegorischen Deutung ein wichtiges Argument. Denn die Höhle ist nicht nur im persischen Kontext oder im Mithraskult, sondern auch in der griechischen Religion, etwa in griechischen Orakel- und Mysterienkulten, ein religiös bedeutsamer Raum: Die natürlicherweise eher dunkle Höhle oder ein vergleichbarer, nach außen nichteinsehbarer Raum, wie z.B. ein Adyton, dient in solchen Kontexten als psychologisch wirkungsvoller Raum des Übergangs in außergewöhnliche, suprarationale Zustände (z.B. Enthousiasmos; Ekstasis; Seelenreisen), ${ }^{\mathbf{4}}$ in denen neue Formen der Kommunikation mit Göttern und Wahrnehmung des Göttlichen erfahrbar und im Ritual wiederholbar gemacht werden. ${ }^{45}$ Die im Ritual eines Mysterienkultes funktionalisierte Höhle erweist sich als Raum des Übergangs und der Schwelle, als liminaler Raum zwischen Leben und Tod ganz in Übereinstimmung mit den von Anthropologen wie Victor Turner und Arnold van Gennep formulierten Charakteristika von, rites de passage'. ${ }^{46}$ Als besonders prominentes Beispiel sei das vor allem beim Mittelplatoniker Plutarch eindrücklich beschriebene Trophoniosorakel in Lebadeia in Böotien genannt: Dort mussten die Orakelbefrager in eine unterirdisch gelegene Höhle hinabsteigen und erlebten dort im Prozess eines festgelegten, rite de passage' ekstatische Seelenzustände. ${ }^{47}$ Höhlen sind in jedem Fall aufs Engste mit der Vorstellung von Katabasis und Anabasis verbunden, die im Mythos (z.B. im

\footnotetext{
${ }^{44}$ Dazu ausführlicher M. ElIADE, Schamanismus und archaische Ekstasetechnik (Frankfurt/M. 1975) 374f. und v.a. Ustinova 2009, 13-28. 47-51.

${ }^{45}$ Mit Blick auf den Usus z.B. im Apollonorakel in Delphi siehe Diod. XVI 26; ausführlicher MäNNLEIN-Robert 2012a, 109 .

${ }^{46} \mathrm{Vgl}$. V. Turner, Das Ritual. Struktur und Anti-Struktur (Frankfurt/M. 2005; The Ritual Process. Structure and Ant istructure, New York $\left.{ }^{1} 1969\right)$ 94-111; A. van Gennep, The Rites of Passage (London 1960; Les rites de passage, Paris ${ }^{1} 1909$ ); siehe auch Männ Lein-Robert 2012a, 110.

${ }^{47}$ Plut. Gen. 21f.; siehe auch Paus. IX 39,5-14.
} 
Falle des Odysseus, Herakles, Orpheus) ${ }^{48}$ recht konkret geschilderte Jenseitsreisen, in religiösen Kontexten dagegen Seelenreisen vom Diesseits ins Jenseits und umgekehrt beschreiben. Auf das Phänomen der Katabasis hatte Porphyrios bereits explizit angespielt, als er zu Beginn von De antro die

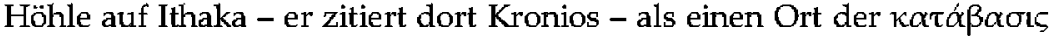
für Götter und Menschen im Kosmos darstellte (De antro 2), freilich ohne das dort ausführlicher zu erklären. Im Kontext von Kapitel 6 stellt er das Phänomen der Katabasis implizit (siehe ká $\theta \circ \delta \circ$, § 6; vgl. § 3), aber deutlich in einen religiösen Kontext, indem er die Einweihung von Mysten in persischen Kulten, spezieller im Mithraskult erläutert $\left(\$ 6\right.$, s.o.)..$^{49}$

Obwohl Porphyrios an dieser Stelle auf den Umstand zu sprechen kommt, dass die Höhle seit alters als dunkel-geheimnisvoller Raum eine religiöse Semantik hat, erwähnt er hier nicht die zahlreichen Figuren und Persönlichkeiten der antiken Literatur und Philosophie, mit deren Namen der meist religiös motivierte Aufenthalt in einer Höhle traditionell verbunden wird. Die Höhle erweist sich in den tradierten Episoden stets als Ort der Schwelle und des Übergangs, etwa des Übergangs vom Nicht-Wissen zum Wissen, vom menschlichen zum göttlichen Wissen, vom Leben zum Tod und umgekehrt oder von einer märchenhaften Sphäre in die konkrete Lebenswelt. So ist etwa bei allegorischer Leseweise von Homers Odyssee (XIII 102-112) auch die Nymphengrotte beim Hafen des Phorkys ein Raum des Übergangs oder der Schwelle, da Odysseus, frisch aus der surrealen Märchenwelt der Phaiaken zurückgekehrt, nun seit langem erstmals wieder in der ,realen' Welt, noch dazu der ersehnten Heimat, angekommen

\footnotetext{
${ }^{48} \mathrm{Zu}$ Odysseus siehe I. MÄNNLBIN-RoBeRT, „Vom Mythos zum Logos? Hadesfahrten und Jenseitsreisen bei den Griechen", in: J. Hamm / J. RoBerT (Hg.), Unterwelten. Modelle und Transformationen. Würzburger Ringvorlesungen Bd. 9 (Würzburg 2014) [31-58] 32-47; zu Herakles siehe Pausanias, der die noch im 2 . h. n. Chr. bei Voura in Achaia gezeigte Höhle der Katabasis des Herakles zu Kerberos erwähnt (Paus. II 35, 10) und Hom. Il. VIII 366-369; Od. XI 623-626; der seit dem 6. Th. v. Chr. (Pind. Pyth. 4,177) bekannte mythische Musiker Orpheus steigt in den Hades hinab, um seine verstorbene Gattin Eurydike mit hinauf zu nehmen (siehe z.B. Eur. Alc. 357-362; Hipp. 952-954, Cycl. 646; sowie Isocr. or. 11,7f.; Plat. Symp. 179d, wo Orpheus' Hadesfahrt kritisiert wird). Aus späteren Quellen (etwa Suda

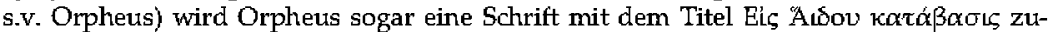
geschrieben (= fr. 1 A 1 DK). Im selben Kontext sind wohl die späteren orphischen Texte zu interpretieren, denen zufolge die Katabasis des Orpheus dem Zwecke umfassender Erkenntnis überhaupt diente, vgl. Orphic fr. 113 KRRN $(=4$ B 2 Colli $=536$ T. I, 1033 T. I, 1070 T. Bernaé́) und Orphic. fr. 33 KeRN ( $=4$ B II CoLli $=407$ F. I BernABÉ). Auch die sog. orphischen Goldblätchen mit ihren Anweisungen über die Topographie des Hades gehört in diesen Kontext. Umfassend dazu ist Ch. RIBDwBG, "Orpheus oder die Magie der musiké. Antike Variationen eines einflussreichen Mythos", in: Th. Furrer / P. Michbl / P. Stotz (Hg.), Geschichten tnd ihre Geschichte (Basel 2004) [37-66] 49-5I.

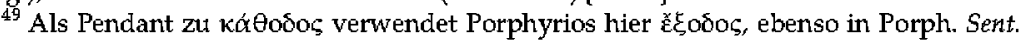
29, 19,14 LAMBERZ; Ch. Riedweg (siehe seinen Beitrag in diesem Band, S. 79 mit Anm. 13) verweist überdies auf ein im Mithrätm in Dura-Europos nachweisbares Graffito eľooбoc / žodo (CIMRM I Nr. 66) und auf VeRMASBREN / VAN EssEN 1965, 197.
} 
ist, seine Ankunft aber noch unbekannt ist und es ja auch bleiben soll. Odysseus befindet sich also gleichsam an der Küste seiner Heimatinsel, hat sich diese noch nicht zurückerobert, steht noch , an der Schwelle, ${ }^{50}$ Darüber hinaus gibt es im griechischen Mythos wie in der Literatur etliche Helden, die nach einem temporären Aufenthalt aus einer Höhle mit neuen, übermenschlichen Erkenntnissen als nunmehr ,göttliche' Weise zurückkehren. ${ }^{51}$ Die Katabasis ist also überaus häufig als Jenseitsreise oder -kontakt zu verstehen, der in einer Höhle stattfindet: Die Höhle symbolisiert dabei einen abgelegenen, besonderen Raum, in dem die Seele im Zustand der Ekstasis den Körper verlassen kann, in dem sie Kontakt mit dem Göttlichen oder mit Göttern aufnimmt. Immer geht es um das Eingehen der Seele in die göttliche Sphäre eines Jenseits, um göttliches Wissen, um das Mysterium der Wiedergeburt, kurz: um die Unsterblichkeit der immer wieder eingekörperten Seele, die konkret mit der Wiederkehr aus einer Höhle beschrieben oder als solche inszeniert wird.

Porphyrios kennt sicherlich die hier skizzierte Semantik der Höhle als Schwellenraum zwischen Leben und Tod, Bewusstsein und Trance, zwischen Diesseits und Jenseits, wie er das ja mit seinem exemplarischen Verweis auf die Initianden des Mithraskultes sowie auf persische Kulte zu verstehen gibt. Die legendenhaft überwucherte, vielfach anekdotische griechische Tradition, in der Höhlen zum topischen Ort suprarationaler Kontakte mit dem Göttlichen werden und im Volksglauben als heilige Stätten verehrt werden (s.u.), dürfte seinem strengen exegetischen Gestus der Präsentation in De antro jedoch gegenläufig gewesen sein.

\section{Die Höhle als Heiligtum oder Tempel}

Porphyrios führt weiterhin (\$ 6) eine Art rücklätufiger historischer Betrachtung über Räume und Stätten der Verehrung für Götter aus, in die er auch Höhlen einordnet. Zusammen mit seinen Angaben ats Kapitel 20, wo er dieses Thema ernetut aufgreift, ergibt sich Folgendes: In der Zeit nach Zoroaster hätten auch andere (Ethnien oder Kultgemeinschaften) ${ }^{52}$ Höhlen und Grotten als Rätume für Mysterienweihen/Initiationsriten genutzt. Als analoge Beispiele verweist Porphyrios hier daratf, dass es für die olympischen

\footnotetext{
${ }^{50}$ Ausführlicher dazu Marzillo 2013, $219 \mathrm{f}$.

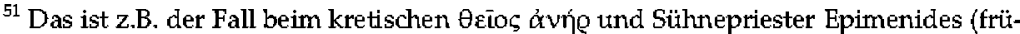
hes 6. Jh. v. Chr.), der bei einem 57 Jahre langen Schlaf in einer Höhle in göttlichen Sphären belehrt worden sein soll (Diog. Laert. I 109-115 = fr. 3 A 1 DK; Plat. Leg. I 642d); vgl. auch Minos (Pind. Olymp. 5,18; Diod. V 70, 2. 4; Plat. Leg. I 624a-b; Ps.-Plat. Min. 319e) und Pythagaras (Porph. VPyth. 9; Diog. Laert. VIII 21 = Hieronymos von Rhodos [ff. 42 WeHRLI] Diog. Laert. VIII 41 [Quelle Hermippos, fr. 20 W EHRLI]) sowie Zalmoxis (Hdt. IV 95), dazu RIEDWEG 2002, 24. 78f.

${ }^{52}$ So BoYanCÉ 1960, 124f.
} 
Götter Tempel, Götterstatuen und feste Altäre, für die irdischen (hier wohl: chthonischen) Götter und Heroen nicht-befestigte Brandstätten und für die unterirdischen Götter Bothroi/Gruben und Schächte als Stätten der Verehrung und der Kultausübung gebe. Darüber hinaus macht er aber deutlich, dass Höhlen als Kultorten ein besonders hohes Alter zukommt, dass es sich bei Höhlen nicht nur um vorhomerische, sondern auch um prähistorische

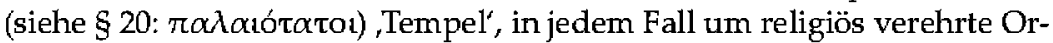
te handelt. Als Beispiele führt er (ebd.) die Zeus geweihte (Dikte-)Höhle der Koureten auf dem Berg Ida auf Kreta an, ${ }^{53}$ ebenso eine der Selene und dem Pan Lykeios geweihte Höhle in Arkadien (gemeint ist hier die beim Berg Lykaion) ${ }^{54}$ eine Dionysos-Höhle auf Naxos ${ }^{55}$ und die weit verbreiteten Mithrashöhlen. Nicht nur Naturgottheiten wie Naiaden resp. Nymphen werden mit Höhlen assoziiert, ${ }^{56}$ sondern auch olympische Götter wie Zeus und Dionysos oder Gottheiten wie Selene und nicht zuletzt das hybride Mischwesen Pan. ${ }^{57}$ Mit Blick auf diese Ausführungen des Porphyrios wird deutlich, dass ihm Höhlen als kulturelles Faktum, als vorhomerische und damit gleichsam prähistorische (Tempel-)Räume für Ritual und Kult wohlvertraut sind und er dies auch bei seinen Rezipienten entsprechend voraussetzen kann.

Tatsächlich sind im gesamten griechischen Kulturraum zahlreiche Höhlenheiligtümer als Stätten kultischer Verehrung von Gottheiten, als Geburts-, Wohn- oder Grabstätten von Göttern, seit der Bronzezeit anhand archäologischer Funde nachweisbar. Ausgesprochen viele Höhlen sind , den Nymphen und Pan' geweiht. ${ }^{58}$ Eine der berühmtesten ist die Korykische Höhle, oberhalb von Delphi im Parnass-Gebirge gelegen (Paus. X 32,5-7) und nach Koryka, einer von Apollon geliebten Nymphe, benannt. Dort

\footnotetext{
${ }^{53}$ Diese wird seit der Bronzezeit als religiöser Ort kenntlich; dem Mythos zufolge soll der neugeborene Zeus vor seinem gewalttätigen Vater Kronos versteckt, sein Babygeschrei durch Tanz und Trommeln der Koureten übertönt worden sein, siehe z.B. Diod. V 70,2.4; viele Belege bei Simonins 1986, 186f. Leicht könnte Porphyrios an dieser Stelle darauf verweisen, dass gerade diese Höhle nicht nur als Ort der Erleuchtung des Pythagoras (Porph. VPyth. 17; Diog. Laert. VIII 3), sondern auch als literarischer Ort in Platons Werk (in den Nomoi als Ziel des Spaziergangs; vgl. Ps.-Plat. Minos) eine erhebliche raumsymbolische Relevanz hat, dazu MänNLBIN-RoEBRT 2012b, 18f.

${ }^{54} \mathrm{Zu}$ der nur hier überlieferten Kultgemeinschaft von Selene und Pan siehe SIMonINI $1986,187 \mathrm{f}$

${ }^{55}$ Zur Erziehung des Dionysos durch Nymphen als Ammen in einer Höhle auf Naxos siehe BoyancB́ 1960, 112f; inschriftlich ist für Mitglieder des Dionysos-Thiasos der Titel $\alpha v \tau$ ¿́ov́ $\lambda \alpha \kappa \varepsilon \zeta$ belegt, dazu sowie zu Dionysos-Höhlen siehe ausführlich Boyancí 1960.

${ }^{56}$ Indem Porphyrios $(\$ 6)$ die Naiaden gleichsam etymologisch mit dem in der Höh-

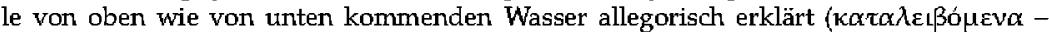

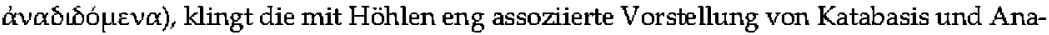
basis einmal mehr an.

${ }^{57}$ Eine in Lebadeia in Böotien gefundene Inschrift nennt die Nymphen, Pan und Dionysos zusammen (IG VII 3092), dazu BoyANĆ́ 1960, 113f.

${ }^{58}$ Siehe dazu ausführlicher Ustinova 2009, 55-68.
} 
ist uralte kultische Verehrung bis in die Kaiserzeit hinein nachweisbar. ${ }^{59}$ Nicht zuletzt wird auch der arkadische Gott Pan, ein hybrides, animalischvegetative Tendenzen verkörperndes Wesen, zusammen mit Nymphen in Höhlen verehrt, so z.B. ${ }^{60}$ am Hang der Athener Akropolis oder - ein besonders berühmtes Beispiel - in der sog. Pan-Höhle von Vari in Attika, für die nicht nur kultische Verehrung, sondern sogar musikalische Kulthandlungen für Pan archäologisch bezeugt sind. ${ }^{61}$ Hier brachte ein gewisser Archedamos von Thera (im späten 5. oder frühen 4. Jh. v. Chr.) zahlreiche Votivtafeln an, um seine religiöse Reverenz gegenüber den Nymphen und Pan zu dokumentieren. Auf einem Ex-Voto bezeichnet er sich

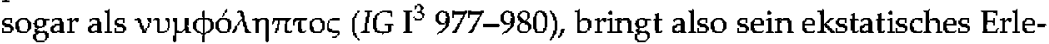
ben und sein hier in dieser Höhle erworbenes höheres Wissen zum Ausdruck, das er auf das göttliche Wirken der dortigen Nymphen zurückführt. Darüber hinaus scheint mit Blick auf die von Porphyrios erklärten Details der homerischen Nymphengrotte bedeutsam, dass Archedamos diese natürliche Höhle, in der über Stalaktiten beständig Wasser rinnt, verschönert und ausgeschmückt hat: So gravierte er selbst (nicht besonders kunstfertig) Selbstporträts auf innere Höhlenwände oder meißelte eine auf einem Thron sitzende Figur (wohl eine Nymphe) sowie einen Omphalos im Inneren der Höhle aus dem Fels, ${ }^{62}$ trug also durch (mehr oder weniger) kunstvolle Bearbeitung des natürlichen Höhlenraumes zu einer individuellen Semantik desselben bei. In einer bei Lykosoura in Arkadien gelegenen Höhle wurden zuerst die Prophezeiungen gebende Nymphe Erato und Pan, ab dem 2. Jh. n. Chr. nur noch Pan verehrt, wie die Inschrift П $\alpha$ vó fenbar bezeugt. ${ }^{63}$ Während nun im Volksglauben und in der traditionellen, mythisch überformten griechischen Religion der wilde Hybrid-Gott Pan in Naturorten wie Höhlen wohnt und verehrt wird, dürfen wir es m.E. dem Philosophen Porphyrios durchaus zutrauen, dass er hier die nahe liegende Transponierung vom konkreten Höhlen-Gott Pan zum abstrakten, als ,All' zu verstehenden ,Kosmos', der sich in Höhlen symbolisch abbildet (s.o.), im Hinterkopf hat - er wird sie aus den einschlägigen ,orphischen' (Kon-) Texten kennen -, ${ }^{64}$ aber vermutlich atus denselben Gründen wie oben - in

\footnotetext{
59 Ausfïhrlicher sind Ustinova 2009, 65-68 und LARson 2001, 234-238.

${ }^{60}$ Siehe aber auch zur Parmes-Höhle in Attika, die in Menanders Dyskolos eine Rolle spielt, Ustinova $2009,57$.

${ }^{61}$ Ausführlich dazu siehe G. Schörner / H. R. GöTte, Die Pan-Grotte von Vari. Mit epigraphischen Anmerkungen von K. HaLLof. Schriften zur historischen Landeskunde Griechenlands I (Mainz 2004) und. LARSON 2001, 242-245.

${ }^{62}$ Mit reicher Literatur dazu siehe Ustinova 2009, 61-64.

63 So Paus. VIII 37; dazu Ustinova 2009, 56f. Weitere, den Nymphen und Pan geweihte Kulthöhlen in Griechenland beschreibt LARson 2001, 232f. 238-258.

${ }^{64}$ Soz.B. Orph. hymn. 11 oder fr. 54 KERN, weitere Belege bei BơANcí 1960, 125 mit Anm. 70 und bei Simonini 1986, $105 f$.
} 
Vermeidung jeglicher volkstümlicher Legenden, Kulte oder Mythen - einen expliziten Verweis darauf ausspart.

Die Höhle als Symbol, konkreter: als gleichsam prähistorischer Tempel des Kosmos, erweist sich vor dem skizzierten Hintergrund als zwar alte, in der Volksreligion und in landläufigen Mythen bekannte, in der realen Lebenswelt verankerte Vorstellung, wird aber bei Porphyrios ganz selektiv ${ }^{65}$ und programmatisch ausschlieslich als religionsphilosophisches Faktum verhandelt und in den Kontext weitreichender philosophischer und astrologischer Interpretationen gestellt (vor allem ab § 10). ${ }^{66}$ Porphyrios, der etliche Jahre (262/263-ca. $268 \mathrm{n}$. Chr. und vermutlich in den letzten Dekaden des 3. Jh.s wieder) in Rom lebte, ${ }^{67}$ kannte mit Sicherheit das dortige Pantheon (ursprünglich des Agrippa), im Wesentlichen ein hadrianischer Bau. Das Pantheon, ${ }^{68}$ also die Gesamtheit aller Götter, wurde als Tempel für alle Götter im Kosmos konzipiert; dabei wird die räumliche Gestaltung maßgeblich von der als Halbkugel gestalteten Decke dominiert, die sich über dem ganzen Rundbau wölbt. ${ }^{69}$

\section{Die Höhle als Symbol der unsichtbaren kosmischen Kräfte}

In einem neuen Anlauf geht Porphyrios einen Schritt weiter (\$ 7): In Anknüpfung an den bereits erklärten Gedanken, die Höhle sei Symbol des - sinnlich wahrnehmbaren ( $\alpha i \sigma \theta \eta \tau o ́ s)$ - Kosmos, fügt er nun hinzu, dass die Höhle den Alten zufolge eben auch ein repräsentierendes

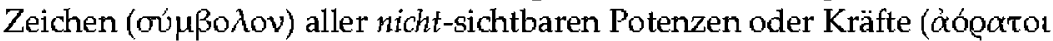

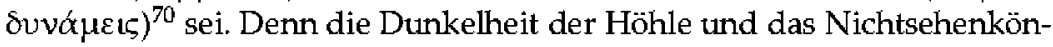

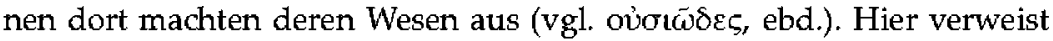
Porphyrios auf mythische, wohl allegorisch zu lesende Beispiele aus ,theo-

\footnotetext{
${ }^{65}$ Vgl. z.B. Longos' erotischen Roman Daphnis und Chloe, wo die Protagonistin als Neugeborenes in einer liebevoll ausgestalteten Nymphenhöhle gefunden wird, welche deutlich die homerische Nymphengrotte anzitiert (Longos I 4); dazu Larson 2001, 56-58. Porphyrios ist freilich ausschließlich an religiösen Konnotationen der Höhle irteressiert.

${ }^{66}$ Das bildhafte Verständnis vom Kosmos als oโro $\varsigma$ findet sich im platonischen Kontext der Kaiserzeit bereits bei Plutarch (Trang. anim. 20, 477C-D), dazu siehe Alt 1982, 274; vgl. ähnlich Plot. IV 3,9,29; 4,36,10, dazu siehe Hirschle 1979, 42.

${ }^{67}$ Zur Rekonstruktion der Biographie des Porphyrios siehe Goulet 2012, 1293-1295.

${ }^{68}$ Der Titel ,Pantheon' wird z.B. bezeugt bei Plin. Nat. XXXVI 38 (Agrippae Pantheum decoravit Diogenes Atheniensis, "Für Agrippa hat Diogenes aus Athen das Pantheon ausgeschmückt").

${ }^{69}$ Nach ZвpF 1958, 373 ist ${ }_{r}$ der Tempel ... zum Kosmos geworden". Dass dieser Bat bereits in der Antike entsprechend. wahrgenommen wurde, bezeugt etwa Cassius Dio (LIII 27,2). Ausführlich zum Pantheon ist W. Martint, Das Pantheon Hadrians in Rom. Das Bathwerk und seine Deutung (Stuttgart 2006).

${ }^{70}$ Siehe Plat. Tim. 52a, wo diese Beschreibung u.a. für die intelligiblen Ideen verwendet wird, dazu Simonini 1986, 106f.
} 


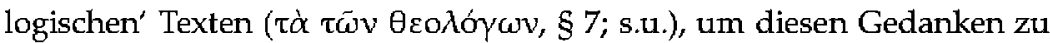
illustrieren: So habe etwa Kronos seine Kinder in einer selbstgebauten Höhle im Okeanos versteckt oder Demeter ihre Tochter Persephone mit Nymphen in einer Höhle erzogen. ${ }^{71} \mathrm{Im}$ Anschluss zitiert er einen Passus aus einem sonst unbekannten Apollon-Hymnos, ${ }^{72}$ der noch einmal das bisher Gezeigte poetisch illustriert, nämlich dass Höhlen Nymphen geweiht sind, die als von den Musen zu göttlichem Gesang inspirierte Urheberinnen von Quellen und somit als segensreich für die Menschen anzusehen sind.

Mit diesem Gedanken nimmt Porphyrios eine beträchtliche, philosophisch bedeutsame Erweiterung der bisher verfolgten These von der Nymphengrotte als Symbol des Kosmos vor: Denn indem er die homerische Nymphengrotte auch als Ort der nicht sinnlich wahrnehmbaren, aber faktischen göttlichen Präsenz ansieht, nimmt er zum einen eine Korrektur des eingangs geschilderten, auf Kronios basierenden Gedankens vor ${ }_{r}^{73}$ wonach die Höhle (nur) als Symbol der materiellen, also sinnlichwahrnehmbaren Welt zu verstehen sei, zum anderen kann er basierend auf dieser zusätzlichen Prämisse nun genuin platonische, den intelligiblen Kosmos der Ideen betreffende Überlegungen in seine allegorische Exegese integrieren, wie er das in ganz ähnlicher Methodik auch in seiner Schrift Пepì $\dot{\alpha} \gamma \alpha \lambda \mu \alpha \dot{\alpha} \omega \omega v$ unternimmt; dort vertritt er die Ansicht, dass die sinnlich wahrnehmbaren Götterbilder auf das nicht-sichtbare Göttliche verweisen. ${ }^{74}$ Allerdings verweist Porphyrios durch die gewählten mythischen Beispiele aus den zitierten ,theologischen' Texten darauf, dass jeweils mit der Höhle (im Fall des Kronos wie der Demeter) nicht nur die Sphäre des Nicht-Sinnlich-Wahrnehmbaren, sondern vielmehr auch die Sphäre des Hades gemeint ist, dessen etymologische Varianten allesamt um Nicht-sehen-Können oder Nicht-gesehen-Werden kreisen. ${ }^{75}$ Vermutlich sind diese Beispiele mit Bedacht auf das gesamte Thema der Seelenwanderung in De antro gewählt, denn dort ist die Höhle sowohl für die

\footnotetext{
${ }^{71}=$ Orph. fr. 279 F III BERNABÉ; vgl. auch ebd. 209 F I.

${ }^{72}$ PLG III, 684 BERGK.

${ }^{73} \mathrm{Vgl}$. die deutliche Kritik des Porphyrios an Kronios z.B. in De Styge (372F.,442f.,10-14 Sмгтн), dazu Alt 1998, 469 mit Antm. 9.

${ }^{74}$ Dazu I. Männlein-RoEkRT, „Porphyrios und die alten Götter: Zeichen deuten - Zeichen setzen", in: dies. (Hg.), Die Christen als Bedrohung? Text, Kontext und Wirkung von Porphyrios ' Contra Christianos. Roma aeterna 5 (Stuttgart 2017) [177-206] 186-190.

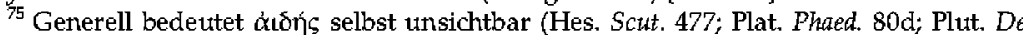
E 21, 394A); im Hades ist nichts zu sehen (Plat. Crat. 403a), dort kann man auch selbst nicht gesehen werden (Plat. Gorg. 493b4f.); Hades ist selbst blind (so LSJ s.v., IG IV ${ }^{2}$ I,I2I Nr. 20, s.o.), ausführlicher siehe I. MäNNLEIN-Ro BerT / O. SCHELSKE, "Kommentar zum ps.platonischen Axiochos" ${ }^{\prime \prime}$, in: I. MännLeIn-Robert (Hg.), Ps.-Platon, Über den Tod. SAPERE 20 (Tübingen 2012) [60-95] 67 Anm. 29. Zum Hades als Höhle (ớv toov) vgl. Hom. Od. XXIV 6-9 und siehe die Beispiele oben Anm. 51 .
} 
Kinder des Kronos also auch für Persephone nur ein temporärer Aufenthaltsort.

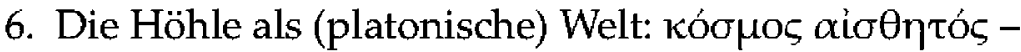 кóouos vơtós}

Die integrative Sicht auf die Höhle ist Porphyrios zufolge nun bei den Schülern und Anhängern des Pythagoras und seiner Philosophie und nicht zuletzt bei Platon nachweisbar. Diese basieren hier auf o.g. Lehre der nicht näher spezifizierten Theologen, die in der Regel als Orphiker gelten. Mit Blick darauf, dass aber bereits seit Aristoteles die von den фvotódoyor abgesetzten, wohl auch zeitlich früher gedachten $\theta \varepsilon$ dóoyo t Homer, Hesiod, Orpheus und Musaios umfassen, ${ }^{76}$ erscheint es naheliegend, nicht nur (neu-)pythagoreische Texte oder Schriften wie die Chaldäischen Orakel, sondern auch die poetischen, alte Sophia enthaltenden, symbolisch kodierten Epen Homers und Hesiods im Kontext von Schriften, die um Seele und Götter kreisen, neben den sonst hier allgemein identifizierten orphischen Schriften anzunehmen. ${ }^{77}$ Außerdem muss ziemlich sicher auch Pherekydes zu den von Porphyrios in De antro genannten $\theta \varepsilon$ códoyo gerechnet werden: Denn Porphyrios bezieht sich auf einen Vorläuferkommentar des pythagoreisierenden Platonikers Kronios, der in der Tradition des Numenios steht. Dieser nun hatte einen allegorischen Kommentar über die $\theta \varepsilon \hat{\lambda} \lambda$ oүot und dabei vor allem über Pherekydes verfasst, der als erster Vertreter von Seelenwanderungsvorstellungen gilt - nicht zuletzt im Zusammenhang mit Höhlen, die nach Pherekydes Wege der Seele in die Welt und aus der Welt seien. ${ }^{78}$ Wir dürfen daher annehmen, dass Porphy-

\footnotetext{
${ }^{76}$ Zur Ambiguität bei Platon hinsichtlich des Begriffes $\theta \varepsilon 0 \lambda$ o $\gamma$ í $\alpha$ siehe I. MänNLBINRobrRT, „Umrisse des Göttlichen: Zur Typologie des idealen Gottes in Platons Politeia II", in: D. Koch / I. Männlein-Robrrt / N. Woidtmann (Hg.), Platon und das Göttliche. Antike Studien 1 (Tübingen 2010) [112-138] 113-115. 118-124; zutreffend Simonini 1986, 109.

7 Allgemein dazu Lamberton 1986, 22-31. Das Verstecken der Kinder in der Höhle durch Kronos lässt sich als das bei Hes. Theog. 459-467 geschilderte Verschlingen der Kinder erklären (vgl. Plotins allegorische Auslegung dazu Enn. V 1,7,30-35); siehe auch oben Anm. 71 und Simonini 1986, 107f; ebenso Porph. De antro 15f., dazu K. Berthrlot, "Philo and the Allegorical Interpretation of Homer in the Platonic Tradition (with an Emphasis on Porphyry's De antro nympharum)", in: M. R. NibHorf (Hg.), Hower and the Bible in the Eyes of Ancient Interpreters. Jerusalem studies in religion and culture 16 (Leiden / Boston 2012) [155-174] 167.

${ }^{78}$ Pherekydes F 88, 117f. Schibl $=$ fr. 7 B 6 DK; vgl. ebcl. fr. A 8. Siehe Alt 1998, 483. Zu beachten ist atch die Anspielung auf den Er-Mythos Platons, als Porphyrios atf die zwei Ausgänge der homerischen Nymphengrotte zu sprechen kommt (\$\$ 22;29;31), siehe Plat. Rep. X 614c-e; $615 \mathrm{~d}-\mathrm{e}$. Allem Anschein nach geht diese Bemerkung bereits auf eine entsprechende Beobachtung des Numenios zurück (vielleicht überliefert durch Krontios' allegorischen Kommentar zu dieser Schrift), siehe Numenios T. 21, 87f. LEEMANs = Prokl. In Remp. II, 96,10-13 KroLl.
} 
rios mit den Texten der 'Theologen' eben diese hier skizzierte, von ihm wohl als pythagoreisch interpretierte Tradition meint. ${ }^{79}$

Porphyrios versucht also eine historische Hierarchisierung des integrativen Höhlenbildes von den frühen, mit religiösen Themen befassten Dichtern (Homer, Hesiod) und den Orphikern über die Pythagoreer bis hin zu Platon, auf dessen berühmtes Höhlenbild er nun etwas ausführlicher zu sprechen kommt. Zuvor zitiert er allerdings einen einschlägigen Vers aus Empedokles' Ka $\alpha \alpha Q \mu o i ́$, der den "seelengeleitenden Kräften" in den Mund gelegt ist: "Wir sind hinunter in diese bedachte Grotte gekommen"). ${ }^{80}$ Die Lebenswelt der Menschen wird als ,Höhle' kenntlich. ${ }^{81}$ Hier klingt die orphisch-pythagoreische Vorstellung an, nach der sich die menschliche Seele im Körper wie in einem Gefängnis oder einem Grab aufhalten muss und daher immer nach Befreiung drängt. ${ }^{82}$ Empedokles scheint Porphyrios als älteste Autorität oder Beleg dafür zu gelten, dass die Höhle Bild des Kosmos sei. Dieses Empedokles-Zitat ist allein in Porphyrios' De antro überliefert. Es entstammt dem Kontext der Unterweisung des verbannten Gottes über seine Inkarnationen im ersten Buch der Katharmoi, wurzelt also in einem Seelenwanderung und Inkarnation(en) thematisierenden Kontext des ,Priester-Philosophen-Dichters' Empedokles, der hier ganz offensichtlich mit zu den (vorher, s.o., und nach-

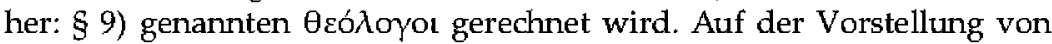
der Welt als Höhle beruht nun Platons berühmtes Bild (zikóv) von der Höhle im siebten Buch der Politeia (das sog. Höhlengleichnis), aus dem Porphyrios in direktem Anschluss (De antro 8) einen Passus zitiert (Rep. VII 514a), allerdings hier die Umkehr und den (möglichen) Weg des Menschen aus der Höhle, den Weg zum Licht außerhalb der Höhle sowie die gesamte Erkenntnis-Problematik ausspart. Platon hatte die ihm vorgängige und zeitgenössische, mythisch-religiöse Tradition des Mythotopos von der Höhle zu einem entmystifizierten, rationalisierten und philosophischen Bild oder Gleichnis transformiert. ${ }^{83}$ Bei Platon ist die Höhle der Raum, an dem sich die Menschen von Geburt an befinden; da sie glauben, dieser Raum sei die wahre Welt, erweist sich die Höhle als Ort der Illusion und der Täuschung, als Gefängnis - die Menschen sind dort a priori gefesselt -, aus dem es allerdings bereits zu Lebzeiten die Möglichkeit des

\footnotetext{
${ }^{79}$ Ausfiuhrlich dazu siehe Edwards 1990; vgl. Lamberton 1992, 123f.

${ }^{80}$ De antro $8=f r .31$ B $120 D K=18$ Mansfeld $/$ Primavesi. Ausführlicher siehe Simonini 1986, 109-112.

${ }^{81}$ Siehe auch Empedokles, fr. 31 B 121,1 DK (freudloser Ort) und 121,4 (Wiese des Unheils), wo vermutlich ebenfalls Bilder für die Menschenwelt formuliert sind; vgl. auch Plot. IV 8,1,34, der mit Blick auf das genannte Empedokles-Zitat unter der Höhle das All (tỏঠe $\tau o ̛ ́ r o ́ v)$ versteht.

${ }^{82}$ Diese Anschaurung findet sich häufiger bei Platon, z.B. Phaed. 62b. 91e; Krat. 400c et al.; Philolaos, fr. 44 B 14 DK, weitere Belege bei Simonini 1986, 110 und ALt 1982, $280 f$.

${ }^{83}$ Ausführlich dazu siehe z.B. MänNLBin-Robert 2012b, 15-19.
} 
Aufstiegs und der Erkenntnis der wahren Welt gibt. Ansonsten verlässt die unsterbliche Seele erst beim Tod des Körpers diese ,Höhle' und geht in jenseitige Bereiche ein, wie Platon das vor allem im Er-Mythos am Ende der Politeia (Buch X) sowie in Gorgias und Phaidon in mythischen Bildern beschrieben hatte. ${ }^{84}$ Während Platons Sokrates dezidiert ein ,Bild' (cikw'v) von der Höhle entwirft und beschreibt, das abstrakt und ohne jede räum-

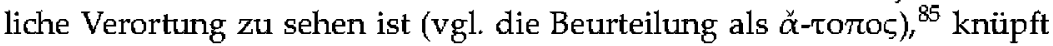
Porphyrios sein Höhlenbild an den Text Homers an, den er auf eine faktische Höhle auf Ithaka bezogen ansieht - er ist also gerade um textuelle wie lebensweltliche Verortung bemüht. ${ }^{86}$ Eine weitere gegenläufige Tendenz zeichnet sich dahin gehend ab, dass es bei Platon im Höhlengleichnis zu einer programmatischen Entsakralisierung der Höhle kommt und er vielmehr eine neue - philosophische - Raumsemantik der Höhle entwirft, wenn Erkenntnis und gleichsam visionäre Schau des Wahren und Göttlichen nun nicht mehr - wie früher - in der Höhle, sondern allein außerhalb der Höhle - in philosophischer Schau oder im Verlassen des Körpers - erfolgen kann. ${ }^{87}$ Porphyrios hingegen blendet zwar ebenfalls die mythischliterarischen Höhlenbilder aus, konstruiert aber mit seinem Text anhand der gewählten Belege und Bezugsautoritäten eine dezidiert religiöse Höhle, die besonders viele Ingredienzien und Elemente aus dem zeitgenössisch virulenten Mithrasmysterienkult enthält, die freilich platonisch interpretiert werden. ${ }^{88}$ Der eigentliche Bezugspunkt zum Höhlengleichnis Platons, das hier nur anzitiert wird, liegt darin, dass die Dinge in der Höhle nur Abbilder der eigentlichen Dinge außerhalb der Höhle sind, aber auf diese transzendenten, intelligiblen Gegenstände verweisen. Porphyrios' reli-

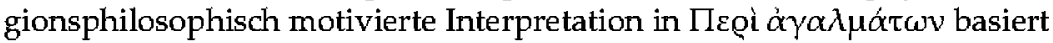
ebenfalls auf der Annahme, dass die sinnlich wahrnehmbaren Götterbilder auf das nicht sichtbare Göttliche verweisen. ${ }^{89}$

Indem Porphyrios nun die Nymphengratte Homers als religiöses Sym-

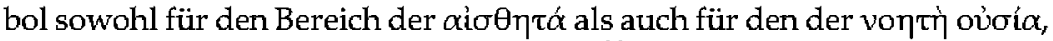

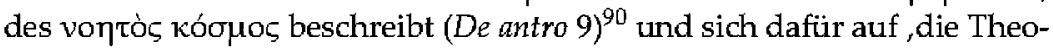

\footnotetext{
${ }^{84}$ Nicht genantut bei Porphyrios werden die höhlenartigen Behausungen im Schlussmythos des Phaidon, die den Menschen irrtümlich als, Welt' gelten (Phaed. 109c3f.: $\eta \mu \bar{\alpha} \zeta$ oṽv

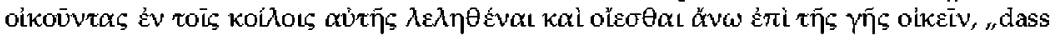
wir also, ohne es zu merken, in ihren Höhlungen wohnen und glatben, oben auf der Erde zu leben"; auch ebd. 109d6f.).

${ }^{85}$ Sc. ein Zitat einer Bemerkung des Glatkon aus Platons Höhlengleichnis, Rep. VII $515 a 4$.

${ }^{86}$ Umstritten ist in diesem Kontext, ob die Polis-Höhle auf Ithaka als Vorbild für Homers Beschreibung gedient haben katn, siehe LaRson 2001, 231f.

${ }^{87}$ Ausführlicher dazu siehe MänNLEIN-RoBвRT 2012a, 114-118.

${ }^{88}$ So wird z.B. Mithras als ,Schöpfer und Vater von allen' als Demiurg aufgefasst, $D e$ antro 6, dazu Alt 1998, 470.

${ }^{89}$ Z.B. Porph. De imaginibus 351F,408,14-24 SMITH; 354F,413f., 42-61 SMITH.

${ }^{90} \mathrm{Vgl}$. anders ZBPF 1958, 382.
} 
logen' (s.o.) beruft (ebd.), von denen er auch Platon als inspiriert ansieht, entwirft er ein ganz eigenes Höhlen-Bild. Denn trotz seiner unverkennbaren platonischen Grundhaltung in dieser allegorischen Interpretation und trotz seiner expliziten Bezugnahme auf Platon mit dem Zitat des berühmten Höhlengleichnisses, weicht er vom streng philosophischen Höhlenkonzept Platons ab: Zum einen harmonisiert er dieses mit der positiven Uminterpretation von der Welt als Höhle bei Aristoteles, ${ }^{91}$ zum anderen wird bei ihm die Höhle wieder zu einem Ort göttlicher Präsenz und göttlichen Wirkens, wird also als religiös-verschlüsselter, zu dechiffrierender "Topos' exegetisch behandelt. Die Sophia der Alten ist in diesem Bild enthalten und muss nun philosophisch entschlüsselt werden. Die homerische Nymphengrotte erfährt bei Porphyrios daher eine neue, über Numenios und Kronios vermutlich hinausgehende, religiöse Semantisierung, in deren Kontext die Mithrasmysterien eine besondere Rolle spielen. ${ }^{92}$

\section{Fazit}

Porphyrios nimmt eine ausgesprochen religionsphilosophisch orientierte Transformation oder Umdeutung des alten Mythotopos der Höhle am Beispiel der Nymphengrotte aus Homers Odyssee vor. Basierend auf der platonischen Lehre von der Unsterblichkeit der Seele und ihrer wiederholten Katabaseis in Körper bietet er hier eine an religiösen Motiven und Deutungen reiche, vielfach orphisch-pythagoreischen Überzeugungen verpflichtete Allegorese der homerischen Nymphengrotte. Die Höhle als mythischer oder als literarischer Raum spielt bei Porphyrios keine Rolle, er konzentriert sich ganz auf Funktion, Rolle und Semantik der Höhle als religiösem Ort und verweist dementsprechend auch nur auf religiöse Höhlentopoi. Porphyrios formuliert dabei in Anlehnung an Platon, Aristoteles und andere (mittel-)platonische Exegeten eine individuelle Erklärung. Dabei lehnt er sich deutlich an vorplatonische religiöse Traditionen an, wenn er in dieser problemorientierten und systematischen Interpretation eine extrem religiöse Semantisierung der Nymphengrotte bei Homer vorlegt. Die Auslegung der Höhle als einer symbolischen Darstellung dient im Grunde einer ,Vergegenwärtigung des Göttlichen". ${ }^{93}$ Denn mit dem philologischen Habitus der Klärung einer A porie verschmilzt der religiöse, priester-

\footnotetext{
${ }^{91}$ Siehe Aristot. fr. 12 Rose (De philosophia fr. 13 W ALzBR / Ross) = Cic. Nat. deor. II 95 u.ö., siehe ausführlicher bei ZвPF 1958, 360f.

${ }^{92}$ Zur Frage, inwiefern De antro deswegen zu den anti-christlichen polemischen Schriften des Porphyrios gerechnet werden kann, siehe die Diskussion bei Edwards 1990 (der diese Schrift für polemisch hält) und Maurgtte 2005; Penati Bernardini 1988, 122 interpretiert den starken Akzent auf dem Mithraskult ebenfalls als gegen die Christen gerichtet.

${ }^{93}$ So mit Cromb 1970, 155.
} 
liche Gestus der symbolischen Deutung eines Bildes voll alter, göttlicher Weisheit. 


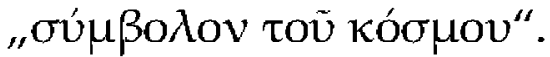 Astronomisch-astrologische Vorstellungen in Porphyrios' De antro Nympharum
}

\author{
Benjamin Topp
}

Bei der Schrift De antro Nympharum des Philosophen Porphyrios handelt es sich nicht um eine astrologische oder astronomische Schrift im engeren Sinne, werden in ihr doch weder astrologische Vorhersagen noch astronomische Vorstellungen oder Berechnungen im eigentlichen Sinne expliziert. Vielmehr stellt sie einen Traktat dar, der die berühmte Beschreibung der Nymphengrotte auf der Insel Ithaka aus Homers Odyssee (XIII 102-112) allegorisch bzw. symbolisch auszudeuten versucht und hierbei Spuren "alter Weisheit" (re vera eher mittel- und neuplatonische eigene Ansichten) aufzudecken versucht. ${ }^{1}$

Dabei stellen - so die These, die im Folgenden überprüft werden soll astronomisch-astrologische Vorstellungen einen nicht unbedeutenden Teil der von Porphyrios in der Homerpassage verorteten alten Weisheit dar, da viele der eigentlich genuin philosophischen, religiösen oder kultischen Details, die in De antro Erwähnung finden, auf kosmologische, astronomische oder auch astrologische Vorstellungen Bezug nehmen oder auf diese zu-

\footnotetext{
${ }^{1}$ Vgl. etwa Porph. Antr. 4: „Bereits unsere Vorfahren hätten es für nötig befunden, all diesen Dingen nachzuspüren tund sie ztt entschlüsseln, und nut sei es atı utns, mit ihrer Hilfe und durch unsere eigenen Möglichkeiten zu versuchen, eine Erklärung zu finden"

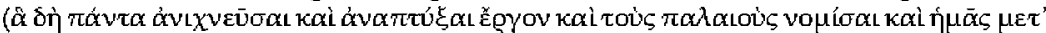

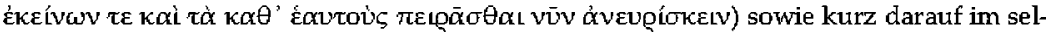
ben Kapitel: ,Je mehr man zu zeigen versucht, dass die Grotte und ihre Gegenstände keine Erfindung Homers sind [...] desto erfiullter von alter Weisheit wird sich das Weihgeschenkerweisen. Und aus eben diesen Gründen ist die Grotte einer genauen Untersuchung wert..."

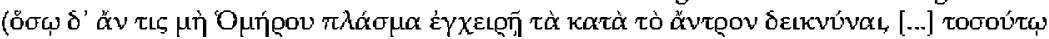

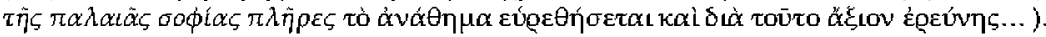
Der Begriff der alten Weisheit, die in den Homertext eingeschrieben sei, findet sich zum Ende der Abhandlung erneut, wo Porphyrios davon spricht, dass Homer gemäß gewisser Wahrheiten ( $\dot{\alpha} \pi \delta$ $\tau\llcorner v a v \alpha \lambda \eta \theta \bar{\omega} v$ ) in seiner Darstellung des Mythos Bilder des Göttlichen versteckt habe (Porph. Antr. 36). Atth an dieser Stelle bezieht er neben Homers Leistungen

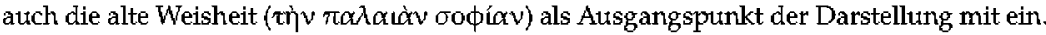
Zum auch in der Astrologie verbreiteten Phätomen, eigene Ansichten durch (fiktive oder reale) Gewährmänner aus alten Zeiten aufzuwerten, siehe unten Anm. 33 bzw. 34 .
} 
rückzuführen sind, sodass die Astrologie (bzw. Astronomie) gerade einen Teil der alten Weisheit ausmacht, auf welche Porphyrios sich beruft. ${ }^{2}$

Bedenkt man die Rolle, welche die Sterne und der von ihnen ausgehende Einfluss in der Antike spielten, muss dies nicht grundsätzlich verwundern, und dies umso weniger, als die Schrift von der Nymphengrotte des Porphyrios durchaus nicht homogen auf ein Fachgebiet (beispielsweise die Philosophie oder den Kult) Bezug nimmt, sondern vielmehr ein heterogenes Gemisch unterschiedlichster Disziplinen in sich vereint und als einen Referenzrahmen in Anspruch nimmt. ${ }^{3}$

Bei Porphyrios greifen dabei mehrere Tendenzen, auf astrologischastronomische Inhalte zu rekurrieren, ineinander: Denn nicht nur die Schule des Platonismus ${ }^{4}$ bzw. Neuplatonismus ${ }^{5}$ zeigt deutliches Inter-

${ }^{2}$ Zur Unterscheidung der Begriffe, Astronomie' und ,Astrologies vgl. z.B. TesTBR 1987, 18-20 und von STUCKRAD 2003, 15f. sowie zur geschichtlichen Entwicklung des Begriffspaares insbesondere die umfassende Darstellung von W. HüBNBR, Die Begriffe „Astrologie" und "Astronomie" in der Antike. Wortgeschichte und Wissenschaftssystematik, mit einer Hypothese zum Terminus, "Quadrivium". Abh. d. Akad. d. Wiss. u. d. Lit. Mainz, geist.- u. soz.-wiss. KI. 1989/7 (Wiesbaden 1989); während in der Antike beide Begriffe für die reine Betrachtutng und Berechnung der Himmelskörper und ihrer Bewegungen (heute: ,Astronomier) ebenso wie für die Deutung ihrer Auswirkungen auf die stublunare Sphäre (also die Erde, die im geozentrischen Weltbild auf der innersten und damit untersten Sphäre liegt) und damit auch auf den Menschen (heute: ,Astrologie') benutzt wurden, hat sich seit Einsetzen der Aufklärung die heute übliche semantische Differenzierung durchgesetzt. Da jedoch umfassende astronomische Grundlagen und Techniken benötigt werden, um das auf ihnen aufbauende Gerüst der Astrologie verstehen und anwenden zu können, wird im Folgenden vornehmlich nur von, Astrologie gesprochen werden (vgl. zu dieser terminologischen Schwierigkeit auch R. BвсK, A Brief History of Ancient Astrology [Malden 2007] 1). Auch wenn dies insofern inkorrekt ist, als bei den, astrologischen Details in De antro Nympharum nicht so sehr deren Wirkungen auf Erde und Metsch im Zentrum stehen, scheint dieses Vorgehen dennoch berechtigt, da die zu Grunde liegenden Vorstellungen ebenso wie fast die gesamte Terminologie (Häuser-Lehre, Kulmination, Kardinalpurkte etc.) eher dem astrologischen als dem mathematisch-astronomischen Kontext zugeordnet werden können.

${ }^{3}$ Zur Disparatheit der Argumentation und der Quellen bei Porphyrios vgl. Alt 1998, 467. (Vgl. hierzu auch das Fazit des Beitrages von Christoph RIBDwbG in diesem Band, S. 96.) Die Bedeutung der Astrologie für insbesondere die nachchristliche Philosophie beschreibt u.a. TвsTER 1987, 49f.

${ }^{4}$ Vgl. u.a. Tester 1987, 16. Insbesondere in der Politeia (Er-Mythos) sowie im Timaios entwickelt Platon ein Weltbild in dem - wenngleich nicht dezidiert astrologisch intendiert - göttliche Himmelskörper die Grundlage einer astrologisch geprägten Kosmologie darstellen (vgl. u.a. Plat. Tim. 40b sowie Leg. 886b).

${ }^{5}$ Insbesondere der Glaube an ein bestimmendes Schicksal spielt im Mittel- und Neuplatonismus eine bedeutende Rolle. In Verbindung mit astralmystischen Lehren (beispielsweise des Hermetismus) sowie der Zahlenspekulationen, wie sie beispielsweise der Schule des Pythagoras inhärent sind, bildet sich hier ein Nährboden für astrologische Ansichten (vgl. von STUCKRAd 2003, 93 sowie Gundel / Gundel 1966, 313-315). Als besonders wirkmächtiges Beispiel sei die Abhandlung Plotins über die Wirkung der Steme (Plot. II 3) erwähnt, in welcher er unterscheidet $\mathrm{zwischen}$ der von ihm anerkannten Tatsache, dass die

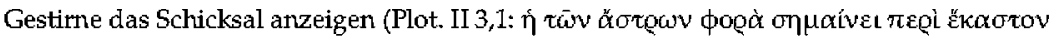
$\tau \grave{\alpha}$ éoó $\mu \varepsilon v \alpha$, "Die Bewegung der Gestime zeigt Einzeldinge betreffend zukürnftige Ereig- 
esse an astrologisch-astronomischen bzw. mythologischen Konzepten; auch der Mithraskult, der insbesondere für De antro eine bedeutende theologisch-religiöse Quelle bietet, bedient sich - obschon auch dieser Kult per se nicht astrologisch im eigentlichen Sinne ist - häufig astrologischastronomischer Symbolik. ${ }^{6}$

Dass Porphyrios darüber hinaus jedoch auch außerhalb religiös-kultischer Bezüge Interesse an dezidiert astrologischen Fragen gehabt haben muss, lässt sich beispielsweise an der in seinem Namen überlieferten (und mit einiger Wahrscheinlichkeit auch von ihm verfassten) Isagoge zur Tetrabiblos des Ptolemaios festmachen. ${ }^{7}$ Dass astrologisch-astronomische Fragen jedoch auch darüber hinaus bei Porphyrios eine nicht unbedeutende Rolle gespielt haben, zeigen auch andere seiner Werke: Hierzu zählt beispielsweise das Fragment 337, in dem astromythologische ${ }^{8}$ sowie astrologisch-divinatorische ${ }^{9}$ Einflüsse erkennbar sind; dabei scheint der

nisse $a^{\prime \prime}$ ) und der von ihm abgelehnten Hypothese, class sie das Schicksal auch bewirkten

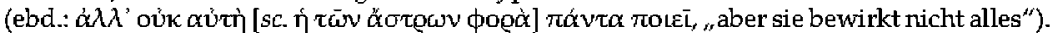
Hierbei wird auch seine profunde Kenntnis astrologischer Theorien und ihrer praktischen Anwendungen evident (vgl. hierzu u.a. auch Gundel / Gundel 1966, 314 sowie Tester 1987, 53f.). Auch der Philosoph Proklos merkt in seinem Kommentar zur Politeia Platons (Procl. In Remp. II, 129,12 KROLL) über - den auch bei Porphyrios mehrfach zitierten - Numenios und seine Darstellung des Auf- und Abstieges der Seelen durch die beiden Tore

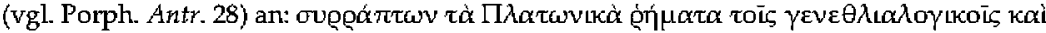

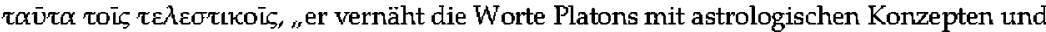
dies wiederum mit den Eigenschaften der Mysterien".

${ }^{6} \mathrm{Vgl}$. MerkelbaCH 1984, 200. BrcK 1988, X setzt als Grundlage seiner Argumentation voraus ${ }_{n}[\mathrm{t}]$ hat the Mysteries were thoroughly impregnated with astrological lore" (ebd.) und spricht der Astrologie Bedeutung als "the framework for the Mysteries" theories" (ebd.) zu. Vgl. hierzu des Weiteren auch Ulansey 1989, 15-24.

${ }^{7}$ Kritische Edition: BorR / WeInstock 1940. Anders als der Name suggeriert, handelt es sich hierbei weniger um einen Kommentar zur Tetrabiblos des Ptolemaios im engeren Sinne, als vielmehr um ein erklärendes Handbuch wichtiger astrologischer Begriffe, das sich neben Ptolemaios auf viele weitere astrologische Quellen stützt (vgl. u.a. HoLD EN 2009, viii ["short dictionary of astrological terms"] sowie JoHnson 2013, [159-164] 161: "like a glossary"). Dass es sich bei der Isagoge um eine echte Schrift des Porphyrios handele, wurde immer wieder bestritten (vgl. z.B. F. BoLl, Sphaera. Neue griechische Texte und Untersuchtangen zur Geschichte der Sternbilder [Leipzig 1903] 7 sowie BorR / WBINsTock 1940, 187); inzwischen wird die Autorschaft des Porphyrios (zumindest für die ersten 45 Kapitel) allerdings weitgehend anerkannt (vgl. D. PingREE, „From Alexandria to Baghdad to Byzantium. The Transmission of Astrology", International Journal of the Classical Tradition 8 [2001] [3-37] 7). Die große Übereinstimmung mit vorhandenen astrologischen Schriften wie beispielsweise des Antiochos von Athen lässt zwar die Frage offen, ob - und wenn ja, inwiefern - Porphyrios selbst als Astrologe tätig war oder ob er lediglich als Schriftsteller auf diesem Gebiet firmierte (vgl. BonR / Wrinstock 1940, 187, die die Arbeit des Porphyrios als reine Exzerptensammlung betrachten); dennoch setzt bereits die literarische Auseinandersetzung mit der komplexen Thematik zumindest eine gewisse Vertrautheit mit der Materie und entsprechenden astrologischen Methoden und. Techniken voraus.

${ }^{8}$ Fr. 337F.7,385 Smith: ó̉ Tò Keóvov kaì Téas (,von Kronos [Saturn] und Rhea").

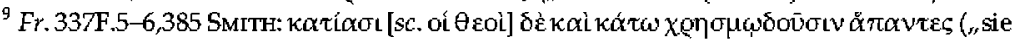
[also: die Götter] steigen alle herab und geben unten Orakelsprüche"). 
Verfasser eine Gleichsetzung der göttlichen Mächte und der Steme sowie des Schicksals zu intendieren. ${ }^{10}$ Auch Fragment $359^{11}$ bezieht sich in seiner Ikonographie des Planetengottes Kronos (Saturn) eindeutig auf astrologische Inhalte und Fragment 360 rekurriert mit der im Widder eingetretenen Sonne-Mond-Konjunktion auf eine genuin astronomische Thematik. ${ }^{12}$ Umgekehrt nehmen auch spätere Astrologen wie der im 4. nachchristlichen Jahrhundert tätige Hephaistion von Theben Bezug auf Porphyrios:

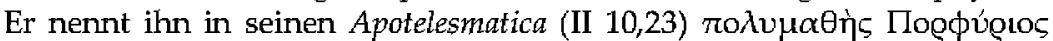
und führt Beispiel-Horoskope aus einem (verlorenen) Werk des Porphyrios an, die offensichtlich nicht aus der (überlieferten) Isagoge entstammen, darunter eventuell auch das Geburtshoroskop des Porphyrios selbst. ${ }^{13}$

Angesichts der unterschiedlichen Kontexte, innerhalb derer der Philosoph Porphyrios mit astrologischer Thematik in Verbindung steht, muss es also nicht verwundern, wenn auch dem Traktat über Homers Nymphengrotte ein astrologischer Referenzrahmen inhärent ist, auf den sich

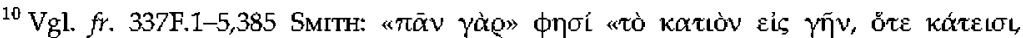

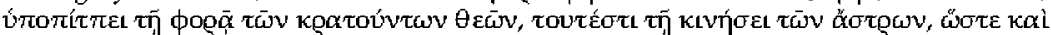

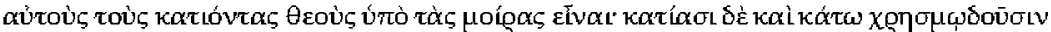

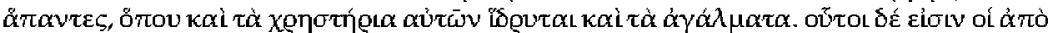

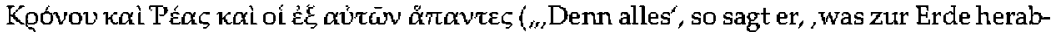
steigt, unterliegt bei seinem Abstieg dem Einfluss der herrschenden Götter, das heift der Bewegung der Gestirne, sodass auch die Götter selbst bei ihrem Abstieg ihrem jeweiligen Schicksal unterliegen: sie steigen alle herab und geben unten dort Orakelsprüche, wo ihre Heiligtümer und Opfergaben sind. Dabei handelt es sich um diejenigen, die von Kronos und Rhea abstammen sowie alle ihre Nachfahren "n).

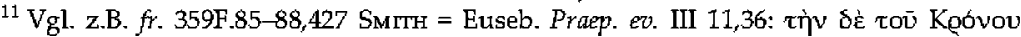

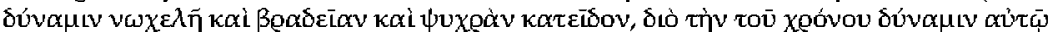

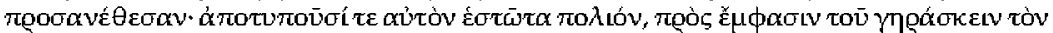
Xpóvov ("Die Kraft des Kronos [Saturn] aber betrachteten sie als schneckenhaft, langsam und kalt, weshalb sie ihm auch die Kraft über die Zeit zuschrieben: sie stellen ihn auch als grauhaarigen Greis dar, um den mit der Zeit voranschreitenden Alterungsprozess zu verdettlichen").

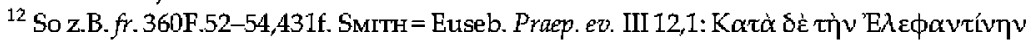

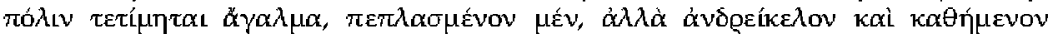

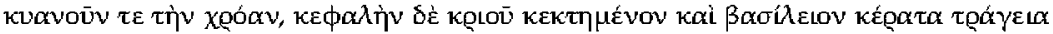

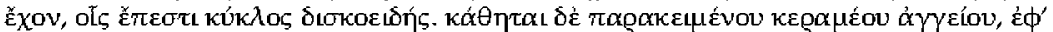

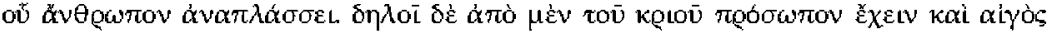

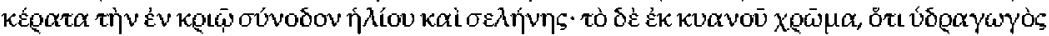

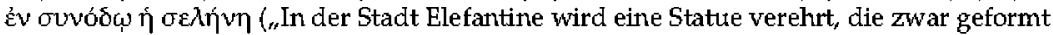
ist, aber eine Figur in Menschengestalt clarstellt, sitzend und mit blatugrüner Hatt, mit dem Haupt eines Widders und Bockshömern als Krone, auf der sich ein Kreis in Form eines Diskos befindet; zu seinen Füßen liegt ein irclenes Gefäß, auf dem ein Metısch abgebildet ist. Das Gesicht des Widders und die Bockshörner aber bedeuten die Konjunktion von Sonne und Mond im Widder; die blaugrüne Hatt hingegen bedeutet, dass der Mond bei der Konjunktion das Wasser zunehmen lässt").

${ }^{13} 489 \mathrm{~F}, 562$ f. SMITH = Heph. II 10,23-27; NguG BbAU BR 1975, 944 datiert es auf den 5.10.234 n. Chr. Zu einer eventuellen Verbindung mit Firmicus Maternus, derihn (Math. VII 1,1) als noster Porphyrius bezeichnet, vgl. u.a. HoLden 2009, viii.
} 
die Argumentation bezieht und innerhalb dessen sie gedeutet werden will und muss. Inwieweit dies gilt und eben astrologisch-astronomische Vorstellungen zum Verständnis von Porphyrios' De antro Nympharum nutzbar gemacht werden können, soll im Folgenden dargelegt werden.

\section{Astronomische Grundvoraussetzungen: Der Lauf der Sonne}

Grundlage und Ausgangspunkt der Astrologie ist die Bewegung der Sonne im Laufe eines Jahres, die innerhalb dieses Zeitabschnittes genatu einmal die Erde umrundet. ${ }^{14} \mathrm{Um}$ sie herum befinden sich, nach Vorstellung der antiken Philosophie, Astronomie und Astrologie, in jeweils konzentrisch größer werdenden Sphären angeordnet die ,Planeten' Mond, Sonne, Venus, Merkur, Mars, Jupiter und Saturn; ${ }^{15}$ die achte und äußerste Sphäre bildet der - mehr oder minder unbewegliche - Fixsternhimmel. ${ }^{16}$

\footnotetext{
${ }^{14}$ Dies trifft natürlich nur aus Sicht des terrestrischen Beobachters zu: realiter ist es selbstverständlich die Erde, die um die Sonne kreist. In der antiken - und übrigens autch weitgehend der modernen - Astrologie wird jedoch immer auf das platonisch-aristotelische (,rgeozentrische") Weltbild rekurriert, in dem die Erde im Zentrum der sphärenförmigen Welt steht. Das gegenteilige, sog, heliozentrische, Weltbild, das von einer Bewegung aller Planeten inklusive der Erde um die Sonne ausgeht, war zwar bereits in der Artike von Aristarchos von Samos (3. Jh. v. Chr.) mathematisch berechnet worden; es wurde jedoch durch die geozentrischen Ansichten des Aristoteles und des Ptolemaios weitgehend verdrängt und spielt für die Astrologie keine Rolle. Die Bedeutung der Sonne und ihres Standes für die Astrologie spiegelt sich in der zentralen Rolle wieder, die beispielsweise Ptolemaios ihr in seinen Apotelesmatica zukommen lässt (Ptol. Apotel. I 4,1). Auch Porphyrios bezeichnet sie in seiner Isagoge (Porph. Isag. 2, 190,14-191,2 Bobr / WeINSTOck) als kpót

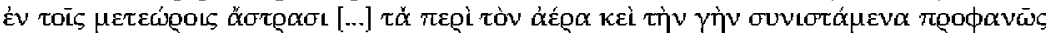

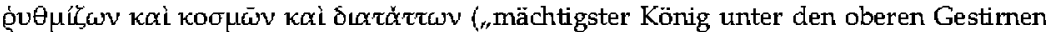
[...], der die Körper in Luft und Erde aufs Genaueste in eine Anordnung bringt, formt und aufstellt").

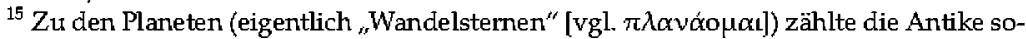

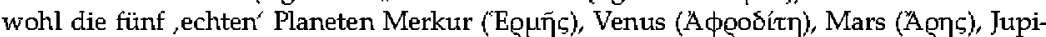

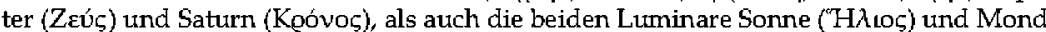
( $\Sigma \varepsilon \lambda$ ívi), da auch diese - im Gegensatz zu den (mehr oder minder) festen Fixsternen in stetiger Bewegung sich befinden. Uranus, Neptun und Pluto, die mit dem bloßen Auge schwer bzw. gar nicht zu sehen sind, wurden erst sehr viel später entdeckt (vgl. BuRKBRT 1962, 279f.). Nicht eithheitlich festgelegt war clabei die Reihenfolge der Planeten: Wichtig sind die ägyptische Planeten-Reihenfolge (Mond - Sonne - Merkur - Venus - Mars - Jupiter - Saturn) sowie das chaldäische Planetenmodell (Mond - Merkur - Venus - Sonne - Mars - Jupiter - Saturn); vgl. hierzu Tester 1987, 166f. sowie HüBngr 2006, 23-26. Das ägyptische Planetenmodell wurde $u$.a. auch von den Platonikern verwendet, bisweilen mit Modifikationen (vgl. HüBngr 2006, 26); das sog. chaldäische Planetensystem ist hingegen Grundlage tunserer Planetenwoche (vgl. BURKRRT 1962, 297). Einen tumfassenden Überblick bietet auch Neugrbaubr 1975, 690-693. Die Reihenfolge der Planeten in De antro 22 scheint auch für Porphyrios die ägyptische Reihenfolge der Planeten zu belegen.

${ }^{16}$ Obwohl auch die ,Fix'-Sterne aus irdischer Sicht einer Bewegung zut unterliegen scheinen, ist diese im Verhältnis zu den Bewegungen der Planeten so gering, dass sie als mehr
} 
Dass diese Vorstellung des Kosmos auch von Porphyrios geteilt wird, lässt sich beispielsweise in De antro 16 ablesen, wo Porphyrios anhand der Bedeutung des Honigs, mit Hilfe dessen Kronos von Zeus ebenso betrunken gemacht wird, wie sein Vater Uranos (und ebenso entmannt wird), auf die Bedeutung der Lust zu sprechen kommt. Diese Lust spiele auch in den kultischen Zeremonien eine Rolle, da - hier geht die mythische nahtlos in eine astronomische Begründung über - Kronos (also Saturn) mit seiner

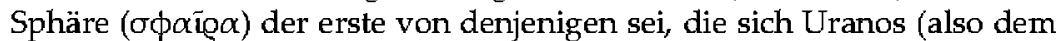

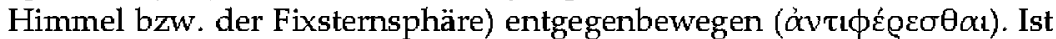
Porphyrios zu Beginn noch klar auf dem Gebiet der Mythologie (genauer des Sukzessionsmythos der alten Gottheiten Uranos und Kronos) ${ }^{17} \mathrm{zu}$ verorten, begibt er sich unmittelbar anschließend auf astronomisches Ter-

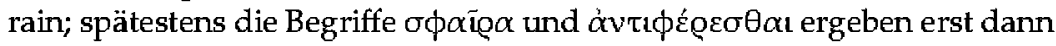
Sinn, wenn hierunter die Bewegung der Planetensphären zueinander verstanden werden soll. ${ }^{18}$ In der Tat dreht sich nach antikem Verständnis die Fixsternsphäre entgegengesetzt zu den Sphären der Planeten, die unter ihr angeordnet sind: Während die Planeten (im Normalfall - ausgenommen sind Phasen der Rückläufigkeit) von Osten nach Westen wandern, bewegt sich die Fixsternsphäre entgegengesetzt von Westen nach Osten. ${ }^{19}$

Bereits an diesem Beispiel wird klar, dass Porphyrios durchaus auf astronomische Vorstellungen Bezug nimmt, um seine Argumentation zu stützen. Bemerkenswert dabei ist, dass seine astronomische Begründung nahtlos aus der mythischen folgt; beide Argumentationsebenen ergänzen sich gleichwertig und stützen sich somit gegenseitig. Dabei wird ebenfalls evident, dass das Gesamtargument nur vor dem Hintergrund von (Astral-)

oder minder unbeweglich gelten konnten; vgl. hierzu beispielsweise die Darstellung Platons (Tim. 40b2-3).

${ }^{17}$ Vgl. z.B. die Darstellung des Hesiod (Theog. 161-210).

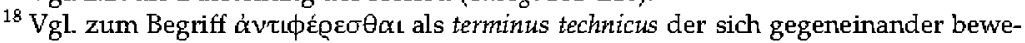

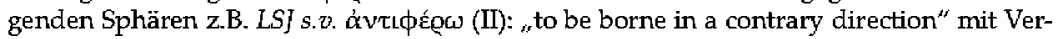
weis auf Arist. Cael. 291b2; in ähnlichem Kontext findet es sich beispielsweise auch bei Proklos (In Tim. II, 264,1f. KRoLL).

${ }^{19} \mathrm{Vgl}$. Brck 1988, 29f. Locus classicus in der philosophischen Literatur ist wohl Plat. Tim. 36c1-d7. Die Bewegung der Fixsterne ist seit Hipparch (2. Jh. v. Chr.) bekannt (vgl. u.a. Testre 1987, 161). Dass die Reihenfolge der Planeten zudem auch im Mithraskult eine Rolle spielte, geht aus einigen Funden hervor (vgl. etwa BвCK 1988, 1-15); Tester 1987, 167 verweist u.a. auch auf eine "Mithraic ${ }^{\prime \prime}$ Reihenfolge der Planeten (Saturn-Sonne-Mond Jupiter -Mars - Venus - Merkur). Dieselbe Vorstellung dürfte auch in der Autssage des Por-

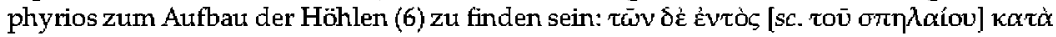

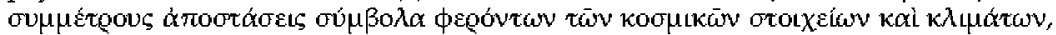
,ihre [sc. der Höhle] Inhalte symbolisierten in wohlproportionierten Abständen die kosmischen Elemente und Himmelszonen" (zum Begriff $\kappa \lambda\lfloor\mu \alpha$, der sowohl die sieben in der Antike relevanten geographischen Zonen der Erde, die auch von Ptolemaios verwendet wurden, als auch entsprechende Abschnitte am Himmel bezeichnen karu, vgl. NgugBBAu-

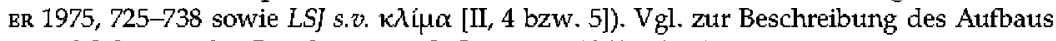
eines Mithräums bei Porphyrios auch CAMPBelL 1968, 54-56. 
Mythos und Astronomie verständlich wird; spätestens bei den astronomi-

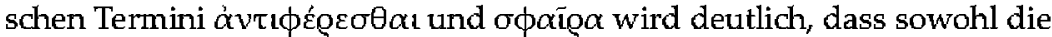
mythischen Gottheiten als auch ihre Planetenpendants gemeint sind. ${ }^{20} \mathrm{Be}-$ reits an dieser Stelle rekurriert Porphyrios also auch auf die Astronomie als eine Argumentationsebene.

\section{Der Zodiakus und die zwölf Sternbilder}

Teilt man die gesamten $360^{\circ}$ der Ekliptik, also der atuf die Himmelssphäre projizierten Kreisbahn der Sonne, in zwölf gleich große Abschnitte zu je $30^{\circ}$ atuf, erhält man den tropischen Tierkreis, der sich an den Wendepunk-

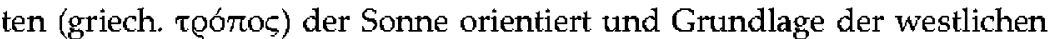
Astrologie ist. ${ }^{21}$ Als Beginn dieses Tierkreises (Zodiakus) wird allgemein der Widderpunkt angenommen, also der Schnittpunkt des Himmelsäquators mit der Ekliptik, der den Tag des Frühlingsäquinoktiums bezeichnet. ${ }^{22}$ Von diesem Frühlingspunkt aus werden von den gesamten $360^{\circ}$ jeweils $30^{\circ}$ für das Sternzeichen des Widders gerechnet, dann folgen der Stier, die Zwillinge, Krebs, Löwe, Jungfrau, Waage, Skorpion, Schütze, Steinbock, Wassermann und zuletzt die Fische. Die Sonne, die für einen gesamten Durchlauf durch alle Zeichen genau ein Jahr braucht, steht entsprechend aus irdischer Sicht einen Monat lang in jedem einzelnen Zeichen, die anderen Planeten, die sich ebenfalls entlang der Ekliptik bewegen, benötigen

\footnotetext{
${ }^{20}$ Dabei kommt Porphyrios natürlich die Polyvalenz der Planetenbezeichnungen gelegen, die eben auch mit den Namen der Planetengottheiten mitsamt ihren Mythen, wie sie u.a. aus Hesiods Theogonie bekannt sind, übereinstimmen. Eine Verbindung dieser Mythen und der Astronomie bzw. Astrologie findet sich beispielsweise bei Arat oder Hygin.

${ }^{21}$ Neben den beiden Sonnwenden (Sommer- und Wintersolstitium) spielen die beiden Punkte der Tag- und Nachtgleiche (Frühlings- und Herbstäquinoktium) ebenfalls eine Rolle. Vgl. hierzu auch insbes. Ptol. Apotel. I 19 mit einer entsprechenden Zuteilung der Sternzeichen. Der daran ausgerichtete tropische Tierkreis darf nicht mit den wirklichen Sternbildern verwechselt werden, die natürlich nicht genau $30^{\circ}$ messen (siderischer Tierkreis). Dies bedeutet, dass die Sonne zu einem bestimmten Zeitpunkt zwar noch einem bestimmten Sternzeichen berechnet wird, realiter jedoch sich bereits in einem anderen Sternbild am Himmel befindet. Für alle astrologischen Fragen ist jedoch der tropische Tierkreis, also jenes mathematisch berechenbare und idealisierte Konstrukt, relevant. Aufgrund der von Hipparch im 2.Jh. v. Chr. berechuneten Präzession der Äquinoktien wandert der eigentliche Frühlingspunkt gegenläufig zu den Sternbildern um ca. $1^{\circ}$ in 72 Jahren. Der Gesamtumlauf durch den gesamten Tierkreis clatert ca. 26000 Jahre und wird als "Großes Jahr" bezeichnet (vgl. von STUCKRAD 2003, 88). Der Wechsel von siderischen (anhand der sichtbaren Sternbilder) zu den aus Babylon stammenden tropischen (und damit abstrakten) Längen wird von Neugebaubr 1975, 293 sowie $593 \mathrm{um}$ ca. $500 \mathrm{v}$. Chr. angesetzt.

${ }^{22}$ Im Allgemeinen beginnt das Sternzeichen des Widders mit dem Widderpunkt. Selbstverständlich kann man bei einem kreisförmig gedachten Tierkreis nicht von einem eigentlichen Anfang sprechen (vgl. bereits Ptol. Apotel. I 10,2); dennoch wurde und wird der Widderpunkt als Beginn der Zunahme der Länge der Tage als Anfangspunkt des Zodiakus betrachtet (vgl. Bouché-L bCLERCQ 1899, 129).
} 
je nach ihrer Umlaufdauer länger (Mars, Jupiter und Saturn) oder kürzer (Mond, Merkur, Venus).

In der Astrologie werden nun den einzelnen Planeten sowie den Tierkreiszeichen gewisse Eigenschaften zugerechnet, die Einfluss auf die sublunare Welt ausüben und deren Wirken anhand der gegebenen Daten (Planetenkonstellationen zu einem bestimmten Zeitpunkt, z.B. der Geburt) ausgewertet werden kann. Hierbei ergeben sich je nach Kombination unterschiedliche Einflüsse und Wirkungen. Somit ergibt sich ein vielschichtiges und höchst detailreiches System, dem ein entsprechendes kosmologisches, astronomisch weitgehend präzise berechenbares Fundament zu Grunde liegt. Rückgriffe auf dieses der Astrologie zugehörige System finden sich auch in De antro.

Ein Beispiel für solche Verbindungen von Planeten und Tierkreiszeichen sind die sog. Planetenhäuser, bei welchen den Planeten jeweils ein bis zwei Zeichen als sog. Häuser (oî́ou) ${ }^{23}$ zugewiesen werden. Von diesen macht auch Porphyrios im 21. Kapitel von De antro Gebrauch: Nachdem er die Grotte als Symbol der Gottesverehrung eingeführt hat, erklärt Porphyrios, warum Homer sie als zweitürig bezeichne, wobei ein Tor, das nördlichere, den Menschen vorbehalten sei, während das südlichere den Unsterblichen zugeeignet sei (21f.). Bei seiner Deutung geht er zunächst von den beiden Extrempunkten, also dem nördlichsten (Krebs) und dem südlichsten Tierkreiszeichen (Steinbock), die zunächst mit den beiden Wendekreisen identifiziert werden, aus. ${ }^{24}$ In einem zweiten Schritt wird das Tierkreiszeichen des Krebses mit dem Mond in Analogie gesetzt, da dieses ebenso wie der Mond - der Erde am nächsten liege; der Steinbock jedoch wird mit dem entferntesten Planeten Saturn zusammengebracht. ${ }^{25}$ Wande-

\footnotetext{
${ }^{23}$ Die Terminologie ergibt sich aus der Vorstellung, dass die Planeten (götter) in ihr Haus einkehren, in welchem sie sich heimisch fühlen. Analoges gilt für die anderen wirksamen Orte, wie beispielsweise in den Erhöhungen. Vgl. beispielsweise die Darstellung bei Paul.

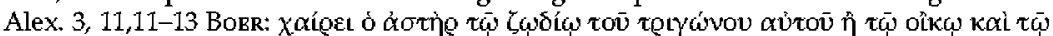
v́$ф \omega ́ \mu \alpha \tau \iota$ (,Das Gestirn freut sich über ein Zeichen seines Dreiecks oder sein Haus oder über seine Erhöhutung").

${ }^{24}$ Porph. Antr. 21 .

${ }^{25}$ Porph. Antr. 21: „Und weil der Krebs uns (= der Erde) am nächsten liegt, wurcle er mit gutem Grund dem der Erde am nächsten gelegenen Mond zugeschrieben; dagegen wurde der Steinbock, weil der Südpol (für uns) noch unsichtbar ist, dem ganz weit entfern-

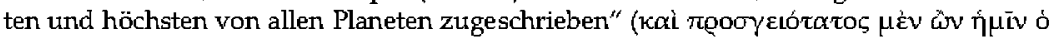

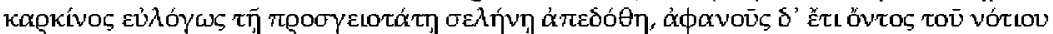

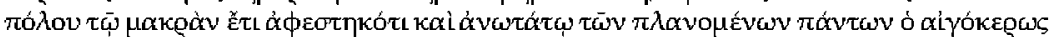
$\alpha \pi \varepsilon \delta \delta \ominus \emptyset)$. Obschon in der Antike unterschiedliche Reihenfolgen cer Planeten geläufig waren (s.o. Anm. 15), galt Saturn üblicherweise als der äußerste und am weitesten entfernteste (vgl. u.a. Bouché-LbCLERCo 1899, 106f. sowie BвсK 1988, 4-8). Fragwürdig ist hingegen die Aussage, das Stembild des Krebses liege der Erde am nächsten, da dieses - nach antiker Vorstellung - wie alle anderen Sternbilder auch auf der Sphäre der Fixsterne liegt und somit von der im Zentrum gelegenen Erde genausoweit entfernt ist, wie alle anderen (vgl. Hü BNBR 2006, 2If.). $\mathrm{Ob}$ Porphyrios hier eine Beziehung zwischen nördlicher Erchalbkugel
} 
re man vom Krebs im Norden zum Steinbock, so finde man der Reihe nach den Löwen als das Haus der Sonne, die Jungfrau (Haus des Merkur), die Waage (Venus), den Skorpion (Mars), den Schützen (Jupiter) und zuletzt den Steinbock (Saturn) im Süden. ${ }^{26}$ Zurück in Richtung Norden folgen zunächst der Wassermann (ebenfalls Haus des Saturn), die Fische (Jupiter), der Widder (Mars), der Stier (Venus) und die Zwillinge (Merkur) sowie schließlich der Krebs (Mond). ${ }^{27}$

Insbesondere aus der Parallel-Darstellung bei Macrobius ${ }^{28}$ bzw. Firmicus Maternus ${ }^{29}$ wird deutlich, wie diese Reihenfolge zu erklären ist: Die so entstandene Zuordnung von Planeten und Zeichen - jeder Planet hat zwei Häuser, ein Tag- und ein Nachthaus, die Luminare Sonne und Mond jeweils nur eines - entspricht nämlich zum einen der allgemein anerkannten Häuserlehre der Astrologie - in diesen Häusern sollen die Planeten besonders wirkungsvoll sein. Zum anderen jedoch wird gleichzeitig jenes Bild skizziert, wie es laut ägyptischem (re vera wohl griechischem) ${ }^{30}$ Welthoroskop sich bot: In exakt dieser Stellung sollen sich die Planeten nämlich im

und nördlichstem Sternbild (vgl. Simonin I 1986, 189f. ad loc.) oder der scheinbaren Erdnähe der Sonne im Krebs im Sommer (vgl. HüBNBR 2006, 22) insinutiert, muss offenbleiben. Dass die Vorstellung, die nördlichsten Stembilder seien der Erde am nächsten, auch ansonsten

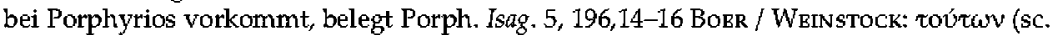

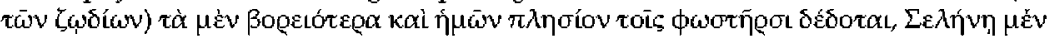

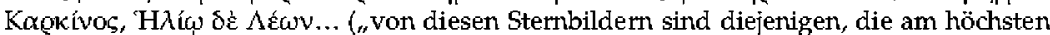
im Norden und uns am nächsten liegen, den Luminaren [Sonne und Mond] zugeteilt worden, dem Mond der Krebs, der Sonne aber der Löwe..."). Doch auch Ptolemaios erklärt die Zuordnung der beiden Luminare zu Krebs und Löwe so, dass die beiden wichtigsten himmlischen Körper den beiden nördlichsten Sternzeichen zugeordnet wurden, da diese

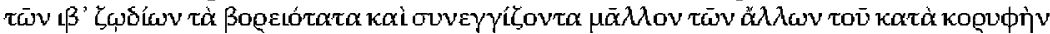

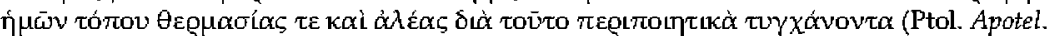
I 17: „von den zwölf Zeichen die nördlichsten seien und näher als die anderen an dem Ort unseres Zeniths seien und daher -hitze und Wärme bewirkten") seien. Zur Unsichtbarkeit des südlichen Himmelspols von der nördlichen Hemisphäre aus vgl. beispielsweise auch Gem. 4,2; Porphyrios selbst kommt auf diese atch in einem ganz anderen Kontext zu sprechen, nämlich in der (kosmologischen) Detutung ces Demeter-Mythos (fr. 358F.417-420

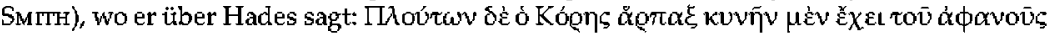

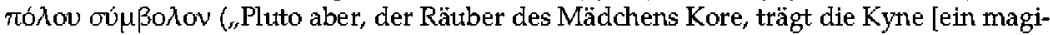
scher Helm, der unsichtbar macht] als Zeichen für den unsichtbaren Pol").

${ }^{26}$ Dies entspricht genau dem Halbkreis, der dem Tag zugehörig ist, also den Taghäusern

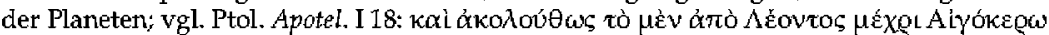

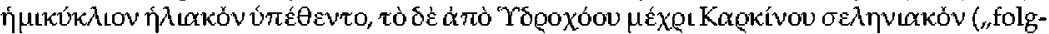
lich bezeichneten sie den Halbkreis vom Löwen bis zum Steinbock als zur Sonne gehörig, den vom Wassermant bis zum Krebs hingegen als zum Mond. gehörig’).

${ }^{27}$ Porph. Antr. 21f. Zu den Planetenhäusern vgl. z.B. Ptol. Apotel. I 8 sowie Firm. Math. II 2 oder Paul Alex. 2, 9,3-6 BoBR.

${ }^{28}$ Macr. Somn. I 21,24-27.

${ }^{29}$ Firm. Math. III 1,1.

${ }^{30} \mathrm{Vgl}$. hierzu insbes. Heilen 2015, 738 sowie Bouché-LbcLerce 1899, 186. 
Moment der Geburt der Welt befunden haben ${ }^{31}$ Die Tierkreiszeichen, in denen sich die beiden Luminare (Mond und Sonne) sowie die fünf Planeten zum Zeitpunkt der Geburt der Welt befunden hätten, bezeichnen also gleichzeitig ihre Häuser, bzw. - bei den echten Planeten - deren Taghäuser. ${ }^{32}$ Es ergibt sich daher folgendes Schema:

\begin{tabular}{lll} 
Planet & Taghaus & Nachthaus \\
\hline Mond & - & Krebs \\
Sonne & Löwe & - \\
Merkur & Jungfrau & Zwilling \\
Venus & Waage & Stier \\
Mars & Skorpion & Widder \\
Jupiter & Schütze & Fische \\
Saturn & Steinbock & Wassermann
\end{tabular}

\section{Die Geburt des Kosmos und die Sothis}

Dass diese Konstellation zugleich das thema mundi ergibt, das in der Antike als ägyptisch galt, angeblich sogar auf Nechepsos und Petosiris zurückgefuihrt werden konnte, ist sicher kein Zufall; denn gerade diese mythischen Ägypter, die auf Grund ihrer Bekanntheit allgemein nur als "die Alten ${ }^{\prime 33}$ o.a.. bezeichnet wurden, galten als Inbegriff uralter Weisheit und geheimen

\footnotetext{
${ }^{31}$ Das sog. thema mundi, welches bereits Nechepsos und Petosiris (s.u. Anm. 34) gelehrt haben sollen (Nech. et Pet fr. 25), findet sich u.a. bei Firmicus Maternus (Math. III 1,1) sowie bei Macrobius (Somn. I 21,23-27) und stellt die Konstellationen zum Zeitpurkt der Geburt der Welt dar. Die Planetenkonstellation, die sich aus dem thema mundi ergibt, findet sich interessanterweise auch im Rahmen des Mithraskultes und der damit verbundenen Vorstellungen wieder, so beispielsweise in einer Darstellung der Stiertötungsszene aus Sidon in Syrien (Abbildung bei CAMPerl 1968, Plate V). Dies impliziert, dass die Zuordnung der Planeten zu ihren Hätsern auch in religiös-kultischem Kontext eine Rolle spielte. Dass dieses Welthoroskop allgemein bekannt gewesen muss, lässt sich u.a. daran erkennen, dass beispielsweise der Astrologe Vettius Valens (2. Jh.) es ohne weitere Erklärutng als bekannt voraussetzt, wenn er den Krebs kommentarlos als Aszendenten der Welt be-

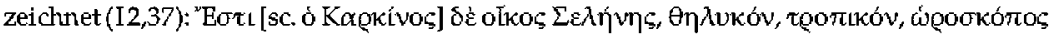

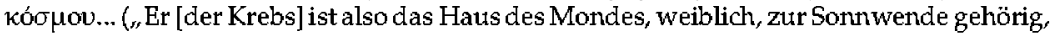
der Aszendent der Welt...").

${ }^{32}$ Da für die zwölf Zeichen nur sieben Planeten zur Verfügung standen, teilte man den beiden Luminaren jeweils ein Hats zu (der nur am Tag sichtbaren Sonne ein Taghaus, dem nächtlich zu sehenden Mond ein Nachthaus), den restlichen fünf Planeten je zwei Häuser, ein Tag- und ein Nachthats; vgl. insbes. Ptol. Apotel. I 18.

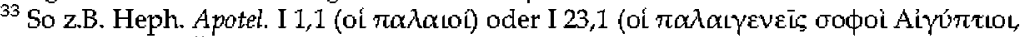
"die alten weisen Ägypter") [im Zusammethang mit dem Aufgang der Sothis]); ebenso auch Val. I 10,27 (ebenfalls in Bezug auf den Aufgang des Sirius); ähnlich Heph. I praef. I

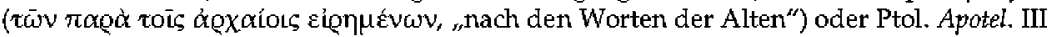

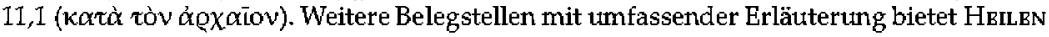
$2015,1033 f$. sowie 1357 .
} 
Wissens - also genau jener $\pi \alpha \lambda \alpha u d$ ooфí $\alpha$, deren Spuren Porphyrios in der Darstellung Homers aufzudecken sucht. ${ }^{34}$

Bezeichnenderweise ist nun dieser Augenblick der Geburt der Welt identisch mit dem (allerdings jährlich wiederkehrenden) Frühaufgang des bei den Ägyptern Sothis genannten ,Hundssterns' Sirius, dessen erstes Erscheinen vor Sonnenaufgang das ägyptische Neujahr bezeichnet habe, wie auch Porphyrios wenig später zu berichten weiß. ${ }^{35}$ Beginn des ägyptischen Sothis-Jahres ist also der heliakische Aufgang des Sirius, mit anderen Worten der exakt einmal im Jahr wiederkehrende Moment, in dem der Fixstern Sirius, der dann auf Grund seiner Helligkeit gut am Nachthimmel sichtbar ist, nach einer Phase der nächtlichen Unsichtbarkeit kurz vor Aufgang der ihn dann überstrahlenden Sonne am östlichen Horizont erkennbar ist. ${ }^{36} \mathrm{Da}$ das sich daraus ergebende siderische Jahr jedoch ca. 3651/4 Tage lang ist, das in Ägypten aber gleichzeitig gebräuchliche bürgerliche (Mond-)Jahr nur 365 Tage misst, verschiebt sich der Aufgang des Sirius alle vier Jahre um einen Tag im Mondkalender und wandert innerhalb von 1460 Jahren einmal durch ihn hindurch (sog. Sothis-Periode). Der Beginn einer solchen Sothis-Periode wurde in der Antike als Neuanfang betrachtet, da zu Beginn des jeweils ersten Jahres die Erde durch Überschwemmungen im Winter und Weltenbrand im Sommer untergehe und neu entstehe. ${ }^{37}$ Dies

\footnotetext{
${ }^{34}$ Vgl. zu Nechepsos und Petosiris insbesondere HeiLrn 2015, 539-562: Der Weise Petosiris und der alte ägyptische König Nechepsos galten als Verfasser des ersten großen astrologischen Handbuches. Dabei handelt es sich aller Wahrscheinlichkeit nach jedoch lediglich um Pseudonyme, um alte (ägyptische) Weisheit zu suggerieren; dennoch galten die auf sie zurückzuführenden, oftmals komplizierten und mystischen astrologischen Lehren, die sicherlich überwiegend der Zeit des Hellenismus entstammen, in der Antike als uralt. Bezeichnenderweise geht Porphyrios in seiner Schrift über die Nymphengrotte ganz ähnlich vor, wenn er im (tatsächlich) alten Homertext Hinweise auf (vermeintlich) alte Weisheit aufzudecken sich anschickt, die sich jedoch tunschwer als (überwiegend zeitgenössische) Vorstellungen neuplatonischer Provenienz erkennen lassen. Auch hier zeigt sich insofern eine Analogie hinsichtlich des Vorgehens bzw. der Argumentation. Zu den $\pi \alpha \lambda \alpha$ toi und Homer vgl. auch den Beitrag von Irmgard Männlein-Robert in diesem Band, S. 100.

${ }^{35}$ Porph. Antr. 24. Nicht ganz klar hierzu ist die Darstellung bei SimoninI 1986, 200. Tatsächlich bezeichnet das in Ägypten übliche Sothisjahr die Zeitspanne "zwischen zwei heliakischen Frühaufgängen des Fixsterns Sirius am gleichen Breitengrad" (vON BOMHARD 1999, 26).

${ }^{36}$ Vgl. von BomHaRd 1999, 26. Der astronomische Aufgang des Sirius ẗber den Horizont ist auf Grund der ihn überdeckenden Helligkeit der Sonne nur mathematisch berechenbar, kann aber nicht mit bloßem Auge beobachtet werden; er findet ein paar Tage vor dem sichtbaren Aufgang des Sirius statt. Zur Verbindung des Sirius-Aufgangs mit persischen Kulten, insbesondere dem Mithraskutt, vgl. MerKeLBACH 1984, 79 Atum. 7.

${ }^{37}$ Vgl. Cens. 18,10f. Vgl. auch die Bezeichnung der Sothis bei Porphyrios (24) als

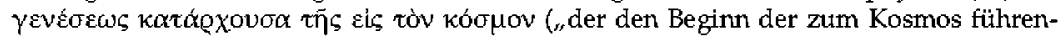
den Entstehung markiert"), die wahrscheinlich auf diese Vorstellung des durch den Siritus angezeigten (bzw. bewirkten) Neuanfang zurückzuführen ist; vgl, hierzu u.a. auch. HBILEN 2015, 1268 sowie unten Anm. 39. Dies wird noch verstärkt, da der Frühaufgang des Sirius auch mit dem Beginn der Nilschwemme in etwa zeitlich zusammenfällt (vgl. Hdt. II 19f.).
} 
bedeutet, der heliakische Aufgang des Sirius fällt streng genommen nur zu Beginn einer Sothis-Periode (also alle 1460 Jahre) mit dem ägyptischen Neujahr zusammen. Dessen ungeachtet verweist beispielsweise auch Ptolemaios im Kontext der Frage nach dem Neujahr auf die Bedeutung des Sirius bei den Ägyptern, ohne jedoch einen eindeutigen Zusammenhang herzustellen. ${ }^{38}$ Während terminologische und inhaltliche Konvergenzen Anlass zu der Vermutung geben, dass Porphyrios an dieser Stelle schlicht der Darstellung des Ptolemaios folgen könnte, darf als sicher gelten, dass die Darstellung bei Porphyrios vereinfacht an seine eigene Argumentation adaptiert wurde, da er auf die Diskrepanz zwischen bürgerlichem Jahr und Sothis-Jahr nicht eingeht und schwierige astronomische Details, die ihm sicherlich bekannt waren, unterschlägt. ${ }^{39}$ Es ist daher nicht unwahrscheinlich, dass Porphyrios mit der astronomisch und mathematisch komplexen Materie des Sirius-Aufgangs zwar durchaus vertraut war, auf nähere Details an dieser Stelle jedoch verzichtet, um die vermeintliche Stringenz seiner Darstellung nicht zu gefährden und den Leser nicht mit zu viel Details zu verwirren.

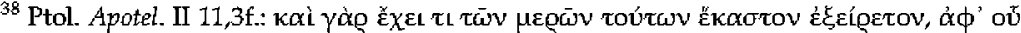

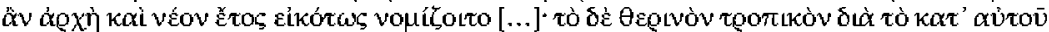

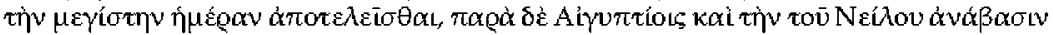

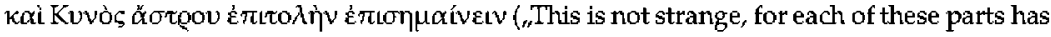
some special claim to being reasonably considered the starting-point and the new year $[\ldots]$; the summer solstice because the longest day occurs at that time and because to the Egyptians it signifies the flooding of the Nile and the tising of the dog star", Übers. Robbins). Hier findet sich ebenfalls der prägnante Gebrauch des Wortes vou $\mu \eta v i \alpha={ }_{\text {"erster Mond }}$ des netuen Jahres (i.S.v. Netjahr)" vorgezeichnet; vgl. die wenig aussagekräftige und it Bezug auf die vorliegende Stelle unzutreffende - gemeint ist ja die Sommersontrwende,

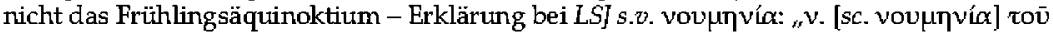
Ě̃ouร of the spring equinox" (leider auch keine Ergänzung im Supplementband). Hinzu kommt, dass der heliakische Aufgang des Sirius vom Beobachtungsort abhängig ist und daher verschieden terminiert wird; Ptolemaios beispielsweise (Ptol. Synt. 8,1) lässt ihn auf $17^{\circ} 40^{\prime}$ des Sternbildes der Zwillinge aufgehen. Auch dieses astronomisch relevante Detail findet bei Porphyrios keine Erwähnung.

${ }^{39}$ Dies gilt umso mehr, als auch in der (hellenistischen) Astrologie der Aufgang des Sirius, insbesondere in den sog. Sothis-Prognosen, eine bedeutende Rolle spielt, wobei anhand seiner farblichen Erscheinung und der mit ihm in Konjunktion stehenden Planeten Vorhersagen für die Zukunft getroffen werden. Hierbei ist natürlich eine genaute Berechnung unabdingbar: Vgl. zu dieser Thematik bereits Chalcid. Comm. 125; Sothisprognosen unterschiedlicher Art bietet beispielsweise Heph. I 23. Dass auch an dieser Stelle bei Porphyrios an eine Verbindung mit dem Geburtsmoment der Welt gedacht ist, macht die zunächst et-

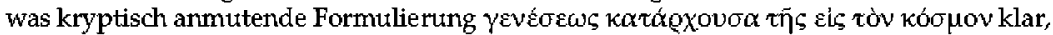
die wohl zu verstehen ist als „, den Beginn der zum Kosmos führenden Entstehung (i.S. des Kosmos als Produkt der Entstehutng) markierend"; vgl. etwa die Bedeutung von $\gamma$ ív

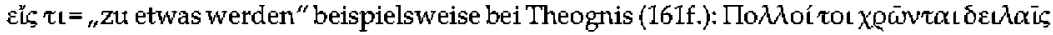

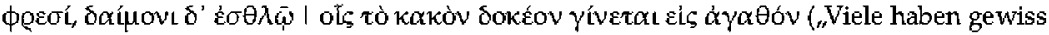
schlechte Herzen, aber einen guten Schutzgott; für sie wird das scheinbar Schlechte zu et-

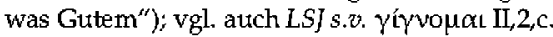


Auch hier wird deutlich, dass Porphyrios seinen Argumentationsgang durch astronomisch-astrologische Argumente zu untermauern versteht; so kann er die Höhle Homers in seinem Sinne als Symbol des Kosmos deuten, da diese, wie der Kosmos, zwei Aus-bzw. Eingänge habe, auf welchen die Menschen und unsterblichen Wesen jeweils ein- und ausgehen. Dabei setzt er die Wendepunkte der Sonne in den Sternbildern des Krebses bzw. des Steinbocks in Analogie zum Ein- und Ausgang der Höhle bzw. den Auf- und Abstieg der Sonne im Laufe eines Jahres zum Auf- und Abstieg in und aus der Höhle. Wie bei Homer bezeichnet der nördlichere Punkt (Krebs) den Abstieg, während der südliche Wendekreis den Aufstieg der Seelen markiert. Auf diesem Wege gelingt es Porphyrios, mehrere Fliegen mit einer Klappe zu schlagen: Denn die astronomisch-astrologische Argumentation erlaubt es ihm nicht nur, seine bereits von Anfang an intendierte Gleichsetzung von Höhle und Kosmos auch vor dem Hintergrund astronomisch-astrologischer "Wissenschaft" anhand der beiden Aus- bzw. Aufgänge zu belegen (und somit in den Referenzrahmen allgemeinen astrologischen bzw. astronomischen Wissens einzubetten), sondern gleichzeitig auch, den Nord-Süd-Antagonismus (Krebs und Steinbock) als Ausgangspunkt der (neuplatonischen, für Porphyrios aber eben von Homer vorgezeichneten) Seelenwanderungslehre zu etablieren. ${ }^{40}$ Gleichzeitig rekurriert er auch mit der Einführung der für einen Anfang stehenden Sothis und dem damit in Verbindung stehenden Geburtshoroskop der Welt auf die Wiedergeburt der Seele. Durch diese Verflechtung unterschiedlicher Argumentationskontexte gelingt es dem Autor, sein theologischmystisches Weltbild in den Homertext einzuschreiben und anhand allgemeingültiger, als uralt konnotierter (ägyptischer) Weisheit zu belegen, um somit seine idiosynkratische, dezidiert philosophische Deutung des poetischen Textes zu verifizieren.

Dass Porphyrios nicht nur die Aufteilung der Planetenhäuser bekannt ist, sondern auch andere Verbindungen der Sternzeichen mit den Planeten, ergibt sich beispielsweise aus Kap. 18, wo er den Stier mit dem Mond in Verbindung bringt und ihn als "Erhöhung" (ü $\psi \omega \mu \alpha$ ) des Mondes bezeichnet. Dieser Ausdruck ist erst vor dem astrologischen Hintergrund verständlich, dass jedem Planeten nicht nur sein (Tag- und Nacht-)Haus zugewiesen wird, sondern zusätzlich dazı jeder Planet einen Ort der Erhöhung (î $\psi \omega \mu \alpha$ ) sowie der Emiedrigung ( $\tau \alpha \pi \varepsilon i v \omega \mu \alpha$ ) hat. Dabei wird jedem Planeten ein Grad im Tierkreiszeichen zugesprochen, an dem sein Wirken besonders stark ist, sowie - diametral gegenüberliegend, also $180^{\circ}$ entfernt - ein Ort, der sein Wirken besonders beeinträchtigt. Als Orte die-

\footnotetext{
${ }^{40}$ Vgl. hierzu auch Alt 1998, 481. Die Analogie von Kosmos und Höhle expliziert Porphyrios bereits zu Beginu seiner Abhandlung (insbes. De antro 5-9). Die Seelenwanderung wird mit der Nord-Süd-Bewegung direkt im Anschluss an die Mithraspassage (ab Kap. 25) verkniüpt.
} 
ser Wirkung der Erhöhung und Erniedrigung der Planeten ergeben sich dann folgende Zeichen: ${ }^{41}$

\begin{tabular}{lll} 
Planet & Erhöhung & Erniedrigung \\
\hline Mond & Stier & Skorpion \\
Sonne & Widder & Waage \\
Merkur & Jungfrau & Fische \\
Venus & Fische & Jungfrau \\
Mars & Steinbock & Krebs \\
Jupiter & Krebs & Steinbock \\
Saturn & Waage & Widder
\end{tabular}

Vor diesem astrologischen Hintergrund wird es verständlich, wenn Porphyrios die Verbindung $z$ wischen Stier und Mond nicht nur über mythische Verbindungen, sondern auch über die astrologische Zuweisung des Stieres als Ort der Erhöhung für den Mond herstellt. ${ }^{42}$ So kann er den Zutsammenhang zwischen Mond und Stier auch anhand astrologischer $\mathrm{Zu}-$ sammenhänge darlegen, die jedem astrologisch hinlänglich kundigen Leser bewusst gewesen sein müssen. ${ }^{43}$

\footnotetext{
${ }^{41}$ Vgl. etwa Sext. Emp. Adv. math. V 35f. sowie Firm. Math. II 3. Zur Begründung der Übertragung der eigentlich einzelnen Punkte auf die gesamten Zeichen vgl. Ptol. Apotel. I 20.

${ }^{42}$ Die Verbindung von Mond tund Stier ist auch ansonsten nicht ungewöhnlich. Tertium comparationis ist zumeist die Sichelform des Mondes, die mit einem Horn assoziiert wird (vgl. z.B. Arat. 790; Hor. Carm. IV 2,57; Lact. Inst. I 21); vgl. beispielsweise auch Nonn.

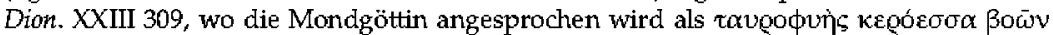
$\varepsilon \lambda \alpha \tau \varepsilon\llcorner\varrho \alpha \Sigma \Sigma \varepsilon \lambda \eta \cup \eta$ (,stiergestaltige, gehörnte Attreiberin der Ochsen, die Mondgöttin").

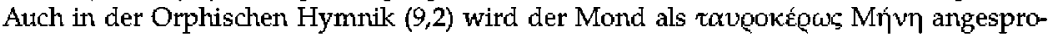
chen.

${ }^{43}$ Die Feststellung, dass man den Mond auch als Biene anspreche, da er yevéocus

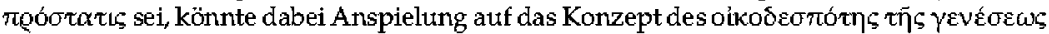

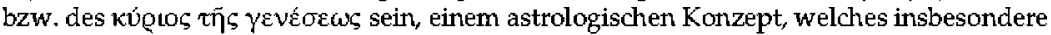
auch von Porphyrios in seiner Isagoge eingehend besprochen wird, jedoch attch bei anderen Schriftstellern Anwendung findet (Porph. Isag. 30, 206,1-208,5 BoER / W EINSTOCK); vgl. auBerdem die Darstellungen des Firmicus Maternus zum dominus geniturae (Math. IV 19,2). Eine moderne Darstellung astrologischen Konzeptes bieten Bouchí-LecLERCo 1899, 405408 (weitgehend veraltet) sowie umfassend HerLen 2015, 1057-1075. Hierbei kann nach verschiedenen Methoden ein (Haus-)Herr des Horoskopes ermittelt werden, der maßgeblich über die Anzahl der Lebensjahre bzw. den Todeszeitpunkt entscheidet (Firm. Math. IV 19,1): Qui, si bene fuerit collocatus in his, in quibus gaudet signis vel in quibus exaltatur, vel in domicilis suis, et conditionis suae genitura fuerit, nec malizolarum nociva radiatione pulsatus nec benivolarum stellarum praesidio destitutus, omnia bona pro naturae suae qualitate decernit et integrum annorum numertum (, Steht er gut in den Zeichen, in denen er sich fretst, in denen er erhöht wird oder in seinen Hätsern, und steht die Geburt utrter seiner Herrschaft und wird er nicht durch einen schlechten Aspekt der Übeltäter behindert oder vom Schutz der Wohltäter im Stich gelassen, so schenkt er der Qualität seiner natürlichen Beschaffenheit gemäß alles Gute uthd die volle Zahl der Planetenjahre"). Die hierbei verwendeten Metho-

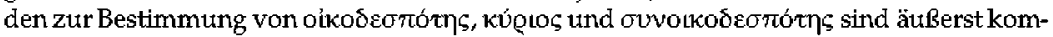




\section{Mithras am Sternenhimmel?}

Durch die Betonung der genannten Gegenüberstellung von Norden und Süden, nicht jedoch Osten und Westen oder der Tag- und Nachtgleichen - im dritten Kapitel hatte Porphyrios noch darauf hingewiesen, dass die Nord-Süd-Ausrichtung bei Homer insofern ungewöhnlich ist, als die meisten Tempel und Götterstatuen entlang der Ost-West-Achse ausgerichtet seien - kommt Porphyrios im 24. Kapitel seiner Schrift über die Nymphengrotte erneut auf die Figur des Mithras zu sprechen, der bereits früher (6) vom Autor eingeführt worden war als "der Schöpfer und Vater von allen"

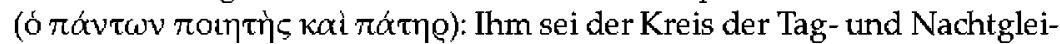
chen als passender Sitz gegeben worden, da er das Schwert des Widders trage, des Zeichens des Mars, und auf dem Stier der Venus reite. Als Demiurg und Herrscher über die Entstehung sei er dort aufgestellt und halte den Norden mit der rechten Hand, den Süden jedoch in der linken Hand. ${ }^{44}$

Auch hier greifen wieder kultisch-mythologische und astrologischastronomische Argumentation nahtlos ineinander: Mit Tag- und Nachtgleichen (ion $\mu \varepsilon$ gíat) sind selbstverständlich das Frühlings- bzw. Herbstäquinoktium gemeint, die sich zu Beginn der Tierkreiszeichen Widder und Waage befinden. Stier und Messer hingegen sind zunächst einmal zur Kult-Ikonographie des Mithras gehörige Attribute, wie anhand zahlreicher archäologischer Funde belegt ist. ${ }^{45}$ Gleichzeitig lassen sie sich jedoch auf

pliziert und müssen hier nicht en détail dargelegt werden; bezeichnend ist jedoch, dass in den meisten Fällen der Mond eine bedeutende Rolle spielt, nach einer bei Firmicus Maternus referierten Ansicht ist es sogar immer der Herr über die Erhöhung des Mondes, der Hausherr der Geburt ist (Firm. Math. IV 19,2: Alii eum dixerunt esse dominum, qui altitudinis Lunae dominus fuisset inventus). Dies würde immer Venus als Hausherren ergeben, da sie Herrin des Stiers ist, in welchem seinerseits der Mond seine Erhöhung hat. Da sich Porphyrios ausführlich in seiner Isagoge mit der Frage nach dem Herm der Geburt beschäftigt hat, scheint es zumindest nicht unwahrscheinlich, auch an dieser Stelle eine Verbindung mit diesem astrologischen Konstrukt zu vermuten. Die Verbindung zwischen astrologischem Hausherrn und dem ägyptischen Jahresbeginn zum Aufgang des Sirius schlägt u.a. Vettius Valens (I 10,10-13).

${ }^{44}$ Die Stelle ist schwierig zu verstehen und bereits textkritisch umstritten. Roger BвCK

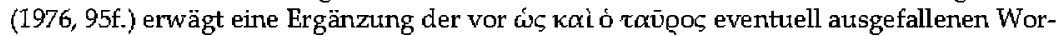

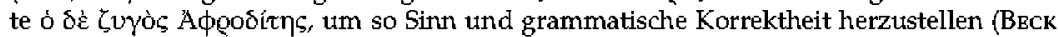
1976, 97): "[A]s it stands, the text not only makes little sense logically but is also suspect on grounds of syntax and style." Kritisch hierzu bereits SrEIDEL 1980, 20 ("Unfortunately this [...] solution is altogether invented and has no support in the manuscript tradition ${ }^{\prime \prime}$ ), der der Figur des Mithras den Himmelsäquator zuweist (ebd., 20-22). Ebenfalls kritisch HübNBR 2006, 29, der die Konjektur für ${ }_{s}$ zut gewagt ${ }^{\prime \prime}$ (ebd.) hält, den Fokus jedoch im Gegensatz zu Speidel auf die Grenze zwischen den zwei Zeichen gerichtet wissen will. Vgl. hierzu auch die Überlegungen von Christoph Riedweg in diesem Band, S. 94-95.

${ }^{45}$ Zum Messer des Ares vgl. insbes. Camprebl 1968, 73f, der auch auf die Verbindung zur im Mithraskult bedeutenden Tauroktorie eingeht. Vgl. hierzu auch CLAuss 2012, 66f. sowie 72-74, der auch auf die Darstellung des Messers bei der Felsgeburt des Mithras sowie dessen Wasserwunder hinweist. Insbesondere der fünfte Weihegrad im Mithraskult, 
einer weiteren Ebene auch astronomisch bzw , astrologisch deuten und so auf den genannten Platz der Tag- und Nachtgleiche beziehen. Denn Aphrodite, deren Nennung zunächst überraschend scheint, ist als Planetengöttin der Venus Hausherrin des Sternbildes des Stiers, welches direkt neben dem Widder sich befindet und damit tatsächlich in der Nähe der Tag- und Nachtgleiche. ${ }^{46}$ Und auch das Messer, eine eher ungewöhnliche Waffe für den griechischen Kriegsgott Ares, bei dem man mindestens ein Schwert erwarten würde, scheint hier zunächst fehl am Platz. Bedenkt man jedoch, dass der Widder das Nachthaus des Mars ist (s.o.) und es in der Nähe dieses Stembildes ein weiteres Sternbild des Messers gibt, das seinerseits zum Sternbild des Perseus gehört, wird auch der astronomische Bezug zu den Tag- und Nachtgleichen evident. ${ }^{47}$ Tatsächlich gibt es verschiedene Möglichkeiten, auch die Figur des Mithras konkret am Himmel zu verorten; insbesondere zwei Sternbilder scheinen ihr gut zu entsprechen: Zum einen der Perseus, ein am nördlichen Sternhimmel gelegenes Sternbild neben der Kassiopeia und dem Fuhrmann, direkt zwischen Widder und Stier. ${ }^{48}$ Zum anderen scheint auch der Orion der bei Porphyrios gebotenen Darstellung in manchem Detail zu entsprechen, doch auch andere Sternbilder wie der Kepheus ${ }^{49}$ könnten bei der Beschreibung des Mithras

der Perser, verfügt über ein persisches Kurzschwert, den sog. Akinakes, als Attribut; vgl. MgRKELBACH 1984, 79 sowie 85.

${ }^{46}$ Auch Arat betont die Zugehörigkeit des Äquinoktiums zu Widder und Stier, wenn

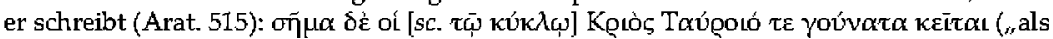
Zeichen liegt bei ihm der Widder und die Knie des Stiers").

${ }^{47}$ Das extrazodiakale, also nicht zum Tierkreis gehörige, Sternbild des Messers (grie-

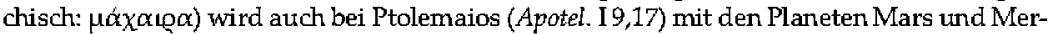
kur in Verbindung gebracht wird; es liegt an der Hand des (ebenfalls nicht zum Zodiakus gehörigen) Sternbildes Perseus, eine weitere $\mu \alpha \chi \alpha \alpha\lfloor\alpha$ befindet sich am Sternbild des Orion (Ptol. Synt. 8,1, 134,19). Hier könnte eine auch sonst nicht unïbliche Gleichsetzung des Mithras mit Perseus-Orion impliziert werden.

${ }^{48}$ Arat $(709-711)$ lässt seinen Kopf und die Schultern mit dem Widder aufgehen. Er entspricht nicht nur sehr gut der bei Porphyrios evozierten räumlichen Anordnung, sondern entspricht auch mit seinen Attributen dem (stiertötenden) Mithras; dazu gehören insbesondere (vgl. Manil. V 22: victor et invisae Perseus cum falce Medusae, „und Perseus, der Sieger über die nicht ansehbare Medusa, mit seinem Krummschwert") das Kurzschwert, die sog. Harpe (vgl. auch die Darstellung des Teukros im CCAG VII, 195,5-9), die nicht nur der bei Porphyrios erwähnten $\mu \alpha \chi \alpha$ L $\alpha$ entspricht, sonclern auch in anderen Mithrasc.arstellungen als dessen Attribut Darstellung findet, sowie die phrygische Mütze, wie sie beispielsweise die Miniaturen im Codex Vossianus Leidensis 79 (f. 40v) oder im reich bebilderten Codex Vaticantus Reginensis Latinus 123 (Perseus auf f. 194v) bieten. Auch Kronos erhält von seiner Mutter Gaia eine Harpe, um seinen Vater zu töten (vgl. Hes. Theog. 175). Hinzu kommt, dass beispielsweise auch die Weihegrade des Mithraskultes ihre Entsprechung in Sternbildern zu haben scheinen (vgl. die Übersicht bei MerkrLBACH 1984, 85).

${ }^{49}$ Auffällig sind beispielsweise die nach beiden Seiten ausgebreiteten Arme. Auch Kepheus trägt wie Mithras in manchen Darstellungen die phrygische Mütze (so etwa auf dem Atlas Farnese). Obschon er eigentlich mit dem Sternbild des Schützen aufgeht (so beispielsweise Arat. 674f.), wird er bisweilen auch mit dem Widder in Verbindung gebracht. 
am Himmel Pate gestanden haben. In diese Richtung geht beispielsweise die Ansicht von Michael Speidel, der in der Darstellung eine Gleichsetzung des Mithras mit dem Sternbild des Orion erkennt und folglich als eine Sternkarte verstanden wissen will. ${ }^{50}$ Darauf aufbauend konnte David Ulansey im Jahre 1989 die These aufstellen, Mithras sei als Sternbild des Perseus am Himmelsäquator aufgestellt zu denken, der jedoch nicht zwischen Waage und Widder gedacht sei, sondern auf Grund der Präzession der Erdachse und den damit verbundenen Verschiebungen dem Himmelsäquator um ca. 4000 v. Chr. entspreche, als er durch die Zeichen Skorpion und Stier verlief; die Szene der Stiertötung sei somit die rituelle Umsetzung jenes astronomischen Phänomens, auf Grund dessen sich im zweiten vorchristlichen Jahrtausend der Frühlingspunkt vom Stier in das Sternbild des Widders bewegt habe und daher eine metaphorische Stiertötung. ${ }^{51}$

$\mathrm{Ob}$ man jedoch davon ausgehen muss, dass Porphyrios hier wirklich ein explizites (himmlisches) Vorbild vor Augen hat, bleibt äußerst fraglich; auch kultische Ikonographie könnte für die Darstellung ausschlaggebend sein. ${ }^{52}$ So zeigt beispielsweise das Barberini-Mithräum in Rom auf einem Fresko die Stiertötungsszene: ${ }^{53}$ Über der zentral sich befindlichen Figur des Mithras ist dabei auch ein Tierkreis (allerdings als Band) von rechts nach links angeordnet; zwischen Jungfrau und Waage, genau in der Mitte des Bildes und somit gleichzeitig auf dem Herbstäquinoktium, steht eine Statue von Kronos-Saturn auf einem Himmelsglobus. Auch auf einem in

\footnotetext{
${ }^{50}$ SPEIDEL 1980, 20 geht von einer Gleichsetzung von Mithras mit Orion aus. Er weist der Mithrasfigur den (Himmels-) Äquator zu (s.o. Anm. 44) und setzt ihn in Folge dessen mit dem ebenfalls am Äquator befindlichen Orion (vgl. Arat. 515 [zitiert in Anm. 46]) gleich. Dies sei besonders passend, da der mythische Jäger auch ansonsten Führer der Gestirne (vgl. z.B. Manil. I 395) sei. Die in der Stiertötungsszene ihre Entsprechung findenden Sternbilder seien also "all those visible together at any one time along the equator behind Taurus and Orion" (SPridel 1980, 18).

${ }^{51} \mathrm{Vgl}$. UlANSBY 1989, 25f. sowie 76-78. Diese Theorie scheint jedoch sehr voraussetzungsreich und äußerst kompliziert und daher wenig für De antro geeignet; dies gilt umso mehr, als die wichtigste Quelle für diese Theorie, Porphyrios selbst, eben keine Erklärung des Mithraskultes, geschweige denn eine derart enigmatisch-verrätselte, lieferm will, sondern den Mithras als ein (!) Argument für die in den Worten Homers überlieferte alte Weisheit in seine Abhandlung aufnimmt. Eine derart komplexe Beschreibung, die lediglich einem esoterischen Zirkel astronomisch Gebildeter zugänglich wäre, scheint - noch dazu ohne wirklichen konkreten Hinweis in diese Richtung - eher tnpassend.

${ }^{52}$ Während Michael Speidel Mithras mit der Konstellation des Orion tund David Ulansey mit dem Sternbild des Perseus gleichsetzen, warnt Roger Beck vor einer eindeutigen Identifizierung der Mithrasfigur (BEсK 1988, 48f.). Er verweist im Gegenzug auf eine MithrasDarstellung mit Tierkreis (sog. Trier-Monument, CIMRM 985), die zur Mlustration der vorliegenden Stelle geeignet sei (ebd., 40 Atrm. 1): ,There could be no neater way, incidentally, of rendering iconographically the difficult cloctrine, recorded by Porphyry" (De antro 24). In diese Richtung weisen auch Kautes und Kautopates, die neben Mithras Erwähnung finden und fest mit dessen Kultikonographie verwoben sind.

${ }^{53}$ CIMRM 390.
} 
London befindlichen Relief sieht man klar, dass die Äquinoktien auf Höhe des Mithras sind. ${ }^{54}$ Besonders passend jedoch ist das sogenannte TrierMonument, eine Darstellung der Felsgeburt des Mithras mit Tierkreis: ${ }^{55}$ Bei diesem Zeugnis fällt auf, dass der Tierkreis nur eben jene sechs nördlichen Zeichen vom Widder bis zur Jungfrau abbildet. Dies bedeutet, Mithras befindet sich hier - wie Porphyrios es beschreibt - an den (beiden!) Äquinoktien, in der linken Hand eine Weltkugel, die rechte Hand am Tierkreis auf der Höhe des Krebses - und damit, wie bei Porphyrios beschrieben, im Norden; ${ }^{56}$ auch die später bei Porphyrios erwähnten Winde (25) sind in den Ecken dieses Monumentes abgebildet.

Ebenso könnte es sich bei der Beschreibung des Mithras um eine räumliche Anordnung, wie sie beispielsweise im Rahmen des Kultes in den Mithräen stattgefunden haben könnte, handeln. So gibt das in Ostia Antiqua ausgegrabene Mithräum delle sette sfere klaren Hinweis, dass nicht nur die himmlischen Gegenden in Form der Tierkreiszeichen hier ihre Entsprechung fanden, sondern sogar die Himmelskreise (Himmelsäquator und Tag-und Nachtgleichen) auf dem Boden abgebildet waren, ${ }^{57}$ die Aussage des Porphyrios könnte also ebenfalls lediglich eine räumliche Anordnung im Kultraum widergeben. ${ }^{58}$

Die ohne weitere Erklärung dargebotene Beschreibung scheint daher auch an dieser Stelle Hinweis zu geben, dass es Porphyrios um eine - zugegebenermaßen recht eigentümliche - Mischung kultischer und astrologisch-astronomischer Vorstellungen geht, die miteinander verquickt die Argumentation stützen sollen und dem Leser - je nach Hintergrundwissen - die Stringenz seiner Ausführungen verdeutlichen soll; eine wie auch immer geartete Sternkarte für einen esoterischen Zirkel des Mithraskult scheint hier hingegen fehl am Platze: Für seine Argumentation kommt es dem Autor vornehmlich auf die Gegensätze der Äquinoktien und Solstitien an, anhand derer die unterschiedlichen Tore, die für den Auf- und Abstieg der Seelen Voraussetzung sind, verifiziert werden sollen.

\footnotetext{
${ }^{54}$ CIMRM 810; Abbildung auch bei MerkelBach 1984, 329 (Abb. 81). Auch hier sind zwei Windgötter am Rand des Reliefs zu erkennen. Ahnlich auch die Kosmogonie, die im Relief in Housesteads (CIMRM 860) dargestellt wirc.

${ }^{55}$ CIMRM 985; Abbildung bei CAMPBELL 1968, Plate XVIII.

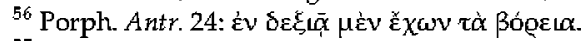

${ }^{57}$ CIMRM 239; Abbildung und Erläuterung auch bei MrRквLвACH 1984, 292 (Abb. 34).

${ }^{58} \mathrm{Vgl}$. Porph. Antr. 6. Siehe hierzu auch den Beitrag von Christoph Riedweg in diesem Band, S. 87-88 mit Anm. 64.
} 


\section{Nord-Süd-Antagonismus: Die vier kévt@d}

Ein weiterer Antagonismus unterschiedlicher Richtungen, die die Seelenwanderung untermatiern sollen, findet sich ernetut etwas später im Text

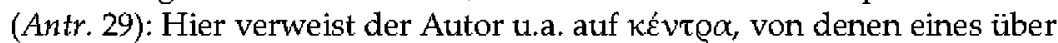
der Erde, eines unter der Erde, eines rechts und eines links sei. ${ }^{59}$ Obschon dies möglicherweise auch auf pythagoreische Vorstellungen von den zehn (gegenteiligen) Prinzipien rekurriert, scheint es jedenfalls unatusweichlich, hier zunächst eine Verbindung mit den astrologischen Kardinalpunkten ( $\kappa \varepsilon ́ v \tau \varrho \alpha$ ), womit die Punkte bezeichnet werden, an denen sich die Ekliptik mit dem Horizont und dem Ortsmeridian schneidet, ${ }^{60}$ herzustellen, was insbesondere durch die Terminologie suggeriert wird, bezeichnet Por-

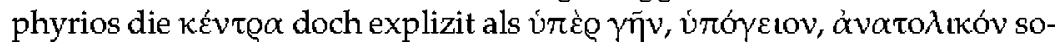

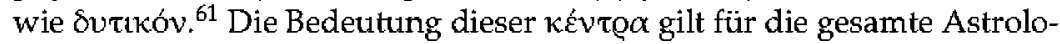
gie und insbesondere Porphyrios betont in seiner Isagoge mehrfach deren Bedeutung und baut sie in ein System astrologischer Zuordnungen ein, welches sich bei ihm zuerst überliefert findet und das auch heute noch nach ihm benannt wird. ${ }^{62}$ Die chiastische Anordnung macht dabei deutlich, dass Porphyrios den westlichen Kardinalpunkt links verstanden haben will, den östlichen hingegen rechts; dem oberen Kardinalpunkt, der

\footnotetext{
${ }^{59}$ Simonini 1986, 223 verweist im Kommentar zur Stelle auf die klassischen pythagoreischen Gegensätze (A rist. Met. 986a), ein Hinweis auf die astrologische Konnotation der kéviog fehlt hingegen.

${ }^{60}$ Hierbei wird im Gegensatz zur jährlichen Sonnenrotation die Tagesrotation von Sonne, Fixsternen und Zeichen betrachtet, die sich innerhalb von 24 Stunden genau einmal $360^{\circ} \mathrm{um}$ einen irdischen Beobachter drehen. So ergeben sich der Aszendent als der Aufgangspunkt im Osten (Schnittpunkt von Ekliptik und Horizont), die obere Himmelmitte als Kulmination im Süden (freilich nicht zwingendermaßen senkrecht über dem Beobachter, je nach Standort), der Untergangspurkt im Westen sowie die untere Himmelsmitte im Norden.

${ }^{61}$ Exakt dieselbe Terminologie findet sich auch für die astrologischen Kardinalpunkte: Hierbei handelt es sich um die Sektoren, die bei der Aufteilung des täglichen Sonnenlaufes auf einen Kreis, dessen Schnittpunkt Horizont und Ortsmeridian sind, entstehen. $\mathrm{Zu}$ den üblichen Bezeichnungen siehe Bouché-Lbclerce 1899, 258: Die obere Himmel-

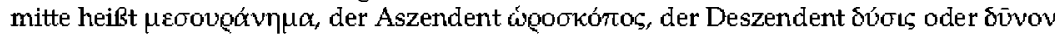

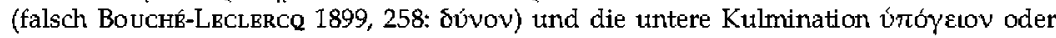

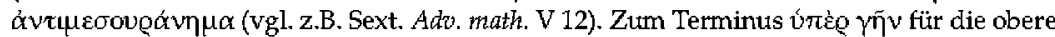
Himmelmitte vgl. etwa Vett. Val. I 21,27, wo die Hemisphäre, die vom Attge des Betrachters aus über dem Horizont liegt, als v́ wo der Mond bis zum Untergang als únépeı

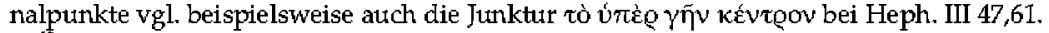

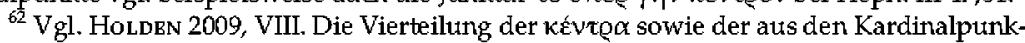
ten gebildeten Quadranten wurde oftmals mit anderen antiken Vierteilungen (Elemente, Jahreszeiten oder der 4-Säfte-Lehre) in Zusammenhang gebracht (vgl. Hü BNER 2003, 112). Bei Hephaistion von Theben beispielsweise findet sich die naheliegende Ineinssetzung mit den Himmelsrichtungen (Heph. III 4,8).
} 
über dem Horizont liegt, wird entsprechend der Tag zugewiesen, dem unter dem Horizont befindlichen die Nacht. ${ }^{63}$

\section{Auf- und Abstieg der Seelen}

Die genannten Antagonismen haben jedoch bei Porphyrios keinen Selbstzweck, sondern dienen als Beleg für die Gegenüberstellung von Auf- und Abstieg der Seelen durch die Planetensphären und den Zodiakus bzw. durch die bereits von Platon vorgezeichneten zwei Tore $(\sigma \tau \dot{\mu} \mu \alpha){ }_{i}^{64}$ dass es sich hierbei um ein bedeutendes Element des neuplatonisch-kultischen Hintergrundes handelt, liegt auf der Hand. ${ }^{65}$ Betrachtet man die bei Porphyrios dargestellten Informationen allerdings genauer, wird schnell deutlich, dass, zumindest in De antro, kein in sich schlüssiges System dargestellt wird. ${ }^{66}$ So identifiziert Porphyrios die beiden Tore zunächst als die beiden Extrempunkte im Tierkreis, Krebs und Steinbock, wobei die Seelen durch den im Norden befindlichen Krebs zur Geburt herabsteigen und durch den südlichen Steinbock wieder hinaufsteigen. ${ }^{67}$ Ebenso gehöre der Nordwind zu den Seelen, die zur Geburt gehen, während der Südwind den Aufstieg von der Erde fort bedeute. Auch die Sonnentore Homers bezieht Porphyrios in diese Darstellung ein, und auch diese bezeichnen seiner Ansicht nach den Steinbock und den Krebs, wobei - hier

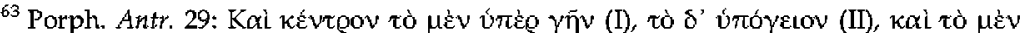

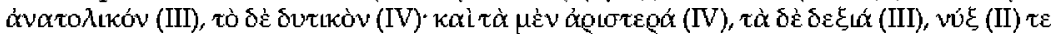

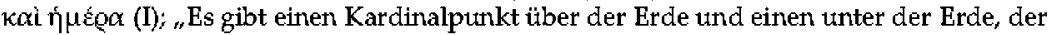
eine liegt östlich, der andere westlich. Entsprechend sind die einen Regionen links und die anderen rechts gelegen, und es gibt Nacht und Tag". Dies stggeriert, entgegen der Darstellung des Mithras (Antr. 24), der in den Westen blickt, eine Südperspektive mit Blick in den Norden. Zur Südperspektive in der Sternbeobachtung und deren Zusammenhang mit den Kardinalpunkten vgl. insbes. HüBNBR 2003, 13. Dass diese Perspektiven bzw. Perspektivwechsel eine wichtige Rolle insbesondere in der Ausrichtung der Mithras-Kultstätten und der darin befindlichen Bilder und Kultgegenstände spielten, ergibt sich nicht nur aus den Darstellungen bei Porphyrios, sondern auch aus den archäologischen Funden (vgl. hierzu insbes. Camprell 1968, 44-56 sowie Hübner 2006, 27-29).

${ }^{64} \mathrm{Vgl}$. hierzu insbes. Hü BNER 2006, 18-37 (mit Hinweisen zu weiterführender Literatur ebd., 19).

${ }^{65} \mathrm{Vgl}$. u.a. JoHnson 2013, 110: "The doctrine of the descent of the soul [...] was at the center of the Neoplatonist cosmological framework".

${ }^{66} \mathrm{Vgl}$. hierzu auch ALT 1998, 482.

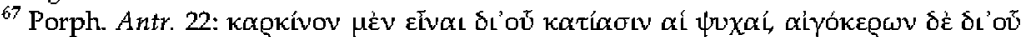

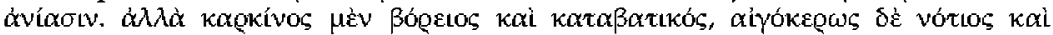

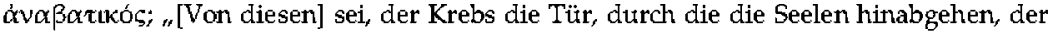
Steirbock aber die, durch die sie hinatufgehen. Der Krebs liegt nördlich und ist zum Hinabsteigen geeignet, der Steinbock dagegen südlich und ist zum Hinat fsteigen geeignet". Dies stimmt passenderweise mit dem Lauf der Sonne innerhalb des Jahres vom nörclichsten (im Krebs) zum südlichsten Stand (im Steinbock) überein; vgl. insbes. Hü BNBR 2006, 21 .
} 
irrt Porphyrios indessen - der Krebs der nördliche Schnittpunkt mit der Milchstraßse sei, der Steinbock der südliche. ${ }^{68}$ An späterer Stelle heißt es weiter (29), die beiden Tore seien bei Platon Sonne und Mond, wobei der Aufstieg durch die Sonne geschehe, der Abstieg durch den Mond. Dies würde folgerichtig bedeuten, das Sonnentor müsste sich im Zeichen des Steinbocks befinden, das Mondtor im Krebs. Dies widerspricht aber der Zuordnung, die Porphyrios im Zuge der Reihenfolge der Planetenhäuser gibt (21), wo zwar dem Mond der Krebs zugeordnet wird, dem Steinbock hingegen klar und deutlich gemäß der astrologischen Häuserlehre Saturn beigegeben wird. Vom Krebs wiederum heißt es zwar zunächst, er sei der Erde ebenso wie sein ,Planet' Mond am nächsten; ${ }^{69}$ später jedoch wird der Krebs als das Tor identifiziert, durch welches die Seelen zur Geburt - also zur Erde - herabsteigen. ${ }^{70}$ Dies würde wiederum implizieren, dass die Seelen von der Erde durch den Steinbock aufsteigen, der somit schwerlich, wie sein Hausherr Saturn, am weitesten von der Erde entfernt sein

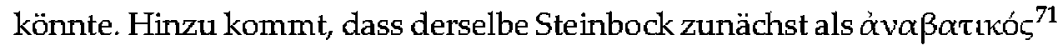
bezeichnet wird, wenige Zeilen später jedoch der Weg von Steinbock weg als herabsteigbar, also als das genaue Gegenteil. ${ }^{72}$

Dass diese Informationen nicht miteinander in Einklang zu bringen sind, dass die unterschiedlichen Lokalisierungen der Tore und die avisierte Reihenfolge der Seelenwanderung durch die Sphären ${ }^{73}$ und Tierkreiszeichen kein in sich geschlossenes Bild ergeben, mag beim ersten Lesen nicht weiter ins Gewicht fallen, wird bei genauerem Hinsehen jedoch

\footnotetext{
${ }^{68}$ In Wahrheit befinden sich die Schnittpunkte von Ekliptik und Milchstraße bereits im Zwilling bzw. im Schützen. Vgl. hierzu auch Hürner 2006, 30. Falsch auch Macr. Somn. I 12,4: ergo descensurae [sc. animae] cum adhuc in Cancro sunt, guoniam illic positae necdum lacteum reliquerunt, adhuc in numero sunt deorum (,wenn die Seelen also herabsteigen wollen und noch im Krebs sind, zählen sie auch noch zu den Göttern, weil sie dort die Milchstrasse noch nicht verlassen haben") sowie Macr. Somn. I 12,5. Den antiken Darstellungen folgt kommentarlos Atr 1998, 477 Anm. 71. Auch hier passt Porphyrios also astronomische Tatsachen seiner Argumentation - bewusst oder unbewusst - an.

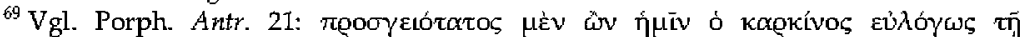

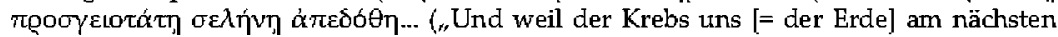
liegt, wurde er mit gutem Grund dem der Erde am nächsten gelegenen Mond zugeschrieben").

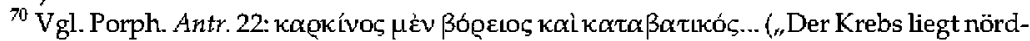
lich und ist zum Hinabsteigen geeignet...").

${ }^{71}$ Vgl. Porph. Antr. 22: alyókę̧ südlich und ist zum Hinaufsteigen geeignet").

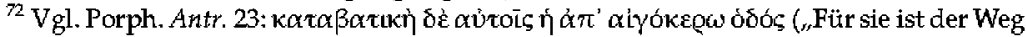
vom Steinbock ats herabsteigbar").

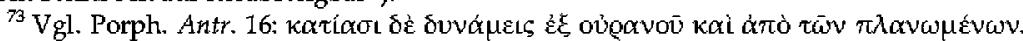

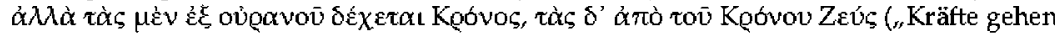
nun sowohl vom ,Himmel als auch von den Planeten aus, aber Kronos nimmt sie sich von Uranos und Zeus von Kronos"). Zur Tatsache, dass die Seelen bei ihrem Abstieg verschiedene Attribute der jeweiligen Sphäre erhalten vgl. auch Macr. Somn. I 12,13-15.
} 
schnell evident. Dass diese Widersprüche auch dem zeitgenössischen Leser nicht verborgen bleiben konnten, darf stark vermutet werden. Dies stört allerdings nicht, wenn man davon auszugeht, dass sich aus den Darstellungen des Porphyrios gar kein eindeutig vorstellbares Bild ergeben kann und soll, da der Autor kein konsistentes Weltbild repräsentiert oder gar eine explizite Sternkarte verbal zeichnen möchte, sondern vielmehr unterschiedliche Vorstellungen miteinander verwebt und in die allegorische Ausdeutung der Darstellung der Nymphengrotte bei Homer einflicht, um seine Gesamtargumentation zu stüzen.

\section{Zusammenfassung}

Wie aus den obigen Ausführungen deutlich geworden ist, finden sich bei Porphyrios zahlreiche Details, die dem astrologisch-astronomischen Bereich entlehnt sind. Dies kann bei einem Autor, dessen Verbundenheit mit diesem Themenkomplex klar bezeugt ist, nicht verwundern. Eigentïmlich hingegen ist die Methode, mit welcher Porphyrios diese Details in sein Werk einwebt und miteinander und mit anderen Themengebieten entlehnten Argumenten verquickt. Denn die eigentlich der Astrologie (sensu latiore) zugehörigen Themen werden vom Autor in einen mystischphilosophischen bzw. religiös-kultischen Kontext eingebettet und erhalten so teilweise Bedeutungsverschiebungen oder neue Implikationen. So ergibt sich eine astrologische bzw. religiös-kultische Mixtur, welche für Porphyrios im Allgemeinen, ${ }^{74}$ im Besonderen jedoch für seine Schrift $D e$ antro Nympharum kennzeichnend ist. Dass dem Autor hierbei nicht an astrologischer (oder gar astronomischer) Korrektheit oder Stringenz gelegen ist, nimmt angesichts des religiös-philosophischen Inhalts der Schrift kein Wunder - astrologische Prognosen oder komplizierte astronomische Berechnungen wird man hier vergebens suchen. Vielmehr geht es Porphyrios als Homer-Exeget darum, einzelne Details unterschiedlicher Themengebiete zusammenzuführen, um sie zu einem kunterbunten Gemenge zusammenzufügen, welches sich mit unterschiedlichen Weltbildern in Deckung bringen lässt; auf logische Argumentation und Geschlossenheit in sich kommt es im Rahmen dessen nur zum Schein an.

So kann Porphyrios beispielsweise den Stier und die Bienen nicht nur kultisch in Zusammenhang bringen, sondern auch astrologisch, indem er den Stier als Erhöhung des Mondes deutet und sich somit klar auf einen astrologischen Referenzrahmen bezieht. Eine ähnliche Verbindung von Mythos und Astrologie findet sich in der Darstellung der Sukzession Uranos $\rightarrow$ Kronos $\rightarrow$ Zeus (De antro 16), wo nach der mythischen Darstellung der Entmannung, die noch klar im Mythos zu verorten ist, nahtlos in eine as-

\footnotetext{
${ }^{74}$ Vgl. hierzu ALt 1998, 467.
} 
tronomische Argumentation übergeleitet wird, wenn die Sphären der jeweiligen Planeten Kräfte bzw. Seelen bei ihrem descensus aufnehmen.

Es wird deutlich, dass Porphyrios eine idiosynkratische Argumentationsstruktur bietet, in der mystische, mythische, philosophische, theologische, kultische und eben astronomische bzw. astrologische Argumente miteinander verwoben werden, um Details in einen Kontext einbetten zu können, die auf den ersten Blick wenig bis nichts miteinander zu tun haben; erst durch die eigentümliche Synthese ergibt sich der aus unterschiedlichen Vorstellungen evozierte Kontext, innerhalb dessen die einzelnen Verknüpfungen zu einem sinnvollen Ganzen sich ergänzen lassen: so gelingt es dem Autor, seinem Verständnis nach alte Weisheit in der Schrift Homers aufzuspüren und zu verifizieren. Evident ist, dass insbesondere auch Astronomie bzw. Astrologie hierbei eine Folie darstellen, die für das Nachvollziehen der Argumentation bzw. des Kausalnexus an einigen Stellen unabdingbar ist, in den Erklärungen und Auslegungen von Porphyrios' $^{\prime}$ De antro Nympharum bisher jedoch - insbesondere im Vergleich zur gelehrten Auseinandersetzung mit den kultischen Einzelheiten - nicht immer die gewünschte Aufmerksamkeit finden konnte. ${ }^{75}$ Dies scheint jedoch umso wichtiger, da insbesondere für den heutigen Leser astronomische und insbesondere astrologische Detailkenntnis, über die der zeitgenössische Leser noch verfügte, keineswegs immer vorausgesetzt werden kann; es ergibt sich, dass der moderne Rezipient auch auf Grund der inzwischen scharf vollzogenen Trennung zwischen (wissenschaftlicher) Astronomie und Astrologie oftmals nicht über das Wissen verfügt, welches dem Autor selbst und seinem antiken Leser zweifellos zur Verfügung stand. Dass dieser 'Kosmos' auch dem modernen Leser, sei er religionsgeschichtlich, philosophisch oder philologisch interessiert, bei der Porphyrios-Lektüre erschlossen werden kann, soll diese Darstellung einen Beitrag leisten.

\footnotetext{
${ }^{75} \mathrm{Vgl.z.B.}$ den ansonsten äußerst hilfreichen und gründlich recherchierten Kommentar von Simonini 1986.
} 



\title{
Littérature au troisième degré - Beispiele kreativer Rezeption von De antro Nympharum
}

\author{
Reinhold F. Glei
}

\section{Höhleneingänge}

Zunächst sind zwei Vorbemerkungen nötig. Die erste ist terminologischer Natur und bezieht sich darauf, was hier unter ,kreativer Rezeption' verstanden werden soll: Gemeint ist damit eine im weitesten Sinn prodtuktive (oder auch: künstlerische) Rezeption, d.h. eine auf die Schaffung (crea-

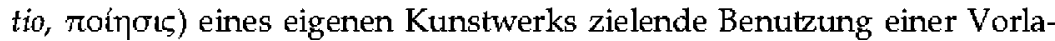
ge. Der Komplementärbegriff wäre eine (wiederum im weitesten Sinn) reproduktive Rezeption, die die Vorlage nicht umformen, sondern, authentisch' re-produzieren will, etwa in Form von Textausgaben, Übersetzungen, Kommentaren oder wissenschaftlichen Abhandlungen. Ich bin mir bewusst, dass die Unterscheidung problematisch ist, weil die Grenzen flieBend sind und einerseits die kreative Rezeption gelegentlich durchaus den , authentischen' Sinn der Vorlage zum Vorschein bringen will, andererseits die reproduktive Rezeption keineswegs, unkreativ' sein muss, sondern im Gegenteil sehr produktiv neue Sichtweisen auf die Vorlage bieten kann, wie es beispielsweise in Hans Blumenbergs luzider Interpretation der Fall ist. In dem Kapitel "Der Höhlenquell des fehlenden Elements" seiner Essaysammlung Höhlenausgänge (1989) erläutert Blumenberg die Faszination der Höhle als Allegorie des Kosmos für den Platoniker Porphyrios damit, dass die Höhle des Platonischen Gleichnisses einen entscheidenden Mangel habe, der sie als Allegorie untauglich mache: „In ihr gibt es kein Wasser" ${ }^{1}$ Symbol des Lebens und des Werdens, das für Porphyrios ein essentieller Bestandteil seiner allegorischen Deutung ist. Blumenbergs Beobachtung ist originell und, wenn man so will, kreativ, aber bleibt doch ein philosophiehistorischer und damit wissenschaftlicher Ansatzpunkt, der mit einer künstlerischen Rezeption nichts zu tun hat. Daher erscheint es aus systematischen Gründen sinnvoll, beide Herangehensweisen zu unterscheiden: Es geht in diesem Beitrag nicht um die Geschichte der wissen-

\footnotetext{
${ }^{1}$ Blumbnerag 1989, 236; zu Blumenbergs Rezeption des Höhlengleichnisses vgl. die Beiträge im Sammelband von M. MöLler ( $\mathrm{Hg}$.), Prometheus gibt nicht auf. Antike Welt und modernes Leben in Hans Blumenbergs Philosophie (Paderborn 2015) Sektion I; Blumenbergs Porphyrios-Rezeption scheint bisher nicht behandelt worden zu sein.
} 
schaftlichen Bearbeitung von De antro Nympharum, sondern um Beispiele künstlerisch-kreativen Umgangs mit diesem Text.

Die zweite Vorbemerkung bezieht sich auf die Eigenschaft des rezipierten Textes selbst: Bei De antro Nympharum handelt es sich - um die Terminologie Genettes (1982) anzuwenden - um einen Metatext, ${ }^{2}$ d.h. um einen Kommentar zum homerischen Hypotext in Form einer philosophischen Allegorese. Generell ist es selten, dass kreative Rezeption sich in einer Art Crossover auf Texte bezieht, die nicht literarische Hypo- oder Hypertexte, sondern ihrerseits re-produktive Metatexte sind. Ohne explizite Hinweise ist es schwierig, überhaupt solche ,Hyper-Metatexte' zu identifizieren, weil sie immer durch Bezüge auf den eigentlichen Hypotext überlagert sind. Beispielhalber sei dazu auf ein Gedicht von Pierre Louÿs über die Nymphengrotte verwiesen: Unter den fingierten Liebesliedern der Bilitis, einer angeblichen Schülerin der Sappho, ${ }^{3}$ findet sich auch eines, das L'antre des nymphes betitelt und an Bilitis' Geliebte und Mitschülerin Mnasidika gerichtet ist. Die beiden ersten Strophen beschreiben die Schönheit des Mädchens, und die beiden letzten lauten dann:

Car, dans le secret de ton corps, c'est toi, Mnasidika aimée, qui recèles l'antre des nymphes dont parle le vieil Homêros, le lieu où les naïades tissent des linges de pourpre.

Le lieu où coulent, goutte à goutte, des sources intarissables, et d'où la porte dư Nord laisse descendre les hommes, et où la porte du Sud laisse entrer les Immortels. ${ }^{4}$

Die hier gegebene Beschreibung der Nymphengrotte enthält keine über Homer hinausgehenden Informationen; allein die Aussage, dass Mnasidika „im Innern ihres Körpers die Nymphengrotte verbirgt" ${ }^{\prime \prime}$,önnte darauf schließen lassen, dass hier auf eine geheime, d.h. allegorisch verschlüsselte Bedeutung angespielt wird, die über die Sappho-Imitation hinausgeht. ${ }^{5}$ Allerdings entspräche die Allegorese in diesem Fall auch nicht der des Porphyrios, weshalb ein Bezug auf De antro Nympharum nur generisch wäre und daher spekulativ bleiben muss. ${ }^{6}$

Das geschilderte Beispiel ist symptomatisch für das Dilemma des hier unternommenen Versuchs, Beispiele kreativer Rezeption des Porphyrios aufzufinden: Gerade das in Literatur und Kunst überaus häufige Motiv

\footnotetext{
${ }^{2}$ GenkTtB 1982, 10

${ }^{3}$ Die Gedichte wurden angeblich von dem deutschen Gelehrten $G$. Heim bei Amathus entdeckt und in Leipzig 1894 ediert (Phantomedition); Louÿs brachte sie dann 1895 unter dem Titel Les chansons de Bilitis traduites du Grec pour la première fois heraus. Vgl. R. F. GLeI, "Sappho die Lesbierin im Wandel der Zeiten", in: G. Binder / B. EFFe (Hg.), Liebe und Leidenschaft. Historische Aspekte von Erotik und Sexualität. BAC 12 (Trier 1993) [145-161] 145.

${ }^{4}$ Loữs 1895, 137.

${ }^{5}$ In den erhaltenen Fragmenten der Sappho wird die homerische Nymphengrotte, soweit ich sehe, nicht erwähnt.

${ }^{6}$ Möglicherweise bezieht sich Louÿs aber auf die Allegorese von La Mothe Le Vayer: s. dazu unten.
} 
der Nymphengrotte zeigt eine vielfältige kreative Rezeption Homers, aber in der Regel keine produktive Rezeption des Porphyrios. Will man eine solche nachweisen, so erscheint sie allererst auf dem Hintergrund einer re-produktiven Rezeption, d.h. einer Verbreitung des Textes durch Druck und Übersetzung, überhaupt möglich, ${ }^{7}$ aber auch dann eher eine Ausnahme geblieben zu sein. Die Regel ist vielmehr die wiederum metatextuelle Beschreibung des vorliegenden Metatextes (wie in diesem SAPERE-Band) - doch bevor sich diese Denkfigur (inzwischen sind wir bei metatextuellen Bemerkungen zu Meta-Metatexten angelangt) als eine Art mise-en-abyme ins Unendliche fortsetzt und wie in der Welt der virtuellen Finanzderivate zu einer gefährlichen ,Blase' wird, sei auf den Boden der ,Realwirtschaft' zurückgekehrt.

Im Folgenden sollen zwei unzweifelhafte, sehr unterschiedliche Beispiele kreativer Rezeption vorgestellt, um ein drittes, allerdings fragliches Beispiel ergänzt und zunächst systematisch differenziert werden. Das erste Beispiel stammt aus dem Frankreich des 17. Jahrhunderts und ist die m.W. einzige direkte, explizite Imitation von Deantro Nympharum, genauer gesagt eine ,destruktive Parodie der porphyrianischen Allegorese, ja geradezu eine Anti-Allegorie. Diese pseudonym verfasste, programmatisch Explication de l'antre des nymphes betitelte Schrift (nach 1630) des François La Mothe Le Vayer (1588-1672) scheint auf den ersten Blick ein seriöses neuzeitliches Pendant zur exegetischen Abhandlung des Porphyrios zu sein, entpuppt sich dann aber als libertinistische Parodie, in der die detaillierte Beschreibung der Nymphengrotte als sexuelle Allegorie gedeutet wird.

Das zweite Beispiel entstammt der Moderne. Zwar fehlen hier, anders als bei Le Vayer, explizite Hinweise auf Porphyrios, aber eine kreative Rezeption von De antro Nympharum dürfte dennoch mit ziemlicher Sicherheit nachweisbar sein. Es handelt sich um die Darstellung der Nymphengrotte auf Ithaka in dem Gemälde The Sea of Time and Space (1821) von William Blake (1757-1827), dessen Wirkungsabsicht als allegorische Visualisierung der philosophischen Konzeption vom $\mathrm{Ab}$ - und Aufstieg der Seele im Sinne des antiken und im England des 18./19. Jahrhunderts emeuerten Neuplatonismus beschrieben werden könnte.

Schließlich soll auf ein mögliches drittes Beispiel an dieser Stelle wenigstens kurz hingewiesen werden: Es handelt sich um einen bekannten Renaissancetext, der sich durch eine besonders kreative Antikerezeption auszeichnet, nämlich die vermutlich von Francesco Colonna (1433/14341527), einem Venezianischen Dominikaner, verfasste Hypnerotomachia Poliphili (Venedig 1499), die man als allegorisierenden Liebesroman bezeichnen könnte. Das Werk erschien lange vor der Erstedition von De antro Nympharum (Venedig 1521), so dass eine Benutzung des Porphyrios frag-

\footnotetext{
${ }^{7} \mathrm{Zu}$ einer eventuellen Rezeption aufgrund handschriftlicher Überlieferung bei Francesco Colonna s. unten im Anhang.
} 
lich ist, aber immerhin scheint die Kenntnis eines handschriftlichen Exemplars möglich ${ }^{8}$ und eine Beeinflussung durch den Florentiner Neuplatonismus sehr wahrscheinlich. ${ }^{9} \mathrm{Ob}$ und inwieweit der Autor seine kreative Gestaltung der Nymphen- bzw. Grottenmotivik oder zumindest die Idee einer Allegorese neben Homer auch dem porphyrianischen Metatext verdankt, ist umstritten und soll daher in einem Anhang thematisiert werden.

Allen Beispielen ist gemeinsam, dass sie den second degré des porphyrianischen Metatextes um eine dritte Stufe erweitern, indem sie einen ,HyperMetatext' erzeugen. Die Wirkungsintentionen der beiden erstgenannten, unstrittigen Rezeptionsbeispiele stehen dabei in geradezu diametralem Gegensatz zueinander: Während Le Vayers parodistische Anti-Allegorese eine wissenschaftlich verbrämte, fast pornographisch zu nennende, letztlich aber wohl karnevalistische Intention aufweist, ist Blakes Gemälde eine komplett entsexualisierte, abstrakt-philosophische und geradezu surrealistische Fortsetzung der Allegorese mit anderen (medialen) Mitteln. Colonnas Roman schließlich, wenn er denn auf Porphyrios anspielt, würde mit seiner erotisch-sublimierenden und idealisierenden Tendenz in gewisser Weise eine Mittelstellung einnehmen. Dies soll nun näher expliziert werden.

\section{Tubertus Ocella, Explication de l'antre des nymphes}

Einen sehr speziellen Zugang (oder besser vielleicht: ,Hintereingang') zum Text des Porphyrios eröffnet die parodistische Allegorese des als Vertreter des Libertinismus bekannten François La Mothe Le Vayer (1588-1672), der den Text unter dem Pseudonym Tubertus Ocella ${ }^{10}$ wohl kurz nach 1630 verfasste $^{11}$ und erst 1670 in veränderter Fassung publizierte. ${ }^{12}$ Angeregt wurde er zu diesem Essay offenbar durch das Erscheinen der griechischlateinischen Ausgabe von Lukas Holste (Rom 1630), denn er stellte (in derselben Manier wie Porphyrios) die Odysseeverse (XIII 102-112) im Original mit der lateinischen Übersetzung von Holste seinem Text voran. Neuerdings publik gemacht wurde der Text durch die kontextualisierend eingeleitete Taschenbuchausgabe von Jean-Pierre Cavaillé, ${ }^{13}$ die neben einer

\footnotetext{
${ }^{8}$ Der Text ist einem Codex des Bessarion in Venedig (Marc. gr. IX9, coll. 1204) erhalten.

${ }^{9} \mathrm{Zur}$ Bekantutheit des Porphyrios im Corycius-Kreis siehe Ph. P. BobbR, s.The Coryciana and the Nymph Corycia", Journal of the Warburg and Coturtauld Institutes 40 (1977) 223-239.

${ }^{10}$ Tuber, "Buckel” = frz, bosse oder motte, für La Mothe; ocellus, "Ätuglein”, für Le Vayer ( $=$ le voyeur $)$.

${ }^{11}$ Nur handschriftlich erhalten im Ms. BNF, fonds Dupuys, no. 835, philologisch-kritisch ediert von Cavaillé 2003.

${ }^{12}$ In seinem Hexaméron Rustique ou Les Six Journées Passées à la campagne entre des personnes studieuses, Paris 1670 (1875) hg. v. G. Los o'UrizbN (Paris 1997); vgl. auch van Gobns 1765, 70f. Wir zitieren im Folgenden nach der Erstfassung (CAvaILlí 2003).

${ }^{13}$ CAVAILLÉ 2004; eine italienische Übersetzung von R. Tomadin erschien in Bari 2008.
} 
orthographisch modernisierten Fassung ${ }^{14}$ der Explication zwei weitere kurze Texte, ${ }^{15}$ die hier nicht weiter berücksichtigt werden, enthält. Da der Text von Le Vayer aber bisher, besonders im nicht-romanischen Sprachraum, $\mathrm{m}$.W. keine große Beachtung erfahren hat, sei er hier etwas ausführlicher vorgestellt.

Zu Beginn rekapituliert Le Vayer in apologetischer Absicht weitschweifig den antiken Topos, dass sich aus dem Werk des Schriftstellers keine Rückschlüsse auf den Schriftsteller selbst, insbesondere nicht auf das moralische oder unmoralische Verhalten desselben ziehen lassen. ${ }^{16}$ Daran schließt sich eine Erörterung der weitverbreiteten Meinung an, Homer sei in allen Künsten und Wissenschaften bewandert, ja bereits ein Philosoph gewesen. Mit Seneca spottet Le Vayer über die Vereinnahmung Homers durch die verschiedenen Philosophenschulen, die den Dichter mal als Stoiker, mal als Epikureer, mal als Peripatetiker und mal als Akademiker avant la lettre beanspruchten (apparet nihil horum esse in illo, quia omnia sunt), ${ }^{17}$ und fügt hinzu: "[Seneque] monstre bien que ce n'est pas dans Homere que nous devons chercher la philosophie" (190). Insbesondere die über die philologisch-historische Deutung des Textes hinausgehende Unterstellung eines "sens mist[e]re ou moral" (ebd.) sei abzulehnen: Mias und Odyssee böten sich als Stoff für alle Esoteriker an, die Le Vayer verächtlich als "interpretes contemplatifs" (ebd.) bezeichnet und die beliebigen, aus dem Zusammenhang gerissenen Stücken eine tiefere Bedeutung zuschrie-

\footnotetext{
${ }^{14}$ Zitiert wird hier jedoch nach der ursprünglichen Orthographie (CAVAILLÉ 2003).

${ }^{15}$ Der eine Text ist die Plainte de Tircis à Cloris, im Untertitel als Allégorie bezeichnet, die Adrien de Monluc (1571-1646) zugeschrieben wird, publiziert als Anhang zu Les Pensées du solitaire (Paris 1630). Formal eine bukolische Klage des von der „ingrate bergère" Cloris verschmähten Tircis, die die sexuellen Wünsche des Helden ziemlich deutlich artikuliert, liegt der eigentliche Skandal aber darin, dass Tircis und Cloris die Namen der Geschwister aus Pierre Corneilles 1629 aufgeführten Komödie Mélite sind und somit ein inzestuöses Verhältnis suggeriert wird. - Der andere Text ist ein Auszug ats dem Roman L'Heure du Berger von Claude Le Petit (1639-1662) und beschreibt unter dem Titel Histoire allegorigue eine Reise in die Stadt Somatte (von griech. $\sigma \bar{\omega} \mu \alpha$ ), also "Stadt der Leiblichkeit" oder "Capitale du Royaume du Monde Amoureux". Beide Texte beziehen sich nicht explizit auf De antro Nymphartun, und es ist fraglich, ob sie überhaupt darauf anspielen.

${ }^{16}$ Zitiert werden einschlägige Stellen bei Plinius (Epist. IX 27), Ovid (Trist. II 359f.), Catull (16,1-4), Gellius (Noct. Att. XIX 9,9) und anderen.

${ }^{17}$ Sen. Epist. LXXXVIII 5 (,Es ist klar, dass nichts von diesen [Philosophen] in ihm [Homer] ist, eben weil alles darin ist" ${ }^{\prime \prime}$, zitiert bei Le Vayer, 69. Aus Seneca (Epist. LXXXVIII 40) fïhrt er weiterhin das Beispiel des Grammatikers Apion an, der behauptete, die beiden ersten Buchstaben der Ilias, also $\mathrm{M}$ und $\mathrm{H}$, deren Zahlenwert 48 ist, sollten die Gesamtzahl der Bücher von Ilias und Odyssee andeuten, was schon deshalb unsinnig ist, weil die Bucheinteilung ja eine alexandrinische Erfindung ist. Talia sciat oportet gui multa vult scire (,So etwas muss wissen, wer mit seinem Wissen angeben will"), kommentiert Seneca trocken (LXXXVIII 41).
} 
ben. Ein besonders eklatanter Fall dieser "machine de l'exégèse allégorique $^{\prime \prime 18}$ sei Porphyrios' Deutung der Nymphengrotte:

Mais il n'y en a peut estre point qui les ait faict plus profondement speculer que celle de l'antre des Nymphes, si partictlierement descript at treziesme livre de l'Odyssee, sur lequel aussi Porphyre a dressé un asses grand discours, out il pretend monstrer que nostre bon aveugle represente le monde entier dans cet antre, dont les deus portes sont celles de la vie et de la mort, et les Nymphes les ames qui s'accommodent aux generations et corruptions consecutives, appropriant ainsi le reste de ceste premiere imagination. (190f.)

Er selbst, so bekennt Le Vayer, habe die Passage immer als ekphrastische Darstellung, quasi als ,Landschaftsmalerei' gelesen, in der der Maler absichtslos seine Phantasie habe spielen lassen, ob die Grotte nun tatsächlich auf Ithaka vorhanden sei oder nicht. Wenn man aber in der Passage schon einen tieferen Sinn sehen wolle, dann doch wohl einen anderen, nämlich "un sens beaucoup moins contrainct, plus naturel, et plus accommodé a la lettre“ (191). Diesen weniger gekünstelten, natürlicheren und dem Text angemesseneren Sinn schickt sich Le Vayer an im Folgenden zu erläutern. Nichts sei natürlicher, als dass Odysseus sich nach zwanzigjähriger Abwesenheit nach seiner Frau, für die er die Unsterblichkeit ausgeschlagen habe, sehne, und zwar auch im körperlichen Sinn. Ebenso wie auf der einen Seite die Bogenprobe mit Ovid als sexuelle Metapher für die (Im-)Potenz der Freier und Penelopes Bedürfnisse zu verstehen sei $^{19}{ }^{19}$ offenbare auf der anderen Seite nun die Nymphengrotte die erotischen Wünsche und Phantasien des Odysseus. Dies wird nun mittels eines Durchgangs durch die elf zitierten Homerverse gezeigt. Dabei greift Le Vayer neben antiken Quellen immer wieder auf zeitgenössische wissenschaftliche Literatur, insbesondere Schriften zur Anatomie, zurück, um seine Deutung zu validieren und gleichzeitig, wie man vermuten darf, den Vorwurf der Pornographie zu vermeiden.

Die ersten beiden Verse (Od. XIII 102f.) beschreiben den dichtbelaubten Ölbaum, der oberhalb des Hafens vor der zugleich lieblichen und dämmrigen Höhle ("le port d'amour", 193) steht. Le Vayer bietet gleich drei allegorische Deutungen an: Die offensichtlichste und keines Beleges bedürftige sei die Deutung des Laubes als Schamhaar (,la plante qui croist en ceste partie ${ }^{\prime \prime}, 193$ ); die zweite leite sich von der Eigenschaft des Olivenzweigs als Friedenssymbol ab und stehe für pax, concubitus foedera und concordia der

\footnotetext{
${ }^{18}$ So Cavallú́ 2004, 17.

${ }^{19}$ Le Vayer zitiert Ov. Am. I 8,47f.: Penelope vires ittventum tentabat in arch / Qui latus argueret, corneus arcus erat (, Penelope pflegte die Kräfte der jungen Märner am Bogen [metaphorisch für: Penis] zu erproben: / ein Bogen aus Horn [besonders hart] war es, der die Potenz nachwies"), und das ebenfalls Ovid zugeschriebene Priapeum 68: Nemo meo melius neroum tendebat Ulysse ("Niemand pflegte die Sehne [metaphorisch für: Penis] besser zu sparnen als mein Odysseus").
} 
Liebenden; ${ }^{20}$ die dritte schließlich beruhe auf dem teils milden, teils herben Geschmack der Oliven und stehe für den Eros $\gamma \lambda$ vкúrıkeos, was mit Stellen aus Lukrez belegt wird. ${ }^{21}$ Besonders die zweite und dritte Deutung erscheinen absichtlich weit hergeholt, um die Absurdität der Dichterallegorese vor Augen zu führen und die erste Deutung als die umso offensichtlichere erscheinen zu lassen. $^{22}$

Der dritte Vers (Od. XIII 104) bezeichnet die Grotte als Heiligtum der Nymphen, die Naiaden genannt würden. Mit anatomischem Detailreichtum, der freilich aus heutiger medizinischer Sicht recht merkwürdig anmutet, werden nunmehr die weiblichen ,Feuchtgebiete' erklärt, wobei insbesondere "ces deux petites membranes aislees", die auch "Nymphes" genannt werden (194), im Mittelpunkt stehen. Darunter werden die Schamlippen verstanden, die, wie zeitgenössische Anatomen irrigerweise annahmen, ${ }^{23}$ gleichzeitig als Schließmuskel des Blasenausgangs fungieren sollen ("que de conduire les eaus du Rubicon, et vuider l'urine", 195), weshalb die Bezeichnung der Nymphen als Naiaden ("Wassernymphen") passend sei.

Im Inneren der Höhle befinden sich steinerne Gefäße, in denen Bienen ihren Honig deponieren (Od. XIII 105f.). Die Biene stehe für Amor (Verweis auf Anakreon und Theokrit), ${ }^{24}$ der Honig für "ceste douce liqueur qui perpetue le genre humain" (195), und die Gefäße für die weiblichen Fortpflanzungsorgane, nämlich Eierstöcke und Gebärmutter (ebd.). Dass die Gefäße aus Stein sind, verweise entweder auf die Festigkeit des Gebärmutterhalses, der als "knorpelig" ("cartilagineus", 196) bezeichnet wird, oder auf den festen Verschluss des Muttermundes nach der Empfängnis. Dadurch, dass hier kein noch so kleines Detail ausgelassen wird, soll die penible Exegese des Porphyrios offenbar parodistisch übererfüllt werden. Sogar das Summen der Bienen ${ }^{25}$ wird in die Deutung einbezogen und mit dem amabile murmur bzw. den dulces gemitus (Ov. Ars II 723f.) der Liebenden erklärt.

Nach einem grotesk anmutenden, wiederum Porphyrios (Antr. 15-17) parodierenden Exkurs über die verschiedenen Arten des ,Honigs' kehrt

\footnotetext{
${ }^{20}$ Nach Ov. Ars II 531-536.

${ }^{21}$ Lucr. IV $1133 \mathrm{f}$. und $1059 \mathrm{f}$.

${ }^{22} \mathrm{Vgl}$. auch die Schlusspassage über den cunnus abus (unten Anm. 34).

${ }^{23}$ Le Vayer beruft sich auf André Du Laurens (1558-1609), dessen Werk Historia Anatomica humani corporis (= LAURENTIUs 1600) für die Gynäkologie bahnbrechend war. Le Vayer zitiert die französische Übersetzung, greifbar in LAURENTIUS 1621, liv. VII, chap. 12.

${ }^{24}$ Le Vayer meint die Gedichte, in denen Amor von einer Biene gestochen wird, also Carm. Anacr. 35 und Ps.-Theocr. 19.

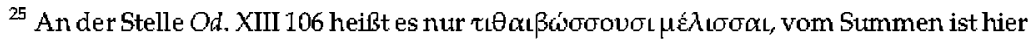
keine Rede. Die Bedeutung des Verbs $\tau\llcorner\theta \alpha \iota \beta \omega \sigma \sigma e t v$ ist wohl "Hortig sammeln" (Porph.

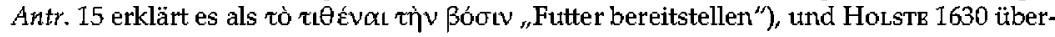
setzte es richtig mit apes ponunt mella, wobei er allerdings zur Füllung des Hexameters das Summen der Bienen hinzufïgte: apes dulci gua pontunt mella susurro. Dadurch erklärt sich die Ergänzung bzw. das Missverständnis Le Vayers.
} 
der Autor zum Homertext zurück, in dem als nächstes die steinernen Webstühle erwähnt sind, auf denen die Nymphen purpurfarbene Gewänder weben (Od. XIII 107f.). Wiederum unter Berufung auf zeitgenössische Anatomen ${ }^{26}$ wird dies als Allegorie des Hymens gedeutet, das aus warzenartigen Verdickungen der Schleimhaut bestehe. Mit dem Zusatz $\theta \alpha \bar{u} \mu \alpha$

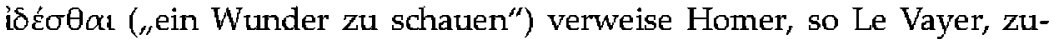
dem auf die Schwierigkeit, das Hymen bei einer Körpersektion überhaupt zu erkennen, was manche Anatomen zu dem Schluss kommen ließ, es existiere gar nicht. Eine Erörterung über die Bedeutung des Hymens und das beim ersten Geschlechtsverkehr fließende Blut (daher das Epitheton

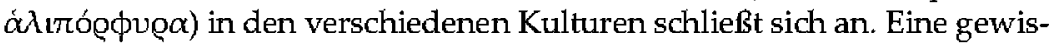
se Unstimmigkeit in der Darstellung Homers sei, so Le Vayer weiter, dass jener das Hymen bei der Beschreibung der Höhle überhaupt erwähne, obwohl Penelope ihre Jungfräulichkeit ja bereits vor über 20 Jahren verloren habe; das sei aber der Freiheit des Dichters geschuldet, der die weibliche Anatomie nun einmal mit der größtmöglichen Vollständigkeit habe beschreiben wollen (200).

Am Schluss stehe nun aber die größte Herausforderung:

Mais ce qui suit jusques a la fin, contient un sens si misterieux, et qui a besoin d'une si profonde spectlation, que je ferois grande difficulté de m'y engager, si la consideration de nostre amitié, et la licence du Caresme prenant ne me donnoient la hardiesse d'aller jusqu'au bout de la quariere qu'elles m'ont faict commencer. (200)

Es sind die zwei Zugänge der Höhle, die nördliche für die Menschen und die südliche für die Götter, die für die Allegorese das schwierigste Problem bedeuten. Apologetisch weist Le Vayer vor allem auf die karnevalistische Lizenz hin, die er hier vielleicht sogar über Gebühr in Anspruch nehme; dies macht den Leser natürlich nur umso gespannter auf die nun folgende Erklärung. Der erste erwähnte Höhleneingang, von Norden her, sei unproblematisch: Es handle sich um den normalen, von der Natur gewiesenen

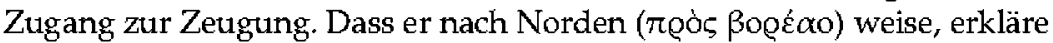
Porphyrios (Antr. 28) etymologisch richtig mit $\dot{\alpha} \pi \dot{\alpha} \tau \bar{\eta} \zeta \beta 0 \varrho \bar{\alpha} \zeta$, a vorando. ${ }^{27}$ Die "porte venerienne“ gelte ja gemeinhin als unersättlich (201). Dann aber schreibt Le Vayer des Längeren über die Bevorzugung der hinteren Pforte, "a laquelle Venus postica presidoit" (ebd.), bei den Griechen, für die man Homer ebenso wie die meisten anderen groß̉en Männer tadeln müsse. Die

\footnotetext{
${ }^{26}$ Gemeint ist neben Du Laurens (LAURENTIUs 1621) der (ebenfalls von Du Latrens erwähnte) Chirurg Séverin Pineau (um 1550-1619), der 1599 sein skandalträchtiges Opusculum Physiologicum über anatomische Details der Empfängnis, Schwangerschaft und Geburt veröffentlicht hatte: Severini PINABI, Carnutensis, Parisiis in Chirurgia Magistri Primi, Opusculum Physiologicum, Anatomicum [... I Tractans analytice Notas primo integritatis et corruptionis virginum, deinde gravitatem, et partum naturalem mulierum etc. (Francofurti 1599).

${ }^{27}$ Die Übersetzung a vorando stammt von Holste. Tatsächlich gehen lat. vorare und griech.

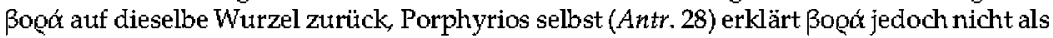

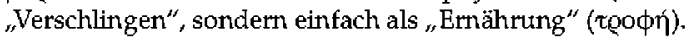


Beliebtheit des Analverkehrs wird mit zahlreichen Beispielen aus der Literatur belegt, u.a. mit Herodot, der von Peisistratos erzähle, dass er mit seiner Ehefrau, weil er von ihr keine Kinder haben wollte, ausschließlich

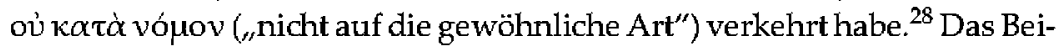
spiel verdeutliche gleichzeitig, dass sich die Angabe bei Homer, der Hintereingang sei den unsterblichen Göttern vorbehalten, nicht nur auf deren Lustknaben ("Ganimedes" ebd.) beziehe, sondern auch auf die irdischen "Großen": "il n'y a que les grands, qui sont les dieus de la terre, qui osent prendre un tel chemin" (ebd.). Aber auch aus anderen Kulturen werden Beispiele herangezogen, ${ }^{29}$ und das Ganze gipfelt in Wortspielen mit con und cul: "Quelle apparence y a il de quitter ceste belle province d"Irlande la Connacrie, ${ }^{30}$ pour aller chercher en terre australe sous un autre pole celle du Culacie ${ }^{31 ،}$ (202). Oder mit satirischer Anspielung auf die Quacksalberei: "n'est pas moins perilleus de faire un cul pro con, en mariage, ${ }^{32}$ qu $^{\prime}$ un qui pro quo, en pharmacie ${ }^{33 \prime \prime}$ (ebd.).

Auch Porphyrios hatte viele Kapitel darauf verwendet, die Bedeutung des südlichen Höhleneingangs zu erklären, und in Le Vayers frivoler Parodie wird das treffend nachgeahmt. Gleichzeitig entschuldigt er sich noch einmal für die freizügige Darstellung, beruft sich erneut auf die „licence des jours gras" (203) und zeigt sich überzeugt, dass seine Interpretation den Homerversen ihren wahren, ,naiven' Sinn zurückgegeben habe, während Porphyrios' Deutung „an den Haaren herbeigezogen” sei (,tiree par les cheveux", ebd.). Auch die Alten hätten ohne Scheu die Dinge beim Namen genannt, was u.a. mit Beispielen für den Gebrauch von cunnus bei Cicero und Horaz belegt wird. ${ }^{34}$ Le Vayer schließit, ringkompositorisch auf den Beginn seines Essays Bezug nehmend, mit der Beteuerung Ovids: Vita

\footnotetext{
${ }^{28}$ Herodot I 61 .

${ }^{29}$ Zitiert werden Busbeq über türkische und Rabbi Moses (d.h. Moses Maimonides) über jüdische Sitten.

${ }^{30}$ Der Name der irischen Provinz Connacrie bzw. Connacie (= engl. Connaught) wird hier von connus/cunnus abgeleitet, vergleichbar wäre etwa im Deutschen „Freudenstadt im Schwarzwald“.

${ }^{31}$ "Culacie" von culus: ebenfalls kaum übersetzbares Wortspiel, vielleicht "Downunder" (im Hinblick auf die genannte terra australis).

${ }^{32} \mathrm{Zu}$ entsprechenden Praktiken in der Ehe wird auf Sen. Rhet. Contr. I 2,22 und sogar auf die Ureltern verwiesen: Der Apfel, zu dessen Genuss Adam verführt werde, stehe, nach der Interpretation gewisser Rabbiner, für die „parties posterieures de sa femme (203).

${ }^{33}$ Gemeint ist die beliebte Praxis der Apotheker, ats Kostengründen den einen gegen den anderen Inhaltsstoff auszutauschen.

${ }^{34} \mathrm{Vgl}$. Cic. Fam. LX 22,3: Der Musiklehrer des Sokrates hieß Connus - num id obscenum putas? (,r. Hältst du das etwa für obszön?"); Hor. Sat. I 2,36: mirator cunni Cupiennitus albi (r, Cupientriuts [sprechender Name: ,der Unersättliche'], ein Bewunderer der weißen Scham”), was Le Vayer im Gegensatz etwa zu Karl Büchner - „Bewunderer des weißgekleideten Weibes" - richtig im Sinne einer Enthaarung des Intimbereichs versteht, denn er zieht Parallelen aus Herodot (II 106) und Diodorus Sicults (I 85,1) herath, um diese Sitte bei den Frauen in Palästina und Ägypten zu belegen.
} 
verecunda est, musa iocosa mihi („,Mein Leben ist anständig, nur meine Muse ist frivol" $)^{35}$

\section{Höhlenausgang I}

Zusammenfassend kann man sagen, dass wir in Le Vayers Explication de l'antre des nymphes eine parodistische, d.h. im Sinne von Verweyen / Witting $^{36}$ gegen die Vorlage gerichtete ,kreative Rezeption' von Porphyrios' De antro Nympharum vor uns haben. Kritisiert wird vor allem die Allegorese als eine an den Haaren herbeigezogene Interpretation von Details, die vielmehr absichtslos tund ohne tieferen Sinn der Dichterphantasie entsprungen seien. ${ }^{37}$ Die Parodie selbst steht in der Tradition des obszönen Vergilcento, ${ }^{38}$ ist als Parodie eines philosophischen Textes aber in dieser Form $\mathrm{m}$.W. einmalig. Sie arbeitet nicht nur mit Wortspielen und sexueller Metaphorik, sondern beruft sich explizit auf zeitgenössische medizinische Werke, v.a. zur weiblichen Anatomie, um der Parodie eine seriöse, ,wissenschaftliche' Grundlage zu geben. Der mehrfache Hinweis auf die karnevalistische Freiheit zeigt überdies, dass es Le Vayer ganz und gar nicht um eine anti-moralistische Haltung ging, wie man dem Libertinismus gern unterstellt; ob das Ganze aber nur ein frivoler Scherz oder ein ernst gemeintes Plädoyer für einen unverkrampften Umgang mit der (insbesondere weiblichen) Sexualität ist, muss hier offenbleiben - ebenso wie die Frage, ob und wie Le Vayers Parodie ihrerseits rezipiert wurde. Immerhin gibt es ein bemerkenswertes Zeugnis: "Porphyry has wrote a volume to explain this cave of the Nymphs, with more piety perhaps than judgement;

\footnotetext{
${ }^{35}$ Ov. Trist. II 354.

${ }^{36}$ Th. VerwBYEn / G. WITTING, Die Parodie in der neueren deutschen Literatur. Eine systematische Einfiihrung (Darmstadt 1979).

${ }^{37}$ Im Prinzip bedient sich Le Vayer dabei (ohne es zu wissen) einer Methode, die Porphyrios seinerzeit selbst in seiner Schrift gegen die Christen angewendet hatte: Dort führte er die christliche Bibelallegorese durch parodistische, Übererfüllung' ad absurdum, indem er eine auf Hektor und. Achill bezogene lliasstelle (wohl XII 462-466 oder eine ähnliche Stelle, z.B. IX 237-239) allegorisch auf den Diabolos und. Christus deutete; vgl. G. BindBR, Eine Polemik des Porphyrios gegen die allegorische Auslegung des Alten Testaments durch die Christen", ZPE 3 (1968) [81-95] 91-93.

${ }^{38}$ Beginnend mit Ausonius' Cento nuptialis (den Le Vayer eingangs und ausgangs ausdrücklich zitiert, 187 bzw. 204) und wieder aufgegriffen in der neulateinischen Centonendichtung, z.B. im Cento Gallus des Lelio Capilupi: vgl. dazu R. F. GLEI, „Vergil am Zeug flicken. Centonische Schreibstrategien und die Centones ex Virgilio des Lelio Capilupi" in: ders. / R. SeIder $(\mathrm{Hg}$.$) , Parodia und Parodie. Aspekte intertextuellen Schreibens in der latei-$ nischen Literatur der Frühen Netzzeit. FN 120 (Tübingen 2006) 287-320; G. H. TuckER, "Érotisme, parodie, et lart du centon dans le Gallus (1543; Centones ex Virgilio, 1555) de Lelio Capilupi", in: D. SACré / J. PAPY (Hg.), Syntagmatia. Essays on Neo-Latin Literature in Honour of Monigue Mund-Dopchie and Gilbert Tournoy. Humanistica Lovariensia 26 (Leuven 2009) 329-343. Ob Le Vayer auch die neuzeitliche Rezeption des Ausonitus bekatnt war, muss offenbleiben.
} 
and another Person has perverted it into the utmost obscenity, and both allegorically." So kommentiert Alexander Pope in seiner Übersetzung der Odyssee unsere Parodie. ${ }^{39}$ Bei aller Entrüstung über die Obszönität der Le Vayer'schen Darstellung teilt Pope doch deren Kritik an der allegorischen Methode: "But I confess I should rather chuse to understand the description poetically, believing that Homer never dream'd of these matters" (67). Es sei besser, hier eine überschäumende Dichterphantasie anzunehmen als "such a laboured and distant allegory" (ebd.). Gegen eine solche Pauschalkritik an der Allegorese und zugleich gegen die damit verbundene Trivialisierung der homerischen Ekphrasis also ,bloße dichterische Phantasie', wie sie bei Le Vayer und eben auch Pope greifbar ist, haben sich spätere Verteidiger des Porphyrios gewendet. Damit kommen wir zu unserem zweiten Beispiel.

\section{William Blake, The Sea of Time and Space}

Das 1821 entstandene Temperagemälde des englischen Dichters und Malers William Blake (1757-1827) wurde erst 1949 in Arlington Court, einem Herrenhaus in North Devon, unter Gerïmpel entdeckt ${ }^{40}$ und nach einer von Blake selbst verwendeten Metapher für die condition humaine sehr passend mit The Sea of Time and Space betitelt. ${ }^{41}$ Für die folgende Darstellung,

\footnotetext{
${ }^{39}$ Popes Übersetzung der Odyssee erschien erstmals $1725 / 1726$, hier zitiert nach vAN GoENS 1765,66 .

${ }^{40}$ Das Bild wurde vermutlich von John Chichester of Arlington direkt von Blake erworben, der es mit "W.Blake/Inventor, 1821" sigtiert hatte. Vgl. dazt die offizielle Website von Arlington Court mit weiteren Informationen: http://www nationaltrustcollections . org.uk/object/985730 (10.05.2016). Genaueres zur Fundgeschichte bei A. WhitBHRAD, "The Arlington Court Picture. A surviving example of William Blake's framing practice", The British Art Journal 8/1 (2007) 30-33.

${ }^{41}$ Der Titel stammt ursprünglich nicht von Blake. Ein Bleistiftentwurf, der sich in der Blake Collection der Pierpont Morgan Library in New York befindet, trägt auf der Rückseite von unbekannter Hand den Titel "The River of Oblivion"; Geoffrey Keynes, der das Bild als erster beschrieb (KkYNBs 1954) und ratlos über seine Bedeutung spekulierte, sprach zunächst einfach nach dem Fundort von "Arlington Court Picture" und schlug den "Titel "The Circle of the Life of Man" vor; in seiner Beschreibung des Bildes heißt es dann (die Geste missdeutend) über die männliche Zentralfigur: "The Man crouches at her feet with arms outstretched, his right foot advanced, seemingly prepared to plunge into the turbulent Sea of Time and Space" (KeYnes 1954, 205). Diese letztere Metapher stammt tatsächlich von Blake selbst: RaINB 1968, I 386 n. 19 verweist auf einen Brief Blakes an Thomas Butts vom 10. Januar 1802, in dem es heißt: „but the nature of such things is not, as some suppose, without trouble or care. Temptations are on the right hand \& left; behind, the sea of time \& space roars \& follows swiftly: ..." (zitiert nach G. KeYNBs [Hg.], The Complete Writings of William Blake. With all the variant readings [London / New York 1957, Nachdr. 1991] 812). Darüber hinaus verwendet Blake die Metapher auch in seinem epischen Gedicht Milton: ,... so Milton's shadow fell / Precipitant loud thundring into the Sea of Time \& Space." (fol. 14, lin. 46 der illustrierten Ausgabe des British Museum [0.O, o.J, vermutlich
} 


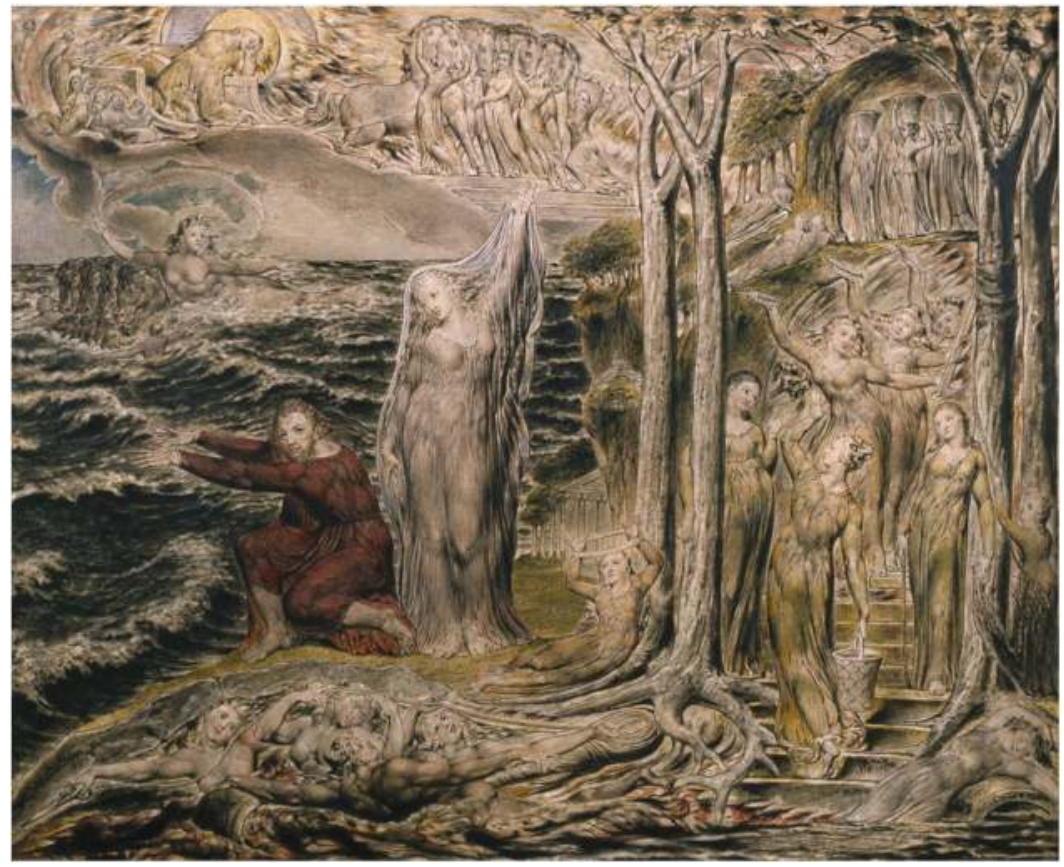

Abb. 1: W. Blake, The Sea of Time and Space ONational Trust Images/John Hammond

die dem Bild freilich nicht in allen Details gerecht werden kann, beziehe ich mich vor allem auf die bahnbrechende Interpretation von Kathleen Raine, ${ }^{42}$ die als erste den Bezug auf Porphyrios erkannte und deren Deutung ich in manchen Punkten ergänze.

Das Bild zeigt in der rechten Bildhälfte die Nymphengrotte, in der linken ein dunkles, aufgewühltes Meer; die beiden Personen in der Bildmitte stellen Athene und Odysseus dar. Letzterer scheint mit abgewandtem Gesicht etwas ins Meer zu werfen - wahrscheinlich den Schleier der InoLeukothea, dic weiter links oben im Meer zu schen ist (Od. V 459-462). Dic Farbgebung des Bildes ist durchgängig in einer Art Schwarzweißtechnik

London um 1811]: vgl. http://www .blakearchive org/exist/blake/archive/object. xq?objectid=milton . a . illbk . 14\&java=no (04.05.2016). Der von Raine auf der Grundlage ihrer Interpretation vorgeschlagene Titel hat sich schließlich eingebürgert.

${ }^{42}$ Ursprünglich als Aufsatz veröffentlicht (K. RaINE, "The Sea of Time and Space", Journal of the Warburg and Courtauld Institutes 20 [1957] 318-337), dann als Kapitel in RaIne 1968, I 69-98. - R. Lamberton, Porphyry. On the Cave of the Nymphs. Translation and Introductory Essay (Barrytown / New York 1983) wählte Blakes Gemälde als Cover für seine PorphyriosÜbersetzung und verwies ausdrücklich auf die Bedeutung der Raine'schen Interpretation (16). 
(die an vergilbte Fotos aus der Frühzeit der Photographie erinnert) ${ }^{43}$ gehalten; einzig Odysseus trägt ein dunkelrotes Gewand (dazu unten). Die Grotte hat zwei Ein- bzw. Ausgänge: Der untere, von Ölbäumen gesäumt, führt vom Meer aus über eine Treppe zur Höhle, der obere, ebenfalls über eine Treppe, in den Himmel, wo am linken oberen Bildrand die aufgehende Sonne (mit einem noch schlafenden, über seinen Wagen gelehnten Sonnengott und den wartenden Pferden) abgebildet ist. Der impliziten Bildgeographie nach ${ }^{44}$ ist daher der untere Eingang der nördliche, durch den bei Homer die Menschen hineingehen, der obere Eingang der südliche, den Göttern vorbehaltene. Auf den unteren Stufen befinden sich mehrere Nymphen, die unterschiedliche Tätigkeiten ausüben: Drei Nymphen arbeiten mit Weberschiffchen an einem angedeuteten Webstuhl, andere sind mit dem Wickeln von Wolle beschäftigt, eine Zentralfigur trägt einen gefüllten Eimer und weist nach oben zum Himmel, während eine andere Nymphe auf einem schwimmenden Fass schlafend im Wasser liegt. Weiter oben, in der Höhle selbst, sind mehrere geflügelte Nymphen abgebildet, die große Behälter auf dem Kopf tragen. Am linken unteren Bildrand schließlich schwimmen die drei Parzen (mit Knäuel, Seil und Schere), begleitet von einer kräftigen männlichen Gestalt (die Phorkys, den „Meeresalten", darstellen soll?).

Schon aus dieser groben Beschreibung dürfte klar geworden sein, dass Blake verschiedene mythische Motive kombiniert hat: Neben der Nymphengrotte sind dies vor allem die Ankunft des Odysseus auf der Phaiakeninsel (Gürtel der Ino-Leukothea), der Wagen des Sonnengottes und die Schicksalsgöttinnen (Parzen); das Hauptthema bleibt freilich die Grotte der Nymphen auf Ithaka (Odysseus' Palast im Hintergrund der Bildmitte als Tempel angedeutet). Wie aber lässt sich beweisen, dass Blake dabei nicht nur Homer, sondern auch die Allegorese des Porphyrios vor Augen hatte? Zunächst zur externen Evidenz. Blake war ein Anhänger des Platonismus, der in England vor allem durch das Werk von Thomas Taylor (1758-1835), mit dem Blake auch persönlich bekannt war, verbreitet wurde. Taylor übersetzte neben dem gesamten Platon und Aristoteles auch zahlreiche neuplatonische Schriften erstmals ins Englische, darunter Plotin, Proklos, Jamblich, Synesios und auch Porphyrios' De antro Nympharum (1788/1789). ${ }^{45}$ Bereits in seinem Gedicht The Book of Thel (1789) habe Blakes

\footnotetext{
${ }^{43}$ Die Daguerreotypie wurde erst um 1835 erfunden; ob Blake auf Vorgängerformen der Photographie anspielt, müssen Medienhistoriker beantworten.

${ }^{44}$ Die aufgehende Sonne (Osten) ist links oben, der obere Bildrand weist daher nach

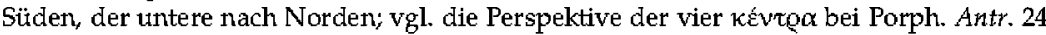
(dazu Benjamin Topp in diesem Band, S. 135-136).

${ }_{45}$ Englische Erstausgabe von Antr. möglicherweise bereits 1788 (nicht nachweisbar), dann in Proclus Bd. II (= TAYLOR 1789, nachgedruckt in RaINB / HaRPBR 1969), aufgenommen in T. TAYLoR, Select Works of Porphyry. Translated from the Greek and with an appendix explaining the Allegory of the Wanderings of Ulysses, by the translator (London
} 
Lektüre der Taylor'schen Übersetzung Spuren hinterlassen, wie Raine vermutet $^{46}$ Thema des Werkes ist der Disput zwischen der ätherischen Nymphe Thel (vielleicht gräzisierend von $\theta \dot{\varepsilon} \lambda \varepsilon v v ?$ ), die die materiefeindliche neuplatonische Philosophie vertritt, und der chthonischen Clay ("Ton"), die die paracelsische Alchemie propagiert. Thel betritt die irdische Welt (Geburt) durch ein Tor von Norden her, das gleichzeitig ein Tor zum Tod ist, während der Ausgang durch das Tor des Todes eigentlich eine Befreiung zum Leben bedeutet. Blake spielt hier natürlich mit neuplatonischen Vorstellungen (womb - tomb, cave - grave); speziell die Symbolik der beiden Tore bzw. Ein- und Ausgänge der Höhle dürfte er dabei Porphyrios' De antro Nympharum entnommen haben, wie sich unten zeigen wird.

Doch zurück zu The Sea of Time and Space und damit zur bildimmanenten Evidenz. Hinweise auf Porphyrios finden sich in Bildelementen, die definitiv von Homer abweichen: Das Meer ist bei Homer nicht dunkel und aufgepeitscht, sondern ruhig, als das Zauberschiff der Phaiaken es überquert, ${ }^{47}$ und der Phorkyshafen liegt ohnehin in einer windgeschützten Bucht, ${ }^{48}$ für Porphyrios dagegen ist, nach Platon, "Meerestiefe, Meer und Wogenschwall (ein Symbol für) den Zustand der Materie" (í ú $u$ akr̀

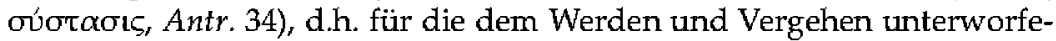
ne Welt, weshalb, so Porphyrios, der Dichter hier vom Hafen des Phorkys spreche (Antr. 35).$^{49}$ Weiterhin erwähnt Porphyrios an dieser Stelle (Antr. 34) einen Ausspruch des Numenios, der treffend gesagt habe, Odysseus repräsentiere das Bild "eines durch die aufeinanderfolgenden Stadien des Werdens gehenden Menschen" (

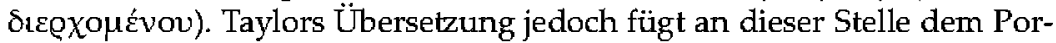
phyriostext etwas hinzu: „Numenius thought the person of Ulysses in the Odyssey represented to us a man who passes in a regular manner over the dark and stormy sea of generation. ${ }^{.50}$ Von ", dark and stormy sea of

1823, Nachdr. 2008). Taylor benutzte die griechisch-lateinische Ausgabe von HoLste (1630) in dem Nachdruck Cambridge 1655 tnd die der Homerausgabe von Josua BarNes (Cambridge 1711) vorangestellte Fassung. Taylor vermerkt noch eine dritte Ausgabe "by some German editor, which I have not seen" (RAINB / HARPER 1969, 297 n. I). Möglicherweise handelt es sich um die Ausgabe des Niederländers van GoBns 1765, die bedeutendste und materialreichste Ausgabe cles 18. Jahrhunderts.

${ }^{46}$ RAINE 1968, I 99.

${ }^{47}$ Es ist lediglich das schnellfahrende Schiff selbst, das eine große Bugwelle vertursacht: Od. XIII 84 .

${ }^{48} \mathrm{Od}$ XIII $99 \mathrm{f}$.

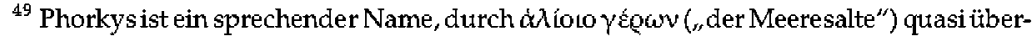
setzt, denn фoekóv bedeutet nach Hesych "weißgrat, runzlig"; vielleicht autch eine Kontamination mit dem "Meeresalten" Protets ( $O d$. IV 365), der allegorisch für die Wandelbarkeit der Materie steht; vgl. atch RaIne 1968, I 387 n. 41.

${ }^{50}$ TAYLOR 1789, 321. Zu dieser Metapher gibt Taylor eine sehr lange Fußnote, die er später als eigenen Essay ("On the wanderings of Ulysses", 1823) veröffentlichte. RAINB / HARPBR 1969, 296, halten es für möglich, dass James Joyce dadurch zu seinem Ulysses inspiriert 
generation" ist im Originaltext keine Rede, sondern lediglich abstrakt von $\gamma^{\prime} \dot{v}$ caı ("Werden”, engl. "generation”). Genau das aber, die dunkle und stürmische See, hat Blake in seinem Gemälde abgebildet, weshalb es vielleicht auch The Sea of Generation hätte betitelt werden können. ${ }^{51}$

Die Nymphen selbst stehen nach Porphyrios (Antr. 12) für "die Seelen,

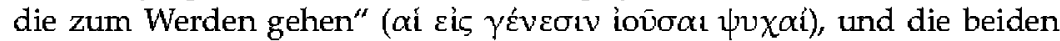
Ein-/Ausgänge der Höhle symbolisieren den Eingang (Abstieg) der Seelen in die Welt des Werdens und den Ausgang (Wiederaufstieg) in die Welt des Ewigen. Der Nordeingang wird bei Porphyrios mit dem nördlichen Wendekreis (des Krebses), mit dem der Abstieg der Sonne beginnt, der Südeingang mit dem südlichen Wendekreis (des Steinbocks) für den Wiederaufstieg der Sonne nach dem Wintersolstitium identifiziert - daher auch als "Tore der Sonne" (†ं $\lambda$ íov $\pi u ́ \lambda \alpha \varsigma$ ) bezeichnet (Antr. 28) ${ }^{52}$ Gleichzeitig nimmt Porphyrios, wiederum nach Numenios, eine Zuordnung der Eingänge zu den Planeten vor: Der Abstieg (Krebs) entspricht der Mondsphäre, die der Erde am nächsten ist, der Aufstieg (Steinbock) der Saturnsphäre, die der Erde am fernsten und dem Fixsternhimmel am nächsten ist (Antr. 22). Die absteigenden, d.h. ins Werden eingehenden Seelen ziehen die Feuchte an sich (Antr. 10) - Wasser ist das charakteristische Element der sublunaren Welt und biologische Notwendigkeit des Werdens, ${ }^{53}$ während die aufsteigenden, gereinigten Seelen sich vom Werden abwenden

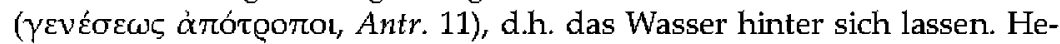

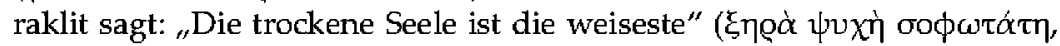
zitiert von Porphyrios ebd.).

Diese Symbolik ist bei Blake, wie Raine plausibel gemacht hat, durch zwei Figuren des Bildes repräsentiert: Die in der rechten unteren Bildecke schlafend im Wasser liegende Nymphe ist die "feuchte", dem Werden verhaftete Seele, die aktive, energische Figur auf der Treppe, die zum Himmel blickt, die "trockene". Der Bezug auf Porphyrios wird vollends bestätigt, wenn man die Gefäße der beiden Figuren heranzieht: Die eine liegt auf einem halb gefüllten Fass, die andere trägt einen gefüllten Eimer. Das verweist auf Porphyrios' Erwähnung der Gorgiasstelle (Antr. 30), wo die Seele als Vorratsgefäßs bezeichnet wird, das je nach Orientierung der Seele mit

worden sei; das mögen die Joyce-Forscher untersuchen (ersten Recherchen zufolge scheint die Frage tatsächlich ungeklärt zu sein; für den Hinweis danke ich H. Versteegen).

${ }^{51}$ Der Titel The Sea of Time and Space (s. dazu oben Anm. 41) ist aber insofern eine treffende Umschreibung für The Sea of Generation, als Zeit und Raum als klassische Merkmale der Welt des Werdens (wenn nicht sogar als Anschautungsformen a priori-Kants Kritik der reinen Vernunft [1781, ${ }^{2} 1787$ ] erschien freilich erst 1838 erstmals auf Englisch, so dass der Bezug zumindest für Blake wohl anachronistisch wäre) aufgefasst werden können.

${ }^{52} \mathrm{Vgl}$. auch Macr. Somn. I 12, 1: has solis portas physici vocaverunt (",diese [beiden Sternzeichen, d.h. Krebs und Steinbock] nannten die Naturphilosophen ,Tore der Sonne ").

${ }^{53}$ Siehe das eingangs gegebene Zitat von Blumenberg. 


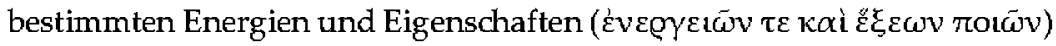
gefüllt ist.

Unklar bleibt, ob die oben rechts abgebildeten geflügelten Nymphen, die Vorratsgefäße tragen, mit den bei Homer erwähnten Bienen zu identifizieren sind, wie Raine vorschlägt; auch der bei Blake nur angedeutete, aber eindeutig hölzerne Webstuhl entspricht nicht dem Homertext, wo lange, steinerne Webstühle erwähnt werden, auf denen die Nymphen "meeres-

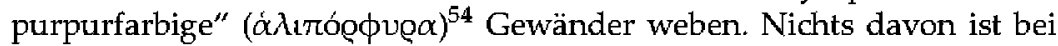
Blake zu sehen, allerdings trägt Odysseus als einzige Person auf dem Gemälde ein farbiges Gewand, und zwar in eben jenem Meerespurpur. Eine Erklärung dafür ließe sich bei Porphyrios finden, der im Weben der purpurnen Gewänder auf steinernen Webstühlen die ,Einkleidung' der Seele mit Knochen, Fleisch und Blut ausgedrückt sieht (Antr. 14). Das purpurne Gewand weist Odysseus somit im Gegensatz zu allen anderen abgebildeten Personen als einen (noch) dem Irdischen verhafteten Menschen "aus Fleisch und Blut" aus, der aber durch seinen Gestus bereits die Feuchte (das Meer) abwehrt ${ }^{55}$ und bald durch die neben ihm stehende Göttin Athene die wahre Heimkehr, d.h. den Aufstieg zum Himmel, antreten wird. Die Farbgebung fände so eine plausible Erklärung auf der Bildebene.

Aber könnte Blake nicht auch auf einer Metaebene mit dem porphyrfarbenen (!) Gewand des Odysseus darauf hinweisen, dass er auf seinem Gemälde eben Odysseus im Gewand des Porphyrios dargestellt hat? Denn tatsächlich hat Odysseus bei Homer in beiden hier kontaminierten Szenen der Odyssee kein solches Gewand an: Bei seiner Ankunft auf Scheria ist er bekanntlich bis auf den Schleier der Ino-Leukothea nackt, und bei seiner (schlafenden) Ankunft auf Ithaka trägt er vermutlich einen Chiton, sicher aber nicht den prächtigen purpurnen (!) $\phi \bar{\alpha} \varrho 0 \varsigma$, mit dem er seine Tränen verbirgt (Od. VIII 84) und den die Phaiaken ihm mitgegeben hatten $(\mathrm{Od}$. XIII 67) ${ }^{56}$ Für die allegorisierende Interpretation Blakes bot sich daher ein Wortspiel mit dem Namen des Porphyrios (= „purple man" bzw. "man clad in purple") unmittelbar an.

\section{Höhlenausgang II}

Zusammenfassend kann man sagen, dass Blake die Inspiration zu The Sea of Time and Space der Homerallegorese des Porphyrios verdanken dürfte, die er in der Übersetzung von Thomas Taylor kannte. In dem Ge-

\footnotetext{
${ }^{54}$ "of purple hue" nach der Übersetzung von Taylor.

${ }^{55}$ Porph. Antr. 34 zitiert dazu Od. XI 122f. = XXIII 269f., wonach Odyssetts in einem Land sterben wird, wo man das Meer nicht kennt.

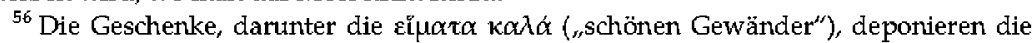
Phaiaken am Fußß des Ölbaums (Od. XIII 122), wo Odysseus sie später findet und nachzählt (Od. XIII 217f.).
} 
mälde hat er die neuplatonische Seelenlehre, insbesondere den Abstieg der Seele in das Reich des Werdens und deren (möglichen) Wiederaufstieg in die intelligible Welt visualisiert. Durch Farbgebung, Komposition und Figurensymbolik sowie durch Ergänzung bzw. Umdeutung einzelner homerischer Details wird deutlich, dass hier nicht ein naturrealistisches Bild der homerischen Nymphengrotte intendiert ist, sondern die Ver(sinn)bildlichung eines neuplatonischen Homerinterpretaments. Es ist der Dualismus der Menschennatur, das unausweichliche Schicksal der Inkarnation und deren Überwindung durch das Abwerfen des Irdischen und die Rückkehr in die wahre Heimat, die Blakes "Vision of the Circle of the Life of $\mathrm{Man}^{\prime 57}$ ausmachen. Damit ist Blakes Interpretation ein Beleg für das vielfältige und kreative Deutungspotential der Höhle bei Homer, das Blumenberg so definiert hat:

Der Reiz der Allegorie für den historischen Betrachter liegt nicht in der ihr eigentüm-
lichen Denkweise, sondern gerade in ihrer Unangemessenheit zu dem, was das Epos
Homers enthält und worautf ein unbefangener philosophischer Blick hätte fallen müs-
sen. Die Verstellung der Aufmerksamkeit auf die dichterische Mächtigkeit der Heim-
kehrszene ist ein Musterstück für die Aufschlüsse, die in den Mißverständrissen der
Tradition - und gerade in ihrem meistverachteten Zweig: der Allegorese - angeboten
sind. ${ }^{5}$

Dass die Allegorese des Porphyrios mit ihrem ,kreativen Missverständnis‘ Homers ihrerseits Anlass zu zumindest zwei eigenen kreativen Rezeptionen gegeben hat, dürfte deutlich geworden sein; ob sich diesen eine dritte hinzufügen lässt, soll abschließend in einem Anhang untersucht werden.

\section{Anhang: Francesco Colonna, Hypnerotomachia Poliphili}

Das in einem Idiolekt aus latinisierendem, mit altertümlichen Elementen durchsetzten Italienisch ${ }^{59}$ abgefasste umfangreiche Werk gehört zu den berühmtesten Erzeugnissen der Druckerei des Aldus Manutius in Venedig, weil es in seiner typographischen Gestaltung ein frühes Meisterwerk der Buchdruckerkunst darstellt, ja als "das schönste und berühmteste Buch

\footnotetext{
${ }^{57}$ KaYnes $1954 \mathrm{im}$ Titel seiner (wenn auch abwegigen) Erstinterpretation des neu aufgefundenen Gemäldes (s, oben Anm. 41).

58 BlumbNeERG 1989, 242.

${ }^{59}$ Das Werk wird daher sowohl für die netaleinische als auch für cie romanische Literatur vereinnahmt. Zur Sprache der Hypnerotonachia Poliphili (im Folgethden HP abgekürzt) vgl. G. Pozzi / L. A. CLapponi (Hg.). Hypnerotomachia Poliphili, 2 Bde. (Padova 1968; ${ }^{2}$ 1980) II 23-36 sowie allgemeiner I. WHITE, "Multiple words, multiple meanings, in the Hypnerotomachia", Word \& Image 31/2 (2015) 74-78. Zitiert wird es hier nach der Ausgabe von ARIANI/ Gabrible 1998 (Faksimile der Aldina 1499). Netterdings gibt es atch eine deutsche Übersetzung: Th. ReIser, Francesco Colonna. Hypnerotomachia Poliphili (Breitenbrunn 2014).
} 
der italienischen Renaissance" bezeichnet wurde. ${ }^{60}$ Außer dem sorgfältig, oft figürlich arrangierten Text enthält es 172 textbegleitende bzw. erklärende Holzschnitte, ${ }^{61}$ die häufig fiktive Artefakte (darunter den berühmten, später von Bernini geschaffenen Elefanten mit Obelisk vor der Basilika Santa Maria sopra Minerva) ${ }^{62}$ darstellen und darüber hinaus Inschriften in lateinischer, griechischer, hebräischer und arabischer Sprache ${ }^{63}$ sowie Pseudo-Hieroglyphen enthalten. Die äußerst detaillierten Beschreibungen der Bauwerke, die sogar Rekonstruktionszeichnungen veranlassten, ${ }^{64}$ haben dem Werk einen ruhmvollen Platz in der Architekturgeschichte verschafft, wobei der Autor häufig in eine Reihe mit Leon Battista Alberti gestellt, ja dieser bisweilen sogar als Verfasser der HP angenommen wurde. ${ }^{65}$

Der gräzisierende Titel Hypnerotomachia besteht wie bei der bereits 1474 gedruckten und daher unter den Humanisten bekannten pseudohomerischen Batrachomyomachia aus drei Bestandteilen und könnte mit "Traum-Liebes-Kampf" wiedergegeben werden. Es handelt sich jedoch nicht um einen "Kampf zwischen Traum und Liebe", wie die Analogie zum "Froschmäusekrieg" nahelegen könnte, sondern um eine Art "Kampf um die Liebe im Traum". Der Roman schildert nämlich in Form der IchTraumerzählung den Kampf, den der Held Poliphilo durchstehen muss, bevor er seine geliebte Polia schließlich auf der (damals zu Venedig gehörenden) Venusinsel Kythera ${ }^{66}$ ehelichen darf. Der bewusst hybride und doppeldeutige Name Poliphilo - Polyphilos, der "Vielliebende”, bzw. Po-

\footnotetext{
${ }^{60}$ O. Pollak, „Der heutige Stand der Poliphilus-Frage", Kunstchronik. Wochenschrift für Kunst und Kunstgewerbe, N.F. 23 (1911/1912) [433-437] 433, zitiert von ARNold 2014, 3.

${ }^{61}$ Zum Text-Bild-Zusammenhang vgl. R. TRIPPE, "The ,Hypnerotomachia Poliphili' Image, Text, and Vernacular Poetics", Renaissance Quaterly 55/4 (2002) 1222-1258; zuletzt BurIoni 2013, ARnOLD 2014.

${ }^{62}$ Vgl. Ariani / Gabrible 1998, II 592-59.5.

${ }^{63}$ Bemerkenswert ist, dass Colonna den drei klassischen Heiligen Sprachen hier als vierte das Arabische hinzufügt; vgl. besonders die drei Tore des Ruhms HP 135; dazu A. M. Pigmontbse, "Le iscrizioni arabe nella « Poliphili Hypnerotomachia " , in: Ch. BurnetT / A. Contadini (Hg), Islan and the Italian Renaissance. Warburg Institute colloquia 5 (London 1999) 199-220.

${ }^{64} \mathrm{Vgl}$. Cruz 2006.

${ }^{65}$ So von L. LBFAIvRB, Leon Battista Alberti's Hypnerotomachia Poliphili. Recognizing the ArChitectural Body in the Early Italian Renaissance (Cambridge/Mass. 1997). Eine andere Zuschreibung (an Niccolò Lelio Cosmico) versucht R. STBwBRING, Architektur und Natur in der "Hypnerotomachia Poliphili" (Mantutits 1499) und die Zuschreibung des Werkes an Niccolò Lelio Cosmico (Hamburg 1996). Angesichts der Selbstzuschreibung der Autorschaft durch das Akrostichon, das die 38 Kapitelinitialen bilden (POLIAM FRATER FRANCISCVSCOLVMNA PERAMAVIT), lässt sich jecloch die Verfasserschaft von Francesco Colonna OP kaum bezweifeln. Auch der gleichnamige Graf von Palestrina (1453-1517) scheidet damit aus.

${ }^{66} \mathrm{Vgl}$. dazu umfassend K. DickHAuT, Positives Menschenbild und s, venezianità". Kythera als Modell einer geselligen Utopie in Literatur und Kunst von der italienischen Renaissance bis zur französischen Aufflärung. Culturae 3 (Wiesbaden 2012).
} 
lifilo, der "Liebhaber der Polia" - verweist bereits auf die antik-moderne Doppelnatur des Romans und das Spiel mit verschiedenen Bedeutungsebenen. ${ }^{67}$

Besonders die in dem Roman vielfältig eingesetzten allegorischen Verfahren - z.B. begegnet Poliphilo fünf Nymphen (!), die sich später als Allegorien der fünf Sinne herausstellen - führten zu der Annahme, dass Porphyrios' allegorische Homerauslegung den Anstoß oder zumindest den Hintergrund für die literarische Machart des Romans gebildet habe. ${ }^{68}$ Nun erschien die editio princeps von De antro Nympharum bekanntlich erst 1521, könnte aber durch einen griechischen Kodex des Bessarion in Venedig bereits im 15. Jahrhundert bekannt gewesen sein. ${ }^{69}$ Andere antike Prätexte (oder mit Genette: Hypotexte) sind allerdings ebenso, wenn nicht sogar in höherem Maße präsent. Das Motiv der Traumerzählung führt auf evidente philosophische Architexte wie Platons Er-Mythos bzw. Ciceros Somnium Scipionis (in der neuplatonischen Deutung des Macrobius) und natürlich auf die kreativen Ausformungen in den ,Traumreisen Lukians; $^{70}$ die Gattung des allegorischen Romans selbst und das Erlösungs- bzw. Initiationsmotiv der HP (Einweihung in den Venuskult auf Kythera) verweisen auf den Isis- (= Venus-)Roman des Platonikers Apuleius. ${ }^{71}$ Auch die in der HP auftretenden Nymphen legen zunächst einmal den Bezug zu den homerischen Naiaden nicht unbedingt nahe, da diese ja als Wassernymphen ein Kollektiv, keine numerisch und funktional differenzierbare Gruppe darstellen. Gleichwohl soll versucht werden, konkrete Hinweise auf Porphyrios' De antro Nympharum in der $H P$ zu eruieren und zu prüfen. Dabei werden zunächst die Verweise in dem die Quellen der $H P$ erschöpfend dokumentierenden Kommentar von Ariani / Gabriele (1998) zugrunde gelegt, jedoch um zusätzliche Stellen erweitert.

Zu Beginn seiner Traumreise findet sich Poliphilo in einem düsteren, unheimlichen Wald (der anspielungsreich als Hercynia silva bezeichnet wird). Beim Herumirren durch das Dickicht zerreißt er sich seine Toga. Diese besteht aus Wolle (HP 101: lanacea toga, an anderer Stelle auch als ,plebeisch' bezeichnet) und wird später von den Nymphen durch ein neues, strahlend weißes und vornehmeres Gewand ersetzt (HP 367: „le plebarie toge dalle assignate nymphe exute, di candida e lautiuscula veste di no-

\footnotetext{
${ }^{67} \mathrm{Vgl}$. NAU 2007, der seinen Aufsatz in Anlehnung an Roland Barthes "S $\mathrm{S} / \mathrm{Z}^{\prime \prime}$ mit "I/Y" $\mathrm{Y}^{\prime \prime}$ betitelte, womit er auf die Alternative Poli- bzw. Poly-anspielte.

${ }^{68}$ Mehrfach mit Parallelstellen belegt im Kommentar von Ariani / Gabrible 1998 (passim, s. unten), inzwischen verewigt im NP Supplementband "Mythen rezeption" s.v. Nymphen.

${ }^{69}$ S. oben Anm. 8 sowie ArIani / Gabrible 1998, II 529.

${ }^{70}$ Diese Bezüge sind $\mathrm{m}$.W. noch nicht untersucht.

${ }^{71}$ Vgl. R. H. F. CARvgr, The Protean Ass. The Metamorphoses of Apuleitus from Antiquity to the Renaissance (Oxford 2007), der der Rezeption des Aptleitus in der HP ein umfangreiches Kapitel widmet (,The Antiquarian Ass", 183-235).
} 
vo me officiosamente vestirono"). Die Kommentatoren ${ }^{72}$ verweisen dazu auf Porph. Antr. 14, wo es heißst, dass die purpurgefärbte Wolle (Ě ڤov), die die Nymphen in der Grotte auf steinernen Webstïhlen weben, dem Körper (aus Knochen sowie Fleisch und Blut) entspreche, der "das Gewand

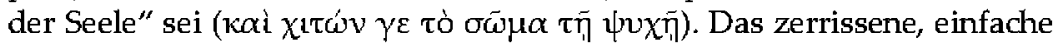
und , plebeische' Gewand des Poliphilo symbolisiere mithin, so Ariani / Gabriele, das alte, ,fleischliche' Leben des Helden, der später geläutert werde. Das ist nicht überzeugend: Poliphilo wird ja nicht zum Asketen, sondern in den (durchaus fleischlichen) Venuskult eingeweiht, und abgesehen davon, dass es bei Homer bzw. Porphyrios gar nicht um verschiedenartige Gewänder geht, verweist das der Volkssprache entstammende Epitheton lautiuscula als antikes Hapax vielmehr auf Apuleius (Met. VII 9: vestemque lautiusculam, "ein ganz schön prächtiges Gewand"), wo ebenfalls ein zerrissenes Lumpengewand gegen ein besseres ausgetauscht wird. ${ }^{73}$

Eine andere, platonische Symbolik findet sich in der HieroglyphenInschrift, die auf dem als Postament des genannten Elefanten dienenden Quaderstein angebracht ist. Das ein antikes verstöpseltes Gefäß darstellende Zeichen wird von Poliphilo als animus entziffert, was auf den ersten Blick überraschend ist. Denn so gängig das Bild vom Körper als ,Gefäß’ der Seele ist ${ }^{74}$ so merkwürdig ist es, das hier das Gefäß gerade die Seele und nicht den Körper darstellt. Die Lösung dieser Schwierigkeit könnte in dem Verweis auf das platonische Bild der Seele als rí⿴os im Gorgias (493a-b) liegen. Dort berichtet Sokrates von einem "geistreichen Mann aus Sizilien oder Italien", der die Seele (bzw. den niederen Seelenteil, der die Neigungen enthält) als Vorratsgefäß bezeichnet habe. Nun könnte der Verfasser der $H P$ das natürlich bei Platon selbst gelesen haben, aber es ist schon interessant, das Porph. Antr. 30 auf die Gorgiasstelle hinweist und gleichzeitig sowohl Homers bekannte zwei $\pi$ í日o des Zeus (Il. XXIV 527) als auch den $\pi i \theta$ os der Pandora (Hes. Erga 94) in denselben Zusammenhang stellt. Erst

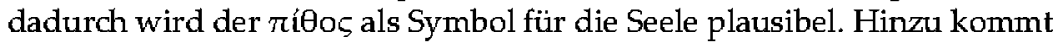
ein Umstand, der von den Kommentatoren bisher übersehen wurde: Der Quaderstein, auf dem die Hieroglyphen eingemeißelt sind, ${ }^{75}$ besteht "di durissimo Porphyro" (HP 37) und wird auch später noch einmal als "por-

\footnotetext{
72 ArLani / Gabrible 1998, II 529.

${ }^{73} \mathrm{Zu}$ vergleichen wäre freilich Odysseus' Verkleidung als Bettler, die später wieder rückgängig gemacht wird; cas Motiv spielt aber bei Porphyrios keine Rolle (allenfalls eine Andeutung in Antr. 34).

${ }^{74} \mathrm{Vgl}$. etwa Cic. Tusc. I 52: corpus quidem quasi vas est aut aliquid animi receptaculum ("der Körper ist ja gewissermaßen ein Gefäß oder eine Art Aufnahmebehälttris für die Seele").

${ }^{75}$ Weitere Hieroglyphen geben für unsere Fragestellung nichts her. Das auf clas Gefäß folgende Symbol ist eine Sandale mit Auge und je einem Oliven- und Palmzweig. Die Olive als Baum der Athene und Symbol der Weisheit ist so universal, dass ein Bezug zu Porphyrios' Auslegung des homerischen Ölbatms am Eingang der Nymphengrotte (Antr. 32f.) richt sehr wahrscheinlich ist.
} 
phyretico basamento" (HP 40/41) bezeichnet. Sollte also der Stein rein zufällig aus Porphyr bestehen oder liegt nicht vielmehr eine Anspielung auf den Namen des Porphyrios vor? Die Einzelstelle ist sicher nicht beweiskräftig, aber es gibt weitere Hinweise. ${ }^{76}$

Auch in der Beschreibung des Nymphenbrunnens, den man geradezu als initiales Paradigma der Renaissance- und Barockbrumenarchitektur bezeichnen könnte, ${ }^{77}$ wird "uno vaso porphyritico" (HP 71) erwähnt: Die beiden aus den Brüsten der auf einem Relief abgebildeten Nymphe (!) strömenden Wasser(!)strahlen (einer mit kaltem, einer mit heißem Wasser) mischen sich in einem doppelten, durch eine Aushöhlung (,alveolo") verbundenen Porphyrbecken. In der Nymphengrotte der Odyssee befinden sich steinerne Misch(!)krüge und Amphoren, die bei Porph. Antr. 12f. als passende Symbole für Wassernymphen, die dem aus den Felsen strömende Wasser "vorstehen", bezeichnet werden - offenbar deshalb, weil nach der Deutung des Porphyrios in diesen Gefäßen das Wasser aufgefangen wird. Dem (freilich abgewandelten) Motiv in der HP könnte hier tatsächlich Porphyrios zugrunde zu liegen, da bei Homer ein Zusammenhang zwischen den Krügen und dem Wasser gar nicht hergestellt wird. Die vielleicht etwas vage und nicht gleich ersichtliche Beziehung zwischen dem Nymphenbrunnen und der Nymphengrotte ${ }^{78}$ (aber immerhin geht es um Nymphen und um Wasser) hätte der Autor der HP in diesem Fall erneut durch den Verweis auf das Material des Auffangbeckens deutlich gemacht.

Eine dritte Stelle schließlich könnte ebenfalls eine Anspielung auf Porphyrios enthalten: In der Ruinenstadt Polyandrion stößt Poliphilo auf ein unversehrtes hexagonales Gebäude mit hutartiger Kuppel, ein sog. Ciborium, ${ }^{79}$ "una opera preclara di narrato, tutta di rubicundo porphyrite" (HP 246). Durch einen versteckten Eingang gelangt Poliphilo in eine darunterliegende Höhle, in der sich u.a. eine Fetıerstätte und ein Altar für die Un-

\footnotetext{
${ }^{76}$ Porphyr als Batsstoff ist zwar auts der Antike bekannt (vgl. Suet. Nero 50: porphyreticus; Plin. Nat. XXXVI 57:porphyrites), wird. aber nicht häufig erwähnt und bleibt insgesamt eher unauffällig. Auch in den besonders im Mittelalter verbreiteten Steinbüchern spielt er (als Nichtedelstein) keine Rolle.

77 Ähnlich Z. A. PATAKL, "nympha ad amoenum fontem dormiens" (CIL VI/5, $3^{*} e$ ). Ekphrasis oder Herrscherallegorese? Studion zu einem Nymphenbrunnen sowie zur Antikenrezeption tund zur politischen Ikonographie an Hof des ungarischen Königs Matthias Corvinus, 2 Bde. (Stuttgart 2005) 111: "Archetypus". Vorlage für Colonna könnte, so Pataki, das pseudo-antike Epigramm Huius nympha loci etc. des Giovanni Antonio Campano (1429-1477) gewesen sein.

${ }^{73}$ D. Scholl, Von den „Grottesken" zum Grotesken. Die Konstituierung einer Poetik des Grotesken in der italienischen Renaissance. Ars Rhetorica 11 (Münster 2004) 223-288 widmet ein ganzes Kapitel der Rolle der HP für die Entstehung der Grot(t)eske in der Renaissance, geht aber nicht auf Porphyrios ein.

${ }^{79}$ Vgl. dazu CRUz 2006, I81-185, mit architektonischer Rekonstruktionszeichnung.
} 
terweltsgötter befinden. ${ }^{80}$ Die Beschreibung der Höhle (mit Feuer, nicht Wasser!) erinnert in Vielem an das Platonische Höhlengleichnis, und der porphyritische Überbau mit einer Öffnung , al rito aegyptico" (HP 248) lieBe sich als Hinweis auf Porphyrios lesen, der in De antro Nympharum mehrfach auf ägyptische Parallelen rekurriert. ${ }^{81}$ Hinzu kommt noch, dass der Porphyrbau als "besonders erzählwürdig" vorgestellt wird - ein metanarrativer Hinweis, der auf Hypotexte hindeutet, die, wie das geschilderte Hypogäum buchstäblich unter dem Ciborium liegt, so unter dem Erzähltext liegen: Platons Höhle und - gegebenenfalls - Porphyrios' Grotte.

Ein weiterer versteckter Hinweis auf Porphyrios könnte in der Beschreibung der Großen Pyramide liegen, die durch ihre auf- und absteigenden Gänge den Weg der Seele symbolisiert. ${ }^{82}$ Nun ist der Ab- und Aufstieg der Seele ein gängiges (neu-)platonisches Bild, ${ }^{83}$ aber ein Detail ist bemerkenswert. In der HP wird der Eingang zur Pyramide mehrfach als "bucca", "apertura di bucca" o.ä. (HP 27f.) bezeichnet. Eine Erklärung dafür böte Porph. Antr. 22, wo bemerkt wird, dass die beiden Öffnungen der Grotte (nach Norden und Süden) astronomischen Konstellationen entsprächen, die bei Platon o'ó $\mu \iota \alpha$, "Mundöffnungen", genannt würden. Eine Platonstelle lässt sich dazu aber gar nicht nachweisen, ${ }^{84}$ so dass die "Mundöffnung" der HP auf Porphyrios (oder jedenfalls auf neuplatonische Deutung) zurückgehen könnte. ${ }^{85} \mathrm{Im}$ Übrigen findet sich bei Porphyrios an der genannten Stelle eine Zuordnung der (sieben) Planeten zu den (zwölf) Tierkreiszeichen - wobei Sonne und Mond je ein, den übrigen Planeten je zwei Tierkreiszeichen entsprechen $-{ }^{86}$ die sich am (siebeneckigen! ${ }^{87}$ ) Tem-

\footnotetext{
${ }^{80}$ Der Altar trägt eine Weihinschrift für Pluto, Proserpina und Cerberus in fingiertem Altlatein. Zu den Inschriften in der $H P$ vgl. M. Furno, Une ufantasie sur l'antiques: le goĥt pour l'épigraphie funéraire dans l'Hypnerotomachia Poliphili de Francesco Colonna (Genève 2003) sowie ders., "Les inscriptions latines du Polyandrion: seconde langue et travestissements romanesques dans l'Hypnerotomachia Poliphili de Francesco Colonna", RHR 75 (2012) 69-86.

${ }^{81} \mathrm{Vgl}$. Porph. Antr. 10; 23; 27 u.ö., sowie den Beitrag von Christoph Riedweg in diesem Band, S. 82-85.

${ }^{82}$ Dazu vgl. vor allem Burioni 2013.

${ }^{83}$ Vgl. z.B. Macr. Somn. I 12

${ }^{84}$ Pol . 615d-e, wo đTóutov den Eingang zur Unterwelt bezeichnet, ist nicht einschlägig. Porphyrios bezieht sich wahrscheinlich auf die Umdeutung durch Numenios.

${ }^{85}$ Zwar verweist auch Macr. Somn. I 12,3 auf die Homerstelle (et hoc est quod Homeri divina prudentia in antri Ithacensis descriptione significat, "tund das ist es, was Homers göttliche Weisheit in der Beschreibung der Grotte von Ithaka sagen will ${ }^{*}$ ), spricht aber von portae, nicht von ostia o.ä.

${ }^{86} \mathrm{Vgl}$. Porph. Antr. 22. Vom Krebs aus gezählt: Löwe-Sontre, Jungfrau-Merkur, Waage - Venus, Skorpion-Mars, Schütze-Jupiter, Steinbock-Saturn. Vom Steinbock aus gezählt: Wassermanu - Saturn, Fische - Jupiter, Widder-Mars, Stier - Vetıts, Zwillinge - Merkur, Krebs - Mond. Zur Erklärtung der ,Tag- und Nachthäuser' vgl. den Beitrag von Benjamin Topp in diesem Band, S. 124-126.

${ }^{87}$ Ein mathematischer Schönheitsfehler besteht darin, dass sich das Siebeneck tricht exakt (mit Zirkel und Lineal) konstruieren lässt; das war bereits Euklid bekannt (wern auch
} 
pel der Venus auf Kythera wiederfinden ${ }^{88}$ Insgesamt bleiben die Bezüge vage, aber immerhin möglich.

Keinesfalls einschlägig dagegen dürfte Porphyrios als Quelle für das ,stille Gebet' des Poliphilo sein, das dieser in der Einsamkeit des Waldes an Diespiter (= Iupiter) richtet. ${ }^{89}$ In Porph. Antr. 27 heißt es zwar, der südliche (göttlichere) Höhlenzugang unterliege einem mittäglichen Schweigegebot, aber zum einen befindet sich Poliphilus nicht am Ein- oder Ausgang einer Höhle, sondern mitten im Wald, ${ }^{90}$ zum anderen ist die schweigende Ver-

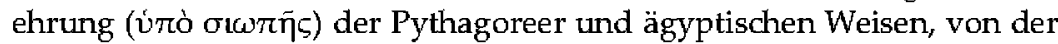
Porphyrios hier spricht, kaum mit dem innerlichen Aufschrei des noch im Dunkel befangenen Poliphilo zu vergleichen.

Mit aller gebotenen Vorsicht dürfte man daher zu folgenden Schlussfolgerungen kommen. Die umfassende Antikerezeption, ${ }^{91}$ der Anspielungsreichtum und die neuplatonische Grundausrichtung der HP lassen eine Benutzung von Porphyrios' De antro Nympharum, das u.U. in Venedig zugänglich war, zumindest als möglich erscheinen. Eindeutige Beweise lassen sich nicht finden, aber verschiedene Anspielungen, die aus dem Ho-

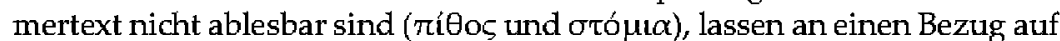
Porphyrios denken. Darüber hinaus könnte die auffällig häufige und exponierte Rolle des Porphyrs als Baustoff in Monumenten der HP ein verschlüsselter Hinweis auf den Namen des Neuplatonikers sein. Es ist im Übrigen bemerkenswert, dass Blake auf dieselben porphyrianischen Stellen Bezug nimmt, die wir hier völlig unabhängig für die $H P$ herangezogen haben: das gorgianische Bild vom $\pi \hat{i} \theta o \varsigma$, die Wassergefäße der Nymphen und insbesondere die Ein- bzw. Ausgänge der Höhle inklusive ihrer astronomischen Bedeutung. Und sollte das Spiel mit der Farbe bzw. dem Stein und dem Namen Porphyrios in beiden Fällen reiner Zufall sein? Weitere Bezüge aufzudecken muss freilich künftiger Forschung vorbehalten bleiben.

erst von Gauß bewiesen). Für den Architekten spielt das freilich keine Rolle, da er ohnehin nur mit Näherungswerten arbeitet.

${ }^{88} \mathrm{Vgl} . \mathrm{HP} 360$ : "Nel fronte anteriore alla dextera il falcifero Saturno assideva, Et alla sinistra la noctiluca cynthia, per ordine incominciando dal primo circinanti terminavano ad Selene. Sotto agli quali nel zophoro in circuito cum maximo exquisito artificio elegantemente celati vedevase gli duodeci signi zodiaci, cum le superiore impressione, \& charactere, cum eximia scalptura expressi."

${ }^{89}$ HP 16, vgl. dazu Ariani / Gabrible 1998, 5.32-534.

${ }^{90}$ Dieser entspricht zwar der Höhle des platonischen Gleichnisses (vgl. HP 16: "Che de uno caeco carcere chi fora advenisse diloricato delle gravose \& molestante cathene, \& uscito de caliginose tenebre $\left.{ }^{\prime \prime}\right)$, aber das hat mit Porphyrios nichts zu tun.

${ }^{91}$ Vgl. dazu allgemein NAU 2007 sowie A. Tournon, "Le choix d'un destin mythique dans le Songe de Poliphile", RHR 72 (2011) 7-26, der besonders auf das antike Motiv der aurea mediocritas verweist. 

D. Anhang 



\title{
Literaturverzeichnis
}

\author{
1. Abkürzungen
}

\begin{tabular}{|c|c|}
\hline ANRW & Aufstieg und Niedergang der Römischen Welt \\
\hline CIMRM & Corpus Inscriptionum et Monumentorum Religionis Mithricae \\
\hline$C C A G$ & Catalogus Codicum Astrologorum Graecorum \\
\hline CMG & Corpus Medicorum Graecortum \\
\hline$D K$ & Diels / Kranz (Hg), Die Vorsokratiter \\
\hline$D N P$ & Der Newe Pauly \\
\hline$D P h A$ & Dictionnaire des Philosophes Antigues \\
\hline FGrHist & Die Fragmente der Griechischen Historiker \\
\hline HWR & Historisches Wörterbuch der Rhetorik \\
\hline IG & Inscriptiones Graecae \\
\hline LIMC & Lexicon Iconographicum Mythologiae Classicae \\
\hline LSJ & Liddell / Scott / Jones (Hg.), A Greek-English Lexicon \\
\hline$M H$ & Musetum Helveticum \\
\hline PLRE & Prosopography of the Later Roman Empire \\
\hline PLG & Poetae Lyrici Graeci \\
\hline$P M G$ & Poetae Melici Graeci \\
\hline$R A C$ & Reallexikon für Antike und Christentum \\
\hline$R h M$ & Rheinisches Museum für Philologie \\
\hline RHR & Réforme, Humanisme, Renaissance \\
\hline TRE & Theologische Realenzyklopädie \\
\hline ZNTW & Zeitschrift für die Neutestamentliche Wissenschaft \\
\hline$Z P E$ & Zeitschrift für Papyrologie und Epigraphik \\
\hline
\end{tabular}

\section{Ausgaben, Kommentare und Übersetzungen}

\author{
Porphyrios, De antro Nymphartum
}

Arethusa-Text

HoLste 1630

NAUCK 1886

Simonini 1986

vaN GoBNs 1765
J. M. Duffy / P. F. Shrridan / L. G. Westerink / J. A. White, Porphyry. The Cave of the Nymphs in the Odyssey. Seminar Classics 609, Arethusa Monographs I (Buffalo 1969)

Porphyrii Philosophi Liber de Vita Pythagorae. Eiusdem Sententiae ad intelligbilia ducentes. De antro Nympharum quod in Odyssea describitur. Lucas Holstenius Hamburgen. Latine vertit (Romae 1630)

A. NAuck, Porphyrii philosophi Platonici opuscula selecta (Hildesheim 1886) 55-81

L. Simonini, Porfirio. L'antro delle Ninfe. Classici 48 (Milano 1986; Nachdr. 2006)

Porphyrius De Antro Nympharum. Graece cum Latina L. Holstenii Versione. Graeca ad fidem editionum restituit, Versionem C. GesNBRI, et Animadversiones suas adjecit R. M. vAN Gobns Trajectinus (Trajecti ad Rhenum 1765) 


\section{Sekundärliteratur (und Ausgaben anderer Autoren)}

\author{
Ariani / Gabrible \\ 1998
}

ALt 1982

ALt 1998

Alvar 2008

Alvar 2009

ARNOLD 2014

B̈̈BLER 2018

Ввск 2004=1976

Ввск 1988

Ввск 1994

BeСK 2004

Beck 2006

BeCKRR 2013

BrCKRR 2016

BLANCHI 1979

BIDEz 1913

BLUMBNBERG 1989

BOER / WEINSTOCK 1940
M. ArIani / M. Gabrigle (Hg.) Francesco Colonna. Hypnerotomachia Poliphili. Tomo primo: riproduzione dell'edizione aldina del 1499. Tomo secondo: introduzione, traduzione e commento (Milano 1998; Nachdr. 2010)

K. ALT, "Diesseits und Jenseits in Platons Mythen von der Seele $\mathrm{I}^{\prime \prime}$, Hermes 110 (1982) 278-299

K. Alt, ${ }_{r}$ Homers Nymphengrotte in der Deutung des Porphyri${ }^{\circ s^{\prime \prime}}$, Hermes 126 (1998) 466-487

J. Alvar Ezqubra, Romanising Oriental Gods. Myth, Salvation and Ethics in the Cults of Cybele, Isis and Mithras. Religions in the Graeco-Roman World 165 (Leiden 2008)

J. Alvar EzQubrRA, "Mithraism and Magic", in: R. L. GoRdon / F. Marco Srmón (Hg.), Magical Practice in the Latin West. Religions in the Graeco-Roman World 168 (Leiden 2009) 519-550

R. ARNold, „Ansichten und Einsichten - die Rolle der visuellen Perzeption in der Hypnerotomachia Poliphill (1499" Renaissance-Mitteilungen 35/1 (2014) 3-20

B. BÄBLER, "Für Christen und Heiden, Männer und Frauen. Origenes' Bibliotheks- und Lehrinstitut in Caesarea", in: P. GemerNhardt / I. Tanasbanu-Döblar ( $\mathrm{Hg}$ ), "Das Paradies ist ein Hörsaal für die Seelen". Institutionen religiöser Bildung in historischer Perspektive (Tübingen 2018) 129-151

R. Bвск, „The Seat of Mithras at the Equinoxes: Porphyry, De Antro nymphartam 24", in: BвсK 2004, 129-132 (= Journal of Mithraic Studies 1 [1976] 95-98)

R. BвсK, Planetary Gods and Planetary Orders in the Mysteries of Mithras (Leiden u.a. 1988)

R. BrCK, Cosmic Models: Some Uses of Hellenistic Science in Roman Religion", in: T. D. Barn bs (Hg.), The Sciences in Greco-Roman Society. Apeiron 4 (Edmonton 1994) 99-117

J. Hinnelus ( $\mathrm{Hg}$ ), Beck on Mithraism. Collected Works with New Essays. Ashgate Contemporary Thinkers on Religion (Aldershot 2004)

R. BвCK, The Religion of the Mithras Cult in the Roman Empire. Mysteries of the Unconguered Sun (Oxford 2006)

M. BeCKRR, Eunapios aus Sardes: Biographien über Philosophen und Sophisten. Einleitung, Übersetzung, Kommentar (Stuttgart 2013)

M. BвcKвR, Porphyrios: Contra Christianos. Neue Sammlung der Fragmente, Testimonien und Dubia mit Einleitung, Übersetzung und Anmerkungen (Berlin / Boston 2016)

U. BLANCHI (Hg), Mysteria Mithrae. Atti del Seminario Internazionale su, La specificità storico-religiosa dei Misteri di Mithra, con particolare riferimento alle fonti documentarie di Roma e Ostia" (Roma e Ostia 2831 Marzo 1978). Études préliminaires atx religions orientales dans l'Empire romain 80 (Leiden 1979)

J. BIDEz, Vie de Porphyre: Le philosophe néo-platonicien. Avec les fragments des traités MEPI ATAMMATON et De regressu animae (Gent / Leipzig 1913)

H. Blum bNBBrg, Höhlenausgünge (Frankfurt 1989)

E. Boer / S. Wernstock, Porphyrii philosophi Introductio in Tetrabiblum Ptolemaei. CCAG V 4 (Brüssel 1940) 185-228 
Bouché-Lbclerco 1899 A. Bouché-Leclbrco, L'astrologie grecque (Paris 1899)

BOYANCÉ 1960

BREMMRR 2014

P. BoYANCÉ, "L'antre dans les mystères de Dionysos", Rendicont della pontificia Accademia romana di Archeologia 33 (1960) 107-127

Brisson 1982

J. N. BREMmer, Initiation into the Mysteries of the Ancient World. Münchner Vorlesungen zu antiken Welten, Bd. I (Berlin 2014)

L. Brisson, "Notices stur les noms propres", in: L. Brisson u.a., Porphyre. La Vie de Plotin, Bd. I, Travatx preliminaires et index grec complet (Paris 1982) 49-142

BRISSON 2000

BuFfí̀re 1956

Burioni 2013

L. Brisson, "Euboulos", DPhA 3 (2000) E 74, 249

F. Buffik̀RE, Les Mythes d'Homère et la pensée grecque (Paris 1956)

M. BurionI, „Das Ich der Baukunst. Traumwandlerische Architekturen in der Hypnerotomachia Poliphili", in: A. BEYER/R. SIMON/ M. STIRRLI (Hg.), Zwischen Architektur und literarischer Imagination (München 2013) 357-384

BURKRRT 1962

W. Burkerт, Weisheit und Wissenschaft. Studien zu Pythagoras, Philolaos und Platon. Erlanger Beiträge zur Sprach- und Kunstwissenschaft X (Nürnberg 1962)

BURKERT 1990

W. Burkert, Antike Mysterien. Funktion und Gehalt (München 1990)

Camprell 1968

Castblletti 2006

Cavaillé 2003

Cavaillé 2004

L. A. CAM PBELL, Mithraic Iconography and Ideology. EPRO 11 (Leiden 1968)

C. Castelletti, Porfirio. Sullo Stige (Milano 2006)

J.-P. CAVAll Lí, „François La Mothe Le Vayer, Explication de l'Antre des Nymphes (Fonds Dupuys, $\mathrm{n}^{\circ} 835$ ). Texte inédit présenté et édité", La Lettre clandestine 11 (2003) 183-204

J.-P. CAVAILLÉ, L'Antre des nymphes (F. La Mothe le Vayer $-\mathrm{A}$. de Monluc - C. Le Petit). Présentées et annotées par J.-P. Cavaillé (Toulouse 2004)

Chalupa 2008

A. Chalupa, „Seven Mithraic Grades: An Initiatory or Priestly Hierarchy?", Religio. Revue pro religionistiku16 (2008) 177-201

Clauss 2012

Coprland / Strutck 2010

Crome 1970

CRuz 2006

M. Clauss, Mithras. Kult und Mysterizm (Darmstadt $2012=\mathrm{urm}$ wichtige Neufunde und Forschungsergebnisse erweiterte Version der Erstausgabe, München 1990)

R. Copeland / P. T. Struck (Hg), The Cambridge Companion to Allegory (Cambridge 2010)

P. CRомв, Symbol und Unzugänglichkeit der Sprache. Jamblich, Plotin, Porphyrios, Proklos (München 1970)

E. A. CRuz, Re-Discovering Antiguity through the Dreams of Poliphilus. Artist Reconstructions of the Architecture and Landscapes described by Poliphilus during his amorous quest through 'Antiguty' (Victoria/Canada 2006)

EgrlhaAf-GaisbR / U. EgrlHAaf-Gaiser / J. RüPKB, ${ }_{s}$ Orte des Erscheinens - Orte des RÜPKB 2000

EDWARDS 1990 Verbergens. Höhlen in Kult und Theologie", Orbis Terrarum 6 (2000) 155-176

M. J. Edwards, "Numenius, Pherecydes and the Cave of the Nymphs", Classical Quarterly 40 (1990) 258-262

Edwards 1996 M. Edwards, „Porphy's ,Cave of the Nymphs' and the Gnostic Controversy", Hermes 124 (1996) 88-100

ERLER 2001

M. ERLER, "Legitimation und Projektion: Die, Weisheit der Alter" im Platonismus der Spätantike ${ }^{\prime \prime}$, in: D. KuHN / H. Stahl (Hg.), Die Gegenwart des Altertums. Formen und Funktionen des Altertumsbezugs in den Hochkulturen der Alten Welt (Heidelberg 2001) 313-326 G. GenkTtE, Palimpsestes. La littérature an second degré (Paris 1982) 
GoRdon 1996=1976

GoRDan 1996=1988

GoRDon 1996

Gornon 2001

GoRDON 2012

GOULET 1982

Goulet 2012

Goulet 2014

Gundel / Gundel 1966

HALFWASSEN 2004

HBILEN 2015

Hirschlb 1979

HOLDEN 2009

HÜBNER 2003

HÜBNER 2006

JoHnson 2013

KAHN 1979

KeYnEs 1954

LAMBERTON 1986

LAMBERTON 1992

LAMBBRTON / KBANEY 1992
R. L. GoRDon, "The sacred geography of a mithraeum; the example of Sette Sfere", in: Gondon 1996, vi (= Journal of Mithraic Studies 1, no. 2. [1976] 119-165)

R. L. Gordon, "Authority, salvation and mystery in the Mysteries of Mithras", in: GoRDon 1996, IV (= J. HunkINSON / M. BEARD / J. ReYNolds [Hg.], Image and Mystery in the Roman World. Three Papers Given in Memory of Jocelyn Toynbee [Cambridge 1988] 4588)

R. L. Gordon, Image and Value in the Graeco-Roman World. Studies in Mithraism and Religious Art. Collected Studies Series 551 (Aldershot 1996)

R. L. GoRDon, "Persei sub rupibus antri: Überlegungen zur Entstehung der Mithrasmysterien, " in: M. VoMBR Gojkovič (Hg), Ptuf im Römischen Reich: Mithraskult und seiner Zeit. Archaeologica Poetovionensis (Pttj 2001) 289-301

R. L. GoRDon, "Mithras", RAC 24 (2012) 964-1009

R. Goulet, "Le système chronologique de la Vie de Plotin", in: L. Brisson u.a., Porphyre. La Vie de Plotin, Bd. I, Travaux préliminaires et index grec complet (Paris 1982) 187-227

R. Goulet, "Porphyre de Tyr I. L'homme et l'œuvre", DPhA 5b (2012) P 263, 1290-1314

R. GoulBt, Eunape de Sardes. Vies de philosophes et de sophistes. Tome II: Edition critigue, traduction française, notes et index (Paris 2014)

W. Gundel / H.-G. Gundel, Astrologumena. Die Astrologische Literatur in der Antike und ihre Geschichte. Sudhoffs Archiv, Beiheft 6 (Wiesbaden 1966)

J. HALFWAssen, Plotin und der Neuplatonismus (München 2004)

S. HeILBN, ,Hadriani genitura' - Die astrologischen Fragmente des Antigonos von Nikaia (Berlin / Boston 2015)

M. HirschlB, Sprachphilosophie und Namenmagie im Netplatonismus. Beiträge zur klassischen Philologie 96 (Meisenheim am Glatı 1979)

J. H. HoLden, Porphyry the Philosopher. Introduction to the Tetrabiblos and Serapio of Alexandria. Astrological Definitions (Tempe ${ }^{3} 2009$ ) W. Hü BNER, Raum, Zeit und soziales Rollenspiel der vier Kardinalpunkte in der antiken Katarchenhoroskopie (München / Leipzig 2003) W. HüBNER, Crater Liberi. Himmelspforten und Tierkreis. Bayer. Akad. d. Wiss., phil.-histor. Kl., Sitzungsberichte 2006/3 (München 2006)

A. P. Johnson, Religion and Identitiy in Porphyry of Tyre. The Limits of Hellenism in Late Antiguity (Cambridge 2013)

Ch. H. KAHN, The Art and Thought of Heraclitus. An Edition of the Fragments with Translation and Commentary (Cambridge 1979)

G. KEYYNBs, „Blake's Vision of the Circle of the Life of Mar", in: D. Mingr ( $\mathrm{Hg}$.), Studies in Art and Literature for Belle da Costa Greene (Princeton 1954) 202-208

R. LAMBERTON, Homer, the Theologian. Neoplatonist Allegorical Reading and the Growth of the Epic Tradition. The transformation of the classical heritage 9 (Berkeley u.a. 1986)

R. LAMBERTON, "The Neoplatonists and the Spiritualization of Homer," in: LAMBERTON / KeANEY 1992, 115-133

R. Lamberton / J. J. Keandy (Hg.), Homer's Ancient Readers. The Hermeneutics of Greek Epic's Earliest Exegetes (Princeton 1992) 
LARSON 2001

LAURENTIUS $1600 / 1621$

LONG 1992

Loư̈s 1895

\author{
MÄNNLEIN-ROBERT \\ 2001 \\ MÄNNLEIN-ROBERT \\ $2012 a$
}

MÄNNLEIN-RoBERT $2012 b$

MänNLBIn-RoperT 2014

MÄNNLEIN-ROBERT 2018

MarksChIEs 2007

Marzillo 2013

Maurette 2005

MgRKвLEACH 1984/1994

MeYBR 2007

Most 2010

MürI 1976

NAU 2007
J. LARson, Greek Nymphs. Myth, Cult, Lore (Oxford 2001)

Historia Anatomica humani corporis et singularitm eitus partium multis controversiis et obseroationibus novis Illustrata. Authore Andrea Laurentio (Francoforti 1600) / Toutes les ceuvres de Me. André Du Laturetıs, traduits en françois par Me. Theophile Gelée (Paris / Roten 1621)

A. A. LonG, "Stoic Readings of Homer", in: LAMEBRTON / KEANEY 1992, 41-66

P. Loư̈s, Les chansons de Bilitis traduites du Grec pour la première fois (Paris 1895; Nachdr. 1926 [Édition ornée de 300 gravures, par Notor])

I. Männ LeIN-Robert, Longin - Philologe und Philosoph. Eine Interpretation der erhaltenen Zeugnisse (München / Leipzig 2001)

I. MäNNLEIN-RoberT, "Götter, Hades und Ekstase: Zur kulturellen Semantik von Höhlen in der griechischen Literatur" ${ }^{\prime \prime}$, Mitteilungen der Gesellschaft für Urgeschichte 21 (2012) 105-120

I. Männlein-Robert, "Von Höhlen und Helden. Zur Semantik von Katabasis und Raum in Platons Politeia", Gymnasium 119 (2012) 1-21

I. Männlein-Robert, „Ordnungskonkurrenz: Polemik und Feindbild in konkurrierenden Ordnungen. Der platonische Philosoph Porphyrios und sein Kampf gegen die Christen", in: E. Fris / M. MeIBr (Hg.), Aufruhr - Katastrophe - Konkurrenz Zerfall. Bedrohte Ordnungen als Thema der Kulturwissenschaften (Tübingen 2014) 117-138

I. MänNLEIN-RoberT, "Kronios, " in: Ch. Horn / Ch. RIEDWEg / D. WYRWA (Hg.), Philosophie der Kaiserzeit und der Spütantike. Grundriss der Geschichte der Philosophie. Die Philosophie der Antike 5 (Basel 2018)

Ch. MarkschIEs, Kaiserzeitliche christliche Theologie und ihre Institutionen. Prolegomena zu einer Geschichte der antiken christlichen Theologie (Tübingen 2007)

P. Marzillo, , "L'antro delle Ninfe. Da locus amoenus a locus functionalis", Estetica. studi $\varepsilon$ ricerche 1 (2013) 217-231

P. MAURETTE, "Porphyry and Mithraism: De antro nympharum and the Controversy against the Christians", Dionysius 23 (2005) 64-81

R. Merkelbach, Mithras (Meisenheim am Glan 1984 / Mithras. Ein persisch-römischer Mysterienkult [Wiesbaden ${ }^{2}$ 1994])

D. MgYвR, "Die verborgene Wahrheit der Dichtung. Zur allegorischen Interpretation in Porphyrios' Schrift über die Nymphengrotte in der Odyssee," in: J. Altrofr ( $\mathrm{Hg}$.), Philosophie und Dichtung in antiken Griechenland. Akten der 7. Tagung der Karl- undGertrud-Abel-Stiftung an 10. und 11. Oktober 2002 in BernkastelKues (Stuttgart 2007) 131-143

G. W.Most , "Hellenistic allegory and early imperial rhetoric", in: Coprland / STRUCK 2010, 26-38

W. MürI, $\Sigma \Upsilon M M B O \Lambda O N$. Wort- und sachgeschichtliche Studie, in: ders., Griechische Studien. Ausgewählte Wort- und sachgeschichtliche Forschungen zur Antike, hg. v. E. VIschBR. SBA 14 (Basel 1976) 1-44

F. NAU, "I/Y : La culture antique dans l'oeuvre de Francesco Colonna", Camenae 2 (2007) 1-23 
Neugrbaubr 1975

OMMARA 2003

Patillon / Segonds 1995

Penati Bernardini 1988

Pépin 1966

Pichler 2006

Prabchter 1910

RAINB 1968

RAINB / HARPER 1969

RIBDWEG 2002 / 2007

RIBDWBg 2005

SMITH 2016

SPEIDEL 1980

von STUCKRad 2003

TAYLOR 1789

Tester 1987
O. Neugbbaubr, A History of Ancient Mathematical Astronomy, 3 Bde. (Berlin u.a. 1975)

D. J. O'Mgara, Platonopolis. Platonic Political Philosophy in Late Antiquity (Oxford 2003)

M. Patillon / A. Ph. Segonds, Porphyre. De l'abstinence livre IV (Paris 1995)

A. Penati BeRnardini, ${ }_{5}$ ll motivo dell'antro nell'esegesi porfiriana di Od. XIII, 102-112", Aevtum 62 (1988) 116-123

J. Ṕ́prN, „Porphyre, exégète d'Homère”, in: Porphyre. Entretiens sur l'Antiquité Classique 12 (Vandoeuvres / Genève 1966) 229272

R. PICHLER, Allegorese und Ethik bei Proklos. Untersuchungen zum Kommentar zu Platons Politeia. Klassische Philologie 2 (Berlin 2006)

K. Prabchtbr, "Richtungen und Schulen im Neuplatonismus", in: C. Robert ( $\mathrm{Hg})$, Genethliahon. Festschrift für Carl Rohert zum 8. März 1910 (Berlin 1910) 105-115

K. RAINE, Blake and Tradition, 2 Bde. (London 1968, Nachdr. 2002)

K. RaIne / G. M. Harper (Hg.), Thomas Taylor the Platonist, Selected Writings (Princeton 1969)

Ch. RIEDWEG, Pythagoras. Leben, Lehre, Nachwirkting. Eine Einfithrung (München 2002; 2007)

Ch. RibDWBG, "Porphyrios über Christus und die Christen: De philosophia ex oraculis haurienda und Contra Christianos im Vergleich", in: A. WLOSOK / F. PAschoud (Hg.), L'apologétique chrétienne grécolatine à l'épogue prénicénienne. Entretiens sur l'antiquité classique de la Fondation Hardt 51 (Genève 2005) 151-203

Saffrey / Segonds 2012 H. D. SAfrerey/A. Ph. Segonds, Porphyre. Lettre à Anébon l'Égyptien (Patis 2012)

H. S. Schirli, Pherekydes of Syros (Oxford 1990)

G. SFAMBNI GASPARRO, "I mitraismo nell'ambito della fenomenologia misterica (with an abstract in English)", in: BLANCHI 1979, 299-348

A. SMITH, "Porphyrian Studies since 1913", ANRW II,36,2 (1987) $717-773$

A. Бм Гтн, Porphyrii philosophi fragmenta (Stuttgart / Leipzig 1993)

A. SMITH, "Porphyry and his School", in: L. P. Gerson (Hg.), The Cambridge History of Philosophy in Late Antiguity, Bd. 1 (Cambridge 2010) 325-357

A. SMITH, "Porphyrios", RAC 27 (2016) 1213-1243

M. Speidel, Mithras-Orion. Greek Hero and Roman Army God (Leiden 1980)

K. von Stuckrad, Geschichte der Astrologie. Von den Anfängen bis zur Gegenwart (München 2003)

Th. TAYLor, The Philosophical and Mathematical Commentaries of Proclus, on the First Book of Euclid's Elements [vol. 2]. To which are added, a History of the Restoration of the Platonic Theology, by the latter Platonists, and a Translation from the Greek of Proclus's Theological Elements (London 1789)

J. Tester, A History of Western Astrology (Woodbricge 1987) 
Toulouse 2005

TURCAN 1975

TURCAN 1982

TURCAN 2000

ULANSEY 1989

Ustinova 2009

VERMASEREN /

VAN ESSBN 1965

WELT 2009

WHITTAKER 1994

ZEPF 1958

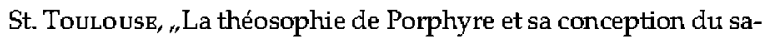
crifice intérieur", int: St. Ggorgoud / R. Косн PIETTRe / F. Schm IDT $(\mathrm{Hg})$, La cuisine et lantel: les sacrifices en questions dans les sociétés de la Méditerranée ancienne. Bibliothèque de l'École des Hautes Études - Sciences religieuses 124 (Turnhout 2005) 329-341

R. TurCan, Mithras Platonicus. Recherches sur l'hellénisation philosophigue de Mithra. Études préliminaires atx religions orientales dans $l^{\prime}$ Empire romain 47 (Leiden 1975)

R. TurCan, Firmicus Maternus. L'erreur des religions païennes (Paris 1982)

R. Turcan, Mithra et le Mithriacisme (Paris ${ }^{2} 2000$ )

D. Ulansby, The Origins of the Mithraic Mysteries. Cosmology and Salvation in the Ancient World (Oxford 1989)

Y. Ustinova, Caves and the Ancient Greek Mind. Descending Underground in the Search for Ultimate Truth (Oxford 2009)

M. J. Vermaseren / C. C. van Essen, The excazations in the Mithraeum of the Church of Santa Prisca in Rome (Leiden 1965)

T. WELT, ,Dichterkritik und Allegorese. Die Rezeption Homers in der antiken Philosophie, " in: B. EFfB / R. Glei / C. Klodt (Hg.)

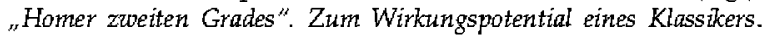
BAC 79 (Trier 2009) 9-35

J. WhITTAKER, Cronios $^{\prime \prime}$, DPhA 2 (1994) C 223, 527f.

M. ZnPF, "Der Mensch in der Höhle und das Pantheon", Gymnasium 65 (1958) 355-382

\section{Abbildungsnachweis}

a. Philosophie und religiöse Praxis in De antro Nympharum

Abb. I (S. 93)

Rinderdiebstahl und Tötung des Stiers durch Mithras, aus: CIMRM 1, Nr. 368 = Fig. 106

b. Littérature aut troisième degré - Beispiele kreativer Rezeption von De antro Nympharum

Abb. I (S. 152)

William Blake, The Sea of Time and Space, ONational Trust Images / John Hammond 



\section{Stellenregister (in Auswahl)}

Apollonios Rhodios I 211-218: 72

Aptleits Met. VII 9: 160

Aratos

515: 132 709-711: 132

Aristophanes Ran. 923-926: 17

Aristoteles fr. 12 Rose: 115 Rhet. III 10,7: 15

Augustinus Util. cred. $5: 15$

Biblici libri Vetus Testamentum Gen. 1,2: 68

Cicero

Fan. IX 22,3: 149

Tusc. I 52: 160

Colonna, $\mathrm{F}$. $H P$

16: 163

27f.: 162

40f: 161

71: 161

101: 159f.

246: 161

248: 162

360: 163

367: 159

Commodianus Instr. I 13: 94

Demetrios

Eloc. 102: 17

Demokrit 68 B 27a DK: 70

Diodorus Siculus V 70,2: 108

V 70,4: 108

Empedokles 31 B 120 DK: 68
31 B 126 DK: 69

Epimenides

3 A 1 DK: 107

Eunapios

Vit. soph.

4,1: $3 \mathrm{f}$

$4,2-5: 5$

$4,4: 4$

4,10: 7

4,10-18: 8

4,18: 8

Euripides

Alc. 357-362: 106

Eusebios

Hist. eccl. VI 19,8: 66

Firmicus Maternus

Err. prof. rel. V 2: 94

Math.

IV 19,1: 130

IV 19,2: 130

Galen

Com. sec. Hipp. 1,5:

100

Gregorios

Thaumaturgos

Pan. or. 7,93-15,183: 5

Heliodor

$X 28,1: 91$

Hephaistion von Theben Apotel.

$$
\text { I praef. I: } 126
$$

I $1,1: 126$

I 23, I: 126

II $10,23: 120$

III $47,61: 135$

Heraklit

Quaest. Hom.

1: 19

Heraklit von Ephesos

22 B 51 DK: 73

22 B 62 DK: 69

22 B $77 D K: 69$

22 B 118 DK: 69
Herodot

I 61: 149

Hesiod

Erg.

90-104: 74

94: 160

Theog.

158: 68

175: 132

459-462: 68

459-467: 112

479-484: 68

Hieronymus

Vir. illustr. 54: 5

Homer

Il.

V 698: 72

V 749: 73

V 751: 73

VI 22: 66

VIII $393: 73$

IX 583: 73

XII 460: 73

XIV 444: 66

XVI 28-35: 16

XIX 38f.: 70

XX 224f: 72

$\times \times 260: 73$

XX 384: 66

XXIV 527: 160

XXIV 528: 74

Od.

I 71-73: 74

V 55-74: 102

V 93: 70

V 459-462: 152

VI 201: 69

VIII 84: 156

IX 43:69

IX 182f.: 102

IX 216f.: 102

XI 122f.: 74, 156

XI 122-134: 74

XII 316-319: 14

XII 317f.: 20

XII 45I-453: 13 
XIII 2: 13

XIII 67: 156

XIII 81-88: 13

XIII 84f.: 154

XIII 96: 28

XIII 99f.: 154

XIII 102: 25, 79

XIII 102f.: 146

XIII 102-104: 66

XIII 102-112: 18,

26, $97 \mathrm{f}$., 106, 117, 144

XIII 103-112: 13

XIII 104: 66, 147

XIII 105f.: 147

XIII 106: 147

XIII 107f.: 148

XIII 111: 73

XIII 122: 156

XIII 154-183: 14

XIII 187: 14

XIII 217f.: 156

XIII 237: 14

XIII 248: 14

XIII 344-351: 14

XIII 346-348: 66

XIII 347f.: 14

XIII 348: 66

XIII 349-360: 66

XIII 356: 66

XIII 358: 14

XIII 361-371: 81

XIII 362-371: 14

XIII 429-438: 74

XVII 211: 14

XVII 240-246: 14

XIX 562f: 74

XXIV 12: 28,73

Horaz

Sat. I 2,36: 149

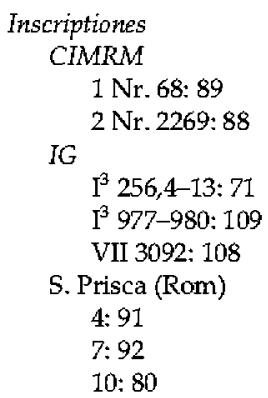

12: 84

Jamblich

Ant.fr. 26

Finamore/Dillon: 91

Protr.

16: 92

21: 84

Theol arithm. $34 \mathrm{de}$

Falco: 91

VPyth. 20,94: 84

Julian

In matr. deor.

5:78

7:89

In reg. sol. 32: 91

Symp. 38: 89

Kelsos

Alethes logos

1,14a: 23

6,10: 23

Kronios (fr. Leemans)

8: 78

9. 78

Kyranides

$3,15: 90$

La Mothe Le Vayer, F.

Explication de lantre des nymphes 190: 145f.

191: 146

193: 146

194: 147

195: 147

196: 147

200: 148

201: 148

202: 149

203: 149

Longos

I 4: 110

Macrobius

Somn.

I 12,1: 155

I 12,3: 162

I 12,4: 137

Manilitus

V 22:132

Nontios

Dion.
VI 103-154: 70

VI 133: 68

XXIII 309: 130

Numenios (fr. des Places)

16, 16:79

31: 91

Origenes

Prin. IV 2,4: 15

Orphicorum fragmenta

54 Kern: 109

113 Kern: 106

187 F II Bernabé: 70 ,

85

209 F I Bernabé: 68 ,

86,111

214 F I Bernabé: 86

220 F Bernabé: 85

222 F Bernabé: 85

225 F V Bernabé: 85

279 F III Bernabé: 68,

86, 111

286 F I Bernabé: 85

291 Kern: 71

Ophicorum hymni

$9,2: 91$

11: 109

Ovid

Am. I 8,47f.: 146

Ars II 723f.: 147

Trist. II 354: 150

Parmenides

28 B 1 DK: 71

Paulus Alexandrinus 3: 124

Pausanias

I 12: 74

II 35,10: 106

VIII 37: 109

Pherekydes

7 A 10 DK: 102

7 B 6 DK: 112

Pindar

Ol. XIII 106: 69

Platon

Gorg.

493a5-6: 74

493a-b: 160

$493 b 7-c 2: 74$

493d5-494a5: 74

Leg. $886 \mathrm{~b}: 118$

Lys. 214b: 17 
Men. 80d4: 21

Phaed.

62b: 113

107d6-108c5: 69

109c3f: 114

Phaedr. 229b-230a: 72

Rep.

II $376 \mathrm{~b}-378 \mathrm{e}: 23$

II 378d: 17

III $387 b-d: 23$

VII 514a: 113

VII 515a4: 114

$X 595 a-605 \mathrm{c}: 23$

X 614b1-621b7:71

Symp.

179d: 106

187b: 73

203b5-6: 70

Tim.

28c3: 87

28c3-e4: 68

40b: 118

40b2-3: 122

41d4: 74

52a: 110

53b4-7:79

$89 \mathrm{e}-90 \mathrm{~d}: 80$

Plinius

Nat.

XXXVI 38: 110

XXXVI 57: 161

Plotin

II 3,1: 118

V 8,4,43: 99

Plutarch

Gen. 21f:: 105

Is. $367 \mathrm{D}: 91$

Tranq. anim 477C-D: 110

Porphyrios

Abst.

I 31, 1: 80

III $4: 7$

III 5:90

IV $16,2: 87,90,103$

IV 16,3:90

IV 16,4f:: 90

IV 16,7: 81

Antr.

$1: 18,21,97$

1-4: 26

2: $26,97,106$

2-4: 98
3: $18 \mathrm{f}, 26,82$

4: $18,20,26,29$,

$82,97,99-101$

104, 117

$5: 24,26,29,78$,

83, $101 \mathrm{f}$.

5-8: 101

5-10: 26

6: $26,79,83,87$,

91, 97, 102-104,

106-108, 114,

$122,131,134$

$7: 26,78,83,86$,

111

8: 26, 113

9: 26, 82f., 113f.

$10: 27,79,82,110$,

155

10-14: 27

$11: 27,79,84,155$

$12: 27,79,84,155$

12f.: 161

13: 27

14: $27,68,80,85$,

156,160

$15: 27,86,88 \mathrm{f}$.

15-19:27

$16: 24,27,68,80$,

$85,89,122,137 \mathrm{f}$.

$17: 27,29,91$

$18: 27,80,84,91 \mathrm{f}$,

129

$19: 25,27,80,84$,

90

$20: 27,29,83,91$,

$104,107 \mathrm{f}$

20-31: 27

$21: 27,66,98,124$, 137

21-24: 80

21f.: 125

22: $27,136,155$,

162

$23: 24,27,29,85$,

137

24: $28 f ., 80,94 f .$,

$104,127,131$,

134,136

25: 28,134

26: 28,85

$27: 28,84,163$

$28: 28,84,148,155$

$29: 28,80,135-137$
$30: 28,155,160$

31: $24,28,102$

32: $21,24 f ., 28$

32-35: 28

32f.: 81,160

33: $28,81,85$

$34: 19,24,28,154$,

156

34f.: 81

$35: 28,82,85,154$

36: $19,21,29,117$

Chr. fr. 6F. Becker: 4

fr. (Smith)

2T,3-5: 8

13T.-14T.: 5

15T.: 5

193'T.-224F: 9

337F.I-5: 120

337F.5-6: 119

337F.7: 119

358F.: 125

359F.85-88: 120

360F.52-54: 120

Imagin. (fr. Smith)

351F.,15: 77

351F.,408,14-24:

99

360F.,95-97: 91

Isag.

2: 121

5: 125

30: 130

Marc.

$1: 7$

4:7

16: 100

Philos ex orac. haur.

1:77

3: 81

Quaest. Hom ad 7 .

XV 13ff.: 97

XX 67ff.: 17

297,16 Schrader: 100

Regr. anim. fr. 300F.

Smith: 90

VPlot.

2,10-15:7

2,12f.: 7

2,31f.: 4

$4,1-6: 5$

$4,6-9: 5$

$6,1-3: 6$ 


6,1-4:7
$7,50: 3$
11,11-19:6
11,16f:: 6
11,18f: 7
12,1-3: 6
14,10-14: 66
16: 10
17,1-6:4
17,4-15:4
19,34-36: 7
23,13f:: 8
24,2-5: 8
Proklos
In Remp. II: 119
Ptolemaios
Apotel.
I 4,1: 121
I 9,17: 132

6,1-4: 7

I 17: 125

I 19: 123

II 11,3f.: 128

III 11, 1: 126

Synt. 8,1: 128, 132

Quintilian

Inst. or.

VIII $6,44: 15$

VIII 6,52: 18

IX 1,4: 15

Seneca

Epist.

LXXXVIII 5: 145

LXXXVIII 40: 145

LXXXVIII 41: 145

Seneca Rhetor

Contr. I 2,22: 149
Sextus Empiricus Adv. math. V 34: 94

Streton

Nero 50: 161

Tertullian

Adv. Marc. I 13,5: 89

Theognis

I61f.: 128

Vergil

Georg. IV 453-527: 70

Vettius Valens

I 2,37: 126

I 21,27: 135

III 11,4: 135

Xenophanes

21 A 36 DK: 101

21 B 27 DK: 67, 101 


\section{Namens- und Sachregister}

Achaia: 106

Achill: $16,70,72-74,150$

Adam: 149

Aeneas: 72

Agrippa: 110

Ägypten: 127, 149

Ägypter: 28, 103, 126-128

Aischylos: 17

Alberti, Leon Battista: 158

Alchemie: 154

Alexandria: $99 \mathrm{f}$.

Allegorese: siehe auch Allegorie, Auslegung, Deutung, Exegese, Interpretation, 16-26, 28f., 66f., 104, $115,143 \mathrm{f} ., 148,150 \mathrm{f}, 153,157$

- Anti-Allegorese: 144

- Bibelallegorese: 150

- Dichterallegorese: 147

- Homerallegorese: 11, 17, 20f., 156

- neuplatonische Allegorese: 23

- philosophische Allegorese: 9, 142

- religionsphilosophische Allegorese: 99, 104

- stoische Allegorese: 17

Allegorie: siehe auch Allegorese, Auslegung, Deutung, Exegese, Interpretation, 15-19, 23, 25f., 29, 74, $98,141,148,157$

- Anti-Allegorie: 143

- homerische Allegorie: 19f., 25, 66

- sexuelle Allegorie: 143

Amathus: 142

Amelios: 4

Ammonios: 6

Anakreon: 147

Anatomie: 146

Anaximander: 66

Anthropologie: 9,81

- platonische Anthropologie: 79-82, 96

Antiachos von Athen: 119

Antonius von Rhodos: 5

Aphrodite: 72, 94f., 132

Apis: 91

Apollon: 90,108

- Apollonorakel: 105

Apollonios: 5
Apuleius: $159 \mathrm{f}$.

Aquinoktium: 123, 132, 134

- Frühlingsäquinoktium: $80,123,128$, 131

- Herbstäquinoktium: $80,94,123,131$, 133

Arat: 123, 132

Archedamos von Thera: 109

Ares: 73, 95, 131f.

Aristarchos von Samos: 121

Aristophanes: 17

Aristoteles: 9, 22, 112, 115, 121, 153

Arkadien: 83, 108f.

Artemidor: 67

Askese: 82

Astrologie: 117-119, 121, 123-125, 128, $135,138 \mathrm{f}$.

Astronomie: $5,10,24,118,121,123,139$

Athen: $5,10,71,103$

Athene: 14, 25, 28, 66, 74, 81, 152, 156, 160

Attika: 109

Attis: 78

Augustinus: 15, 90

Augustinus von Dakien: 15

Auslegung: siehe auch Allegorese,

Allegorie, Dettung, Exegese,

Interpretation, $73,80,83,95,99,115$, 160

- allegorische Auslegung: 16, 20, 68, 101, 112

- Homerauslegung: 16, 21, 159

- neuplatonische Auslegung: 22

- philosophische Auslegung: 78

Ausonius: 150

Bär (Sternbild): 72

Bassai: 67

Batanea: 3

Begierde: 80

Bernini, Gian Lorenzo: 158

Bessarion: 144, 159

Bienen: $13,18,25,27,71,80,84,90-92$, $130,138,147,156$

- Bienensymbolik: 27

Bildung: 20 
Bilitis: 142

Blake, William: 143f., 151, 153-157, 163

Böotien: 105, 108

Boreas: 28, 72

Bulgarien: 88

Busbeq: 149

Butts, Thomas: 151

Caesarea Maritima: 5

Campano, Giovanni Antonio: 161

Capilupi, Lelio: 150

Cerberus: siehe Kerberos

Chaldäer: 103

Chichester, John: 151

Christen: 10, 115, 150

Christentum: 9f., 24

Christus: 150

Chrysipp: 17

Cicero: 149,159

Clay: 154

Cloris: 145

Colonna, Francesco: 1436., 158, 161

Connacrie/Connacie: 149

Corneilles, Pierre: 145

Cosmico, Niccoló Lelio: 158

Cunnus: 149

Daimon: 68

Dämonen: 80

Dardanos: 72

Delphi: 105,108

Demeter: 68, 70, 83f., 86, 111

- Demeterkult: 27

Demetrios: 5,17

Demiurg: 25, 28, 79, 81f.

- Hilfsdemiurg: 73,81

Demokrit: 70

Deutung: siehe auch Allegorese, Allegorie, Auslegung, Exegese, Interpretation, 24, 88, 92, 95, 115f., 124, I61

- allegorische Deutung: $16,20,25,70$, $74,82,99,105,141$

- neuplatonische Deutung: 19, 159, 162

- philosophische Deutung: 129

Diabolos: siehe auch Teufel, 150

Dialektik: 5

Diatribe: 21

Dichter: 113

Dichtung: 10, 16f., $23 \mathrm{f}$.

Dike: 72

Diogenes aus Athen: 110

Diokletian: 8
Dionysios von Alexandria: 66

Dionysos: 68, 83, 108

Diotima: 70

Dualismus: 74, 157

Du Laurens, André: 147f.

Ekphrasis: 13f., 99, 146, 151

Ekstasis: 105, 107

Elefantine: 120

Elias: 6

Empedokles: 68-70, 74, 83, 113

England: 143, 153

Enthousiasmos: 105

Epimenides: 107

Epimetheus: 74

Epiroten: 74

Epirus: 74

Epos: 13, 112, 157

-homerisches Epos: 10, 20, 66

Erato: 109

Erechtheus: 72

Erichthonios: 72

Erkenntnis: 18, 22, 68, 114

- Selbsterkenntnis: 23

Er-Mythos: 71, 112, 114, 118, 159

Eros: $70,72,147$

Ethik: 5, 9

Eubulos: 67f., 87, 103

Euklid: 162

Eumaios: 14

Eunapios: $3 f_{1}, 8$

Eury dike: 106

Eusebios von Caesarea: 78

Eustochios: 7

Exegese: siehe auch Allegorese, Allegorie, Auslegung, Deutung, Interpretation, 79, 83, 85, 100f., 105 , 147

- allegorische Exegese: 101, 111

- Bibelexegese: 15

- Homerexegese: 138

- philosophische Exegese: 78-82, 87

- religions-philosophische Exegese: 102

Firmicus Matemus: 92, 120, 125f, , 130f.

Fische (Tierkreiszeichen): 123, 125f., 130, 162

Fixsternsphäre: 80, 122

Fuhrmann (Sternbild): 132

Gaia: 132

Galen: 100

Gallienus: $5 f$. 
Ganimedes: 149

Gebet: 14, 81, 163

Geist (Nous): 22f.

Geist (Pneuma)

- Gottes Geist: 68

Gellius: 21

Geographie: 19, 24

Geornetrie: 5

Gerechtigkeit 80f.

Gespenster: 83f.

Gestirne: 73, 79-81, 86, 118, 120, 133

Gnostiker: 10, 24

Goethe, Johann Wolfgang von: 26

Gott: 25, 81, 89, 92, 94f., 100, 113

Götter: 7, 9, 13, 16, 23, 27f., 68f., 71, 74, $80,82-85,90,996 ., 106-108,110,112$. 119f., 122f., 137, 148f., 153

- chthonische Götter: 83, 108

- Götterbilder: 9, 67, 83, 99, 111, 114

- Götterverehrung: 107

- himmlische Götter: 81, 85

- homerische Götter: 17

- Meeresgötter: 81

- olympische Götter: 83, 108

Gottheiten: siehe Götter

Grammatik: 10

Gregor der Wundertäter: 5

Griechen: 73, 101, 148

Griechenland: 5

Grotte: siehe auch Höhle, 13f., 18, 21, 25-27, 66f., 81-83, 87, 97, 107, 117, 124, $146,153,160,162$

- als Gottesverehrung: 124

- als Kosmos: 24, 26f., 111

- als Kultort: 66

- als Nymphenheiligtum: 147

- Grottenmotivik: 144

- Nymphengrotte: 13f., 18-20, 22, 25-28, $66,68,74,81 f$., 84f., 97-106, 109-112, 114f., 117f., 120, 127, 131, 138, 142f., 146, 152f., 157, 160f.

- Urgrotte: 91

- Zeusgrotte: 83

Hades: 73, 106, 111

- als Höhle: 111

Harmonie: 73

Heiligtum: 82, 84, 99

Hekataios von Milet: 66

Hektor: 74, 150

Helios: 14, 20

Henologie: 22

Hephaistion von Theben: 120, 135
Hera: 73

Herakles: 93, 106

Heraklit aus Ephesos: 69

Hermeneutik: 77

Hermes: 70, 73, 93

Hermetismus: 118

Hermias von Alexandria: 72

Herodot: 149

Hesiod: 24, 86, 112f., 122f.

Hesych: 154

Himmelssphäre: 70

Hipparch: 122

Höhle: siehe auch Grotte, $19,25,28$, 66, $68,70 \mathrm{f} ., 78-83,86 \mathrm{f}, 92-94,97-103$, $105-115,122,129,146-148,153-155$, $157,161-163$

- als Götterheiligtum: 99

- als Kosmos: 78, 83, 101, 103f., 110f., $113,129,141$

- als Kultort: 67, 108

- als Materie: 101

- als Schwelle des Übergangs: 66, $106 f$.

- Dionysos-Höhle: 108

- Höhle der Koureten: 108

- Höhlengleichnis: 68, 83, 97, 113-115, $141,162 \mathrm{f}$.

- Höhlenmotivik: 26

- Korykische Höhle: 108

- Mithrashöhle: 103f, 108

- mythische Höhle: 104

- Nymphenhöhle: 68, 99, 101f., 110

- Pan-Höhle: 109

- Parnes-Höhle: 109

- Polis-Höhle: 19, 114

Holste, Lukas: 144

Homer: 10, 13f., 16, 18-20, 23-25, 28f., 66-69, 73f., 79, 81f., 97-106, 112-115, $117,120,124,127,129,131,133,136$, 138f., 142-145, 148f., 153f., 156f., 160-162

- als Philosoph: 10, 145

- als Theologe: 68

Honig: 13, 18, 27, 69f., 80, 84, 86, 88f., 122,147

Horaz: 149

Horen: 73

Horoskop: 120, 129

- Welthoroskop: 125f.

Housesteads: 134

Hygin: 123

Ibykus: 72

Ida: 108 
Idee: 68,91

- platonische Ideen: 22f., 79, 82, 103, $110 \mathrm{f}$.

nissos: 72

Inder: 103

Inkarnation: $27,71,806 ., 84,92,96,113$, 157

Ino-Leukothea: 152f., 156

Intellekt (Nous): 102

Interpretation: siehe auch Allegorese, Allegorie, Auslegung, Deutung, Exegese, 20, 77, 86, 110, 114f., 141, 149f, 157

- allegorische Interpretation: 98, 103, 115,156

Italien: $7,74,160$

Ithaka: 13f, 19, 25, 66, 74, 82, 102, 106, $114,117,143,146,153,156,162$

Jamblich: 9, 153

Jenseits: 71,107

- Jenseitsreise: 106f.

Julian: $78,89,91$

Jungfrau (Tierkreiszeichen): 123, 125, 130, 133f., 162

Jupiter (Planet): 70, 89, 121f., 124-126, 130,162

Justin: 87

Kalais: 72

Kalydon: 73

Kalypso: 13, 70, 102

Kardinalpunkte: 73, 118, $135 \mathrm{f}$.

Karthago: 7

Kassiopeia (Sternbild): 132

Kautes: 72, 91, 95, 133

Kautopates: 72, 91, 95, 133

Kelsos: 23

Kepheus (Sternbild): 132

Kerberos: 106, 162

Kleanthes: 17

Kore: 83, 85f.

Körper: 79f., 82f., 85, 98, 103, 107, $113-115,125,160$

- als Grab der Seele: 69

Koryka: 108

Kosmogonie: 134

Kosmologie: 118

Kosmos: siehe auch Welt, 16, 24-28, 67, $69,79,81-83,87,101-104,106$, 109-111, 113, 122, 128f, 139, 141

Koureten: 108

Kraft
- kosmische Kräfte: 17

- unsichtbare Kräfte: 26, 83, 110

Krebs (Tierkreiszeichen): 27f., $72 \mathrm{f}$., 91 , 94, 123-126, 129f., 134, 136f., 155

Kreta: 68, 71, 83, 108

Kronios: 18f., 24, 66f., 71, 78, 82, 97f., 100, 106, 111f., 115

Kronos: 24, 27, 68, 70f., 83, 85f., 108, II1f., 120, 122, 132f., 137f.

Kult: 17f., 82, 87, 91, 94, 108, 110, 118f., 134

- Kultpraxis: 19

- persischer Kult: 106f., 127

Kunst: 97, 142

Kyklopen: 28, 74

Kyrill von Alexandria: 9

Kythera: 158f., 163

La Mothe Le Vayer, François: 142-151

Lebadeia: 105,108

Leben: $69,89,92,96,105-107,141,154$, 160

- tugendhaftes Leben: 81

- vegetarisches Leben: 9

Leipzig: 142

Le Petit, Claude: 145

Libertinismus: 144, 150

Liebe: 81,158

Lilybaion: $6 \mathrm{f}$.

Literatur: 26, 86, 97, 106, 142, 146, 149, $157 \mathrm{f}$.

- griechische Literatur: 17, 101, 107

- Periplus-Literatur: 66f.

- philosophische Literatur: 122

Logik: 9

Logos: 23f., 69

London: 134

Longin: $4-7,10,77,99 \mathrm{f} ., 103$

Louÿs, Pierre: 142

Louparda: 71

Löwe (Tierkreiszeichen): 123, 125f., 162

Lukian: 159

Lukrez: 147

Lykaion: 108

Lykosoura: 109

Macht

- göttliche Mächte: 120

- untsichtbare Mächte: 82

Macrobitus: 71, 125f., 159

Maimonides: 149

Malkos: 4

Manutius, Aldus: 157 
Markella: 7f.

Marmarospilia: 19

Mars (Planet): 70, 89, 94, 121f., 124-126, 130-132, 162

Materie: 22, 24, 26, 68, 78f., 81f., 91 , 101-103, 154

Mathematik: 5

Maximos von Tyros: 98

Medusa: 132

Meleagros: 73

Menander: 109

Merkur (Planet): 70, 89, 121f., 124-126, $130,132,162$

Metapher: 15-17, 22, 69, 71, 146, 151, 154

Metaphorik: 150

Metaphysik: 9

Metempsychose: 90

Metis: 70

Metrodoros vom Lampsakos: 16

Milchstraße: 28, 73, 84, 137

Minos: 107

Mithras: 24, 67, 71f., 79, 86-95, 103, 105, 131-134, 136

- als Demiurg: 68, 80f., 95, 114, 131

- als Sonnengott: 67

- als Sternbild: 28

- als Stiertöter: 67

-Mithraskult: 26f., 67, 70f., 74, 81 , 85-89, 91, 93f., 103, 105-107, 115, 119 . 122, 126f., 131-134

- Mithrasmysterien: 67, 87, 89f., 95, 104, $114 f$.

- Mithrasweihe: 87, 91,93

Mithräum: 72, 83, 87f., 99, 104, 122, 134

- Barberini-Mithräum (Rom): 133

- bei Heddernheim: 95

- der Sieben Sphären (Ostia): 104, 134

- von Dura-Europos: 79, 89, 106

- von S. Prisca (Rom): 80, 84, 89, 91f., 95, 104

Mittelplatoniker: 99

Mittelplatonismus: 20, 102, 118

Mnasidika: 142

Mond: 70f., 91f., 120-122, 124-126, 128-131, 137f., 162

Monluc, Adrien de: 145

Musaios: 112

Musen: 16, 26, 111

Musik: 73

Musikwissenschaft: 10

Mysterien: 17, 119

-Mysterienkult: 17, 67, 103-105, 107

-Mysterienrituale: 105
- persische Mysterien: 87

Mythologie: 122

- orphische Mythologie: 85

Mythos: 17, 19, 23, 66, 68, 71f., 82f., 86, $96,105,107 \mathrm{f} ., 110,117,123,138$

- Astral-Mythos: 123

- orphischer Mythos: 68

Naiaden: siehe auch Nymphen, 18, 26f., $66,79,84,108,147,159$

Natur

- intellektuelle Natur: 81

Naturwissenschaft: 10

Nausikaa: 69

Naxos: 83, 108

Nechepsos: $126 \mathrm{f}$.

Negation: 22

Nemertios: 6

Neptun (Planet): 121

Neuplatoniker: 22,68

Neuplatonismus: 20, 24, 68, 118, 143

- Florentiner Neuplatonismus: 144

Nikolaus von Lyra: 15

Nonnos von Panopolis: 68

Numenios: 18, 24, 66, 68f., 71, 73, 78-80, $95,98,112,115,119,154 f ., 162$

Nymphen: siehe auch Naiaden, 13f., 18, 26f., 66-68, 71, 78, 83, 90, 97, 108f., 111, $147 \mathrm{f} ., 153,155 \mathrm{f} ., 159-161,163$

- als Seelen: 26f.

- Nymphenmotivik: 144

- Nymphenverehrung: 14

- Wassernymphen: 79, 147, 159, 161

Ocella, Tubertus: siehe La Mothe Le Vayer

Odysseus: 13f., $25,28,66,69,74,81,98$, 106f., 146, 152-154, 156, 160

Oineus: 73

Okeanos: 83, 96, 111

Olymp: 73

Olympiodor: 74

Ontologie: $78-82$

- neuplatorische Ontologie: 22,24

- platonische Ontologie: 22

Opfer: 81, 84f.

- Abwendungsopfer: 82

- Reinigungsopfer: 82

- Tratkopfer: 84

Orakel: 78

- Chalcäische Orakel: 112

- Orakelkult: 105

Oreithyia: 72 
Origenes: 4f., 10, 15

Orion (Sternbild): 132f.

Orontius: 6

Orpheus: 68, 70, 85f., 106, 112

Orphik: 23f., 69, 83-86

Orphiker: $70,74,112 \mathrm{f}$.

Ovid: 146,149

\section{Palästina: 149}

Pallas: 90

Palmyra: 7

Pan: 71, 108f.

- Pan Lykeios: 83, 108

Pandora: 74,160

Parmenides: 71

Parnass: 108

Parodie: 143, 149-151

Parzen: 153

Patroklos: 16, 70

Pausanias: 74, 106

Peisistratos: 149

Peleus: 16

Penelope: 146, 148

Penia: 70

Periegese: 66

Persephone: $68,70,111 f$.

Perser: 87, 90, 103

Perseus: 132

Perseus (Stembild): 72, 132f.

Persien: 87

Petosiris: 126f.

Phaiaken: 13f., 66, 69, 81, 106, 154, 156

Phaidros: 72

Pherekydes: 74, 102, 112

Philolaos: 74

Philologie

- alexandrinische Philologie: 10

- Homer-Philologie: 10

Philosophen: 24, 98, 102

- Philosophenschulen: 6, 145

- vorsokratische Philosophen: 25,67

Philosophie: $3,5,9,69,77,83,106,112$, 118,121

- griechische Philosophie: 101

- Homers Philosophie: 10

- netuplatonische Philosophie: 154

- Philosophiegeschichte: 9

- platonische Philosophie: 20, 68

- Porphyrios' Philosophie: 22

Phönix: 73

Phönizien: 7

Phorkis: 74

Phorkys: 14, 28, 66, 106, 153f.
Physik: 5

Pindar: 17

Pineau, Séverin: 148

Planeten: 27, 70, 121-126, 128-130, 137, $139,155,162$

- ägyptische Planetenreihenfolge: 121

- chaldäische Planetenreihenfolge: 121

- Planetenhäuser: 71, 124, 129, 137

- Planetenreihenfolge: 70,121

- Planetensphäre: $70,80,122,136$

Platon: 15, 17, 22-25, 66, 68f., 71f., 79-81, $83,86,90,97,99 \mathrm{f} ., 108,112-115$, 118f., 136f., 153f., 159f., 162

Platoniker: 66f., 86, 91, 103, 121

- pythagoreisierende Platoniker: 66

Platonismus: 9, 79, 95, 118, 153

Plotin: 3-10, 21, 23, 66, 78, 87, 99f., 103, $112,118,153$

Plutarch: 15, 105, 110

Pluto: 121, 162

Polemik

- antichristliche Polemik: 77

- christliche Polemik: 86f.

Polia: $158 \mathrm{f}$.

Poliphilo: 158-161, 163

Polyandrion: 161

Polyphem: 102

Pope, Alexander: 151

Poros: 70

Porphyrios: 3-10, 14, 17-22, 24-26, 29, 66-74, 77-85, 87-115, 117-125, $127-139,141-144,146-157,159-163$

Poseidon: 14, 74

Priamos: 74

Probus: 6

Progymnasmata: 99

Proklos: 68, 71, 119, 122, 153

Prometheus: 74

Proserpina: 162

Proteus: 154

Ptolemaios: 119, 121f., 125, 128, 132

Pythagoras: 9, 23, 68, 73, 84, 107f., 112, 118

Pythagoreer: $28,66,71,74,78,83,113$, 163

Pythagoreismus: 69, 84

Quellen: $13,27,66,79,87,91,111$

Rabbiner: 149

Reinkarnation: siehe auch Wiedergeburt, $70 f, 80,87,90,92$

Religion: 77, 82-96 
- griechische Religion: 101, 105, 109

- polytheistische Religion: 10

- Religionspraxis: 9

Religiosität

- pagane Religiosität: 9

Rezeption: 141

- kreative Rezeption: 141-143, 150, 157

- produktive Rezeption: 143

- reproduktive Rezeption: 141, 143

Rhea: 68, 71, 119f.

Rhetorik: 10, 15, 17f.

Ritual: 83, 86, 89, 103, 105, 108

- christliches Ritual: 87

- chthonisches Ritual: 84

- Hochzeitsritual: 84

Ritus: 67, 81f., 84, 89, 96

Rogatianus: 6

Rom: 5-8, 103f., 110

Roman

- allegorischer Roman: 159

Sabinillus: 6

Salonina: 6

Sappho: 142

Sarpedon: 72

Saturn: 72

Saturnalien: $24,27,72,85$

Saturn (Planet): 70f., 90, 120-122,

$124-126,130,133,137,162$

Scheria: 156

Schicksal: 74, 118-120, 157

Schule: 20

- neoplatonische Schule: 20

- platonische Schule: 20

- pythagareische Schule: 68

Schütze (Tierkreiszeichen): 123, 125f., $132,137,162$

Seele: $9,22 \mathrm{f} ., 25-28,68 f$., $71,73 f ., 79-85$, 87, 90-92, 94f., 98, 103, 107, 112-114, $119,129,134,136 f ., 143,155-157,160$, 162

- Freiheit der Seele: 27

- Rettung der Seele: 93

- Seelenführung: 67

- Seelenlehre: $9,66,157$

- Seelenreise: $70,105 \mathrm{f}$.

- Seelenwanderung: 26, 69, 71, 101, $111-113,129,135,137$

- Unsterblichkeit der Seele: 69, 107, 115

Selene: $71,83,91 \mathrm{f}$., 108

Seneca: 145

Sidon: 126

Sirius: $72,126-128,131$
Sizilien: $6-8,74,78,160$

Skorpion (Tierkreiszeichen): 95, 123, 125f, $130,133,162$

Sokrates: $74,114,149,160$

Solstitium: 134

- Sommersolstitium: 123

- Wintersolstitium: 123, 155

Sommersonnenwende: 80

Sonne: $67,70,72,85,90-92,120-123$, 125-127, 129f., 135, 137, 153, 155, 162

- Sonnenlauf: 121, 135f.

Sophia: siehe auch Weisheit, 100, 103 , $105,112,115$

Sophokles: 24

Sothis: 72, 126-129

Steinbock (Tierkreiszeichen): 27, 72f, 91 , 94, 123-126, 129f., 136f., 155, 162

Steklen: 88

Sterne: $88,118,120$

- Fixsterne: 73, 121f., 124, 135, 155

Sternzeichen: 123,129

Stier (Sternbild): 72

Stier (Tierkreiszeichen): 71f., 95, 123, 125f., 130, 132f., 162

Stier (Tötung des Stiers): 88, 90-95, 126, 133

Stobaios: 78

Stoiker: 17

Styx: 10

Symbol: 20f., 24-28, 70f., 79, 82-84, 88, 93, 98, 101, 103f., 110f., 114, 124, 129, $141,154,1606$.

Synesios: 153

Syria Phoenice: 3

Syrien: 126

Taylor, Thomas: 153f., 156

Teiresias: 74

Tempel: 67, 82f., 85, 99, 108, 110, 131, 153

Teufel: siehe auch Diabolos, 95

Teukros: 132

Theagenes von Rhegion: 17

Thel: 154

Theognis: 128

Theokrit: 147

Theologen: $24,68,71,86,112 \mathrm{f}, 115$

Theologie: 5,10

- apophatische Theologie: 22

- neuplatorische Theologie: 23

- Onto-Theologie: 81

Theosophie: 77

Thetis: 16,70

Theurgie: 9 


\section{Thoosa: 74}

Thrakien: 72

Tierkreis: siehe auch Zodiakus, 123 , 132-134, 136

Tierkreiszeichen: $27,72,88,90,124,126$, $129,137,162$

Tircis: 145

Thepolemas: 72

Tod: 69, 84, 92, 96, 105-107, 114, 154

Tradition

- exegetische Tradition: 18, 24

- literarische Tradition: 24, 26, 104

- orphische Tradition: 16, 27

- philosophische Tradition: 23f., 266.

- platonische Tradition: 70

- pythagoreische Tradition: 113

- religiöse Tradition: $23 \mathrm{f} ., 27$

Transzendenz: 22

Traum: 158

Trier: $133 \mathrm{f}$.

Trojaner: 73

Trophoniosorakel: 105

Tugend: 17, 19,81

Tyros: $3-5,7$

Unsterblichkeit: siehe auch Seele, 23,91, 146

Unterwelt. $66,73,162$

Uranos: $68,86,122,137 \mathrm{f}$.

Uranus: 121

Vari: 109

Venedig: 144, 157-159, 163

Venus: 72,163

- Venuskult: 159f.

Venus (Planet): 70, 89, 121f., 124-126, $130-132,162$

Vergil: 70,92

Vernunft $25,28 \mathrm{f}$.

Vettius Valens: 126, 131

Vollkommenheit

- ethische Vollkommenheit: 80
Vorsokratiker: 67

Voura: 106

Waage (Tierkreiszeichen): $94 \mathrm{f} ., 123$, 125f., 130f., 133, 162

Wahrheit: 20, 29, 68, 71, 117

Wassermann (Tierkreiszeichen): 123, $125 f$., 162

Weisheit: siehe auch Sophia, 28f., 67, 82f., 99f., 103, 116-118, 126, 133, 139, 160, 162

- ägyptische Weisheit: 127, 129

Welt: siehe auch Kosmos, 16, 25, 27, 71, 78-81, 83, 101f., 104, 106, 111f., 114, $121,124,126-129,154 f, 157$

- als Höhle: 113, 115

- als Tempel Gottes: 80

- geozentrisches Weltbild: 118, 121

- heliozentrisches Weltbild: 121

- platonisches Weltbild: 78

- Weltbild: 118, 129, 138

Widder (Tierkreiszeichen): 72, 94f., 120, 123, 125f., 130-134, 162

Wiedergeburt: siehe auch Reinkarnation, 107,129

Wintersonnenwende: 80,85

Xenophanes aus Kolophon: 67, 101

Zagreus: 68

Zalmoxis: 107

Zarathustra: 24, 67, 87, 91, 103, 107

- Zarathustrakult: 67

Zenon: 17

Zetes: 72

Zeus: $68,71,73 f$., $85 f$., $90,108,122,137 \mathrm{f}$, 160

Zodiakus: siehe auch Tierkreis, 104, 123, 132,136

Zoroaster/Zōroástrēs: siehe Zarathustra

Zwillinge (Tierkreiszeichen): 123, 125f., $128,137,162$ 


\section{Die Autoren dieses Bandes}

Prof. Dr. Manuel Baumbach ist Professor für Klassische Philologie mit Schwerpunkt Gräzistik an der Ruhr-Universität Bochum. Zu seinen Forschungsfeldern gehören die hellenistische Dichtung (Poseidipp, Theokrit), die Literatur der Kaiserzeit (Lukian, Quintus Smyrnaeus, Chariton), das antike Epyllion sowie die Forschungs- und Rezeptionsgeschichte der griechisch-römischen Antike.

Schriftenauswahl: Lukian in Deutschland. Eine forschungs- und rezeptionsgeschichtiche Analyse von Humanismus bis zur Gegenwart (München 2002); Ein literarischer Prometheus. Lukian aus Samosata und die Zweite Sophistik (Heidelberg 2017, zusammen mit P. von Möllendorff); Hg. (zusammen mit B. Acosta-Hughes / E. Kosmetatou), Papyrus Leazes: Perspectives on an Eprigram Collection Attributed to Posidippus (Cambridge Mass. 2004); $\mathrm{Hg}$., Quintus Smyrnatus. Transforming Homer in Second Sophistic Epic (Berlin / New York 2007); Hg. (zusammen mitS. Bär), Brill's Companion to Greek and Latin ,Epyllion'and Its Reception (Leiden / Boston 2012); Hg. (zusammen mit N. Dümmler), Imitate Anacreon! Mimesis, Poiesis and the Poetic Inspiration in the Carmina Anacreonta (Berlin / New York 2014).

Dr. phil. Dr. theol. Matthias Becker ist wissenschaftlicher Mitarbeiter am Sonderforschungsbereich 1136 "Bildung und Religion" (Georg-August-Universität Göttingen). Seine Forschungsschwerpunkte liegen im Bereich (1.) des Neuen Testaments und seiner griechischrömischen Umwelt, (2.) der kaiserzeitlichen und spätantiken Literatur, Rhetorik und Philosophie sowie (3.) des frühgriechischen Epos.

Schriftenauswahl: Eunapios aus Sardes. Biographien iiber Philosophen und Sophisten. Einleitung, Übersetzung, Konmentar (Stuttgart 2013); Porphyrios. Contra Christianos. Nete Sammlung der Fragmente, Testimonien und Dubia mit Einleitung, Übersetzung und Anmerkungen (Berlin / Boston 2016); "Der Vergleich des Lebens mit einem Gastmahl als Verhaltensanweisung. Lk 14,7-11 und 22,26-27 im Lichte von Texten Epiktets und Dions von Prusa", Zeitschrift fitr die netutestamentliche Wissenschaft 107 (2016) 206-231; Die Bedrohtung der Polis. Hesiods, Werke und Tage' als Zetgnis literarischer Bedrohungskommunikation (Tübingen 2018).

Prof. Dr. Reinhold F. Glei ist Ordentlicher Professor für Klassische Philologie (Latinistik) an der Ruhr-Universität Bochum. Seine Forschungsschwerpunkte liegen im Bereich des antiken und neulateinischen Epos (inklusive der Sekundärformen wie Parodie und Cento), der christlichen Islamrezeption, der Übersetzungstheorie und der neulateinischen Literatur.

Schriftenauswahl: Die Batrachomyomachie. Synoptische Edition und Kommentar (Frankfurt 1984); Petrus Venerabilis. Schriften zum Islam (Altenberge 1985); Der Vater der Dinge. Interpretationen zur politischen, literarischen und kulturellen Dimension des Krieges bei Vergil (Trier 1991); Pius II. Papa. Epistola ad Mahumetem (Trier 2001); Marcus Hieronymus Vida. Christias (Trier 2013); Ludovico Marracci at work: The Evolution of his Latin Translation of the Quran (Wiesbaden 2016).

Prof. Dr. Irrigard Männlein-Robert ist Inhaberin des Lehrstuhls für Griechische Philologie an der Universität Tübingen. Thre Forschungsschwerpurtkte sind Platon, kaiserzeitlicher und spätantiker Platonismus (in literarischer wie philosophischer Hinsicht) sowie hellenistische Dichtung, griechische Religion, Poetik und Ästhetik.

Schriftenauswahl: Longin: Philologe und Philosoph. Eine Interpretation der erhaltenen Zetugnisse. Beiträge zur Altertumskunde Band 143 (München / Leipzig 200I); Stimme, Schrift und Bild. Zum Verhältnis der Kïnste in der hellenistischen Dichtung. Bibliothek der Klassischen Altertumswissenschaften, N.F. 2. Reihe, Band 119 (Heidelberg 2007); „Ordnungskonkurrenz: 
Polemik und Feinde in konkurrierenden Ordnungen. Der platonische Philosoph Porphyrios und sein Kampf gegen die Christen", in: E. FrIE / M. MeIrr (Hg.), Aufruhr -Katastrophe -Konkurrenz-Zerfall Bedrohte Ordnungen, Bd. 1 (Tübingen 2014) 117-138; ,Zeichen dett-

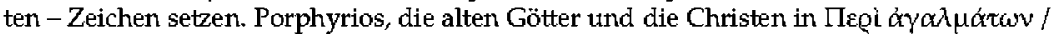
De imaginibus", in: I. MänNLeIN-RoBerT, Die Christen als Bedrohtung? Text, Kontext und Wirkung zon Porphyrios" "Contra Christianos" (Stuttgart 2017) 177-206.

Prof. Dr. Christoph Riedweg ist Ordentlicher Professor für Klassische Philologie / Gräzistik an der Universität Zürich. Zu seinen Forschungsschwerpunkten gehören Frühgriechische Dichtung und Philosophie (u.a. Orpheus/Orphik, Pythagoras/Pythagoreismus), Rhetorik, Philosophie des 4. Jh. v. Chr. sowie der Kaiserzeit und Spätantike (insbesondere Platonismus), die jüdisch-hellenistische und die frühchristliche Literatur.

Schriftenauswahl: Mysterienterminologie bei Platon, Philon und Klemens von Alexandrien (Berlin / New York 1987); Jüdisch-hellenistische Imitation eines orphischen Hieros Logos Beobachtungen zu OF 245 und 247 (sog. Testament des Orpheus) (Tübingen 1993); Ps.-Justin (Markell von Ankyra?), Ad Graecos de vera religione (bisher "Cohortatio ad Graecos"). Einleitung und Kommentar (Basel 1994); Pythagoras: Leben - Lehre - Nachwirkung. Eine Einführung (München 2007); Kyrill von Alexandrien, Werke Bd. I: »Gegen Julian«, Teil 1: Buch 1-5 (Berlin / Boston 2016).

Benjamin Topp ist wissenschaftlicher Mitarbeiter am Institut für Romanistik und Latinistik (Latein/Neulatein) der Universität Osnabrück. Zu seinen Forschungsschwerpunkten gehören insbesondere Astrologie und Astronomie der Antike und der frühen Neuzeit, der Neuplatonismus sowie die Rezeption der Antike in der Renaissance. In seiner Dissertation beschäftigt er sich mit den Disputationes adversus astrologos des italienischen Humanisten Giovanui Pico della Mirandola (Einleitung, Editition und Übersetzung der ersten vier Bücher).

Schriftenauswahl: Deutsche Übersetzung von Joh. Lyd. de mens. 4,26 pp. 84-86 Wünsch, in: S. HeIlen, "Hadriani genitura" - Die astrologischen Fragmente des Antigonos von Nikaia. Edition, Übersetzung und Kommentar (Berlin u.a. 2015) 975-979; „Sanus Orestes? - Emendation einer Korruptel in Picos Disputationes (cap. 3,16 vol. I p.330 G.)", Neulateinisches Jahrbuch 21 (2019) [zusammen mit Stephan Heilen; zum Druck angenommen]. 